\title{
Performance of the fruit crop industry in Ghana: Empirical Results and Policy Implications
}

\author{
Dissertation \\ to obtain the Ph.D. degree \\ in the International Ph.D. Program for Agricultural Sciences in \\ Goettingen (IPAG) \\ at the faculty of Agricultural Sciences, \\ Georg-August-University Goettingen, Germany \\ presented by \\ Mensah Amos \\ born in Koforidua - Ghana
}

Göttingen, November 2014 
D7

1. Name of supervisor: Prof. Dr. Bernhard Brümmer

2. Name of co-supervisor: Prof. Dr. Stephan von. Cramon-Taubadel

Date of dissertation: $11^{\text {th }}$ November 2014. 
For My Family 


\section{Contents}

$\begin{array}{ll}\text { 1. Introduction } & 1\end{array}$

1.1. Evolution of the Ghanaian Fruit Industry ...............................................................

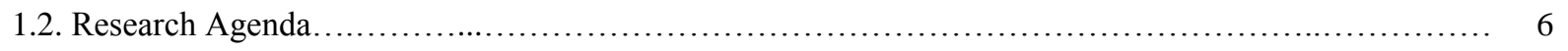

1.3. Expected Contribution of Thesis to the Existing Literature....................................... 6

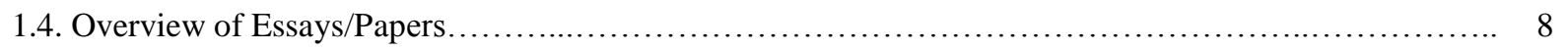

2. Drivers of Technical Efficiency and Technology gaps in Ghana's Mango Production Sector: A Stochastic Metafrontier Approach

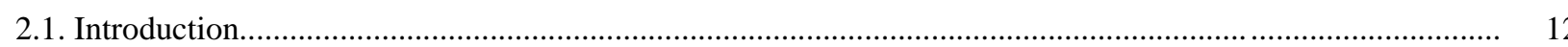

2.1.1 Research Objective

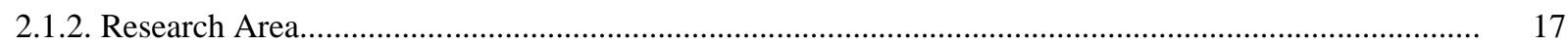

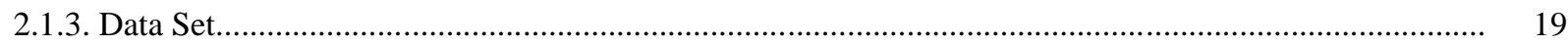

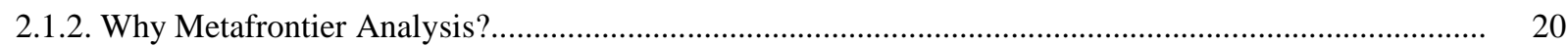

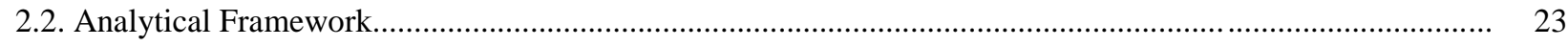

2.2.1 The Stochastic Metafrontier Model................................................................................................. 23

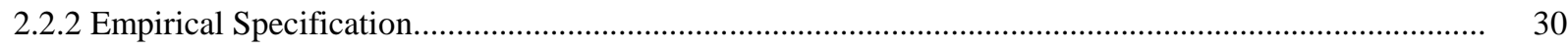

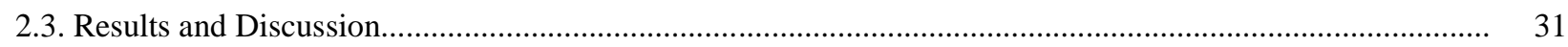

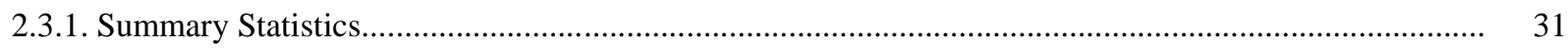

2.3.2. Test for Model Specification...................................................................................................... 32

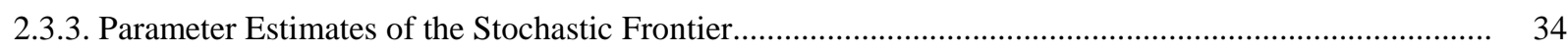

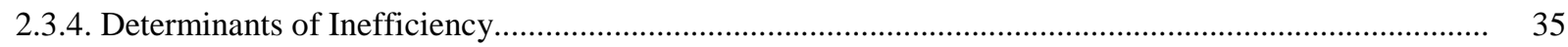




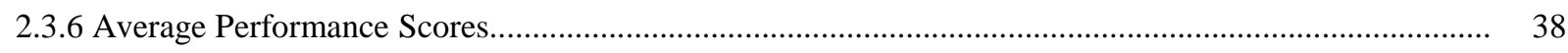

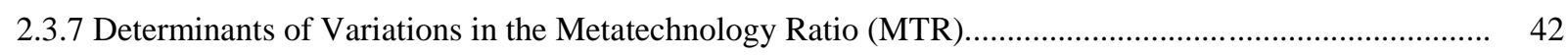

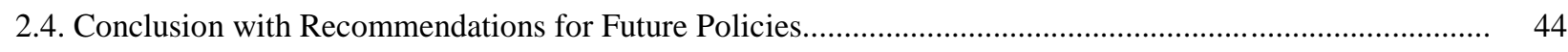

Appendix A

3. Determinants of MD2 Adoption, Production Efficiency and Technology Gaps in the Ghanaian Pineapple Production Sector

3.1. Introduction.

3.1.1. Research Objectives.

3.1.2. Research Area.

3.1.3. Data Set.

3.2. A Brief History of Ghana's Pineapple Industry. 


\section{A Multi-Output Production Efficiency Analysis of Commercial Banana Farms in the Volta Region of Ghana: A Stochastic Distance Function Approach}

4.1.1. Research Objectives

4.1.2. Study Area.

4.1.3. Data Set.

\section{Summary}




\section{List of Tables}

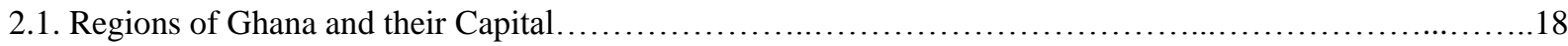

2.2. Agro-ecological Zones of Ghana (from north to south) .......................................................19

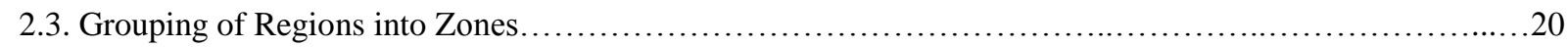

2.4. Hypothesis Testing for Stochastic Production Frontier Model......................................................................33

2.5. First Order Estimates of the Translog Stochastic Production Frontier Models...................................................35

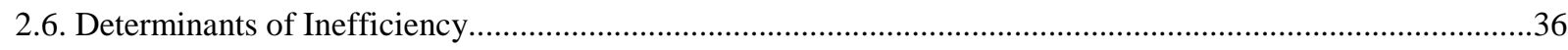

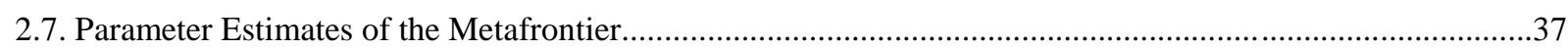

2.8. Summary Statistics of Technical Efficiency (TE), Meta-Technology Ratio (MTR), and Meta-

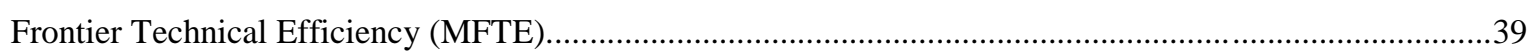

2.9. Determinants of the Meta-Technology Ratio (i.e. variables influencing the nature of the

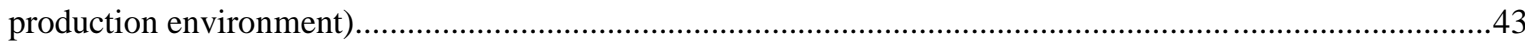

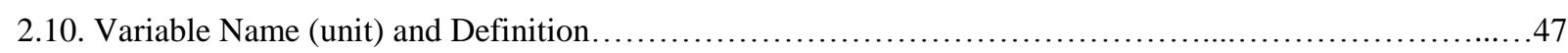

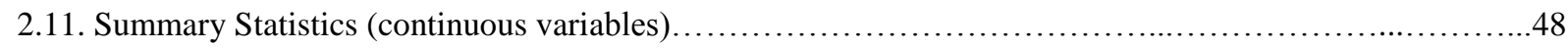

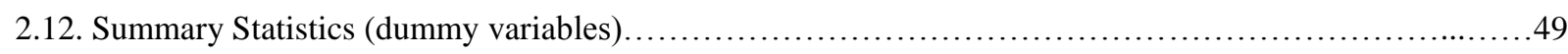

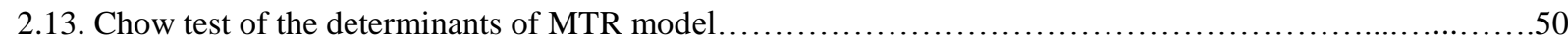

2.14. Estimates of Stochastic Production Frontier (Translog Models) .......................................51

2.15. Detail summary statistics of Technical Efficiency (TE), Meta-Technology Ratio (MTR), and

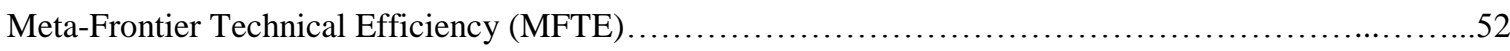

3.1. Hypothesis Testing for Stochastic Production Frontier Model........................................................................74

3.2. Factors Influencing Adoption of MD2 Variety (Logistic Model).................................................................77

3.3. Estimates of the Translog Stochastic Production Frontier Models.......................................... 80

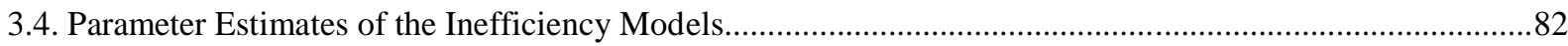

3.5. Summary statistics of Technical Efficiency (TE), Meta-Technology Ratio (MTR), and Meta-

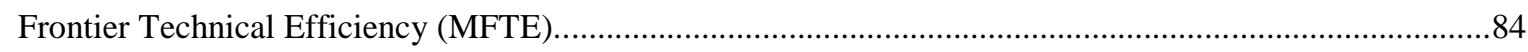

3.6. Determinants of the Meta-Technology Ratio (i.e. variables influencing the nature of the

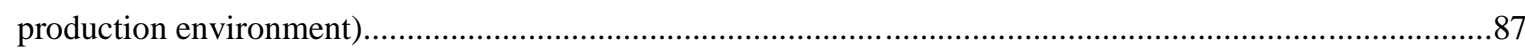

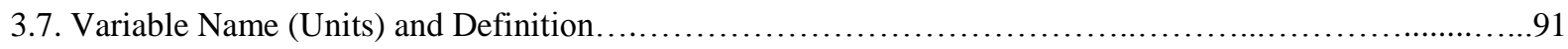




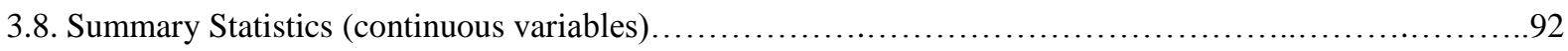

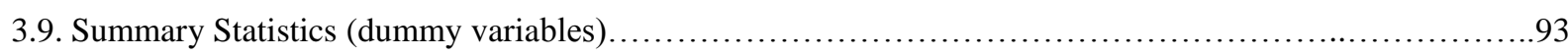

3.10. Estimates of Translog Stochastic Production Frontier Models....................................94

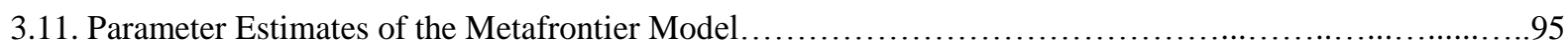

3.12. Detail Summary Statistics for Technical Efficiency with Respect to Group Frontier......................96

3.13. Detail Summary Statistics for Meta-Technology-Ratio.......................................... 96

3.14. Detail Summary Statistics for Meta-Frontier-Technical Efficiency..................................97

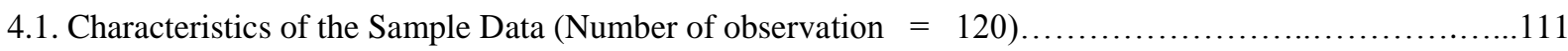

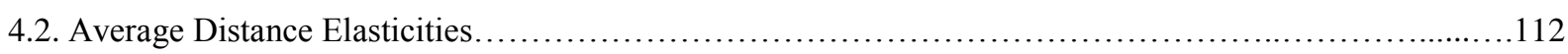

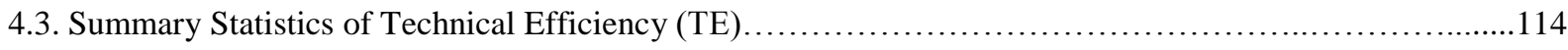

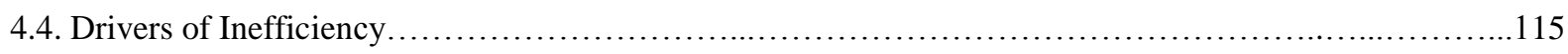

4.5. Distance Function and Determinants of Efficiency Estimates.................................... 118

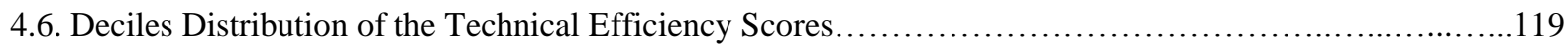




\section{List of Figures}

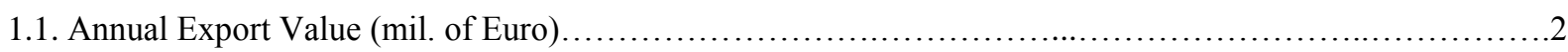

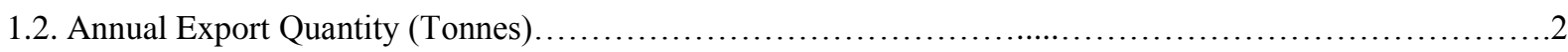

2.1. Total Annual Value of Mango Exported to the EU (value in mil. of Euro, $2000-2013) \ldots \ldots \ldots \ldots \ldots \ldots \ldots . . . . .14$

2.2. Total Annual Quantity of Mango Exported to the EU (100kg, 2000 - 2013)................................14

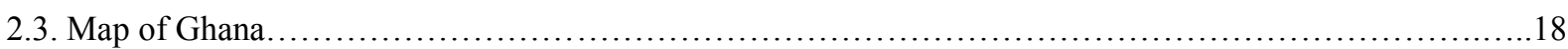

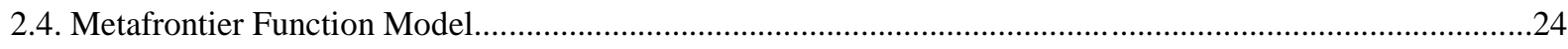

2.5. Histogram, Bar Chart and Boxplot of TE, MTR and MFTE for the three Zones involved in the

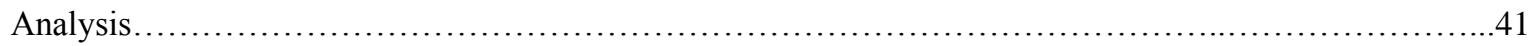

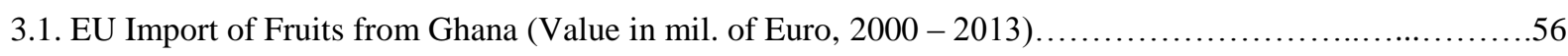

3.2. Number of Farmers Sampled in each Region (organic and conventional systems)........................................61

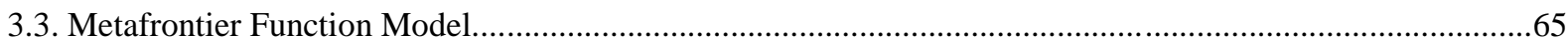

3.4. Bar Chart of Variety Type under Cultivation (Organic and Conventional farming systems)...........................75

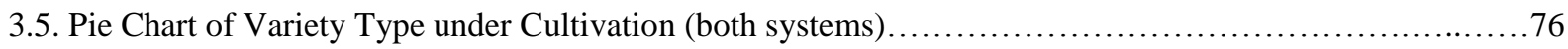

3.6. Histogram, Bar chart and Boxplot of TE, MTR and MFTF for the Two Production Systems..................85

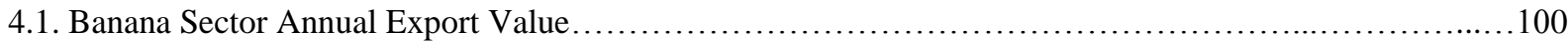

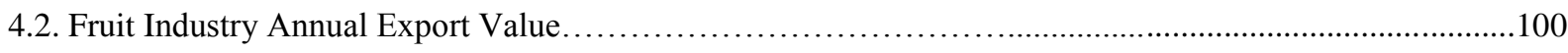

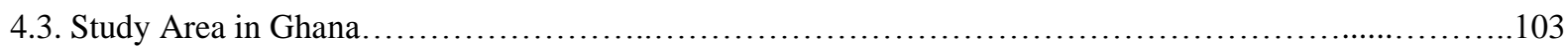

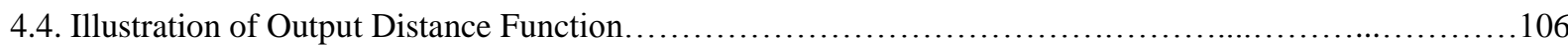

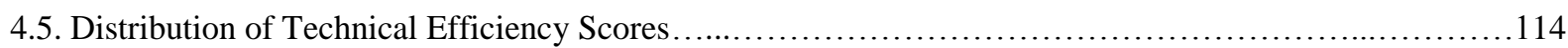




\section{List of Abbreviations}

\begin{tabular}{|c|c|}
\hline ADRA & Adventist Development and Relief Agency \\
\hline $\mathrm{CD}$ & Cobb Douglas functional form \\
\hline DEA & Data Envelopment Analysis \\
\hline ERP & Economic Recovery Program \\
\hline EU & European Union \\
\hline GDP & Gross Domestic Product \\
\hline GEHR & Ghana Export Horticulture Review \\
\hline GEPC & Ghana Export Promotion Council \\
\hline GIPC & Ghana Investment Promotion Centre \\
\hline GIZ & German Society for International Cooperation \\
\hline GSS & Ghana Statistical Service \\
\hline LP & Linear Programming \\
\hline MD2 & Pineapple variety developed by Del Monte of Costa Rica \\
\hline MFTE & Meta-Frontier Technical Efficiency \\
\hline MOAP & Market Oriented Agricultural Program (of GTZ/GIZ) \\
\hline MOFA & Ministry of Food and Agriculture (Ghana) \\
\hline MRT & Marginal Rate of Transformation \\
\hline MRTS & Marginal Rate of Technical Substitution \\
\hline MTR & Meta-Technology Ratio \\
\hline NGOs & None Governmental Organisations \\
\hline NTEP & Non-Traditional Export Products \\
\hline $\mathrm{PPF}$ & Production Possibility Frontier \\
\hline QP & Quadratic Programming \\
\hline $\mathrm{R} \& \mathrm{D}$ & Research and Development \\
\hline RTS & Return To Scale \\
\hline SE & Standard Error \\
\hline SFA & Stochastic Frontier Analysis \\
\hline Std. Dev. & Standard Deviation \\
\hline $\mathrm{TE}$ & Technical Efficiency \\
\hline TGR & Technology Gap Ratio \\
\hline TIPCEE & Trade and Investment Program for a Competitive Export \\
\hline
\end{tabular}




\section{Economy}

TL

Translog functional form

USAID

United State Agency for International Development

\section{Conversions}

Metric units are used where possible in this report.

$\begin{array}{lll}1 \mathrm{~kg} & = & 0.001 \mathrm{~T} \\ 1 \mathrm{~T} & = & 1000 \mathrm{Kg} \\ 1 \mathrm{ha} & = & 2.471 \mathrm{Acres} \\ 1 \mathrm{acre} & = & 0.4047 \mathrm{Ha}\end{array}$




\section{Acknowledgements}

This dissertation is the final result of four years of Ph.D. study at the Georg-AugustUniversity Göttingen, Germany, Faculty of Agriculture; Department of Agricultural Economics and Rural Development. During this time, a lot of people supported me in various ways making it virtually impossible to name them all here. However, this work will not be complete without expression of my sincere thanks to the following personalities:

I am profoundly grateful to Prof. Dr. Bernhard Brümmer (Professor at the above mentioned department) for supervising me as a Ph.D. student. I am very grateful for his support, guidance and comments during the entire study period. I have benefited a lot from his wide methodological and theoretical knowledge. His expertise in efficiency and productivity analysis improved my research skills and has prepared me for the future challenges.

My sincere thanks go to Prof. Dr. Stephan von Cramon-Taubadel (Professor at the above mentioned department) for being the second supervisor of this thesis. I am grateful for his helpful comments and evaluation of this dissertation. I thank him for his valuable advice on how to structure and focus the research to arrive at a good paper.

My special appreciation goes to Prof. Dr. Matin Qaim (Professor at the above mentioned department) for being the examiner of my dissertation. I am grateful for his time and comments.

I would like to thank Dr. Gunnar Breustedt and Dr. Sebastian Lakner for reviewing my progress reports papers. Their valuable contributions, feedback and experience help advanced my work. I am grateful to Nina Enke for taking time out of her busy schedule to proof read the thesis.

I gratefully acknowledge the help I receive from all the people and institutions (i.e. students and extension officers as interviewers) during data collections. I thank all our respondents for their patience and cooperation. I thank my brother, Mr. Ebenezer Asante-Darko for taking time out of his busy schedule to assist me organize the field survey. I am grateful for the financial support from the Courant Research Center and Department of Agricultural Economics and Rural Development, Georg-August-University Göttingen during my field survey. I am grateful to all colleagues at the Department for all their support and help. 
Last, but not the least, I want to thank Svenja Kleinetz, Calvin Kwesi Mensah and Ellinor Abena Mensah, Jayden Kwedwo Mensah and my entire family for their immense support, love and understanding. This thesis is dedicated to them.

Mensah Amos, Göttingen, $18^{\text {th }}$ September 2014 


\section{Chapter One}

\section{Introduction}

\subsection{Evolution of the Ghanaian Fruit Industry}

Agriculture plays a very important role in Ghana's economy; in 2010 it contributed about $30 \%$ of GDP and employed over $60 \%$ of the working population (Ghana Statistical Service, 2010). Ghana over the past decades has relied heavily on a few primary commodities such as cocoa, timber and gold for foreign exchange earnings. Until recently ${ }^{1}$, gold and cocoa exports made up around 50-65 percent of total exports ((Ghana Statistical Service, 2010)(Wolter, 2008)); consequently the overall performance of Ghana's economy was dependent very much on the performance of these two commodities in the international market. Timber and wood products constituted Ghana's third largest export commodity after gold and cocoa within the time frame. In 2005 for example, timber and wood products accounted for 8.2 percent of the export revenue generating about $€ 184$ million (Ghana Forestry Commision, 2006).

In an effort to promote export diversification to reduce the country's dependence on these few primary commodities and also as a way of mitigating vulnerability of the economy to external shocks such as the cocoa price collapses experienced in the 1980s. The Government of Ghana as part of the Economic Recovery Program (ERP) initiated a series of export diversification programs (e.g. Trade and Investment Program for a Competitive Export Economy (TIPCEE)) in the 1990s. Principal among the objectives of the ERP is enhancing production shares and export competitiveness of selected Non-Traditional Export Products (NTEP) (mainly high value fruits and vegetables products) ${ }^{2}$ in the international market.

Since its inception, the fruit crop industry has contributed immensely to the economic development of Ghana (i.e. in terms of employment, fiscal revenue and foreign exchange). In the last two decades, Ghana has developed a considerable fruit industry exporting assorted

\footnotetext{
${ }^{1}$ Ghana statistical service 2010 rebasing of the national accounts puts the services sector as a leading contributor to GDP with $48.8 \%$. GDP distribution in 2013 is as follows: Agric $=21.3 \%$, Industry $=28.1 \%$, Services $=50.6 \%$

${ }^{2}$ The importance of the fruit crop industry for Ghana's development has increased over the past decades. This is due to the fact that, increasing export orientation and moving towards higher value fruit supply chains have opened up new pathways towards reducing poverty in both rural and urban areas.
} 
fresh and processed tropical fruit produce (e.g. pineapple, banana, mangoes etc.) to Europe ${ }^{3}$. The industry export to the EU (i.e. 2000 - 2013) generated approximately $€ 562$ million to Ghana's economy (Eurostat, 2013) ${ }^{4}$. Figure 1.1 shows the total and the sectoral annual EU import values of fruits from 2000 - 2013. The value of total foreign exchange earnings for the fruit industry increased steadily from $€ 26,30$ million in 2000 to $€ 58,50$ million in 2004 . A sudden drop to $€ 49,10$ million was experienced in 2005 (i.e. 16.1\% drop). However, revenue from fruit export recovered its steady increase from 2006 reaching a new record of $€ 71,70$ million in 2010 (Eurostat, 2013). The drop in 2005 was mainly ascribed to the crisis in the pineapple sector while the drop in 2009 was mainly attributed to incidence of fruit flies and erratic rainfall pattern (Zakari, 2012).

Figure 1.1.: Annual Export Values (mil. of Euro)

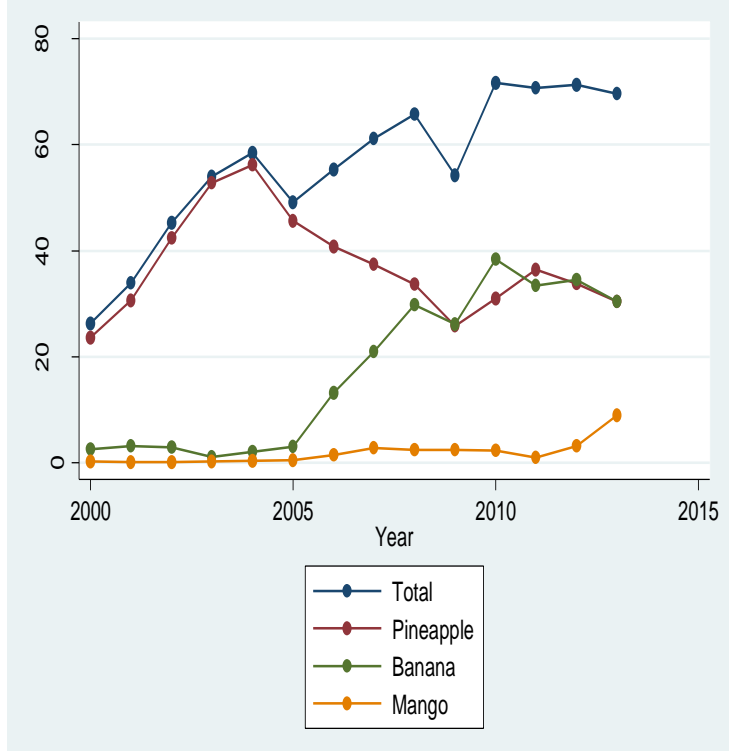

Data source: (Eurostat, international trade statistics)
Figure 1.2.: Annual Export Quantities (Tonnes)

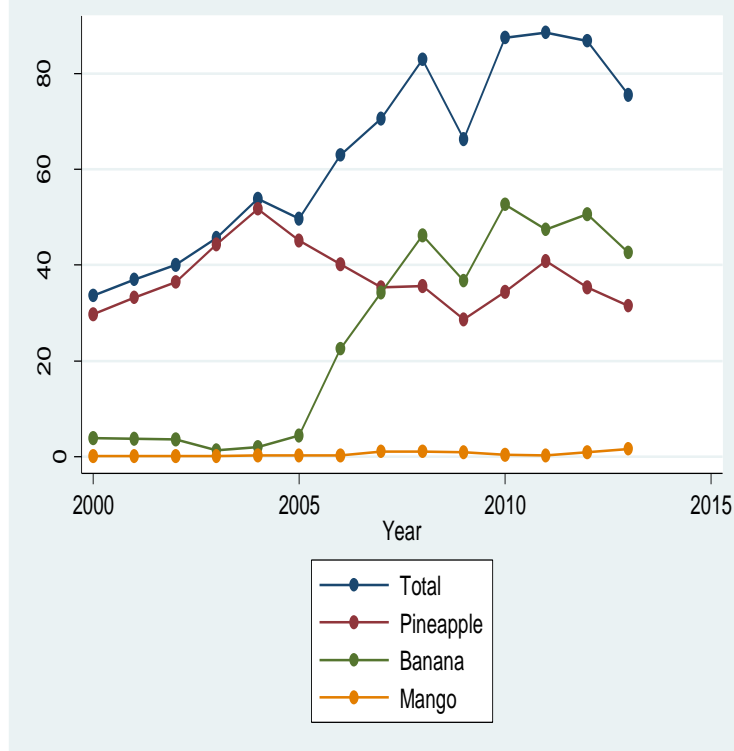

Data source: (Eurostat, international trade statistics)

In terms of quantity exported, Figure 1.2 shows the total and the sectoral export quantity trend to the EU from 2000 to 2013. The export volume of pineapple increased rapidly from virtually zero in 1990 to 52,000 tonnes in the 2004 production year. Banana exports to the EU

\footnotetext{
${ }^{3}$ EU-Ghana trade measures (i.e. import values and quantities) are discussed here because the EU is the principal export market for the Ghanaian fruit industry. Also, we focused primarily on the export performance to the EU due to data availability and reliability. Though, incorporation of fruit trade data with other major markets like the United State of America, China and the Middle East could enhance the analysis, unfortunately, we could not include them due to lack of reliable data.

${ }^{4}$ Eurostat is the official statistical office of the European Union.
} 
grew from a mere 1,788 tonnes in 2004 to 52,357 tonnes in 2010 ((Agritrade, 2012) (Eurostat, 2013)). Mango exports to the EU grew from a mere 1,220 tonnes in 2000 to 16,273 tonnes in 2013 (Eurostat, 2013).

The tremendous employment and income generation potentials of the industry ${ }^{5}(\mathrm{Jaeger}$ 2008) are being explored as a fresh avenue for tackling issues of rural poverty and improvement in rural livelihood by national and international development agencies/NGOs (e.g. ADRA, GIZ etc.) as well as donor agencies (e.g. USAID etc.) ((Jaeger, 2008)(Wolter, 2008)). The industry's potential has also attracted multinational fruit companies such as Golden Exotics, Bio Exotica and Britain's Blue Skies to establish fruit processing plants and export companies in Ghana as well as supporting farmers in various capacities to expand production.

Besides providing direct employment to fruits farmers and income opportunities for rural on-farm workers (engaged on permanent or temporal basis) in fruit production, the industry also provide indirect employment (i.e. through its forward-backward linkages with other sectors) by supplying various sectors of the economy with raw materials (i.e. fruits) while receiving input services from other sectors. Fruits are extensively utilized in the local agroprocessing sector (i.e. food processors and foodservice providers), the cosmetic and medicine producing sector, the export sector as well as the retail sector of the economy. The uses and benefits of fruits in human daily food and nutrient requirements are well documented.

The total output performance of the industry (as portrayed in Figure 1.1 and 1.2) shows signs of output stagnation (i.e. from 2010 to 2011) and decreasing trend from 2012 through to 2013. A look at the sectoral performance shows; output has continued to decrease for the industry's leading export crops (i.e. pineapple since 2004 and banana since 2010). Though the strong output expansion of banana (i.e. 2005 - 2008) minimized the adverse side effect of the decline in the pineapple sector and helped sustain the industrial total performance; pineapple still continue to be the backbone of the fruit industry (i.e. pineapple $=66.2 \%$ share, banana $=$ $30.6 \%$ share, Mango $=3.2 \%$ share contribution to $2000-2013$ total export value) (Eurostat, 2013). Thus, the combined decline in the pineapple and the banana sectors had the following negative implications for the Ghanaian economy:

\footnotetext{
${ }^{5}$ Besides direct on-farm jobs for farmers and farm labourers, local and multi-national fruit processing companies provide a lot of jobs in the industry (e.g. Golden Exotics operation in 2008 was estimated to provide some 11,000 jobs in Ghana with about 2,200 employed directly in production) (Jaeger, 2008).
} 
(1) Worsening unemployment and poverty situations for the immense bulk of people whose livelihood depend on the industry's output performance (i.e. due to closing down of many small-medium scale domestic agro-processing companies while the surviving ones (i.e. big multinational companies) make up the deficit gap for raw materials through import to enable them meet their daily minimum requirement of their plants (Ablordeppey \& Arku, 2013).

(2) Loss of international market share and foreign exchange (i.e. due to insufficient quantity of fruits for export, the number of registered fruit exporters fell from 42 in 2004 to 8 in 2007(Manasseh, (2007)).

Ghana's pineapple export volumes to the EU fell by $40.4 \%$ from 52,000 tonnes in 2004 to 31,000 tonnes in 2013 while the banana sector fell by $19 \%$ from 53,000 tonnes in 2010 to 43,000 tonnes in 2013 (Eurostat, 2013). These figures indicate that, the performance of Ghana's fruit industry in recent past years has been disappointing since it failed to convert the excellent comparative advantages Ghana possesses in producing tropical fruits into real competitive advantage in the international market. The industry has not been able to take full advantage of the rapidly growing domestic and international demand for tropical fruits by expanding outputs to meet such demand trends. The slummy performance trend of the industry should be of great concern to policy makers due to the fact that, higher parts of rural and urban populations' livelihood and wellbeing are dependent on the industry's production and export operation.

A variety of factors contribute to the current sluggish productivity growth and dismal output performance trend in the industry. Such factors could be classified into two main groups as described below:

1) Factors under the influence of farmers (i.e. technical/production efficiency factors): these are factors which farmers could easily improve with the help of expect knowledge and technical support from agricultural professionals (i.e. extension officers) to enable them achieve higher outputs. Such factors typically include improving farmer's production skills (craftsmanship), knowledge and managerial capabilities in using available production techniques and resources more efficiently to help achieve higher outputs. Basic but important farm husbandry operations like; disease, pest and weed control as well as controlling the devastating effects of wind and water erosion or improving the cultivation methods of new varieties etc could be easily altered or improved with the help of expect knowledge through capacity build- 
ing or knowledge improvement of farmers. Though, finances (i.e. investment capability) and other socioeconomic characteristics of individual farmers (like education and experience) may dictate the pace/speed and extent of improvement that could be achieved. Still, these improvements could be perceived as being under the influence of farmers.

2) Factors outside the influence of farmers (i.e. factors which may cause a production region/area to lag behind technologically): these are conditions/factors prevailing in the production environment which farmers cannot easily change even with help from extension officers. This is because the financial and technical obligations to alter such factors may be beyond that of individual farmer capabilities. Such factors typically include construction, maintenance and or improvement in certain basic but important agricultural infrastructures and services. Provision and maintenance of infrastructures such as rural road network, electricity, ports, harbour, irrigation dams and important services such as those provided by extension workers may be outside the control/influence of individual farmer. Also, regulation of labour laws, land reforms and agricultural credits schemes which may influences production outcomes lies outside the influence of individual farmers. Development of commercial grade and specialized output enhancement technologies such as chemical fertilizer, pesticide, and certain improved green technologies may also be beyond the capabilities of individual farmers. Similarly, certain climatic and cultural conditions may place limitation on type of technology applicable in a region causing such regions to lag behind technologically.

This research therefore focuses on identifying and analyzing how these factors (i.e. both under and outside the influence of farmers) affect production performance of fruit farmers and how it impacts the industry output (productivity) as a whole. Considering the important contribution of the industry in Ghana's economy, it is reasonable to infer that significant economic and social progress could be achieved with massive performance improvement in the industry. Empirical information gathered from this study could be used by policy makers in two different ways in designing performance enhancing programs in the industry:

1) The technical efficiency estimates (i.e. a component of the analysis which measures the distance from an input-output point to the group frontier) could be used in designing production enhancing programs in a region. This involves changes or improvement to farm management capabilities and effectiveness of how farmers use available technologies and resources in that region to achieve higher yields. 
2) The estimates of technology gaps (i.e. a component of the analysis which measures the distance between the group frontier and the metafrontier) could be used in designing programs that enhance the production environment to enable farmers' in regions lagging behind technologically access the best production technologies in the industry.

Since many sectors of the economy depend directly or indirectly on the industry (due to the forward and backward linkages); a sound productivity enhancing policy mechanism base on empirical information will consolidate sustainable performance development efforts in the industry thereby contributing to the overall economic growth of the nation.

\subsection{Research Agenda}

The Ghana fruit industry is under intense pressure to increase its output to meet the increasing demand of both domestic and international markets as well as complying with burdensome quality and safety regulations from importing countries. To satisfy such escalating demand, the industry among other things has to dramatically enhanced production and output. The principal aim of this research is therefore to investigate the factors hindering successful and efficient performance of farmers in the fruit production industry using a cross country survey data from Ghana. In particular, we assessed the potential impact of technical inefficiencies and technology gaps on farmer's production outcome ${ }^{6}$. The study assesses possible socioeconomic and regional characteristics of sampled farm-households which drive production efficiency (i.e. which factors drive differences in technical efficiency in the Ghanaian fruit farming).

To ensure detailed and comprehensive study of the industry to aid achieve the above stated aim, this research uses both farm and household level survey data gathered across the major fruit producing regions. ${ }^{7}$ A range of research methods are employed to assessed the performance of the three major sectors which constitute the backbone of the Ghanaian fruit produc-

\footnotetext{
${ }^{6}$ Productivity clearly can influence the Ghanaian fruit industry participation and survival in the international market as well as the benefits accrued from participating in international trade. Achieving and maintaining high level of production efficiency is essential in the industry if output is to grow at a sufficient rate to meet the demand for export and local agro processing industries. Failure to achieve steady output growth in the industry to meet export demand could result in a drain of foreign exchange which in turn can seriously affect the growth of the industry. Enhancing production efficiency is therefore essential in increasing output while reducing production cost, thereby ensuring the competitiveness of the industry in the international market arena.
}

${ }^{7}$ The cross country field survey was done from June - December 2012 
tion industry (i.e. Mango production sector, Pineapple production sector and Banana production sector). These sectors constitute the core of the industry due to their economic importance and contribution to GDP. Empirical insights (i.e. results and conclusions) regarding the performance of these core sectors can guide policy makers in formulating better future polices to enhance the performance of the industry as a whole. Depending on research questions and specific objectives in each essay/paper, different methodological approaches were used to aid analyze production performance in the industry.

\subsection{Expected Contribution of Thesis to the Existing Literature}

Efficiency and productivity analysis studies of various agricultural produce have been reported from across the African continent; however, studies addressing the growing problems of decreasing productivity in the tropical fruit production industry (i.e. South-North flows of fruits) have received comparatively little attention in the literature on global high-value fruit chains. In this section, we briefly review of some of the recent studies in the field of efficiency and productivity analysis using frontier estimation techniques and how our study contributes in filling the gap in the existing literature.

Rao et al, (2012) used metafrontier and propensity score matching to analysed the effects of participation in supermarket chains on production efficiency of vegetable farmers in Kenya. Result of this study shows participation in supermarket channels increases productivity by $45 \%$. Okon et al, (2010) used stochastic frontier analysis to analysed technical efficiency effects on garden egg production in Uyo metropolis in Nigeria. The result of the study reveals that smaller farms were more efficient than larger ones.

Amor et al, (2010) applied stochastic production frontier in estimating technical efficiency of irrigated agriculture in Tunisia. Result of this study reveals wide variation of technical efficiency effect across farms where education, farmers age and irrigation technique were to reduce inefficiency. Nkamleu et al, (2010) use metafrontier estimation technique to investigate productivity potentials and efficiencies in cocoa production in West and Central Africa. Results were obtained by analysing a comprehensive data set collected from Cameroon, Ghana, Nigeria and Cote d'Ivoire. The result shows that technology gaps play an important role in explaining the ability cocoa sector in the Central African countries to compete with countries from West Africa. 
Kyei et al, (2011) used stochastic frontier estimation technique to analyse the factors affecting technical efficiency of cocoa farmers in the Offinso district of Ghana. The result of the analysis shows that farmer's education level, farming experience and farm size enhances efficiency. Dadzie et al, (2010) analysed the influence of Gender difference on the level of efficiency of arable food production in Ghana using metafrontier production function approach. Results of the study show that male farmers are more efficient than their female counter part in production of arable crops.

Onumah et al, (2010) applied stochastic frontier examined technical efficiency and its determinants of aquaculture farms in Ghana. The result of the study shows a mean technical efficiency of $80.8 \%$ in the aquaculture farms in Ghana. Similar study was carried by carried by Onumah and Brümmer (2010), however, the result of this study shows that, combined effect of operational and farm specific factors increase technical efficiency by $16 \%$ through adoption of practices of best fish farms. Onumah et al, (2013) employed metafrontier analytical technique to compare the efficiency level of organic and conventional cocoa production in Ghana. The result shows that conventional system of cocoa production is more technically efficient than the organic system.

Some of the articles/papers ${ }^{8}$ circulating online mostly in a form of reports/appraisal to governmental agencies, NGOs, international donor organizations on issues relating to the Ghanaian fruit industry include; Ghana horticulture scoping review by (Jaeger, 2008) prepared for Ghana's Ministry of Food and Agriculture (MOFA), the World Bank (WB) and the European Union (EU) examined ways to improve the value chain performance of the industry. Zakari, (2012) made an assessment report of Ghana's mango value chain to the international trade center (Geneva). Manasseh, (2007) assessed the role of certification in fair trade, a news brief to fair-trade foundation producer profile online. Though, most of such reports we came across contain valuable information on the state of the fruit industry, none of these reports embarked on empirical study utilizing a nationwide data set in the Ghanaian fruit industry to identify and distinguish causes of production inefficiency and technology gaps.

To the best of our knowledge, analysis specifically addressing causes of production inefficiency, technology gaps and its determinants for the entire fruit industry in Ghana are rare and so this thesis fills this void and contribute to the existing literature by using a unique set of

\footnotetext{
${ }^{8}$ These articles have not been published in any scientific or academic journal (i.e. not peer reviewed).
} 
cross-country data (i.e. data gathered from all the major commercial fruit production regions from the north to the southern parts of Ghana). Based on research objectives in each paper and using a statistical test; the appropriate analytical technique was employed to aid assessment of the performance of the industry.

\subsection{Overview of Essays/Papers}

This thesis consists of three studies, each of which aims to answer specific questions concerning factors affecting production performance in that sector of the industry by applying suitable methods. The first two papers are based on a stochastic metafrontier analytical approach while the third uses a stochastic distance function approach. The core of this dissertation is organized into chapters as follows:

I. Chapter Two: Drivers of Technical Efficiency and Technology gaps in Ghana's Mango Production Sector: A Stochastic Metafrontier Approach

II. Chapter Three: Determinants of MD2 Adoption, Production Efficiency and Technology Gaps in the Ghanaian Pineapple Production Sector

III. Chapter Four: A Multi-Output Production Efficiency Analysis of Commercial Banana Farms in the Volta Region of Ghana: A Stochastic Distance Function Approach

Chapter Five: presents general conclusion with some recommendations for future policies. The contributions of other sectors in ensuring the successful performance of the industry are highlighted. Research limitation and possible extension are discussed. A copy of field survey questionnaire, Curriculum Vitae and declarations requirement for the dissertation are included in this chapter.

Chapter Two: This chapter begins by highlighting the economic importance and contribution of the mango production sector to the Ghanaian economy. It presents a brief background describing how the sector has evolved over time. The current challenges facing the sector serve as the research motivation. Detailed information of the data structure and research area is presented in the essay. Stochastic metafrontier analytical approach was used to analyze factors affecting production performance in the sector (see section 2.1.4 in chapter two for detail discussion and justification for using this analytical approach). The metafrontier analytical tool adopted enabled us to separate inefficiencies caused by management and production practice 
from that of technology gaps. Result from the study reveals that each production zone requires specifically targeted program(s) in other to improve production efficiency and thereby increasing output. For instance, the efficiency estimates and distributions reveals that, in the northern zones where majority of farmers are observed to be operating on or near the zonal frontier but with a huge technology gap to the industrial frontier, policy intervention measures of raising technology level (such as introduction of high yielding mango varieties better suited to this zone) as well as improvement in infrastructure to aid breach the technology gap will be appropriate intervention policy for this zone. In the middle and southern zones, where average zonal performance indicate that majority of farmers are performing far below their zonal frontiers, policy intervention measures (such as enhancing access and improvement in extension service delivery) to help improve crop husbandry and management capabilities of farmers to enable better use of available technological know-how in these zones will be cost effective and prudent intervention strategy.

Chapter Three: This chapter starts by presenting brief background information on the pineapple production sector. Detail information on phases of success and crisis/challenges in the sector is discussed in the essay. A logistic regression model for the binary adoption variable is used to test the factors affecting farmers' decision to adopt MD2 variety in response to changes in international market demand. Result shows that farmers with higher off-farm income, capable of installing irrigation facilities to irrigate their farms, having access to regular and reliable pineapple market as well as farms located in the eastern regions are more likely to adopt the MD2 variety. Increasing health and environmental concerns especially in central Europe has encouraged the rapid growth of premium organic niche market in the EU. This has consequently force fruit exporters wishing to take advantage of such niche markets to exert pressure on farmers to also produce organic pineapple by enticing them with slightly high farm-gate prices. A metafrontier analytical model was therefore utilized to assess and compare the production performance of farmers producing organic or conventional pineapples in the sector. The empirical result shows high performance scores for the majority of farmers in both organic and conventional farming given the current technology available to the sector.

Chapter Four: This chapter begins with background information on commercial banana producers. It highlights the importance of the research area for banana production and the eco- 
nomic benefits of banana production to farmers, retailers and exporters. Traditionally, banana export trade has been dominated by a few multinational companies like Dole, Chiquita etc, however, the increasing use of refrigerated containers (i.e. the so called "reefer containers") in ships and regular direct cargo flights to Ghana's main export destination (i.e. EU) enabled easy delivery of high quality banana to supermarkets and retailers. This opened up opportunities for local exporters to directly supply the EU fruit market. However, unstable and low farm-gate price couple with frequent devastating effect of banana wilt disease forced a lot of farmers to resort to producing other crops beside banana as means of risk averting strategy. As a result of multi-output production nature of farmers in our sample, this chapter assess the production performance of commercial banana producers in the Volta region of Ghana using a stochastic multi-output distance function estimation technique. The empirical result shows, household socioeconomic factors such as farmer's education level, experience in farming, household size and regular contact to extension workers were found to improve production performance. However, the study recommends policy measures which facilitate transition from current traditional production techniques to use of modern production technologies in conjunction with improvement in transport, logistics and technical support services to enhance productivity gain on a sustainable basis in the sector. 


\title{
Chapter Two
}

\section{Drivers of Technical Efficiency and Technology gaps in Ghana's Mango Production Sector: a Stochastic Metafrontier Approach}

\begin{abstract}
Increasing mango output to meet demands for export, domestic agro-processing industries and the fresh fruit retail sector has become a major challenge to Ghana's fruit crop industry. After a successful take-off of the industry in the early 2000s, output over the subsequent years has continually decrease leading to closing down of many domestic agro-processing and exporting companies, lose of international market share and foreign exchange, high unemployment and worsening poverty situations in both rural and urban areas. The aim of this research is therefore to investigate the factors hindering successful and efficient performance of the mango production sector using a cross country survey data from Ghana. In particular, we assessed the potential impact of technical inefficiencies and technology gaps on farmer's production performance and productivity. The metafrontier analytical tool adopted enabled us to separate inefficiencies caused by management and production practice from that of technology gaps. The result from the study reveals that each production zone requires specific targeting program(s) in other to improve production efficiency and thereby increasing output.
\end{abstract}

Keywords: Stochastic Frontier, Metafrontier, Technical Efficiency, Meta-Technology Gap Ratio, Ghana Mango Sector.

\subsection{Introduction}

The mango sector plays a very important role in Ghana's economy. The sector generates employment as well as contributing fiscal revenue and foreign exchange to the economy (Afarisefa, 2007). Commercial mango production used to be concentrated mainly in the middlesouthern parts of Ghana (i.e. eastern and Volta region), however, the development of mango cultivation projects in the northern parts of Ghana by MOFA in collaboration with international development agencies (such as GIZ, ADRA and MOAP) as part of their rural employ- 
ment and poverty reduction strategy have contributed positively to the steady output growth in the sector. Ghana possesses an excellent comparative advantage in terms of climate, labour, and soil conditions in producing mango all year round ((Jaeger, 2008)(Mensah et al, 2012)). According to industry sources, Ghana is one of the few countries in the world with two major mango seasons; this means, improvement in production practices could enable the sector capitalized on its bi-seasons production capabilities to supply high volumes of quality fruits to the international mango market all year round (Ganry, 2007).

Due to the sector's high economic and growth potential, some agro-processing companies like the Integrated Tamale Fruit Company (ITFC) are in a contractual agreement to purchase all outputs from local farmers in outgrower schemes. At the time of data collection (i.e. 2012), the ITFC was supporting over 1,300 smallholder organic and conventional farmers around the Tamale municipality with inputs and other production resources to aid output expansion. The sector has also attracted some major multi-national agro-processing companies (e.g. Blue Skies with operations in South Africa, Ivory Coast etc.) to established production plant in the southern part of Ghana, processing high volumes of tropical fruits into specialized products (i.e. fresh cuts, dried, juice and concentrates) for export. The operational activities of such companies create jobs for both farmers in the rural areas and factory workers in the urban centres (Jaeger, 2003).

The sector generated about $€ 18,131$ million of foreign exchange revenue to the Ghanaian economy between 2000 and 2013 (Eurostat, 2013). The sector is currently the third major contributor of foreign exchange from the fruit industry to the economy. The steady expansion of production throughout the country has increased employment opportunities for many through its forward and backward linkage to other sectors of the economy. Among the variety of mangoes cultivated in Ghana, attention has been given to the cultivation of kent and keitt due to their low fibre content and high demand in the international markets.

The European Union is Ghana's main export market for mangoes and other tropical fruit products. In 2007, Ghana signed a bilateral trade agreement with the EU (i.e. the Economic Partnership Agreement-light (EPA-light))(Ashitey et al, 2012). This agreement greatly enhances the EU market access to the Ghanaian fruit industry since it get rid of tariffs on all Ghana's agricultural export to the EU and $80 \%$ of Ghana's imports from the EU over the next 15 years. The EU export mostly intermediate and processed agricultural products (e.g. frozen 
meat, poultry, milk powder etc) to Ghana. In 2011, Ghana's import from the EU accounted for about 35\% of total import value (Ashitey et al, 2012).

Figure 2.1.: Total Annual Value of Mango Exported to the EU (mil. Euro, 2000 - 2013)

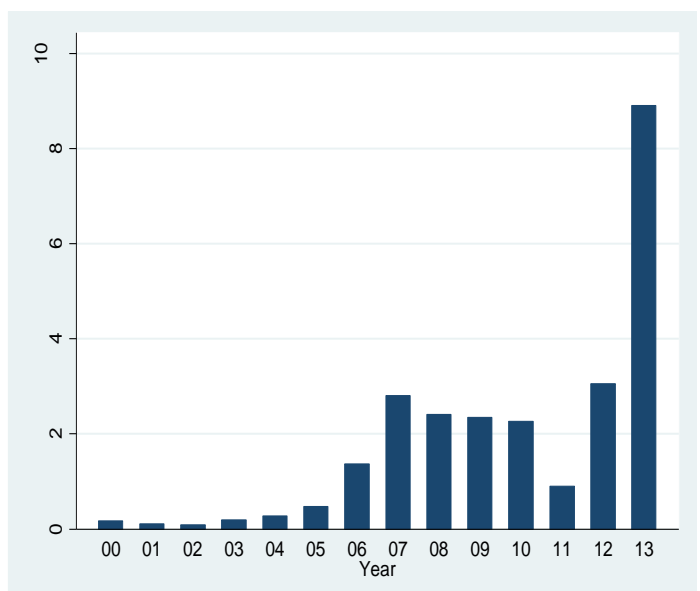

Source: Eurostat international trade data
Figure 2.2: Total Annual Quantity of Mango Exported to the $\mathrm{EU}(100 \mathrm{Kg}, 2000-2013)$

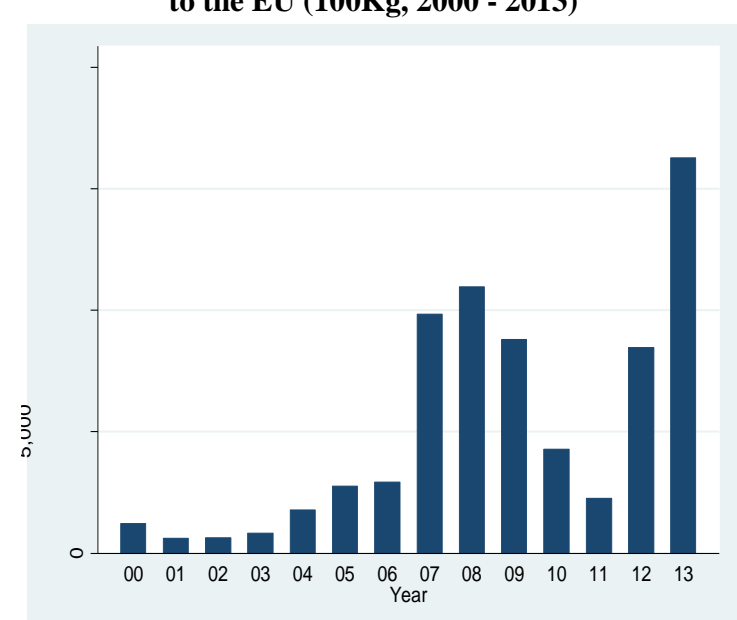

Source: Eurostat international trade data

In 2004, the European Union imported 170,000 metric tonnes of mangoes valued at more than $\$ 288,367$ million from around the world. Out of this, Ghana mango sector registered only 179 metric tonnes representing less than one percent of the total volume of mango imported to the EU (Ganry, 2007). In 2008, imports of mangoes into the EU-27 from around the world stood at 231,613tonnes, up by an average 8 percent annually since 1999 . In value terms, imports reached $€ 270,1$ million in 2008, up 6 percent annually over the period 1999 - 2008 (Eurostat, 2013). The mango sector exported just around 1000 tonnes of fresh mangoes valued at $\$ 3,553$ million to the EU in 2008(Trade maps, 2013). The total value import from around the world in 2013 stood at $\$ 791,644$ out of which Ghana registered only $\$ 11,953$ million (Trade maps, 2013). As weather conditions do not support commercial cultivation of tropical fruits in most parts of the EU, there is a high tendency that EU import volumes of such exotic tropical fruits will continue to grow in the coming years as demand for these fruits continue to expand (Pay, 2009).

Given Ghana's excellent comparative advantage for tropical fruit production and its close geographical proximity to the EU (Mensah, 2012); more could be done to expand output to enable the sector take full advantage of the rapidly expanding tropical fruit market in the EU. The initial export trend as depicted in Figure 2.1 above (i.e. 2000 - 2008) made some industry experts predict export quantity to exceed 40,000 tonnes if measures are put in place to im- 
prove production practices in the sector (Jaeger, 2008) as production area increased to over 17,000ha in 20009 (USAID/TIPCEE, 2009). However, this optimism was short lived as export volumes plummeted the subsequent year, and continued to decrease throughout 2011 . Though, the sector has begun exhibiting signs of recovery $(2012-2013)$, the generally low output performance of the sector as well as its low share in the international market (i.e. it currently supplies less than $1 \%$ of the EU market requirement) may be ascribed to a host of factors, among them are;

1) Deficiencies emanating from the production side of farmers do cause the export sector to perform suboptimal in the international market. Production inefficiency increases production cost through the waste of the inputs. This in turn reduces the price competitiveness of the sector in the international market.

2) Weakness in the supply chain mechanisms as well as the poor infrastructure state of the industry in Ghana. Enhancing shelf life and maintaining quality of fruits before it reaches its final sale destination is very dependent on postharvest care and handling. Thus, lack of proper storage or park houses couple with bad roads and improper transporting vehicles facilitates deterioration leading to high rejection rates of fruits marked for export.

3) Lack of adequate technical support mechanisms in a form of flexible production credit to enable resource poor farmers acquire output enhancing technical inputs (like fertilizer, pesticides etc.), hampers production efforts of such farmers who constitute the majority in the sector. However, programs which make available such support mechanisms for farmers could facilitate farmers' access to better production technologies which will in turn enhance output.

4) Socioeconomic as well as environmental factors (i.e. certain religious and cultural norms as well as unfavourable weather conditions prevailing in a production region could adversely affect the type of production technologies and therefore farm output).

These factors may be broadly categorized into two main domains; (1) the factors under the control of farmers (i.e. technical efficiency factors) and (2) those outside the control of farmers (i.e. technology gaps factors). This study has therefore embarked on identifying, and analysing these factors (i.e. those under and outside farmers' control) which influence farmers' production efficiency and output level in the mango production sector. We argue in this paper that, the best way to promote and sustain sectoral growth in the Ghanaian fruit industry is to be innovative, productive and efficient as much as possible. Lack of innovative technological 
advancement in the industry undoubtedly has undermined the performance of the entire fruit industry. However, output growth is not only determined by technological innovations in an industry but also by the efficiency with which available technologies are used by farmers in that industry (Nishimizu et al, 1982). Thus, in an industry where opportunities for development and spread of modern production technologies are lacking, efficiency and productivity analysis study is significant to assess how output in the mango sector could be raised with available production technologies.

Optimizing the use of available technological resources through improvement in production efficiency (i.e. obtaining maximum output with minimum inputs) to achieve higher yields could drastically enhance the price competitiveness of the sector through reduction in production cost. Likewise, policy strategies aim at taking out the impediments or inhibitions prevailing in the production environment causing a region to lag behind technological will help consolidate the objectives of future production enhancing measures (Battese et al, 2004). Empirical information gathered from this study could therefore be useful to policy makers in designing effective future intervention measures to help the sector harness its full economic potential.

\subsubsection{Research Objectives}

This study seeks to identify which factors drive differences in technical efficiency in the Ghanaian mango farming sector (i.e. the socioeconomic characteristics in the production environment and farm husbandry or management practices that influence mango production in Ghana). Specific objectives include:

1) Appropriate modelling of the underlying technologies of mango crop production in Ghana

2) Measurement of performance differences in the surveyed mango production regions in Ghana and decomposing these differences into technical efficiency and technology gap effects

3) Identification of factors influencing technical efficiency as well as technology gaps in the sampled regions so as to aid appropriate designing of production enhancing programs. 
Policy implication: To enhance effective policy formulation aim at improving production efficiency to support the ERP export diversification program (i.e. enhancing production, competitiveness and shares in the international market), it is of interest to distinguish between improvement programs aim at enhancing management capabilities of farmers (i.e. changes which improves farmers' efficiency of production) and programs aim at improving the production environment. Such specific targeting programs will guide intervention measures as to which region(s) needs technological and infrastructural enhancement to raise productivity (i.e. help move regional frontier as close as possible to the industrial frontier) and in which region it will be more prudent to support improvement of usage of current available technological knowhow (i.e. to guide expand output level as close as possible to the regional frontier). The study goes beyond just obtaining estimates of technical efficiency and technology gaps between production zones, but also analysed factors influencing these estimates. Hence, policy makers are provided with detailed empirical information to aid the formulation of future productivity enhancement programs.

\subsubsection{Research Area}

Ghana with a total land area of $238,533 \mathrm{~km}^{2}$ lies in the center of the West African coast and share land borders with Burkina Faso $(548 \mathrm{~km})$ to the north, Cote d'Ivoire $(668 \mathrm{~km})$ to the west and Togo $(877 \mathrm{~km})$ to the east. To the south are the Gulf of Guinea and the Atlantic Ocean. The country is divided into ten administrative regions as presented in Table 2.1 and Figure 2.3 below. These regions are characterised by huge differences in infrastructure (roads, inputs and outputs markets etc), climatic and soil conditions. Based on climatic conditions, the country is divided into six agro-ecological zones (see Table 2.2 below). Mangoes are tolerant to a wide range of soil and weather condition, making it possible to be grown commercially in many regions in Ghana. The growing areas extend from the coastal savannah through the deciduous forest in the middle zone to the Guinea savannah in the north.

The majority of commercial mango producing farms are located in the deciduous forest zones especially in the eastern and Volta regions. However, with involvement and support from NGOs and other development agencies, production in other regions (especially in the northern region) is rapidly expanding. 


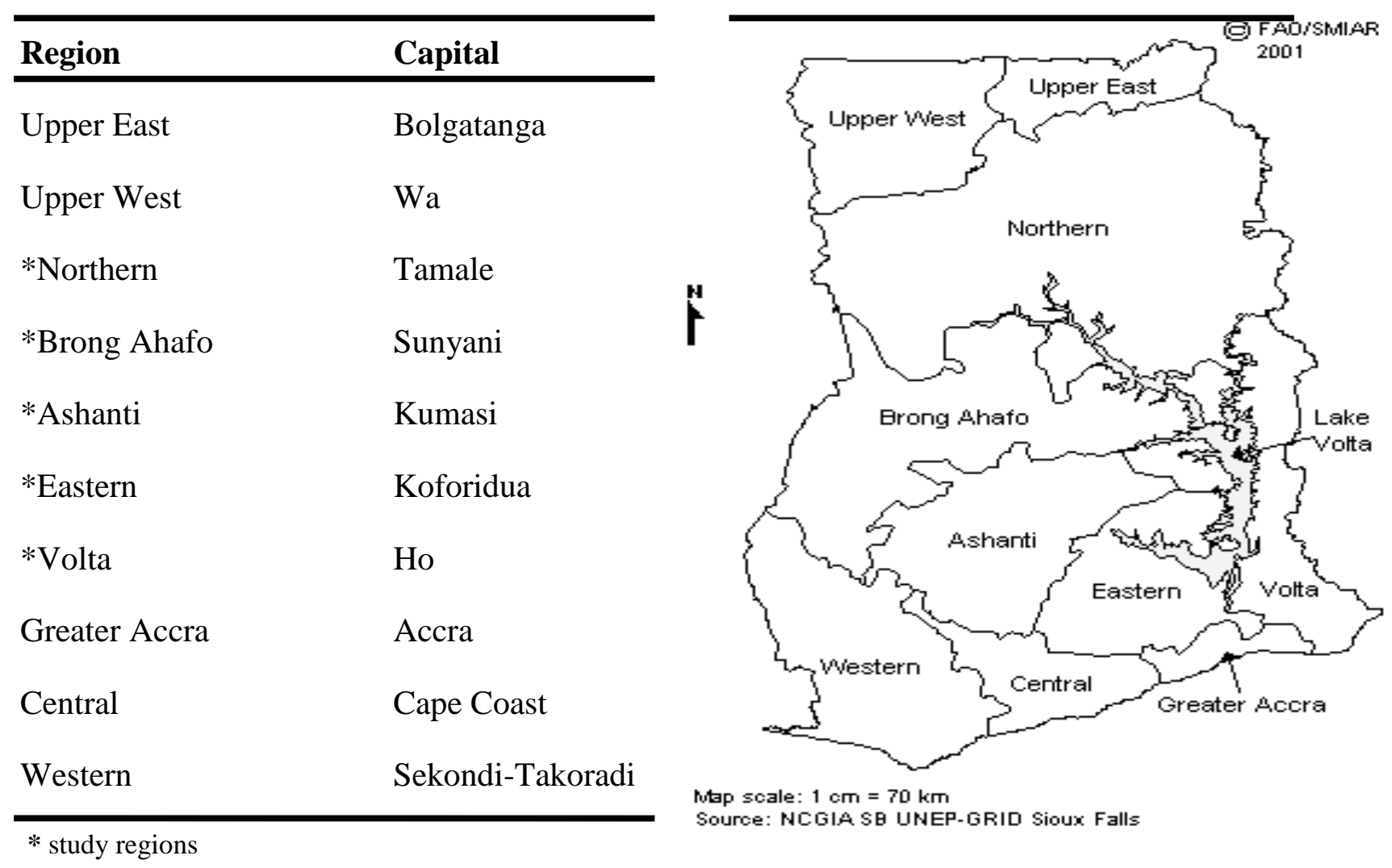

Information gathered from extension workers during data collection indicates; in regions where cocoa production is dominant or is the main farm activity (especially parts of Brong Ahafo, Western and Ashanti), adoption of mango as an alternative cash crop faces some resistance due to land scarcity as well as scepticism of old farmers with large land size refusing to undergo training to enter new production and marketing terrain of mangoes.

A distinct dry season (i.e. more than three months) is required to assist with initiation of fruit set. However, the intensity and extent of rainfall or harmattan dry season causes tree yield to fluctuate significantly from year to year depending on variety type. For instance, prolong rain season in the forest zones increases the incidence of fungal diseases and vegetative growth while a prolonged drought/dry season also increases water stress which affect flowering and fruit development. Seasonal variation in climatic factors therefore may affect the type of production technology (e.g. variety type) employed in a particular region. Annual farm outputs are directly influenced by regional weather conditions which induces alternate bearing characteristics inherent in certain varieties of mango trees. 
Table 2.2.: Agro-Ecological Zones of Ghana (from north to south)

\begin{tabular}{|c|c|c|c|c|c|c|c|c|c|c|c|}
\hline \multirow{2}{*}{$\begin{array}{l}\text { Agro-ecological } \\
\text { zone } \\
\text { Sudan savannah }\end{array}$} & \multirow{2}{*}{$\begin{array}{c}\begin{array}{c}\text { Area } \\
\left(\mathrm{km}^{2}\right)\end{array} \\
2200\end{array}$} & \multirow{2}{*}{$\begin{array}{l}\begin{array}{r}\text { Average annual } \\
\text { rainfall }(\mathrm{mm})\end{array} \\
1000\end{array}$} & \multicolumn{3}{|c|}{$\begin{array}{l}\text { Range } \\
(\mathrm{mm})\end{array}$} & \multicolumn{2}{|c|}{$\begin{array}{l}\text { Major rainy } \\
\text { season }\end{array}$} & \multicolumn{4}{|c|}{$\begin{array}{l}\text { Mi nor rainy } \\
\text { season }\end{array}$} \\
\hline & & & 600 & - & 1200 & May & - & Sept & & - & \\
\hline Guinea savannah & 147900 & 1000 & 800 & - & 1200 & May & - & Sept & & - & \\
\hline Transition zone & 8400 & 1300 & 1100 & - & 1400 & March & - & July & Sept & - & Oct \\
\hline Deciduous forest & 66000 & 1500 & 1200 & - & 1600 & March & - & July & Sept & - & Nov \\
\hline Rain forest & 9500 & 2200 & 800 & - & 2800 & March & - & July & Sept & - & Nov \\
\hline Coastal savannah & 4500 & 800 & 600 & - & 1200 & March & $-\mathrm{J}$ & July & Sept - & $\mathrm{Oc}$ & \\
\hline
\end{tabular}

Source: Ghana meteorological department, Accra-Legon

The magnitude of weather effect on output in Ghana depends on the severity of such factors in each of the three zones as classified in Table 2.2 above. In light of the high possibility of non-homogeneous production technology across the country and confirmation of statistical tests, this study uses a metafrontier estimation technique (see section 2.1.4 for further clarification) to assess the factors affecting production performance of farmers in the mango production sector.

\subsubsection{Data Set}

This research uses an integrated approach that draws upon both quantitative and qualitative ${ }^{9}$ methods of primary data collection. Based on information from district extension offices in each region, villages in each district where commercial mango production is prevalent are selected. Households producing mangoes were then sampled randomly from such villages. Selected households which refuse to take part in the survey were replaced with other households in a second round of sampling. Also, certain households just refused to continue or cooperate with interviewers in the later part of survey and were dropped from the sample without any replacement due to time constraints. In total, our sample comprises 365 mango farmers. Due to nearness and or some farms stretching between two regions, no significant difference in terms of soil and weather conditions could be observed. Hence, we decided to group the data into three zones as presented in Table 2.3 below. Using a structured questionnaire,

\footnotetext{
${ }^{9}$ Qualitative information are obtained during interaction with farmers, extension officers, village heads etc. while quantitative information are obtained using structured survey questionnaire (see chapter 5, page 137 for sample of questionnaire).
} 
detail information on mango production (e.g. input use, farm output volumes etc.) as well as some socioeconomic characteristics of sampled farmers was obtained.

Table 2.3.: Grouping of Regions into Zones

\begin{tabular}{lcc}
\hline \hline \multicolumn{1}{c}{ Zone } & Region(s) & Number of observation \\
\hline \hline 1. Northern Zone & Northern & 93 \\
2. Middle Zone & Brong-Ahafo and Ashanti & 91 \\
3. Southern Zone & Eastern and Volta & 181 \\
\hline \hline
\end{tabular}

Source: study findings base on 2012 field survey

Lack of proper documentation (i.e. systematic book keeping of production activities) of farm records by most farmers means most information obtained are recall information ${ }^{10}$. Ideally, all ten administrative regions in Ghana should have been included in the survey; however, upper east and upper west regions were dropped due to lack of commercial mango producers. Also, Western region could not be covered due to lack of records on an ample number of commercial mango producers since this region is predominantly cocoa producing region. No commercial mango production activity records could be obtained in the central region; hence, this region could not survey. In a nutshell, due to limited financial budget, time and logistical constraints, the above mentioned regions (as documented in Table 2.3) which reflect a fair representation of mango producing areas in Ghana were conceded appropriate for the survey.

\subsubsection{Why Metafrontier Analysis?}

Efficiency estimation ${ }^{11}$ using stochastic frontier analysis (SFA) and or data envelopment analysis (DEA) often assumes homogeneous production technology for all farmers in the in-

\footnotetext{
${ }^{10}$ Ideally, systematically well documented farming information would have been prefer as compare to recall information; since recall information could aggravate the problems of outlier in statistical estimation; This could be a draw back and so has to be kept in mind for interpretation.

${ }^{11}$ Recent developments in frontier modeling and efficiency measurement have been well documented by many authors (T. J. Coelli, 1995)(Bravo-ureta \& Pinheiro, 1977)(Andrew, 2010). Thus, a comprehensive review of the overall literature would require a whole research paper. Therefore, references cited may be consulted for further details on recent methodological developments.
} 
dustry. However, often in agricultural production, farmers in the same industry due to a variety of reasons such as quality and availability of important agricultural infrastructures (e.g. roads, ports etc), resource endowment (e.g. human and financial capital) and climatic constraints may be forced to operate under different production technologies. Such variation or differences in available stocks of physical, human and financial resources in terms of quality and availability compel farmers to use different production technologies (e.g. different plant variety or different bundle of input quality, application rate/frequency and amount).

As stated by Battese et al, (2004) "Technical efficiencies of firms that operate under a given production technology, which is assumed to be defined by a stochastic frontier production function model, are not comparable with those of firms operating under different technologies." Thus, failure to account for these technological differences risk attributing production shortfall due to technological gaps to technical inefficiency of farmers in that industry, ${ }^{12}$ hence, the need to employ an analytical method which allows technology gaps to be distinguished from technical inefficiency.

In this study, we adopt the metafrontier model proposed by Battese et al, (2004). This method enables the estimation of comparable technical efficiencies and technological gaps ratios for farms under different technologies relative to the potential technology available to the industry as a whole ${ }^{13}$. In an agricultural production context, the use of a metafrontier is usually justified when statistical test together with prior knowledge confirm farmer's in different regions uses different production technologies. Physical conditions (such as climate, soil and infrastructure) and other constraints prevailing in the production environmental may prevent farmers from making full use of certain production techniques even though it is available to them. Occasionally and in exceptional cases, application of such high output technology may be possible but only in the long run after scientist have introduced technologies which are able to deal with barriers posed by such physical condition (e.g. drought or frost resistant varieties). In other circumstances, farmers are not constrained by their physical environment in making use of a better production technology but still are not in a position to use such technologies because of lack of required infrastructure and or financial/investment constraints. Such situation typically arises with perennial fruit crops such as mangoes where pro-

\footnotetext{
${ }^{12}$ Labelling unobserved heterogeneity in production technology as inefficiency is inappropriate since it leads to bias estimation of the technical inefficiency parameters.

${ }^{13}$ Technological gaps due to climate conditions cannot be closed through policy or intervention programs, however, such empirical information is worth noting in shaping future policies in such regions.
} 
duction cycles span many decades. Often it is not feasible for farmers to replant their trees in the short or medium term even though more productive varieties may have become available since the initial planting (Villano et al (2010). Farmers in the northern savannah zone of Ghana face different climatic and soil conditions as well as lagging behind in terms of infrastructural development compared to that of the middle and the southern zones and this may induce variability in production practice.

We therefore use the metafrontier model to study and compare the productivity and efficiency of mango farmers in the different production regions of Ghana. The model enables us to separate causes of performance inefficiencies due to poor production practice (i.e. technical inefficiency) from that of technological lags (i.e. technology gap between the region and the industry). Empirical information gathered from technical efficiency and technology gaps estimates could be used in two different ways in designing performance enhancing programs:

1) Technical efficiency estimates (i.e. a component of the analysis which measures the distance from an input-output point to the regional/group frontier) could be used in designing performance enhancing programs involving changes to the management capabilities and effectiveness of how farmers use available technologies and resources in that region/zone to achieve higher yields.

2) Estimates of technology gaps (i.e. a component of the analysis which measures the distance between the group frontier and the industrial frontier) could be used in designing programs to enhance the production environment to enable farmers' access the best production techniques available in the Ghanaian fruit production industry.

Stakeholders and policy makers can influence the production environment through labour laws, market regulations and infrastructural development such as building roads to facilitate transport of both inputs and outputs. However, policy makers have very limited capacity in influencing certain physical conditions such as soil texture, structure, water holding capacity and infiltration rate or temperature, humidity and rainfall patterns as well as some cultural characteristics (e.g. religions, local traditions, customs and norms) of the production environment. If empirical analysis confirmed that such physical conditions prevent a region from making full use of available technologies and hence cause such regions to exhibit technology gaps or lags: Such information is worth noting but renders little or no help in designing programs to directly alter such physical conditions in order to improve the production environment. Such information however, does shed light on the suitability or comparative advan- 
$\operatorname{tage}^{14}$ of such regions in producing such a crop, hence, could shape future agricultural development policies towards such regions.

With this in mind, lessons learned from this study hopefully should assist both farmers and policy makers to device appropriate strategies to aid improve production efficiency and hence output in the sector. This could be achieved as farmers receive help and advice on how to improve production efficiency to enable them operate as close possible to their regional frontier and or policy makers improving the production environment through legislation and infrastructural development. Such specific targeting measures are cost effective and economically sustainable and will help improve the performance of the fruit crop industry as a whole.

\subsection{Analytical Framework}

\subsubsection{The Stochastic Metafrontier Model}

Building on the work of Hayami (1969), Hayami and Ruttan (1970, 1971), Battese and Rao (2002) and Battese et al, (2004) propose the stochastic metafrontier technique as an improved estimation approach over the classic stochastic frontier approach (SFA) and data envelopment analysis (DEA) to investigate the technical efficiencies of firms in the same industry that may not have or use the same technology ${ }^{15}$. The metafrontier conceptually represent a boundary of an unrestricted technology set potentially available to the industry as a whole, while the zonal frontier represent the boundaries of restricted technology sets where the restrictions may be due to constraints prevailing in the production environment (e.g. lack of agricultural infrastructure) which limit farmers in certain zone/region from using the full range of technologies potentially available to the industry (O’Donnell et al, 2008).

The metafrontier estimation technique therefore enables technology gaps to be estimated for groups under different technologies relative to the potential technology available to the industry as a whole. In line with Battese et al, (2004) the metafrontier is assumed to be a smooth function (not a segmented envelope) that envelope all the frontiers of the individual groups (zones) in the industry. This could be conceptually depicted as in Figure 2.4 below:

\footnotetext{
${ }^{14}$ For instance, if empirical evidence shows that, mango needs more production resources (e.g. water) than could be available in a region, then using scarce resources to continue mango production may not be the most cost effective production venture in term of economic reasoning for such a region.

${ }^{15}$ Technology in this study is broadly defined as the state of knowledge, skills and production tools pertaining to the transformation of agricultural inputs into outputs.
} 


\section{Figure 2.4.: Metafrontier Function Model}

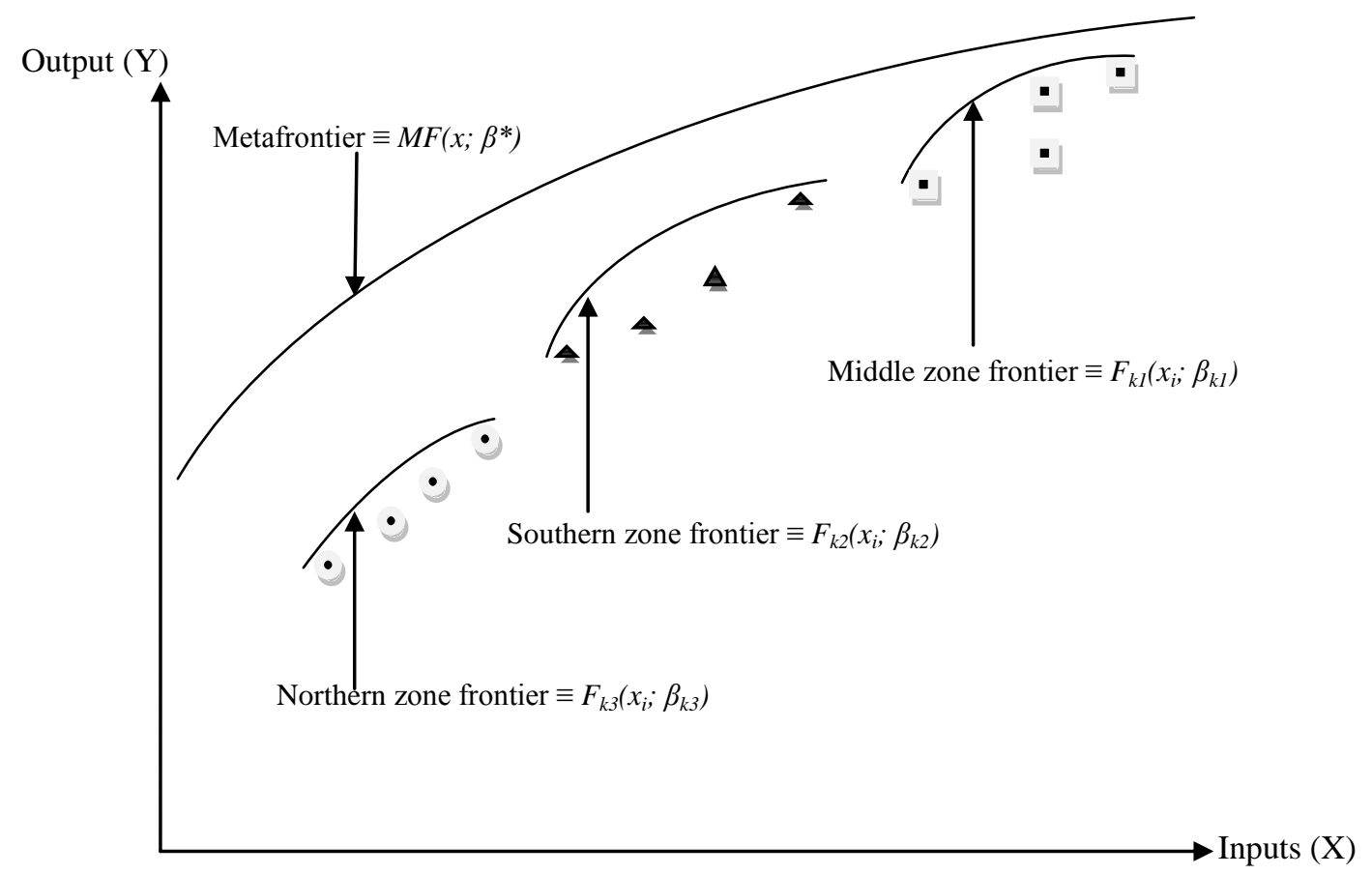

Source: author's owned conceptual depiction

In 2012, a field survey was carried out to gather data on production inputs and output by farmers in the Ghanaian mango sector. If we then, assume that stochastic frontier production function model is appropriate for the $k$ different zones as classified in Table 2.3 in the sector. Then considering $k$ zones in the mango sector, a standard stochastic frontier model for zone $k$ could be specified as:

$$
Y_{i(k)}=f\left(x_{i}, \beta_{(k)}\right) e^{v_{i(k)}-u_{i(k)}} \equiv e^{x_{i} \beta_{(k)}+v_{i(k)}-u_{i(k)}} .
$$

The expression in model (1) assumes that the exponent of the frontier production function is linear in the parameter vector, $\beta_{(k)}$, so that $x_{i}$ is a vector of functions (e.g. logarithms) of the inputs for the ith farmer involved in the sector. Where $Y_{i(k)}$ denotes the output for the ith farmer for the kth zone; $x_{i(k)}$ denotes a vector of inputs used by the ith farmer in the kth zone; the functional form $f($.$) is specified as translog function as defined in section (3.2), so$ $\beta_{(k)}$ denotes the parameter vector/coefficients associated with the $X$-variables for the translog stochastic frontier for the $k t h$ zone; the $v_{i(k)}$ s are noise error term which is assumed to be identically and independently distributed as $N\left(0, \sigma_{v(k)}^{2}\right)$ (Aigner et al, 1977) random variables, 
independent of the inefficiency term $u_{i(k)}$. The $u_{i(k)} \mathrm{s}$ are a systematic and non-negative random variables which account for technical inefficiency in production which is under the influence of farmers and are assumed as the truncation (at zero) ${ }^{16}$ of the $N\left(0, \sigma_{u_{i(k)}}^{2}\right)$ distributions such that the $u_{i(k)}$ S are defined as in (Wang \& Schmidt, 2002);

$\sigma_{u_{i(k)}}=\exp \left\{z_{i(k)} \delta_{j}\right\}$

Where $z_{i(k)}$ is explanatory variables of the variance of inefficiency term $\sigma_{u_{i(k)}}$ for the ith farmer; $\delta$ is a vector of parameters to be estimated, reflecting the impact of the variables $Z_{i(k)}$ on technical inefficiency (i.e. equation (2) captures the impact of specified farmers input endowments and socioeconomic variables hypothesised to influence technical efficiencies in the mango production sector). A positive or negative estimate of $\delta$ indicates that the corresponding variable leads to an increasing or decreasing variance of the inefficiency term (i.e. increasing or decreasing technical efficiency). Model (2) generally known as "heteroscedasticitymodel" was developed by Wang and Schmidt in (2002) for stochastic production frontier estimation framework. This model was chosen as an inefficiency determinant model for this study due to the fact that it correct for possible heteroscedasticity which is often present in cross-section survey data(s). The specification of model (1) which implicitly assumes that, both error terms (i.e. $v$ and $u$ ) are homoscedastic (i.e. conditioned on the explanatory variables, the variance of the unobserved combined error term $(\varepsilon=v+u)$ are constant $)$. However, since our sample is a cross section survey data and considerable variation in terms of farm size and other inputs usage were observed, it is likely both error terms are affected by heteroscedasticity (i.e. the inefficiency term would vary according to farm size with larger farms having more variation than small farms (Lakner et al, 2013). Hence, if such heteroscedasticity effects are not corrected, it implies estimated standard errors are biased and we cannot use tstatistics for drawing inferences.

The metafrontier production function model for farmers in the whole mango production industry could be expressed as:

\footnotetext{
${ }^{16}$ i.e. half-normal distribution are assumed for the $u_{i(k)} \mathrm{s}$
} 
$Y_{i}^{*} \equiv f\left(x_{i} ; \beta^{*}\right)=e^{x_{i} \beta^{*}}, \quad i=1,2, \ldots, N_{k}, N=\sum^{3}{ }_{j=1} N_{j}$

Where $Y_{i}^{*}$ is the metafrontier output and $\beta^{*}$ denotes the vector of parameters for the metafrontier function satisfying the constraints:

$x_{i} \beta^{*} \geq x_{i} \beta_{(k)}$ for all $k=1,2,3$.

Model (4) specifies that the metafrontier dominates all the zone frontiers. The metafrontier production function as specified by equation (3) is a log linear production function form and the constraint imposed in equation (4) does not allow the metafrontier function to fall below the deterministic functions for the three zones involved in the sector (Battese et al, 2004). The model is underpinned by a single data generating process as suggested by O'Donnell et al (2008). The estimated metafrontier function which enveloped the three estimated zonal frontier was obtained by solving the optimization problems in equations (10) and (11).

The observed output for the ith farmer defined by the stochastic frontier for the $k t h$ zone in equation (1) is alternatively expressed in terms of the metafrontier function of equation (3) by:

$Y_{i}=e^{-u_{i(k)}} \times \frac{e^{x_{i} \beta_{(k)}}}{e^{x_{i} \beta^{*}}} \times e^{x_{i} \beta^{*}+v_{i(k)}}$

The first term on the right-hand side of equation (5) is the technical efficiency of the ith farmer relative to the stochastic frontier for the kth zone. Equation (6) which is the same as the first term on the right hand side of equation (5) allows us to examine the performance of the $i$ th farmer relative to his/her individual zonal frontier.

$T E_{i(k)}=\frac{Y_{i}}{e^{x_{i} \beta(k)+v_{i(k)}}}=e^{-u_{i(k)}}$ 
The second term on the right-hand side of equation (5) is what Battese et al, (2002, 2004) call Technology Gap Ratio(TGR)while O’Donnell et al, (2008) call it Meta Technology Ratio (MTR) for the observation of the sample farms involved in the sector. This is expressed as:

$$
\operatorname{MTR}_{i(k)}=\frac{e^{x_{i} \beta(k)}}{e^{x_{i} \beta^{*}}}
$$

This measures the ratio of the output for the frontier production function for the $k t h$ production zone relative to the potential output that is defined by the metafrontier function, given the observed inputs. This ratio provides an estimate of the technology gap between the zones and the mango sector as a whole. The MTR plays an important part in explaining the ability of farmers in one zone to compete with farmers from different zones in the sector. The technology gap ratio has values between zero and one because of equation (4). Values close to one imply that the farmers in that zone are producing on or nearer to the maximum potential output given the technology available to the sector as a whole.

The technical efficiency of the $i t h$ farmer compared to the metafrontier, is denoted by $T E_{i}{ }^{*}$ and is defined in a similar way to equation (6). It is the ratio of the observed output of the ith farmer relative to the metafrontier output (i.e. last term on the right hand side of equation(5)) adjusted for the corresponding random error, such that:

$T E_{i}^{*}=\frac{Y_{i}}{e^{x_{i} \beta^{*}+v_{i(k)}}}$

Following equations (5), (6), and (7), the $T E_{i}^{*}$ can alternatively be expressed as

$$
T E_{i}^{*}=T E_{i(k)} \times M T R_{i(k)}
$$


So the technical efficiency relative to the metafrontier $\left(T E_{i}^{*}\right)$ is the product of the technical efficiency relative to the stochastic frontier of a given zone $\left(T E_{i(k)}\right)$ and the metatechnology ratio $\left(M T R_{i(k)}\right)$ for that zone. Because both $T E_{i(k)}$ and $M T R_{i(k)}$ are measures between zero and one, the value of $T E_{i}^{*}$ is also between zero and one but could be less than or equal to the technical efficiency relative to the stochastic frontier for the zone of the ith farmer (i.e. $\left.T E_{i}^{*} \leq T E_{i(k)}\right)$.

In line with Battese et al, (2004) and O'Donnel et al, (2008), we estimated the parameters and measures associated with the metafrontier model of equations (3) and (4) as follows:

1) We obtained the maximum likelihood estimates, $\hat{\beta}^{\mathrm{k}}$ for the $\beta^{\mathrm{k}}$ parameters of the stochastic frontier for the $k t h$ zone using the statistical software OxMetrics (Doornik version 7).

2) We then estimated, $\hat{\beta}^{*}$, for the $\beta^{*}$ parameters of the metafrontier function such that the estimated function best envelops the deterministic components of the estimated stochastic frontiers for the different zones.

3) The metafrontier parameters are obtained by minimizing the sum of squares of deviations and the sum of absolute deviations of the metafrontier values from those of the group ${ }^{17}$.

The numerical values of the metafrontier parameters are obtained using the OxMetrics programming language (Doornik) in solving equations (10) and (11) below ${ }^{18}$ :

$\min L P \equiv \sum_{i=1}^{N}\left|\left(\ln f\left(X_{i}, \beta^{*}\right)-\ln f\left(X_{i}, \hat{\beta}_{K}\right)\right)\right| \quad$... Linear optimization function ${ }^{19}$

\footnotetext{
${ }^{17}$ Please refer to Battese et al, (2004) and Rao, Brümmer and Qaim (2012) and O’Donnell et al, (2008) for detailed outline of how to obtain both the minimum sum of absolute deviations and minimum sum of squares of deviations.

18 As outlined by (Rao et al., 2012) in solving equation (10) and (11), the $\hat{\beta}_{\mathrm{K}}$ are treated as fixed. So that the second term in the summation is constant with respect to the minimization.

${ }^{19}$ The $f\left(X_{i}, \beta^{*}\right)$ in equation (3) is log-linear in the parameters (as assumed in this thesis), hence the optimization problem in equation (10) could be solved by linear programming (O'Donnel et al, (2008).
} 
s.t. $\ln f\left(X_{i}, \beta^{*}\right) \geq \ln f\left(X_{i}, \hat{\beta}_{K}\right)$ for all $i$.

$\min Q P \equiv \sum_{i=1}^{N}\left(\ln f\left(X_{i}, \beta^{\sim}\right)-\ln f\left(X_{i}, \hat{\beta}_{K}\right)\right)^{2}$

s.t. $\ln f\left(X_{i}, \beta^{\sim}\right) \geq \ln f\left(X_{i}, \hat{\beta}_{K}\right)$ for all $i$

Where $\ln f\left(X_{i}, \hat{\beta}_{K}\right)$ is the logarithm of the estimated deterministic component of the stochastic frontier for the $k t h$ region, associated with the translog production function that is used in the empirical application.

Estimates for the technical efficiencies of all farmers relative to the metafrontier function were then obtained by:

$\hat{T E}_{i}^{*}=\hat{T E_{i(k)}} \times \hat{M T R}_{i(k)}$

Where $T E_{i}$ is the predictor for the technical efficiency relative to the given zone frontier as proposed by O'Donnell et al, (2008). The $M T R_{i(k)}$ is the estimate for the $M T R_{i(k)}$ for the ith farm in the kth group relative to the sectoral potential, obtained by using the estimates for the parameters involved (specifically, the MTR is estimated by substituting estimates of $\beta_{(k)}$ and $\beta^{*}$ into equation (7), the constraints in the LP problem defined by equation (10) guarantee that metatechnology ratios estimated in this manner will lie in the unit interval). Standard errors for the estimators for the metafrontier parameters were obtained using statistical simulations (specifically, we used the estimated asymptotic distributions of the zonal frontier estimators to draw $\mathrm{M}=5,000$ observations on the zonal frontier parameters. Each draw was then used to calculate the right-hand side of the constraints in the LP/QP problems. The estimated standard errors of the metafrontier estimators were calculated as the standard deviations of the M solutions to these LP/QP problems (Battese et al, 2004). 


\subsubsection{Empirical Specification}

The empirical result for this study was obtained using translog stochastic frontier production function model. The choice of translog model is based on confirmation of a statistical test (see table 2.4 below) and its flexibility which allows us to examine interaction between production inputs. A translog model of equation (1) which is assumed to represent the production technology for mango farmers in a particular zone could be defined as:

$\ln y_{i}^{k}=\beta_{0}^{k}+\sum_{j=1}^{J} \beta_{j}^{k} \ln x_{j i}^{k}+1 / 2 \sum_{j=1}^{J} \sum_{m=1}^{J} \beta_{j m}^{k}\left(\ln x_{j i}^{k}\right)\left(\ln x_{m i}^{k}\right)+\sum_{s=1}^{S} \beta D_{s}+v_{i}^{k}-u_{i}^{k} 20$

Where $\ln x_{j i}^{k}$ represents the $j$ th input $(j=1,2, \ldots . J)$ of the $i$ th farmer $(i=1,2, \ldots N)$ in the $k t h$ zone $(k=1,2, \ldots K) \cdot \beta_{j m}^{k}=\beta_{m j}^{k}$ for all $j$ and $m$. $\ln y_{i}^{k}$ denotes the natural logarithm of the total fruit output (measured in $\mathrm{kg}$ ) for the ith farmer in the $k t h$ zone. The $X_{s}$ represents the various continuous/discrete production inputs variables (i.e. land, labour, fertilizer cost and plant age). $\mathrm{D}_{\mathrm{s}}$ are dummy variables (i.e. extension, irrigation, credit access, gender and farmer association) intended to capture unique regional and household socioeconomic characteristics which may influence production output(s) levels of farmers. The discrete variables in the model were scaled to have unit means so that, the first-order coefficients of the translog function can be interpreted as elasticities of output with respect to inputs evaluated at the sample means (Coelli et al, 2005).

For appropriate policy interventions, it is not enough to only have estimates of technology gaps between each zone and the industrial frontier but also information on what might have contributed to the formation of these gaps. We therefore specify an average response function to capture the determinants of the technology gap ratio as follows:

$M T R_{i}=\beta_{0}+\sum_{j=1}^{J} \beta_{j} q_{i j}+\varepsilon_{i}$

\footnotetext{
${ }^{20}$ The $u_{i}^{k}$ is assumed to be defined as in equation (2).
} 
Model (14) specifies climatic, soil, infrastructural and Government program variables outside the control of farmers hypothesised to influence the production environment of the mango production sector (i.e. the $q_{i j}$ are hypothesised explanatory variables influencing MTR in each zone). The $\varepsilon_{i}$ captures any statistical noise and is assumed to be identically and independently distributed as $N\left(0, \sigma_{v}^{2}\right)$ random variables.

\subsection{Results and Discussion}

Empirical results were obtained by using Stata $\left(11^{\text {th }}\right.$ edition $)$ and OxMetrics statistical software. The translog stochastic frontier model which incorporates the inefficiency model, defined by equations (13) and (2) respectively was estimated using data on mango farmers in a given zone. The technical efficiency of individual mango farmers are estimated relative to the technology of that zone as defined by the translog stochastic frontier model (13) whiles technical efficiencies of all mango farmers in the sample were estimated relative to the metafrontier function as defined by model (12). Determents of the MTR were obtained using equation (14). Full tables are presented at the end of the paper in a chronological order as the rest of this section (see appendix A for full tables).

\subsubsection{Summary Statistics}

The total number of mango farmers sampled across the three zones is 365 . Table 2.2 in page 19 presents information on how the regions where data were collected are grouped into zones and the number of observation for each zone. Descriptive statistics and definition of all the variables used in the analysis are presented in Tables 2.10, 2.11 and 2.12 (see appendix A). A look at the means and standard deviation of the various variables shows considerable differences between these three zones. For instance, on average; farmers in the southern zone have higher farm output, allocated more land area to mango production and have better access to extension. They also have higher expenditure on agrochemicals and a large proportion of farmers irrigate their plantations. These differences between the three zones suggest that production practices or the type of production technology may differ between these zones. Even though the descriptive analysis gives us a quick overview of our sampled data, it does not however, give any detail causal information (i.e. chance, errors or statistical significance). It does not tell us whether these differences affect farmer's efficiency of production or what 
accounts for these inefficiencies, hence; we use a metafrontier estimation model to obtain estimates of farmer's technical efficiency level and technology gaps between these zone as well as factors influencing these estimates.

\subsubsection{Test for Model Specification}

Table 2.4 below presents information on the various hypotheses tested in this study (These hypotheses are tested using the generalized likelihood-ratio statistic; $L R=-2[\ln \{L(\mathrm{H} 0)\}-$ $\ln \{L(\mathrm{H} 1)\}]$, where $L(H 0)$ and $L(H 1)$ are values of the likelihood function under the null $(H 0)$ and alternative $(H 1)$ hypotheses, respectively. $L R$ has approximately a Chi-square (or mixed Chi-square) distribution if the given null hypothesis is true with a degree of freedom equal to the number of parameters assumed to be zero in (H0). Coelli (1995) proposes that all critical values can be obtained from the appropriate Chi-square distribution. However, if the test of hypothesis involves $\gamma=0$, then the asymptotic distribution necessitates the mixed Chi-square distribution (Kodde and Palm 1986; Table 1).

A use of metafrontier is meaningful and justified only if a statistical test confirms the presence of competing technologies or differences in the underlying technology between groups in the same industry(O’Donnell et al, 2008). A likelihood-ratio test was performed to examine if all farmers in the three zones share the same underlying technology. Using maximum likelihood estimation procedure, value of the log-likelihood function for the stochastic frontier estimated by pooling the data for all zones and the sum of the values of the log-likelihood functions from the individual zonal production frontiers was computed to verify if the various groups share different technologies and hence the necessity to adopt a metafrontier as an appropriate framework to estimate and to compare the technical efficiency across zones.

As presented in Table 2.4 below, the null hypothesis of homogeneous technology among all mango farmers across Ghana was strongly rejected; hence, the metafrontier framework adopted for the analysis is appropriate and justified. The null hypothesis that the CobbDouglas frontier is an adequate representation of the data for all zones was strongly rejected indicating that the translog model represents the data better. The null hypothesis that technical inefficiency is not present in all zones was also rejected implying majority of farmers operate below the production frontier. 
Table 2.4.: Hypothesis Testing for Stochastic Production Frontier Model

\begin{tabular}{|c|c|c|c|c|}
\hline Null hypothesis (Ho) & $\chi^{2}$ Statistics & $\begin{array}{l}\text { Deg. of } \\
\text { freedom }\end{array}$ & $x^{2}$ Critical & P-value \\
\hline Homogenous technology across all regions & 118.02 & 53 & 70.99 & 0.00 \\
\hline \multicolumn{5}{|l|}{ Cobb-Douglas functional form is appropriate: $\beta_{\mathrm{ij}}=0$} \\
\hline Northern Zone (Northern region) & 26.12 & 6 & 12.59 & 0.01 \\
\hline Middle Zone (Brong-Ahafo \& Ashanti region) & 33.46 & 6 & 12.59 & 0.00 \\
\hline Southern Zone (Eastern \& Volta region) & 1.96 & 6 & 12.59 & 0.01 \\
\hline \multicolumn{5}{|l|}{ No technical Inefficiency effects: $\gamma=0=\delta 1=\ldots=\delta 9=0$} \\
\hline Northern Zone (Northern region) & 27.13 & 9 & 14.067 & 0.01 \\
\hline Middle Zone (Brong-Ahafo \& Ashanti region) & 10.07 & 9 & 14.067 & 0.01 \\
\hline Southern Zone (Eastern \& Volta region) & 14.68 & 9 & 14.067 & 0.01 \\
\hline
\end{tabular}

Source: study findings based on 2012 field survey data.

For the determinants of the MTR model, a likelihood-ratio Chow test performed (see table 2.13 in appendix A) rejects the null hypothesis that the pooled model regression coefficients do not differ between the three zones. This suggests that using information from the zonal regression coefficients for program designed is more reliable.

\subsubsection{Parameter Estimates of the Stochastic Frontier}

The full table of the maximum likelihood estimates for the parameters of the translog zonal stochastic frontier production function together with the inefficiency model are presented in Table 2.14 of appendix A. The dependent variable is total farm output measured in kilograms. ${ }^{21}$ Independent variables includes: land, labour, fertilizer cost, extension, irrigation, credit access, and gender and farmer association. Table 2.5 presents the estimated first order coefficients of these inputs and their impact on the output (i.e. it shows how much mango output would increase in percentage terms if the use of these respective inputs was increased

\footnotetext{
${ }^{21}$ Farm output as measured here does not take into account fruit size, quality, the number of harvesting times and post harvest losses. This could be a draw back and so has to be kept in mind for interpretation.
} 
by $1 \%$ ). The result in Table 2.5 reveals some differences between the different zones in terms output elasticities with respect to these inputs.

Total farm output is positively and significantly influenced by total amount of land allocated to fruit crop production in all three zones. This reflects the importance of access to land in mango production. The northern zone experienced the highest output elasticity with respect to the input variable land. The positive and significant coefficient of land (i.e. 1.05) implies a an increasing return to scale in terms of land expansion (i.e. increasing marginal productivity with respect to land access) in the northern zone while the opposite effect of decreasing return is experienced in the southern and middle zones.

Increasing population growth due mainly to rural-urban youth migration particularly from the northern zone to the southern and middle zones urban centres (i.e. Accra and Kumasi respectively) couple with rapidly increasing urbanization process in these two zones relative to the northern zone put pressure on potential agricultural land for mango cultivation. Hence, farmers in the northern zone have relative ease of expanding their plantations compare to farmers in the middle and southern zones.

The total hours of time workers spend working on a plantation have a positive and significant effect on output in the southern and middle zone but surprisingly not in the northern zone. Increasing labour participation in farm maintenance and other agronomic practices should ideally have positive and significant effect on output; hence, the non-significant effect of labour input in the northern zone contradicted our expectation. However, this observation could be explained by decreasing labour availability due to constant youth migration from the northern zone to the southern and middle zone which limits farmers in the northern zone access to youth labour. As revealed during data collection, farmers in the northern zone often use more animal draft power and farm machinery (e.g. donkeys, tractors, knapsack sprayers etc) in performing most farm operations compare to their counter parts farmers in the middle and southern zones which rely on abundantly cheap influx of youth labour force from the north in performing most farm operations. Fertilizer use has significant positive effects only in the northern zone whiles plant age have the same effect except in the middle zone.

A set of dummy variables which are assumed to capture regional and household socioeconomic characteristics had positive and significant effects on total farm output. However, the effect of these variables differs remarkable on how they influence the production possibility frontier between the three zones. For instance, extension has positive and significant effect 
in the northern and middle zones whiles irrigation has the same effect except in the northern and southern zones. Male farmers have significantly positive effect on output in the middle and southern zones whiles being a member of a farm association have the same effect only in the northern zone. Positive and significant effects were also observed by interaction of land with fertilizer in all zones (see Table 2.14 in appendix A).

Table 2.5.: First Order Estimates of the Translog Stochastic Frontier Models

\begin{tabular}{|c|c|c|c|c|c|c|c|c|}
\hline \multirow{2}{*}{$\begin{array}{c}\text { Variable } \\
\text { Name }\end{array}$} & \multicolumn{2}{|c|}{ All zones pooled } & \multicolumn{2}{|c|}{ Northern Zone } & \multicolumn{2}{|c|}{ Middle Zone } & \multicolumn{2}{|c|}{ Southern Zone } \\
\hline & $\begin{array}{l}\text { Coeffi- } \\
\text { cient }\end{array}$ & SE & $\begin{array}{l}\text { Coeffi- } \\
\text { cient }\end{array}$ & SE & $\begin{array}{l}\text { Coeffi- } \\
\text { cient }\end{array}$ & SE & $\begin{array}{l}\text { Coeffi- } \\
\text { cient }\end{array}$ & SE \\
\hline Constant & $-0.310 * *$ & 0.118 & -0.137 & 0.181 & -0.252 & 0.165 & -0.367 & 0.259 \\
\hline log land & $0.597 * * *$ & 0.069 & $1.050 * * *$ & 0.267 & $0.861 * * *$ & 0.120 & $0.469 * *$ & 0.211 \\
\hline log labour & $0.450 * *$ & 0.210 & -0.801 & 1.066 & $0.975 * *$ & 0.396 & $0.696 *$ & 0.429 \\
\hline $\log$ fertilizer cost & $0.220 * * *$ & 0.056 & $1.894 * * *$ & 0.297 & 0.175 & 0.147 & 0.230 & 0.159 \\
\hline log plant age & $0.310 * * *$ & 0.107 & $0.970 * * *$ & 0.150 & -0.074 & 0.253 & $0.415^{* *}$ & 0.173 \\
\hline Extension (dummy) & $0.093 *$ & 0.056 & $0.409 * * *$ & 0.101 & $0.203 * *$ & 0.101 & -0.072 & 0.089 \\
\hline Irrigation (dummy) & $0.226 * * *$ & 0.075 & $0.343 * * *$ & 0.086 & -0.069 & 0.113 & $0.448 *$ & 0.235 \\
\hline Credit access (dummy) & $0.090 *$ & 0.053 & -0.144 & 0.126 & 0.090 & 0.109 & 0.019 & 0.069 \\
\hline Gender (dummy) & 0.087 & 0.066 & $-0.203^{*}$ & 0.113 & $0.311 * *$ & 0.119 & $0.139 *$ & 0.082 \\
\hline Farmer assoc (dummy) & 0.074 & 0.089 & $0.516 * * *$ & 0.084 & -0.016 & 0.139 & 0.079 & 0.118 \\
\hline
\end{tabular}

Source: study findings based on 2012 field survey data.

$*$, **, *** Significant at the $10 \%, 5 \%$ and $1 \%$ level, respectively.

Note: Coefficients and standard errors have been rounded off to three decimal places. Square and interactions terms have been omitted in this table (see table 14 in appendix A for full table).

The value of gamma which gives an indication of how much of the deviation in an observed output from the production frontier could be associated with inefficiency was estimated to be $51 \%, 95 \%$ and $77 \%$ for the northern, middle and southern zones respectively (see Table 2.14 in appendix A). This implies that, a large percentage in output shortfall could be attributed to farmer's inefficiency in input usage.

\subsubsection{Determinants of Inefficiency}

The result of the inefficiency model (i.e. the heteroscedasticity-model of equation 2) presented in Table 2.6 below enables identification of sources of variation in the technical efficiency estimates (i.e., it enables us to assess the impact of input endowment and socioeconomic variables on farmers efficiency level in each zone). The result shows some substantial 
differences between the three zones. A positive or negative coefficient indicates increasing or decreasing effect of the variable(s) on farmer's production efficiency.

Increasing land size increases efficiency (or reduces inefficiency) in all zones, however, this effect is significant only in the northern zone. This implies farmers with large farm size have more incentive and resources to employ efficiency enhancing labour saving technologies during production compare to farmers with smallholdings.

Labour and agrochemical cost reduces inefficiency in the northern and southern zones and opposite effect in the middle zone. These effects were however not statistically significant. Contrary to our expectation; farmer's education, experience, membership to farmer association and own land status have a significant effect in increasing inefficiency in the northern zone. Irrigation practice significantly reduces inefficiency in the northern zone as compared to the insignificant and opposite effect in the middle and southern zones.

Table 2.6.: Determinants of Inefficiency

\begin{tabular}{|c|c|c|c|c|c|c|c|c|}
\hline \multirow{2}{*}{$\begin{array}{c}\text { Variable } \\
\text { Name }\end{array}$} & \multicolumn{2}{|c|}{ All zones pooled } & \multicolumn{2}{|c|}{ Northern Zone } & \multicolumn{2}{|c|}{ Middle Zone } & \multicolumn{2}{|c|}{ Southern Zone } \\
\hline & Coefficient & $\mathrm{SE}$ & Coefficient & $\mathrm{t} \mathrm{SE}$ & Coefficient & $\mathrm{SE}$ & Coefficient & $\mathrm{SE}$ \\
\hline Constant & $-1.326 * * *$ & 0.296 & $-43.355 * *$ & 5.596 & $-0.788 *$ & 0.441 & -3.116 & 3.070 \\
\hline $\log$ land & $-0.414 * *$ & 0.187 & $-3.640 * *$ & 1.505 & -0.248 & 0.309 & -0.322 & 0.465 \\
\hline $\log$ Labour & -0.784 & 0.770 & -1.236 & 1.443 & 0.787 & 0.991 & -0.415 & 0.969 \\
\hline $\log$ fertilizer cost & $0.202 * *$ & 0.076 & $-7.351 * * *$ & 1.491 & 0.050 & 0.143 & 0.189 & 0.536 \\
\hline log agrochemical cost & -0.011 & 0.035 & -0.083 & 0.153 & 0.090 & 0.089 & -0.508 & 0.373 \\
\hline log experience & 0.096 & 0.399 & $11.640 * * *$ & 3.231 & -0.042 & 0.452 & 0.371 & 0.875 \\
\hline Irrigation (dummy) & 0.322 & 0.227 & $-3.886 * * *$ & 1.168 & 0.121 & 0.363 & 1.989 & 2.867 \\
\hline Education (years) & 0.014 & 0.012 & $0.337 * * *$ & 0.092 & 0.008 & 0.022 & 0.016 & 0.023 \\
\hline Farmer assoc (dummy) & -0.264 & 0.336 & $1.815^{* * *}$ & 0.458 & -0.244 & 0.309 & -0.159 & 0.383 \\
\hline Land status (dummy) & -0.037 & 0.122 & $4.306^{* * *}$ & 0.899 & $0.318^{*}$ & 0.189 & -0.007 & 0.182 \\
\hline
\end{tabular}

Source: study findings based on 2012 field survey data.

$*, * *, * * *$ Significant at the $10 \%, 5 \%$ and $1 \%$ level, respectively.

Note: Coefficients and standard errors have been rounded off to three decimal places

The non-statistical significance of most of the individual variables in the southern and middle zones is rather surprising; however, the value of gamma which gives an indication of how much of the deviation in the observed output from the production frontier could be associated with inefficiency was estimated to be $95 \%$ and $77 \%$ for the middle and southern zones respectively. This implies that, a large percentage in output shortfall could be attributed to farmer's inefficiency in input usage. This also suggests that, the combined effect of all the hypothe- 
sised variables included in the inefficiency model collectively contribute in explaining how inefficiency affects the output in these zones.

\subsubsection{Parameter Estimates of the Metafrontier}

The rejection of homogeneous technology for all farmers in all zones as confirmed by statistical test presented in Table 2.4 suggest, performance estimates obtained using the zonal stochastic frontiers are not comparable since farmers in each zone operate under different technology.

Table 2.7.: Parameter Estimate of the Metafrontier

\begin{tabular}{lllll}
\hline \hline Variable & \multicolumn{2}{l}{ LP (sum of absolute deviation) } & \multicolumn{2}{l}{ QP (sum of square deviation) } \\
Name & Coefficient & SE & Coefficient & SE \\
\hline Constant & -0.088 & 0.181 & -0.102 & 0.173 \\
$\log$ land & $0.756^{* * *}$ & 0.111 & $0.708^{* * *}$ & 0.103 \\
$\log$ labour & 0.495 & 0.397 & $0.575^{*}$ & 0.332 \\
$\log$ fertilizer cost & $0.268^{* *}$ & 0.122 & $0.304 * * *$ & 0.098 \\
log plant age & 0.123 & 0.177 & 0.065 & 0.179 \\
Extension (dummy) & 0.062 & 0.108 & 0.079 & 0.112 \\
Irrigation (dummy) & 0.139 & 0.134 & 0.135 & 0.112 \\
Credit access (dummy) & 0.100 & 0.081 & 0.113 & 0.081 \\
Gender (dummy) & $0.264^{* * *}$ & 0.092 & $0.269 * * *$ & 0.095 \\
Farmer assoc (dummy) & 0.022 & 0.124 & 0.029 & 0.117 \\
$.5 * \log$ land^2 & 0.015 & 0.215 & -0.068 & 0.193 \\
$.5 * \log$ Labour^2 & 0.172 & 1.985 & -0.084 & 1.716 \\
$.5 * \log$ fertcost^2 & -0.053 & 0.069 & -0.043 & 0.067 \\
$\log$ land*log Labour & -0.211 & 0.390 & -0.159 & 0.348 \\
$\log$ land*log fertilizer cost & $0.167 * *$ & 0.085 & $0.181 * *$ & 0.073 \\
$\log$ Labour*log fertilizer cost & -0.071 & 0.189 & -0.049 & 0.164
\end{tabular}

Number of observations

365

365

Source: study findings based on 2012 field survey data.

$*, * *, * * *$ Significant at the $10 \%, 5 \%$, and $1 \%$ level, respectively.

Note: Coefficients and standard errors have been rounded off to three decimal places.

Hence, the metafrontier technique which enables comparisons of farmer's performance in each zone relative to a potential technology (or a metatechnology) available to the mango producing industry as a whole is employed. Parameter estimates of the metafrontier presented in Table 2.7 above were obtained by solving the linear and quadratic programming optimiza- 
tion problem (i.e. equations 10 and 11) for the entire sample. In line with Battese et al. (2004) and O'Donnell et al. (2008), statistical simulations were used to get estimates of standard errors of the two metafrontier parameters (LP and QP in table 2.7). All metafrontier results were obtained using the OxMetrics 6 programming language (Doornik). Both the LP and QP gave similar estimates; hence, the QP estimates were used for computation of MTR and are used for discussion under this section. Land, labour, fertilizer cost, gender as well as interaction of land with fertilizer had positive and significant effects on total metafrontier farm output.

\subsubsection{Average Performance Scores}

Table 2.8 presents summary statistics of the metatechnology ratio (MTR), metafrontier technical efficiency (MFTE), and group specific technical efficiency (TE) as defined in equation (5). The MTR values in Table 2.8 reveals that, mango farmers across the three zones produces, on average, $48 \%, 79 \%$ and $70 \%$ respectively of the potential output given the technology available to the mango industry as a whole. These values also capture the average technology gap faced by each zone when their performance is compared with the industrial level $^{22}$.

Consequently, on average, the middle zone is (31\% and $9 \%$ percentage points) more productive than the northern and southern zones respectively. Even though farmers in the northern zone achieved a high average output performance of $94 \%$ with respect to their zonal frontier, their output performance still lag behind the industrial performance with a technology gap of $48 \%$. The mean values of the efficiency performance (TE) with respect to each zone frontier vary from a low of $72 \%$ (middle zone) to a high of $94 \%$ (northern zone). However, zone specific performance scores cannot be compared with each other since they are estimated with respect to different frontiers.

Comparisons of efficiency performance across zones are therefore made using the metafrontier technical efficiency (MFTE) scores. Performance of farmers in the middle and southern zones were identical when their average technical efficiency scores are compared to the metafrontier. The average technical efficiency score of the northern zone relative to the metafrontier was substantially small compare with that of the other zones. These differences in per-

\footnotetext{
${ }^{22}$ This also suggests, on average, mango farmers in the middle zone have better access to modern technologies compare to the northern and southern zones.
} 
formance scores with respect to the MTR, TE and MFTE have consequence for policy design. It provides information on the type of intervention measures needed to be put in place in each zone to enhance productivity in the sector.

Table 2.8: Summary statistics of Technical Efficiency (TE), Meta-Technology Ratio (MTR), and Meta-Frontier Technical Efficiency (MFTE)

\begin{tabular}{|c|c|c|c|c|c|c|c|c|c|}
\hline & \multicolumn{3}{|c|}{ Northern Zone } & \multicolumn{3}{|c|}{ Middle Zone } & \multicolumn{3}{|c|}{ Southern Zone } \\
\hline & TE & MTR & MFTE & TE & MTR & MFTE & TE & MTR & MFTE \\
\hline Mean & $0.94 * * *$ & $0.48 * * *$ & $0.45^{* * *}$ & $0.72 * * *$ & $0.79 * * *$ & $0.56 * * *$ & 0.80 *** & $0.70^{* * *}$ & $0.56^{* * * *}$ \\
\hline Minimum & 0.44 & 0.29 & 0.19 & 0.32 & 0.44 & 0.25 & 0.38 & 0.44 & 0.28 \\
\hline Maximum & 1.00 & 0.95 & 0.86 & 0.95 & 1.00 & 0.92 & 0.98 & 1.00 & 0.86 \\
\hline Std. dev. & 0.13 & 0.15 & 0.15 & 0.17 & 0.12 & 0.15 & 0.13 & 0.13 & 0.12 \\
\hline Numb Obs. & 93 & & & 991 & & & 181 & & \\
\hline
\end{tabular}

*, **, ***, Significant at the 10\%, 5\%, and 1\% level, respectively.

Source: study findings from 2012 field survey data

Note: Coefficients and standard errors have been rounded off to three decimal places.

For instance, in the northern zones where majority of farmers are observed to be already operating on or near the zonal frontier (i.e. $94 \%$ TE) but with a huge technology gap (i.e. $48 \%$ MTR) to the industrial frontier, measures of raising technology level (such as introduction of mango varieties better suited to this zone, improvement in agricultural infrastructures etc) to breach the technology gap will be appropriate while in the middle and southern zones where there is much scope for output improvement with available technologies (i.e. TE of $72 \%$ and $80 \%$ respectively), measures such as enhancing access and improving quality of extension services delivery to enable farmer improve their crop husbandry and management capabilities (i.e. better use of current technological know-how) will be prudent and cost effective intervention policy.

Frequency distributions for the TE, MTR, and MFTE for the three zones are presented in Figure 2.5 below. The bar plots in Figure 2.5 reveals that the performance of farmers with respect to their zonal frontier is more diverse in the middle and southern zones than the northern zone. Substantial variability in MTR was found in all zones, however, the distribution in the northern zone skewed more to the right; indicates that more farmers in the northern zone are lagging behind technologically compared to the other two zones. This observation is a reflection of the relatively better developmental state in the middle and southern zones which enables farmers in these zones to have better access to improved production technologies (for 
example, more inputs stores as well as other infrastructures which enhance production like ports, harbours and agro-processing companies are situated in the middle and southern zones). The distributions of MFTE for farmers in the northern and middle zone were more divers but much less variability was observed for farmers in the southern zone.

The boxplot distribution of the TE, MTR and MFTE for the three zones also shows substantial performance differences between and within these zones. For the northern zone it shows; in terms of TE, the boxplot is comparatively short, implying less variability in term of performance. It shows large numbers of farmers (about 75\%) are located above the upper median performance score or are within the upper $25 \%$ quartile while some few farmers could be observed exhibiting extremely low performance scores located below the lower $25 \%$ quartile (i.e. outliers or points located below the lower whisker are due to the strong skewness of the distribution to the left). The distribution for the MTR however shows some differences for farmers within this zone. This implies farmers in this zone are not affected equally by factors prevailing in the production environment (so for example, farmers with more financial resources are able to overcome certain inhibitions (like lack of inputs) in this zone by purchasing them from the southern or the middle zones). Not much variability difference could be observed between the MTR and the MFTE distribution for this zone.

For the middle and the southern zones it shows; in terms of TE, more than $50 \%$ of farmers are located below the middle quartile or below the median performance score exhibiting wide range of performance variability within this quartile. The very long whiskers (i.e. towards the lower $25 \%$ quartile) and short whiskers (i.e. toward the upper $25 \%$ quartile) of the TE in these zones implies, performance are more varied in the lower $25 \%$ quartile but less varied (very similar) in the upper $25 \%$ quartile. In terms of the MTR, farmers in these zones appear to be affected in bell shape pattern by inhibitions in the production environment. The MTR performance scores are distributed almost evenly around the median performance score.

To sum up, the distribution of the TE (as depicted in 2.5 below) shows the actual opportunity for improvement in each zone while the MTR gives an idea of the potential performance improvement that might be realised if all zones could have access to the best practice technologies in the industry. The result of the analysis as portrayed in Figure 2.5 below is consistent with the notion that, technological gap plays an important role besides technical inefficiency in accounting for the dismal performance of the mango sector as a whole. 
Figure 2.5.: Histogram, Bar chart and Box plot of TE, MTR and MFTE for the three Zones involved in the Analysis
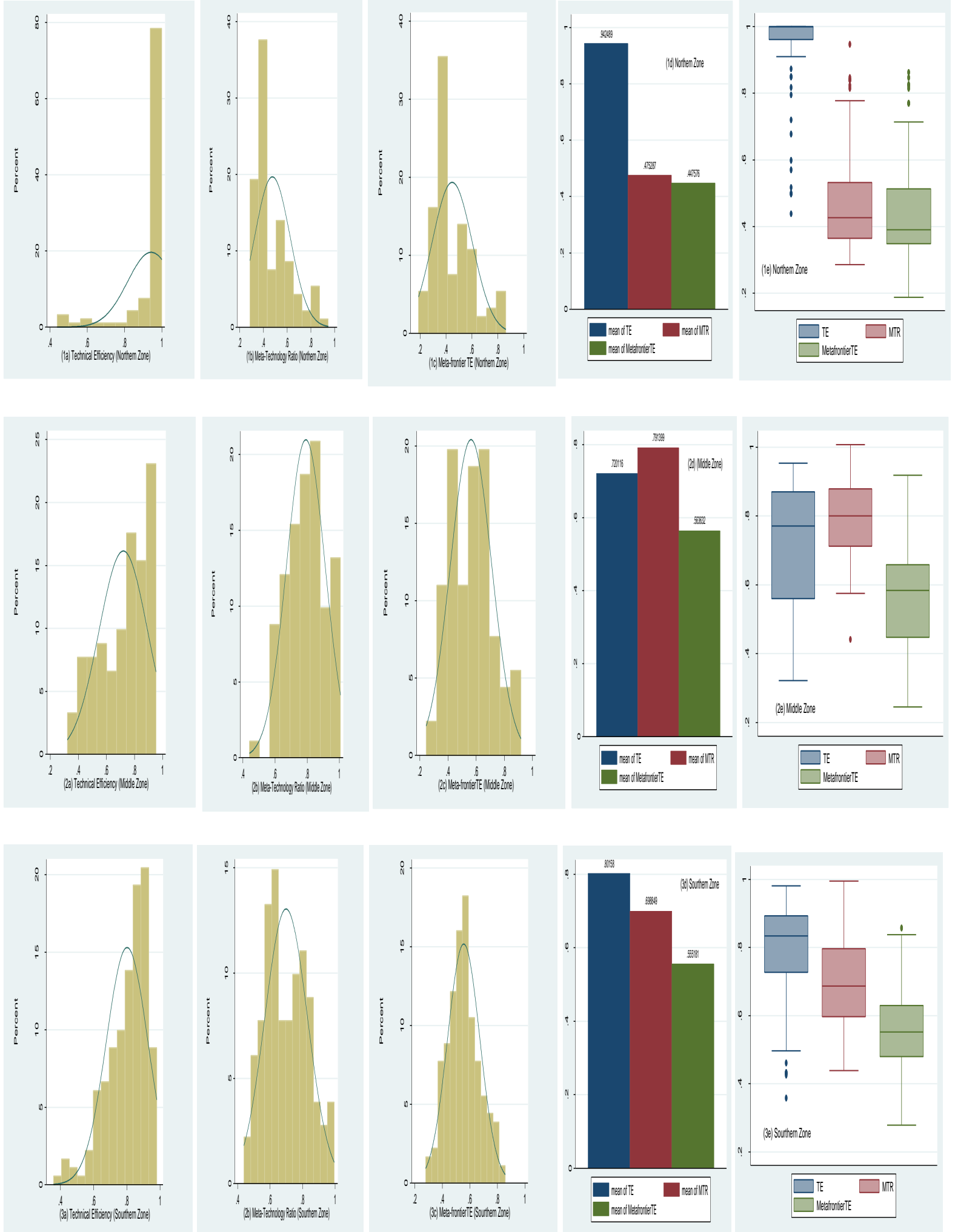

Source: study findings from 2012 field survey data 
This is typically reflected in the performance distribution of the northern zone with respect to its zonal frontier as well as the metafrontier. Though an overwhelming majority of farmers in this zone is producing near to their zonal frontier, the zonal average output performance lag behind the sectoral maximum with a technology gap of $48 \%$. This means, if all farmers in this zone could have access to similar production technologies as currently available in the industry, they could theoretically increase zonal output level by $52 \%$.

\subsubsection{Determinants of Variations in the Metatechnology Ratio (MTR)}

The MTR captures the technological gap between each zone and the industrial frontier (the value of the MTR gives an idea of the potential performance improvement which could be achieved resulting from improvement in the production environment). Normally, measures to bridge these gaps lies outside the control of individual farmers. These measures typically include improvement changes in the environment in which production take place. Stakeholders and policy makers can improve the production environment using various legal instruments such as reforms in labour and land laws or infrastructural development, such as constructing rural roads to facilitate transport of both inputs and other important end products to such areas.

To analyse the reasons for the wide variations in the MTRs in the different zones, a multivariate regression function was estimated as defined in equation (14). The R-square values of the analysis presented in Table 2.9 reveals that, $59 \%, 68 \%$ and $69 \%$ of variation in the MTR could be explain by such factors embodied in government programs, private and public participation in input and output markets, infrastructural, soil and climatic variables in the three zone respectively. Access to better road conditions, connection to the electric grid, access to more than one fruit buyer and availability of inputs stores positively and significantly influence the MTR ( i.e. reduces the technology gap). Access to extension services has positive and significant effect on MTR in the northern zone, an insignificant effect in the middle zone but a surprisingly negative and significant effect in the southern zone.

This observation in the southern zone contradict economic expectation, however, this observation indicates how lack of incentive, motivation and work materials/tools needed for effective extension work could hamper efficient extension delivery. 
Table 2.9.: Determinants of the Meta-Technology Ratio (i.e. variables influencing the nature of the production environment)

\begin{tabular}{|c|c|c|c|c|c|c|}
\hline \multirow{2}{*}{$\begin{array}{c}\text { Variable } \\
\text { Name }\end{array}$} & \multicolumn{2}{|c|}{ Northern Zone } & \multicolumn{2}{|c|}{ Middle Zone } & \multicolumn{2}{|c|}{ Southern Zone } \\
\hline & Coefficient & SE & Coefficient & SE & Coefficient & $\mathrm{SE}$ \\
\hline \multicolumn{7}{|l|}{ Infrastructure } \\
\hline Road condition & $0.056^{*}$ & 0.032 & $0.058 * *$ & 0.224 & $0.057 * * *$ & 0.017 \\
\hline Electricity & $0.094 * *$ & 0.034 & $0.051 * *$ & 0.229 & $0.068 * * *$ & 0.015 \\
\hline \multicolumn{7}{|c|}{ Government support programs } \\
\hline Extension & $0.089^{*}$ & 0.045 & 0.016 & 0.021 & $-0.036 * *$ & 0.173 \\
\hline Input subsidy & $0.087 * * *$ & 0.033 & 0.017 & 0.026 & 0.029 & 0.019 \\
\hline \multirow{2}{*}{\multicolumn{7}{|c|}{$\begin{array}{l}\text { Private and public market partici- } \\
\text { pation }\end{array}$}} \\
\hline & & & & & & \\
\hline Fruit traders & $0.027^{*}$ & 0.017 & $0.015^{* * *}$ & 0.005 & $0.006 * *$ & 0.003 \\
\hline Input stores & $0.061 * * *$ & 0.021 & $0.022 * * *$ & 0.007 & $0.008 * * *$ & 0.003 \\
\hline \multicolumn{7}{|l|}{ Soil and Weather } \\
\hline Erosion & -0.003 & 0.029 & -0.023 & 0.027 & $-0.177 * * *$ & 0.016 \\
\hline Floods & -0.046 & 0.029 & $-0.083 * * *$ & 0.025 & $-0.029 *$ & 0.016 \\
\hline Bushfires & $-0.111 * * *$ & 0.031 & $-0.045^{* *}$ & 0.022 & -0.017 & 0.015 \\
\hline Soil quality & 0.042 & 0.296 & 0.006 & 0.056 & 0.005 & 0.007 \\
\hline Constant & $0.188^{*}$ & 0.108 & $0.522 * * *$ & 0.058 & $0.643 * * *$ & 0.035 \\
\hline Number of observations & 93 & & 91 & & 181 & \\
\hline $\mathrm{R}$ squared & 0.5872 & & 0.6815 & & 0.6943 & \\
\hline
\end{tabular}

Interaction with extension workers across the country during data collection (i.e. June - December 2012) revealed how extension work in the country is being hampered as they express concern over lack of work materials and delays in financial grants they urgently need to enable them do their work effectively. Hence, to promote effective performance with reference to extension service delivery in the country, ways of motivating or incentivising extension workers through proper remuneration and material support should be worked out by all stake holders. Also, methods of extension service delivery especially in the southern zone should be reviewed and improved to suit the needs of farmers in this zone.

Subsidies on inputs surprisingly had significant effect only in the northern zone. Seasonal floods, bush fires and erosion negatively affect the MTR in all zones(i.e. prevents farmers from using certain technologies); however, the effect of floods is significant only in the middle and southern zones whiles bush fires exhibit significant effects on in the northern and 
middle zones. Variables with positive effects on the MTR could be interpreted as measures which favourably improve the production environment and therefore enhances farmer's ability to improve output towards the industrial level. The opposite effect is true for variable with negative effect on MTR.

\subsection{Conclusion with Recommendations for Future Policies}

Declining productivity in the fruit production industry has become a major concern in Ghana due to the fact that some major processing and exporting companies struggle to get raw materials to process and or export. Consequently, most of these companies have close down or relocated to other countries leading to loss of jobs in both rural and urban areas. Inability of the industry to meet export demand has lead to lose of international market share and foreign exchange the country urgently needs. In light of the above mentioned problems, our study which uses cross country on-farm and household data to identify and analysis potential ways of enhancing farmer's productivity in the fruit industry is a giant step in the right direction. Information gathered from this study provides policy makers with empirical information relevant for designing performance enhancing programs to boost output in the industry.

The study uses metafrontier estimation technique to derive performance estimates of mango farmers given the technology available to both their zonal production frontier and the industrial production frontier (metaproduction). The data and estimation technique used in this study supports the notion that, besides technical inefficiency, technology gaps play an important part in explaining the ability of mango farmers in one zone to compete with farmers in other zones. This has important implication for policy targeting program design.

Empirical result shows that the average technology gaps of $48 \%, 79 \%$, and $70 \%$ in the northern, middle and southern zones respectively are due to inhibitions prevailing in the production environment which impairs potential maximum output attainment to the industry output level. This means that, if the courses of inefficiency due to these inhibitions in the production environment as identified in this study are properly addressed, farmers in the respective zones could potentially increase output by $52 \%, 21 \%$ and $30 \%$. For instance; Result of model (14) which identifies some variables influencing the production environment reveals that; improvement in road condition, expansion in rural electrification to enable more farmers connect to the electric grid, measures which encourages more people to enter the fruit trade and also increasing the numbers of inputs stores have a positive and significant effect on MTR. 
This indicate that such measures favourably improve the production environment and therefore enhances farmer's ability to access important market information and other production technologies which enable them to improve output towards the industrial level (see Table 2.9).

The middle and southern zones have average zonal technical efficiency of $79 \%$ and $80 \%$ respectively with relatively high proportion of farmers having less than $50 \%$ efficiency score $^{23}$ (see distribution in Figure 2.5). In terms of developing policy strategies to improve these two zones, these estimates suggest; it will be economically more prudent to design programs which enhance farmers' managerial capabilities or skills, thereby enabling such farmers to make better use of existing technologies to increase output towards their zonal frontier $^{24}$. The ability of farmers to efficiently use the resources and production technologies at their disposal has a dual effect of simultaneously increasing output while reducing production cost. Lower production cost and higher output (will enhance the sectors competitiveness) result in higher profit margins and hence enhances farmers' welfare.

In general, the study reveals that there is much scope for output improvement in all zones; however, attainment of maximum output is possible only if causes of inefficiency due to technology gaps and farmers effectiveness of using available resources are properly addressed. Even though our analysis shed some insights into the problems facing the mango industry and recommend some remedies, it should be stressed that these recommendations are not in any way a panacea to all the problems facing the industry (i.e. improvement in production efficiency by farmers is necessary but not sufficient in overcoming all the problems facing the industry. Important intermediate processes such as post harvest quality maintenance through packaging, storage, transportation, technical support in marketing etc all contribute to the improvement of the fruit industry. Research into ways of improving these aspects of the industry is therefore highly recommended).

The ultimate goal of harnessing the maximum output potential of the industry does not depend only on efficiency improvement of farmers but also on improvement in all the interlinking branches (i.e. logistics and services sub-sectors) of the industry. Investment in basic but

\footnotetext{
${ }^{23}$ This implies that, efficient use of zonal resource endowment with prevailing technologies could potentially increase output by $21 \%$ in the middle zone and $20 \%$ in the southern zone as compared to only $6 \%$ in the northern zone.

${ }^{24}$ Efficient use of current know-how implies more output can be produce with existing input endowment.
} 
important agricultural infrastructures (such as improvement in conditions of rural/feeder roads, access to inputs, storage houses etc) and flexible credit market which enable farmers' access modern production technologies could prove vital in promoting successful and efficient performance of the industry.

Finally, to make the industry more competitive in the international market, it is imperative that, policy makers and all stakeholders; invest in innovative agricultural research and development which introduces modern production technologies (e.g. high yielding varieties) suitable to Ghana's agro ecological zones to push output beyond and above that of current industrial frontier. The fact that significant increases in output could be obtained by making better use of available technological know-how and improvement in the production environment does not mean that research designed to generate and introduce new technologies to the industry should be overlooked (Bravo-ureta and Pinheiro, 1993). 


\section{$\underline{\text { Appendix A }}$}

Table 2.10.: Variable name (unit) and definition

\begin{tabular}{|c|c|}
\hline Variable name (Units) & Definition \\
\hline Output (kg) & Total farm output \\
\hline Labour (hours) & Total number of hours farm labourers devote working on plantation \\
\hline Land (ha) & Total land area under mango cultivation only \\
\hline Crop density & Number of mango plants per hectare \\
\hline Education(years) & Years of schooling of decision maker or household head \\
\hline Plant Age(years) & Age of the mango plantation \\
\hline Experience(years) & Number of years as mango farmer \\
\hline Hage(year) & Age of farm operator or decision maker \\
\hline Hsize & Household size \\
\hline $\operatorname{Distmkt}(\mathrm{km})$ & Distance from farm household to market \\
\hline Agrochem(new Gh cedis) & Total cost of Agrochemicals \\
\hline Fertcost(new Gh cedis) & Total cost of chemical fertilizer \\
\hline Fruit traders & Number of fruit traders farmer regularly sells fruit to \\
\hline Input stores & Number of input stores/dealers in the area farmer regularly patronize \\
\hline land status & Dummy $(1=$ Owned land; $0=$ Otherwise $)$ \\
\hline gender & $\operatorname{Dummy}(1=$ male $; 0=$ Otherwise $)$ \\
\hline farmer association & $\operatorname{Dummy}(1=$ Member of mango farm association; $0=$ Otherwise $)$ \\
\hline credit access & $\operatorname{Dummy}(1=$ Have access to credit; $0=$ Otherwise $)$ \\
\hline extension & $\operatorname{Dummy}(1=$ Receives extension advice; $0=$ Otherwise $)$ \\
\hline irrigation & Dummy $(1=$ irrigates; $0=$ Otherwise $)$ \\
\hline manure & $\operatorname{Dummy}(1=$ Applies manure; $0=$ Otherwise $)$ \\
\hline fertilizer & $\operatorname{Dummy}(1=$ Applies chemical fertilizer; $0=$ Otherwise $)$ \\
\hline Input subsidy & $\operatorname{Dummy}(1=$ Inputs are subsidized by government or NGOs; $0=$ Otherwise $)$ \\
\hline Road condition & $\operatorname{Dummy}(1=$ Access to good road condition; $0=$ Otherwise $)$ \\
\hline Electricity & $\operatorname{Dummy}(1=$ Connected to the electric grid, $0=$ Otherwise $)$ \\
\hline Erosion & $\operatorname{Dummy}(1=$ Affected by erosion; $0=$ Otherwise $)$ \\
\hline Floods & $\operatorname{Dummy}(1=$ Affected by seasonal floods; $0=$ Otherwise $)$ \\
\hline Bushfires & $\operatorname{Dummy}(1=$ Affected by seasonal Bushfires; $0=$ Otherwise $)$ \\
\hline Soil quality & Rank variable $(1=$ very low, $2=$ low, $3=$ medium, $4=$ high, $5=$ very high $)$ \\
\hline
\end{tabular}


Table 2.11.: Summary Statistics (continuous variables)

\begin{tabular}{|c|c|c|c|c|c|c|c|c|c|}
\hline \multirow[t]{2}{*}{ Variable } & \multicolumn{3}{|c|}{ Northern Zone $(n=93)$} & \multicolumn{3}{|c|}{ Middle Zone $(\mathrm{n}=91)$} & \multicolumn{3}{|c|}{ Southern Zone $(\mathrm{n}=181)$} \\
\hline & Mean & Min & $\operatorname{Max}$ & Mean & Min & $\operatorname{Max}$ & Mean & Min & Max \\
\hline $\begin{array}{l}\text { Farm output } \\
(\mathrm{kg})\end{array}$ & 404.00 & 100.00 & $4 \quad 4400.00$ & 2555.28 & 190.00 & 17500 & 58819.49 & 150.00 & 20000 \\
\hline Labour (hours) & 3.54 & 3.00 & 5.00 & 4.21 & 3.00 & 8.00 & 5.34 & 3.00 & 8.00 \\
\hline Land (ha) & 0.69 & 0.40 & 4.00 & 2.88 & 0.40 & 15.40 & 5.17 & 0.40 & 20.00 \\
\hline $\begin{array}{l}\text { Crop density } \\
\text { (plants/ha) }\end{array}$ & 56.42 & 40.00 & 100.00 & 92.46 & 35.00 & 105.00 & 94.11 & 40.00 & 110.00 \\
\hline $\begin{array}{l}\text { Education } \\
\text { (years) }\end{array}$ & 8.61 & 4.00 & 28.00 & 12.04 & 0.00 & 25.00 & 12.74 & 4.00 & 24.00 \\
\hline $\begin{array}{l}\text { Plant age } \\
\text { (years) }\end{array}$ & 8.30 & 6.00 & 12.00 & 7.76 & 6.00 & 18.00 & 10.60 & 6.00 & 25.00 \\
\hline $\begin{array}{l}\text { Experience } \\
\text { (years) }\end{array}$ & 9.23 & 6.00 & 14.00 & 8.79 & 6.00 & 18.00 & 11.59 & 6.00 & 26.00 \\
\hline $\begin{array}{l}\text { Age of Farmer } \\
\text { (years) }\end{array}$ & 52.16 & 30.00 & 75.00 & 51.80 & 30.00 & 74.00 & 55.27 & 30.00 & 76.00 \\
\hline $\begin{array}{l}\text { Household } \\
\text { size }\end{array}$ & 8.37 & 2.00 & 13.00 & 5.77 & 2.00 & 10.00 & 5.95 & 2.00 & 14.00 \\
\hline $\begin{array}{l}\text { Distance to } \\
\text { market }(\mathrm{km})\end{array}$ & 7.42 & 5.00 & 17.00 & 10.67 & 4.00 & 26.00 & 12.16 & 4.00 & 32.00 \\
\hline $\begin{array}{l}\text { Agrochemical } \\
\text { cost (cedis) }\end{array}$ & 53.01 & 0.00 & 106.40 & 56.74 & 0.00 & 175.00 & 82.67 & 0.00 & 195.00 \\
\hline $\begin{array}{l}\text { Fertilizer cost } \\
\text { (cedis) }\end{array}$ & 2.45 & 0.00 & 40.00 & 34.89 & 0.00 & 210.00 & 59.45 & 0.00 & 230.00 \\
\hline Fruit traders & 3.10 & 1.00 & 5.00 & 7.00 & 3.00 & 12.00 & 8.00 & 1.00 & 13.00 \\
\hline Input stores & 2.00 & 1.00 & 3.00 & 5.00 & 3.00 & 9.00 & 5.00 & 0.00 & 10.00 \\
\hline
\end{tabular}

Source: study findings based on 2012 field survey data.

Note: Coefficients and standard errors have been rounded off to two decimal places 
Table 2.12.: Summary Statistics (dummy variables)

\begin{tabular}{|c|c|c|c|c|c|c|}
\hline \multirow[t]{2}{*}{ Variable } & \multicolumn{2}{|c|}{ Northern Zone $(n=93)$} & \multicolumn{2}{|c|}{ Middle Zone $(\mathrm{n}=91)$} & \multicolumn{2}{|c|}{$\begin{array}{l}\text { Southern Zone }(\mathrm{n}= \\
181)\end{array}$} \\
\hline & Proportion & Std. Err. & Proportion & Std. Err. & Proportion & Std. Err \\
\hline \multicolumn{7}{|c|}{ Land status } \\
\hline 0 & .56 & .052 & .37 & .051 & .29 & .034 \\
\hline $1 \mid$ & .44 & .052 & .63 & .051 & .71 & .034 \\
\hline \multicolumn{7}{|l|}{ Gender } \\
\hline $0 \mid$ & .12 & .034 & .12 & .034 & .07 & .019 \\
\hline $1 \mid$ & .88 & .034 & .88 & .034 & .93 & .019 \\
\hline \multicolumn{7}{|c|}{ Farmer assoc } \\
\hline 0 & .87 & .035 & .44 & .052 & .27 & .033 \\
\hline $1 \mid$ & .13 & .035 & .56 & .052 & .73 & .033 \\
\hline \multicolumn{7}{|c|}{ Credit access } \\
\hline 0 & .88 & .034 & .43 & .052 & .24 & .031 \\
\hline $1 \mid$ & .12 & .034 & .57 & .052 & .76 & .031 \\
\hline \multicolumn{7}{|c|}{ Extension } \\
\hline $0 \mid$ & .87 & .035 & .44 & .0523 & .23 & .031 \\
\hline $1 \mid$ & .13 & .035 & .56 & .0523 & .77 & .031 \\
\hline \multicolumn{7}{|l|}{ Irrigation } \\
\hline 0 & .68 & .049 & .56 & .052 & .23 & .031 \\
\hline $1 \mid$ & .32 & .049 & .44 & .052 & .77 & .031 \\
\hline \multicolumn{7}{|l|}{ Manure } \\
\hline $0 \mid$ & .85 & .037 & .37 & .051 & .20 & .029 \\
\hline $1 \mid$ & .15 & .037 & .63 & .051 & .80 & .029 \\
\hline \multicolumn{7}{|l|}{ Fertilizer } \\
\hline $0 \mid$ & .95 & .024 & .31 & .049 & .17 & .028 \\
\hline $1 \mid$ & .05 & .024 & .69 & .049 & .83 & .028 \\
\hline \multicolumn{7}{|c|}{$\begin{array}{l}\text { Road condi- } \\
\text { tion }\end{array}$} \\
\hline 0 & .60 & .051 & .45 & .052 & .27 & .033 \\
\hline $1 \mid$ & .40 & .051 & .55 & .052 & .73 & .033 \\
\hline \multicolumn{7}{|c|}{ Electricity } \\
\hline $0 \mid$ & .63 & .050 & .46 & .053 & .34 & .035 \\
\hline $1 \mid$ & .37 & .050 & .54 & .053 & .66 & .035 \\
\hline \multicolumn{7}{|c|}{ Input subsidy } \\
\hline $0 \mid$ & .30 & .048 & .67 & .049 & .82 & .029 \\
\hline $1 \mid$ & .70 & .048 & .33 & .049 & .18 & .029 \\
\hline \multicolumn{7}{|l|}{ Erosion } \\
\hline $0 \mid$ & .49 & .052 & .65 & .050 & .62 & .036 \\
\hline $1 \mid$ & .51 & .052 & .35 & .050 & .38 & .036 \\
\hline \multicolumn{7}{|l|}{ Floods } \\
\hline $0 \mid$ & .38 & .050 & .67 & .049 & .72 & .033 \\
\hline $1 \mid$ & .62 & .050 & .33 & .049 & .28 & .033 \\
\hline \multicolumn{7}{|l|}{ Bushfires } \\
\hline 0 & .34 & .049 & .64 & .051 & .34 & .035 \\
\hline $1 \mid$ & .66 & .049 & .36 & .051 & .66 & .035 \\
\hline
\end{tabular}

Source: study findings based on 2012 field survey data.

Note: Coefficients and standard errors have been rounded off to two decimal places 
Table 2.13.: Chow Test of the Determinants of MTR Model

- 1rtest (pooled) (Zone1 Zone2 Zone3), stats

Likelihood-ratio test

LR $\operatorname{chi2}(22)=162.25$

Prob > chi2 = 0.0000

Assumption: (pooled) nested in (Zone1, Zone2, zone3)

\begin{tabular}{r|rrrrrr}
\hline Mode1 & Obs & 11 (nu11) & 11 (mode1) & df & AIC & BIC \\
\hline pooled & 365 & 78.23714 & 268.6875 & 11 & -515.3751 & -472.4762 \\
Zone1 & 93 & 20.67513 & 61.81367 & 11 & -101.6273 & -73.76875 \\
Zone2 & 91 & 43.59491 & 95.65021 & 11 & -169.3004 & -141.681 \\
Zone3 & 181 & 85.1014 & 192.3493 & 11 & -362.6987 & -327.5152 \\
\hline
\end{tabular}

Note: N=obs used in calculating BIC; see [R] BIC note 
Table 2.14.: Estimates of Stochastic Production Frontier (Translog Models)

\begin{tabular}{|c|c|c|c|c|c|c|c|c|}
\hline \multirow{2}{*}{$\begin{array}{c}\text { Variable } \\
\text { Name }\end{array}$} & \multicolumn{2}{|c|}{ All zones pooled } & \multicolumn{2}{|c|}{ Northern Zone } & \multicolumn{2}{|c|}{ Middle Zone } & \multicolumn{2}{|c|}{ Southern Zone } \\
\hline & Coefficient & $\mathrm{t} \mathrm{SE}$ & Coefficient & it $\mathrm{SE}$ & Coefficient & SE & Coefficient & SE \\
\hline \multicolumn{9}{|l|}{ Production frontier model } \\
\hline Constant & $-0.310 * *$ & 0.118 & -0.137 & 0.181 & -0.252 & 0.165 & -0.367 & 0.259 \\
\hline $\log$ land & $0.597 * * *$ & 0.069 & $1.050 * * *$ & 0.267 & $0.861 * * *$ & 0.120 & $0.469 * *$ & 0.211 \\
\hline $\log$ labour & $0.450 * *$ & 0.210 & -0.801 & 1.066 & $0.975^{* *}$ & 0.396 & $0.696^{*}$ & 0.429 \\
\hline $\log$ fertilizer cost & $0.220 * * *$ & 0.056 & $1.894 * * *$ & 0.297 & 0.175 & 0.147 & 0.230 & 0.159 \\
\hline log plant age & $0.310 * * *$ & 0.107 & $0.970 * * *$ & 0.150 & -0.074 & 0.253 & $0.415^{* *}$ & 0.173 \\
\hline Extension (dummy) & $0.093 *$ & 0.056 & $0.409 * * *$ & 0.101 & $0.203 * *$ & 0.101 & -0.072 & 0.089 \\
\hline Irrigation (dummy) & $0.226 * * *$ & 0.075 & $0.343 * * *$ & 0.086 & -0.069 & 0.113 & $0.448^{*}$ & 0.235 \\
\hline Credit access (dummy) & $0.090 *$ & 0.053 & -0.144 & 0.126 & 0.090 & 0.109 & 0.019 & 0.069 \\
\hline Gender (dummy) & 0.087 & 0.066 & $-0.203^{*}$ & 0.113 & $0.311 * *$ & 0.119 & $0.139 *$ & 0.082 \\
\hline Farmer assoc (dummy) & 0.074 & 0.089 & $0.516^{* * *}$ & 0.084 & -0.016 & 0.139 & 0.079 & 0.118 \\
\hline $.5 * \log \operatorname{land}^{\wedge} 2$ & $-0.222 * *$ & 0.090 & -0.129 & 0.192 & -0.082 & 0.223 & -0.349 & 0.277 \\
\hline $.5 * \log$ Labour $^{\wedge} 2$ & -0.130 & 0.808 & $-7.861 * * *$ & 1.766 & -1.403 & 1.427 & -0.142 & 2.759 \\
\hline $.5 * \log$ fertilizer $\cos ^{\wedge}{ }^{\wedge}$ & $-0.088 * *$ & 0.039 & $0.669 * * *$ & 0.147 & $-0.187 * *$ & 0.073 & -0.091 & 0.064 \\
\hline $\log$ land*log Labour & 0.003 & 0.208 & $-0.777 *$ & 0.441 & 0.047 & 0.326 & 0.177 & 0.778 \\
\hline $\log$ land*log fertilizer cost & $0.177 * * *$ & 0.033 & $0.349 * * *$ & 0.069 & $0.289 * * *$ & 0.072 & $0.204 * *$ & 0.088 \\
\hline $\log$ Labour*logfertilizercost & -0.139 & 0.097 & $0.600 *$ & 0.395 & -0.054 & 0.215 & -0.206 & 0.239 \\
\hline \multicolumn{9}{|l|}{ Inefficiency model } \\
\hline Constant & $-1.326 * * *$ & 0.296 & $-43.355 * *$ & 5.596 & $-0.788^{*}$ & 0.441 & -3.116 & 3.070 \\
\hline $\log$ land & $-0.414 * *$ & 0.187 & $-3.640 * *$ & 1.505 & -0.248 & 0.309 & -0.322 & 0.465 \\
\hline $\log$ Labour & -0.784 & 0.770 & -1.236 & 1.443 & 0.787 & 0.991 & -0.415 & 0.969 \\
\hline $\log$ fertilizer cost & $0.202 * *$ & 0.076 & $-7.351 * * *$ & 1.491 & 0.050 & 0.143 & 0.189 & 0.536 \\
\hline $\log$ agrochemical cost & -0.011 & 0.035 & -0.083 & 0.153 & 0.090 & 0.089 & -0.508 & 0.373 \\
\hline $\log$ experience & 0.096 & 0.399 & $11.640 * * *$ & 3.231 & -0.042 & 0.452 & 0.371 & 0.875 \\
\hline Irrigation (dummy) & 0.322 & 0.227 & $-3.886 * * *$ & 1.168 & 0.121 & 0.363 & 1.989 & 2.867 \\
\hline Education (years) & 0.014 & 0.012 & $0.337 * * *$ & 0.092 & 0.008 & 0.022 & 0.016 & 0.023 \\
\hline Farmer assoc (dummy) & -0.264 & 0.336 & $1.815^{* * *}$ & 0.458 & -0.244 & 0.309 & -0.159 & 0.383 \\
\hline Land status (dummy) & -0.037 & 0.122 & $4.306^{* * *}$ & 0.899 & $0.318^{*}$ & 0.189 & -0.007 & 0.182 \\
\hline Log-likelihood & -120.543668 & & -10.0840349 & & -10.7959386 & & -38.7112554 & \\
\hline Number of observations & 365 & & 93 & & 91 & & 181 & \\
\hline Gamma & 0.6738 & & 0.5111 & & 0.9488 & & 0.7676 & \\
\hline
\end{tabular}

Source: study findings based on 2012 field survey data.

$*, * *, * * *$ Significant at the $10 \%, 5 \%$ and $1 \%$ level, respectively.

Note: Coefficients and standard errors have been rounded off to three decimal places. 
Table 2.15.: Detail Summary Statistics of Technical Efficiency (TE), Meta-Technology Ratio (MTR), and Meta-Frontier Technical Efficiency (MFTE)

\begin{tabular}{|c|c|c|c|c|c|c|c|c|c|}
\hline & \multicolumn{3}{|c|}{ Northern Zone } & \multicolumn{3}{|c|}{ Middle Zone } & \multicolumn{3}{|c|}{ Southern Zone } \\
\hline & $\mathrm{TE}$ & MTR & MFTE & $\mathrm{TE}$ & MTR & MFTE & $\mathrm{TE}$ & MTR & MFTE \\
\hline \multicolumn{10}{|c|}{ Measure of center } \\
\hline Mean & $0.94 * * *$ & $* 0.48 * * *$ & $* 0.45^{* * *}$ & $0.72 * *$ & $* 0.79 * * *$ & $0.56^{* * *}$ & $0.80 * * *$ & * $0.70 * * *$ & $0.56^{* * *}$ \\
\hline Median & 0.99 & 0.43 & 0.39 & 0.77 & 0.78 & 0.58 & 0.84 & 0.69 & 55 \\
\hline Mode & 0.99 & 0.39 & 0.41 & N/A & 0.83 & N/A & N/A & 0.63 & /A \\
\hline \multicolumn{10}{|l|}{ Range } \\
\hline Minimum & 0.44 & 0.29 & 0.19 & 0.32 & 0.44 & 0.25 & 0.38 & 0.44 & 0.28 \\
\hline Maximum & 1.00 & 0.95 & 0.86 & 0.95 & 1.00 & 0.92 & 0.98 & 1.00 & 0.86 \\
\hline \multicolumn{10}{|c|}{ Measure of spread } \\
\hline Std. dev. & 0.14 & 0.14 & 0.14 & 0.17 & 0.12 & 0.14 & 0.14 & 0.14 & 0.12 \\
\hline Variance & 0.02 & 0.02 & 0.02 & 0.03 & 0.01 & 0.02 & 0.02 & 0.02 & 0.01 \\
\hline \multicolumn{10}{|c|}{ Measure shape } \\
\hline Skewness & -2.68 & 1.17 & 0.98 & -0.59 & -0.24 & 0.19 & -1.05 & 0.22 & 0.19 \\
\hline Kurtosis & 9.28 & 3.79 & 3.38 & 2.18 & 2.59 & 2.44 & 3.88 & 2.29 & 2.78 \\
\hline Numb Obs & & 93 & & 9 & 1 & & & 181 & \\
\hline
\end{tabular}

Source: study findings based on 2012 field survey data

$*, * *, * * *$, Significant at the $10 \%, 5 \%$, and $1 \%$ level, respectively.

Note: Coefficients and standard errors have been rounded off to three decimal places. 


\title{
Chapter Three
}

\section{Determinants of MD2* Adoption, Production Efficiency and Technology Gaps in the} Ghanaian Pineapple Production Sector

\begin{abstract}
This study examined the response of the Ghanaian pineapple production sector to the 2004/05 crisis where a swift shift of international market demand from the traditional smooth cayenne and sugar loaf variety to MD2 variety nearly destroyed the entire fruit industry(Gatune et al, 2013). Seven years after the crisis, we studied how Ghanaian pineapple farmers have responded to international market demand. We estimated the proportion of our sample farmers cultivating the MD2 and analysed the factors influencing adoption of MD2 variety using a logistic regression model. We further employed metafrontier analytical techniques to assess the current productivity level of organic and conventional pineapple producers using a cross sectional data set gathered from 404 farm-households in three regions where commercial production is most concentrated. Even though recent media reports (Ablordeppey \& Arku, 2013) indicated a productivity decline in the industry, accompanied by closure of domestic agroprocessing factories due to lack of raw materials. The results of our analysis reveal that, the majority of farmers in both organic and conventional production systems was operating quite near their group frontier as well as the industrial frontier (i.e. 97\% mean TE and $95 \%$ mean MTR). This suggests that there is not much scope for productivity gain given the current state of technology available to the industry. This implies: to substantially increase output levels in the industry to meet rapidly expanding domestic and international market demands, Government policies should aim at agricultural-research $(R \& D)$ development framework which not only encourages but expedite technological progress through the introduction of innovative production techniques to aid push output levels beyond what is currently achievable in the industry.
\end{abstract}

Keywords: Ghanaian pineapple production industry, Adoption of MD2, Drivers of Technical Efficiency and Technology gaps.

*MD2 is a name of a new pineapple variety developed by Del Monte in Costa Rica 


\subsection{Introduction}

The pineapple sector plays a very important role in Ghana's fruit industry (Jaeger, 2008). The technical and financial support for the pineapple sector at the early establishment phase of the fruit industry generated a lot of employment opportunities for farmers, traders and exporters which in turn enhanced welfare and poverty reduction in both rural and urban areas. The pineapple sector took leadership in the Ghanaian fruit production industry by contributing a greater share of foreign exchange earnings to the economy (i.e. it accounted for $66.2 \%$ share of foreign exchange earnings from the fruit industry, 2000 - 2013; Eurostat). From 1994 to 1999 , the total value of Ghana's pineapple exports increased nearly threefold, from US $\$ 5,30$ million to US \$15, 50 million (Safa-Dedeh, 2007). From 2000 to 2004, the export value of the sector increased from $€ 24$ million to $€ 56,20$ million. Though the sector went through some setbacks beginning 2005 production year, it still maintains its dominating position in the fruit industry by contributing a total of about $€ 372$ million to the economy from 2000 to 2013 (Eurostat, 2013).

Over the last decade the EU has been constantly recording a trade deficit in fresh and processed fruit and vegetables, totalling $€ 9,8$ billion in 2011(DG Agric, 2012). However, a closer look at the balance (i.e. the gap between exports and imports) reveals that this deficit in fruit trade is particularly due to tropical fruits in particular for bananas and pineapples. Imports of tropical fruits have been steadily growing over the period (Pay, 2009). The market for fresh pineapples is one of the fastest growing fruit markets in Europe. Imports grew at an average annual growth rate of 12 percent from 317,478 tonnes in 2000 to 873,936 tonnes in 2008 . These volumes correspond to a total value of imports of $€ 555$ million in 2008 (Pay, 2009). This fast growing pineapple market in the EU therefore presents an excellently huge opportunity for the Ghanaian fruit industry to explore since a bilateral trade agreement in 2008 with the EU opens up the entire EU market to the industry due to removal of all trade barriers for agricultural produce from Ghana (Wolter, 2008).

The ease of cultivation and comparative advantage by the sector in producing pineapple is mostly driven by the following factors (Jaeger, 2008);

1. Favourable climate and soil conditions for the production of pineapples all year round. 
2. Geographical location of Ghana (i.e. a closer proximity to its main export markets in the EU) which guarantees low air and sea freight charges to Europe and ensures competitiveness of its export produce.

3. Abundantly cheap skilled and unskilled labour force working on plantations at relatively low monthly wages (i.e. low labour costs).

4. A relatively stable political situation in the country which creates a good investment environment for investors.

These factors present the sector with an excellent comparative advantage of becoming a major producer and supplier of quality but inexpensive pineapple products to the EU markets. As depicted in Figure 3.1 below, the pineapple sector played a prominent role in driving forward the impressive performance of the fruit industry at the initial establishment stages (i.e. up to 2004).

Figure 3.1.: EU Import of Fruits from Ghana (Value in mil. of Euro, 2000 - 2013)

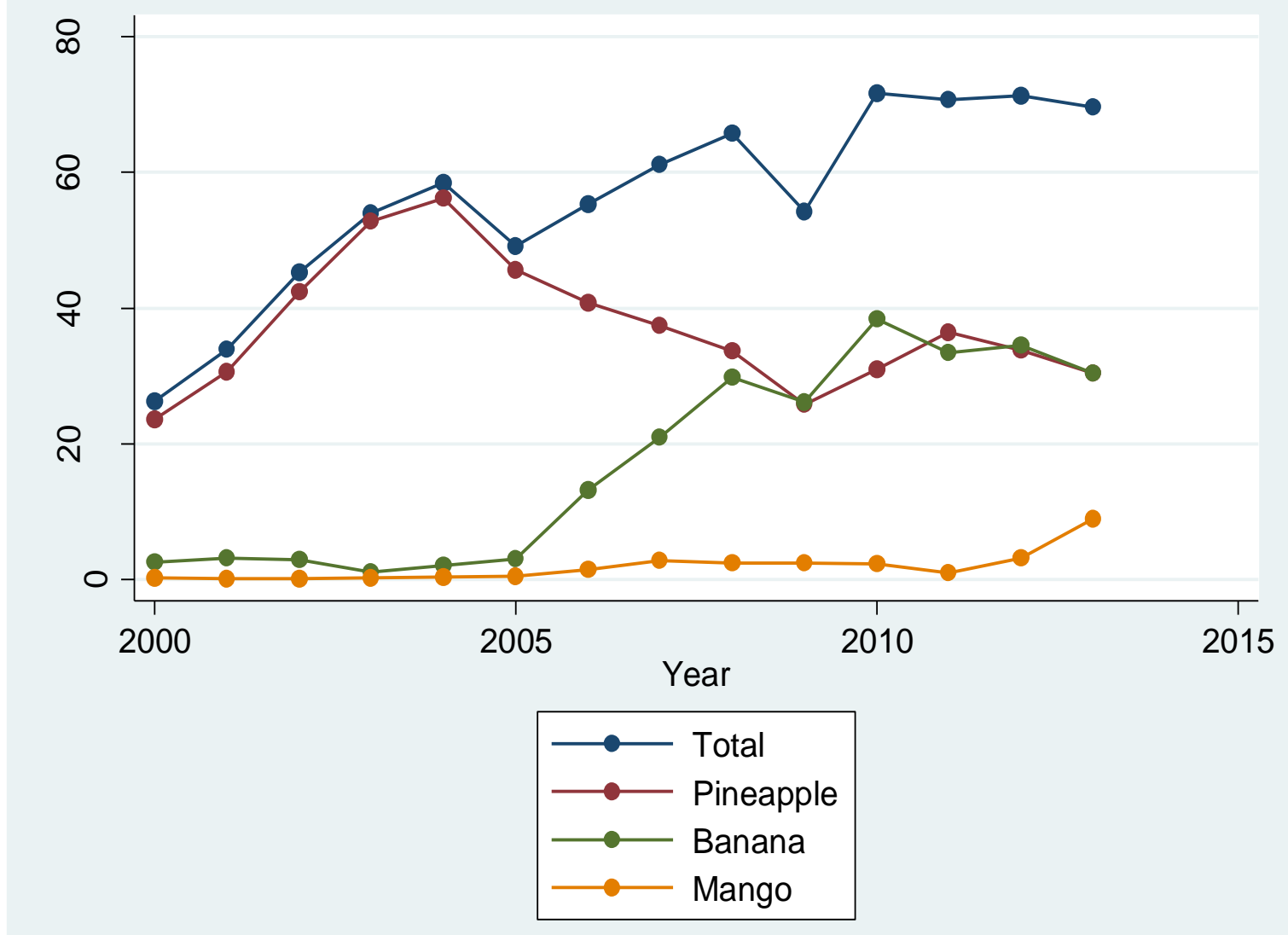

Data source: Eurostat international trade data 
With high demand for the fruit locally and internationally (Kleemann, 2011; 2014), pineapple became not only the first but also the most important export fruit of Ghana (Gatune et al, 2013)(Jaeger, 2008). Export volume increase rapidly from virtually zero in 1990 to around 68,000 tonnes in 2004 production year generating over U.S \$59,20 million ((USAID/TIPCEE, 2005). The success story of the pineapple sector was abruptly interrupted as the sector was suddenly hit by a series of crisis starting 2005:

1. First, international market preference (i.e. export demand) shifted swiftly in 2005 from the traditional well adopted smooth cayenne and sugar loaf varieties to MD2 ${ }^{25}$ variety developed by Del Monte in Costa Rica. The swift pace of shift badly affected small scale growers who constitute a sizable portion of the sectors' producers.

2. Second, strict certification standards (e.g. global gap) for ensuring quality and safety were set for farmers and companies who want to export to EU.

3. Third, increasing demand trend for organically produce fruits (pineapple) in the EU market means farmers wanting to take advantage of this demand trend have to switch from conventional to organic system of production.

The consequence of above crisis was sharply reflected in the share of EU import from 2005 2013. The value of pineapple exports dropped significantly from a peak of $€ 59,20$ million to around $€ 30$ million (i.e. $49.3 \%$ drop in the total value of pineapple exports (Eurostat, 2013)). In terms of quantity; trade volumes fell by about $40 \%$ from a peak of 51,726 tonnes in 2004 to less than 32,000 tonnes in 2013 (Eurostat). Despite this huge decline, pineapple is still a major foreign exchange contributor to the economy when compared to other fruit sectors of the industry (GEPC, 2005).

At the peak of the crisis, the favourable comparative advantages of Ghana (i.e. location, freight, climate and labour) were no longer sufficient in making the sector competitive enough to challenge competing nations (especially Costa Rica) in the European markets. Large commercial farm entities (like Bomarts ${ }^{26}$ and Golden Exotics Ltd) with sound financial and technical resources were able to switch approximately $98 \%$ of their production to MD2 by the end of 2007 (Manasseh, 2007). However, large proportion (i.e. over 70\%) of the sectors produc-

\footnotetext{
${ }^{25}$ It currently accounts for approximately three quarters of the European pineapple market.

${ }^{26}$ In 2008, 6,000 tonnes of MD2 pineapples were produced by Bomarts of which 2,200 tonnes were sold to the Fairtrade markets in the EU.
} 
tion is based on small scale ${ }^{27}$ out-grower farmers often with weak financial backing. Overwhelming majority of such small-scale farmers could not react quickly and effectively to these sudden changes. These changes require that farmers have to incur extra cost in replacing existing stocks with the new MD2 variety which requires intensive use of specific inputs in order to achieve maximum output (Gatune et al, 2013). Also, switching production from conventional to organic produce in order to take advantage of rapidly expanding premium niche organic markets in EU entails substantial cost in terms of meeting certification standards. Consequently, huge portions of harvested pineapple were left to rot on the field as the local market could not absorb all outputs. Demoralization and frustration by farmers lead to a downward productivity trend as farmers switched to producing other crops or completely abandoned their pineapple fields (Gatune et al, 2013) ( Jaeger, 2008).

In an effort to restore farmers' confidence and revamp production, various government agencies, NGOs and other stakeholders intervened to provide both technical (i.e. supply of MD2 crowns) and financial support (input credits) to farmers. The adoption rate and the effect of such intervention measures on output are yet to be quantified empirically as done in this study. A few decades ago, the bulk of pineapples on the European market were sourced from West Africa (mainly from Ghana and Ivory Coast). However, while competing nations in pineapple production (especially Costa Rica) have dramatically improved their efficiency of production, little or no such improvement could be observed in the Ghanaian pineapple production sector (Gatune et al, 2013).

Consequently, average yield per hectare is far below that of Costa Rica. Costa Rica is by far the largest exporter of pineapples to the European market, supplying 670,119 tonnes or 73 percent of all imports in 2008, while Ghana currently accounts for only 4 percent $(35,601$ tonnes) of total import. The financial and economic consequence of decreasing trend of export volume from over 50,000 tons in 2004 to about 31,000 tons in 2013 cannot just be ignored due to its ripple effect on other sectors of the economy. Production decline in the industry does affect forward linkage (i.e. supply side) activities such as agro-processing, exporters and transportation, and backward linkage (i.e. demand side) activities through the provision of inputs and services to the sector). The phenomena of decreasing output trend require concrete actions to reverse course and to enhance productivity in the industry. Employment in the industry has significantly slumped from over 600,000 to less than 60,000 in 2013 due to closing

\footnotetext{
${ }^{27}$ By 2004, it was estimated that smallholders contributed over $50 \%$ to export volumes (Julius Gatune 2013)
} 
down of fruit-processing companies while the surviving ones are struggling to get raw materials to process (Ablordeppey \& Arku, 2013).

The phenomenon of falling output and export levels in the sector could be assigned to a range of factors beside volatility in the international marketplace. Among which are deficiencies emanating from the production side (i.e. farmers inefficiency), poor service delivery in the transport and logistics sector reflecting the poor infrastructural state of the country (i.e. bad road conditions, improper packaging and transportation systems, lack of storage and post harvest handling facilities etc.) as well as impact of random factors (i.e. weather effects) prevailing in the production environment. These factors may be broadly categorized into factors under the control of farmers (i.e. technical efficiency factors) and those outside the control of farmers (i.e. climatic and lack of access to basic production infrastructures with potential to induce technology gaps). This study therefore embarks on analysing the effect of such factors on the production efficiency of farmers and how they impact the output performance of the sector as a whole.

We believe measures designed to increase output level in the sector should be based on sound empirical information and not on ad hoc political expedience as is often the case in most developing countries. Formulation of informed productivity enhancement mechanisms is therefore a necessary condition for enhancing sustainable development in the sector. The Empirical insights gained from this study should aid policy makers in formulating appropriate future intervention programs to help boost output levels in the sector.

\subsubsection{Research Objectives}

This study seeks to identify some socioeconomic, infrastructural and institutional factors in the production environment as well as farm management practices that influence pineapple production efficiency in the sector. Specific objectives include:

1. To assess farmers' response to international market demand of MD2 variety by quantifying the proportion of MD2 variety under cultivation in both systems of production as well as analysing the factors influencing the adoption of MD2 variety in the Ghanaian pineapple production sector. 
2. To assess how output level of farmers using conventional or organic production system(s) are affected by farm management decisions and production practices (i.e. effects of Technical Efficiency on output)

3. To investigate to what extent conditions prevailing in the production environment (such as road condition, inputs markets, technical support, environmental factors and other resource endowment) affect output of both conventional and organic farmers.

4. Identify the drivers of technical efficiency and technology gaps of both farming systems.

The study concludes by suggesting some appropriate policy interventions measures to help improve the output level of both farming systems.

Policy implication: Lack of empirical information on factors affecting production efficiency of farmers in the Ghanaian pineapple producing sector limits policy maker's ability to formulate appropriate intervention measures to enable farmers increase output. This study therefore contributes by filling this gap using a comprehensive data set covering all the three major pineapple production regions in Ghana. The study goes beyond obtaining just estimates of technical efficiency and technology gaps between regions but also identify factors influencing these estimates. Hence, policy maker are provided with detailed empirical information in formulating better future productivity enhancement programs.

\subsubsection{Research Area}

Pineapple production is viable in most of Ghana's ten administrative regions, however, due to logistic and financial constraints; data collection took place only in the three major producing regions (i.e. eastern, central and Volta regions) where average annual rainfall and temperature regimes support commercial production. These three regions constitute a fair representation of the main pineapple production areas in Ghana. These regions are characterised to some degree by similar climatic and soil conditions, however, there exist disparities in terms of quality and availability of certain basic agricultural infrastructures (e.g. rural roads conditions, number of extension workers per farmer, electricity access, input stores/dealers etc) needed to enhance performance in the sector. 
Such disparities in quality and access to important agricultural infrastructure may impose limitation on the type of production technology employed in a specific region or production area. Cultural diversity across these three regions may also influence production practices. Confirmation of statistical test (using likelihood ratio) together with our prior knowledge of different production technologies between conventional and organic pineapple production across the three regions justified the metafrontier estimation technique used for analysing factors influencing production performance in the sector.

\subsubsection{Data Set}

This research uses an integrated approach that draws upon both quantitative and qualitative methods of primary data collection. Based on information from district extension offices in each surveyed region, pineapple farmers were sampled randomly (i.e. simple random sampling method used in selecting both villages and households).

Figure 3.2: Number of Farmers Sampled in Each Region (organic and conventional systems)

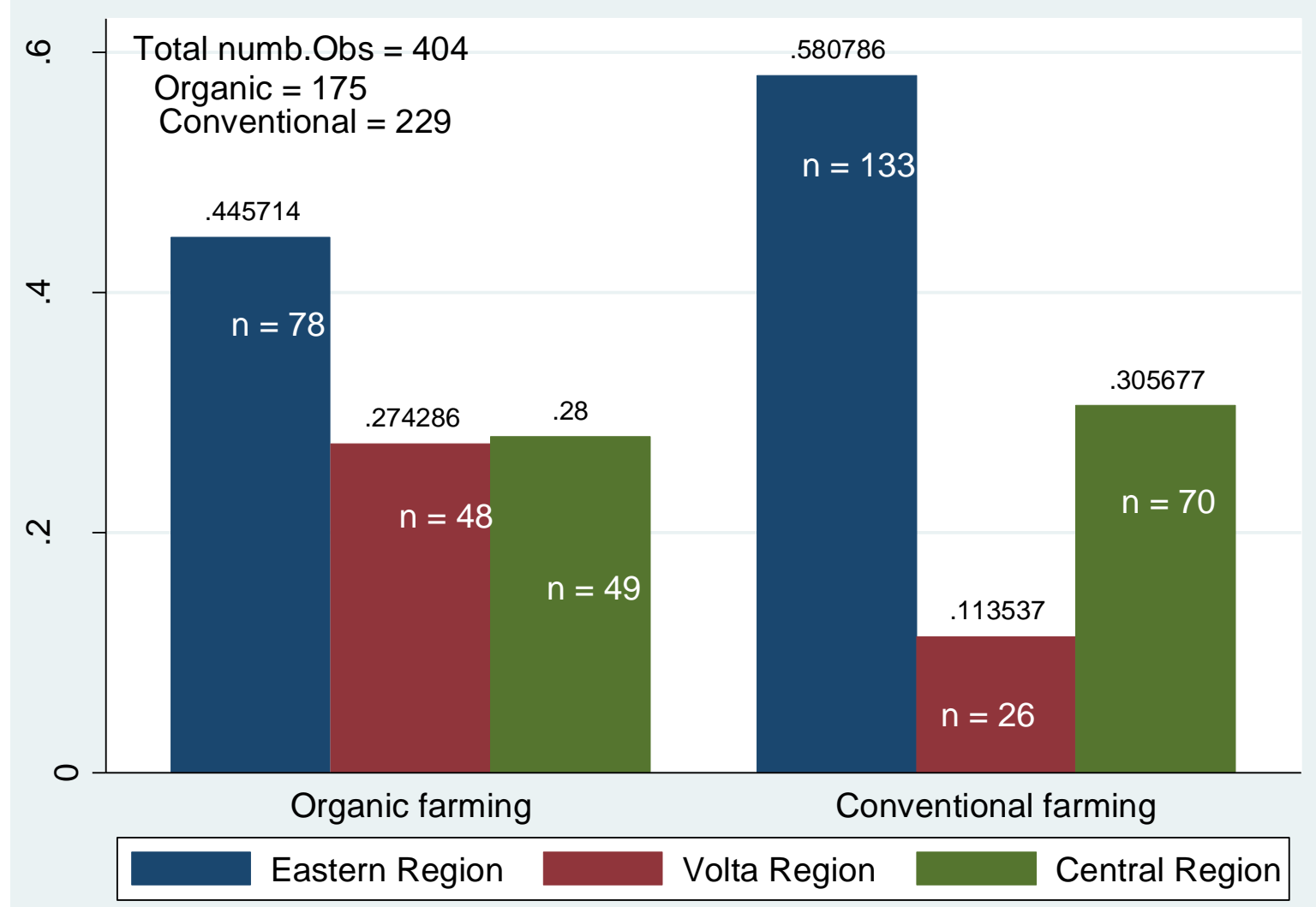

Source: study findings based on 2012 survey data 
Unequal sample number across the regions was mostly due to some farmers' unwillingness to continue with interview or incomplete questionnaire. Also more farmers were selected from the eastern region (around Nsawam area) to capture the large number/concentration effect of farmers in this region as most commercial pineapple growers in the sector are located in this region.

In total, our sample comprises 404 pineapple farmers. Figure 3.2 above presents an overview of the number of farmers' sampled using organic or conventional system of farming across the three regions. Using a structured questionnaire, detailed information on pineapple production activities (e.g. input use, farm output etc) as well as on socioeconomic characteristics was obtained. Lack of proper documentation of farm records by most farmers' means most information obtained could be classified as recall information.

\subsection{A Brief History of Ghana's Pineapple Production Sector}

Ghana started the intensive commercial exploitation of its immense productive resources and comparative advantage in producing tropical fruits to supply the international markets as part of an export diversification program in the 1990s. Within the two decades that followed, the economic potential of the various tropical fruits Ghana produced has helped transform the entire fruit sector into a formidable industry creating jobs in both rural and urban areas. Commercial Production of pineapple for export reached peak export level of 52,000 tonnes in 2004 with market share increasing from virtually zero to $10 \%$ in EU fruit markets around the same time.

The proximity of Ghana to Europe made the EU market a target export destination due to low sea and air freight charges (Mensah, 2012). The initial rapid growth in the pineapple sector through a knock-on effect induced strong growth in other sectors of the economy especially in the export sector, the transport and logistics sector, the agro-processing sector and the local retail sectors; This lead to increased employment and wealth generation in both rural and urban areas of the country (Pay, 2009).

The two major traditional varieties grown in Ghana are smooth cayenne and sugar loaf. Sugar loaf is conical in shape with very sweet juicy pulp while smooth cayenne is middle sweet with very intensive flavour. These varieties due to their relatively large size are very 
suitable for extraction of pineapple juice and making pineapple salad; however, they don't have the intensively sweet and bright yellow colour which most EU consumers associate with a ripe and healthy pineapple fruit. There are claims that, the relatively bigger size and shape of smooth cayenne and sugar loaf varieties pose some difficulty for orderly arrangement and space conservation in the EU super-market shelves (Wardy et al, 2009)(Achuonjei et al, 2003).

The introduction of MD2 (developed by Del Monte in Costa Rica) to the European market marked the beginning of demand decline for Ghanaian smooth cayenne and sugar loaf pineapple varieties (Pineapple exports declined by $40 \%$ between 2004 and 2013). Ghana dropped down from $3^{\text {rd }}$ to $5^{\text {th }}$ place in the supplier rankings and market share dropped from $10.5 \%$ to 4\% between 2005 and 2007 (Jaeger, 2008).

The MD2 is relatively small and uniform in size and ripeness with intensively sweet taste and bright yellow colour which renders it aesthetically appealing to most EU consumers. It is said to have higher shelf life and allows better arrangement on the super market shelf (Achuonjei, 2003). The introduction of MD2 nearly collapsed the Ghanaian pineapple sector since most small-scale farmers, which constitute the bulk of producers could not easily switch to the MD2 variety as demanded by changes in the international market. Information gathered during data collection (i.e. June - December 2012, in Ghana) from local farmers indicates; "it is more expensive to cultivate an acre of MD2 than the locally well adopted smooth cayenne and sugar loaf varieties since one of the major weaknesses of the MD2 variety is its extremely high susceptibility to the Phytophthora fungal disease". Interaction with some extension workers during data collection claimed "the MD2 variety was intentionally bred to suit climatic, soil and other production conditions prevailing in Costa Rica".

Due to the sector's inability to react quickly to changes in international market demands; both market share and comparative advantage were lost to Costa Rican exporters. ${ }^{28}$ Despite intervention measures by Government agencies and NGOs, smallholder farmers' adoption response to the MD2 variety has been very slow, due primarily to higher production and adjustment cost involved in transition to the MD2 variety.

At such difficult period, surviving farmers in the sector had a choice to make.

\footnotetext{
${ }^{28}$ The ideal growing conditions of MD2 in Costa Rica lowered production cost which then neutralized the Ghanaian cost advantage gained from lower freight costs as a result of its proximity to Europe.
} 
1. Either to switch completely to cultivation of MD2 variety to help regain international market share thereby risk forfeiting secure revenues from local markets/consumers or

2. Be innovative through quality improvement in securing new buyers for the local varieties while taking time to adjust to the MD2 variety.

Information gathered during field interview indicates; majority of small scale farmers eventually stick to production of the local smooth cayenne and sugar loaf varieties and are now concentrating on achieving higher fruit quality to serve emerging new buyers and local agroprocessing industries demanding high volumes on a weekly basis. This is due to the fact that the juice yield of Smooth Cayenne and the sugar loaf is significantly greater than the MD2 variety (i.e. approximate juice volumes of $205.72 \mathrm{ml} / \mathrm{kg}$ of Sugar loaf compare to $134 \mathrm{ml} / \mathrm{kg}$ of MD2, (Wardy et al, 2009)).

The high volume demand by these new buyers provides a new opportunity to revive production in the sector. However, the long term sustainability of the sector will not depend on serving only the local market but will depend on drastic improvement in production efficiency to sustain output growth in serving both local and the international markets.

Seven years after the 2005 crisis, we studied how Ghanaian pineapple farmers have responded to international market demand. We estimated the proportion of farmers cultivating the internationally preferred MD2 variety and analysed the factors influencing its adoption using a logistic regression model. We further employed metafrontier analytical techniques to assess the current productivity level in the sector and identify the factors which affect production efficiency of farmers in the pineapple sector. We conclude by recommending some potential ways to aid policy makers' formulation of future intervention programs to help boost output.

\subsection{Analytical Framework}

\subsubsection{The Stochastic Frontier Model}

The metafrontier estimation technique proposed by Battese et al, (2004) subsequently enhanced by O'Donnell et al, (2008) as an improvement over the traditional stochastic frontier estimation technique in situations where the implicit assumption of; "access to homogeneous technology for all firms in an industry" is violated. The metafrontier estimation technique enables technology gaps to be estimated for firms under different technologies relative to a 
potential technology available to the industry as a whole. In line with O'Donnell et al, (2008) the metafrontier estimation technique employed in this study involves a single process ${ }^{29}$ data generation technique where the estimates from the group specific frontiers are enveloped by a metafrontier such that the envelope covers from above the deterministic maximum outputs predicted from the estimated group-specific frontiers.

The metafrontier conceptually represents a boundary of an unrestricted technology set potentially available to the industry as a whole, while the individual production frontiers represent the boundaries of restricted technology sets where the restriction could be due to constraints imposed by the type of production technology and conditions prevailing in the production environment (e.g. lack of economic infrastructure) which limit farmers from using the full range of technologies available to the industry (O’Donnell et al, 2008).

The metafrontier is assumed to be a smooth function (not segmented) that envelopes all the frontiers of individual groups (where group $k_{c}=$ Conventional production system (c) and $k_{o}=$ Organic production system (o)) system. This could be conceptually depicted as in Figure 3.3 below:

\section{Figure 3.3: Metafrontier Function Model}

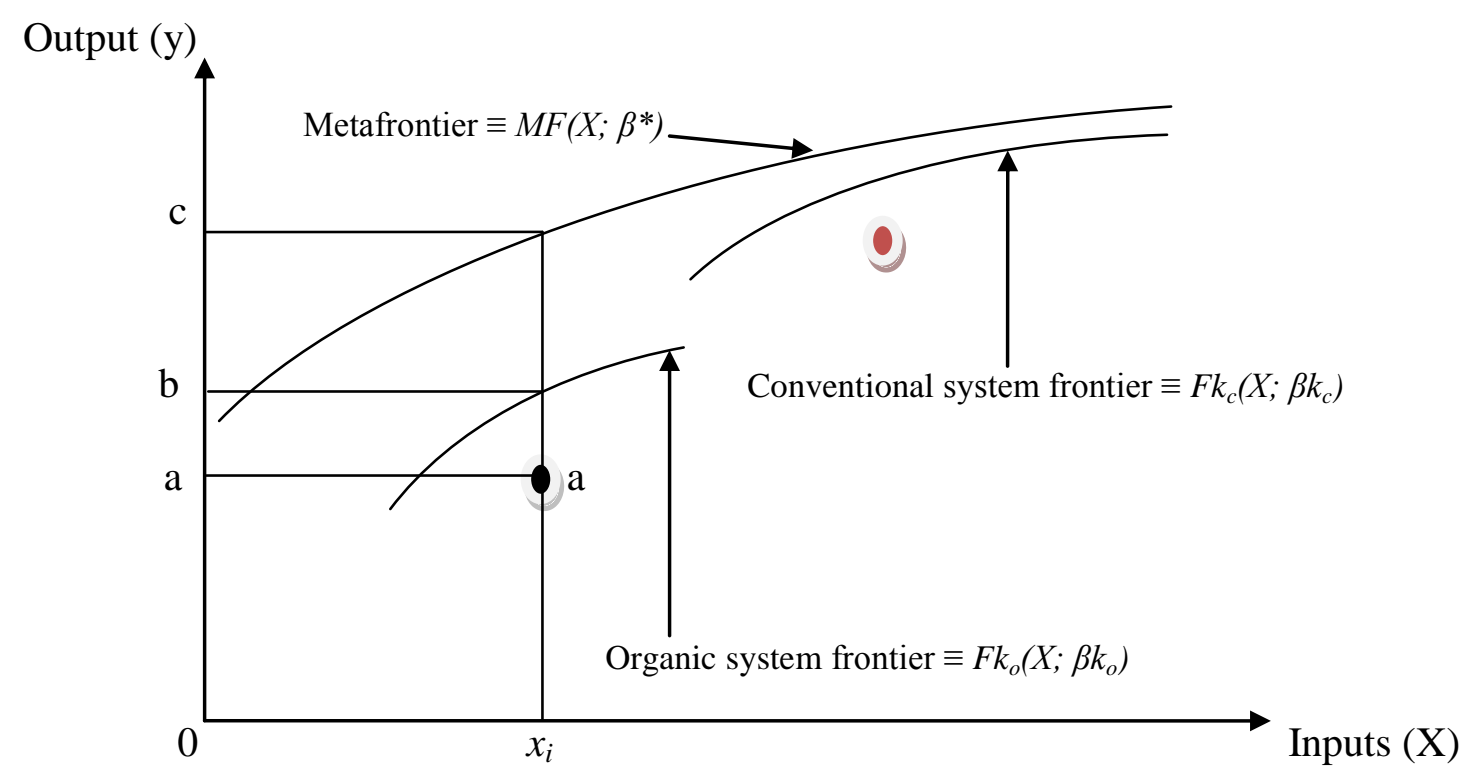

Source: author's owned conceptual depiction

\footnotetext{
${ }^{29}$ Please refer to O’Donnell et al. (2008) for detailed discussion on single process data generation technique for a metafrontier analysis.
} 
Thus, considering $k$ systems of production in the pineapple sector, a standard output oriented stochastic frontier model for production system $k$ could be specified as follows ((Battese et al, 2004) (O’Donnell et al, 2008) :

$Y_{i(k)}=f\left(x_{i}, \beta_{(k)}\right) e^{v_{i(k)}-u_{i(k)}} \equiv e^{x_{i} \beta_{(k)}+v_{i(k)}-u_{i(k)}}$.

Where the expression in model (1) assumes that the exponent of the frontier production function is linear in the parameter vector, $\beta_{(k)}$, so that $x_{i}$ is a vector of functions (e.g., logarithms) of the inputs for the ith farmer involved in the pineapple sector. $Y_{i(k)}$ denotes the total pineapple output for the ith pineapple farmer in the $k t h$ farming system; $x_{i(k)}$ denotes a vector of inputs used by the ith farmer in the kth zone; the functional form $f($.$) is specified as translog$ function (as defined in section (3.2)), so $\beta_{(k)}$ denotes the parameter vector/coefficients associated with the $x$-variables for the translog stochastic frontier for the $k t h$ production system; the $v_{i(k)} s$ are noise error term which is assumed to be identically and independently distributed as $N\left(0, \sigma_{v(k)}^{2}\right)$ (Aigner et al (1977)) random variables, independent of the inefficiency term $u_{i(k)}$.

The $u_{i(k)} \mathrm{s}$ are a systematic and non-negative random variables which account for technical inefficiency in production which is under the influence of farmers and are assumed as the truncation (at zero) $)^{30}$ of the $N\left(0, \sigma_{u i(k)}^{2}\right)$ distributions such that the $u_{i(k)}$ s are defined as (Wang and Schmidt (2002));

$\sigma_{u_{i(k)}}=\exp \left\{z_{i(k)} \delta_{j}\right\}$

Where $z_{i(k)}$ is explanatory variables of the variance of inefficiency term $\sigma_{u_{i(k)}}$ for the ith farmer; $\delta$ is a vector of parameters to be estimated, reflecting the impact of the variables $Z_{i(k)}$ on technical inefficiency (i.e. equation (2) captures the impact of specified farmers' input endowments and usage and socioeconomic variables hypothesised to influence technical effi-

\footnotetext{
${ }^{30}$ i.e. half-normal distribution are assumed for the $u_{i(k)} \mathrm{s}$
} 
ciencies in the pineapple production sector). A positive or negative estimate of $\delta$ indicates that the corresponding variable leads to an increasing or decreasing variance of the inefficiency term (i.e. increasing or decreasing technical efficiency). Model (2) generally known as "heteroscedasticity-model" was developed by Wang and Schmidt in (2002) for stochastic production frontier estimation framework. This model corrects for possible heteroscedasticity which is often present in cross-section survey data(s). The specification of model (1) which implicitly assumes that both error terms (i.e. $v$ and $u$ ) are homoscedastic (i.e. conditioned on the explanatory variables, the variance of the unobserved errors $(v+u)$ are constant $)$. However, since our sample is a cross section survey data and we observed considerable variation in terms of farm size and other inputs usage, it is likely both error terms are affected by heteroscedasticity (i.e. the inefficiency term would vary according to farm size with larger farms having more variation than small farms (Lakner et al (2013)). Hence, if such heteroscedasticity effects are not corrected, it implies estimated standard errors are biased and we cannot use $\mathrm{t}$ statistics for drawing inferences.

The metafrontier production function model for farmers in the pineapple production sector could be express as:

$$
Y_{i}^{*} \equiv f\left(x_{i} ; \beta^{*}\right)=e^{x_{i} \beta^{*}}, \quad i=1,2, \ldots, N_{k}, N=\sum_{j=1}^{2} N_{j}
$$

Where $Y_{i}^{*}$ is the metafrontier output and $\beta^{*}$ denotes the vector of parameters for the metafrontier function satisfying the constraints:

$$
x_{i} \beta^{*} \geq x_{i} \beta^{k} \text { for all } k=1,2, \ldots \mathrm{K}
$$

Model (4) specifies that the metafrontier dominates all the two systems frontiers. The metafrontier production function as specified by equation (3) is a log linear production function form and the constraint imposed in equation (4) does not allow the metafrontier function to fall below the deterministic functions for the two systems involved in the sector (Battese et al, 2004). The model is underpinned by a single data generating process as suggested by 
O'Donnell et al, (2008). The estimated metafrontier function which enveloped the two estimated frontier was obtained by solving the optimization problems in equations (10) and (11).

The observed output for the ith pineapple farmer defined by the stochastic frontier for the $k t h$ system of production in equation (1) is alternatively expressed in terms of the metafrontier function of equation (3) by:

$Y_{i}=e^{-u_{i(k)}} \times \frac{e^{x_{i} \beta(k)}}{e^{x_{i} \beta^{*}}} \times e^{x_{i} \beta^{*}+v_{i(k)}}$

The first term on the right-hand side of model (5) is the technical efficiency of the ith pineapple farmer relative to the stochastic frontier for the $k t h$ production system. Equation $(6)^{31}$ which is the same as the first term on the right hand side of equation (5) allows us to examine the performance of the $i t h$ farmer relative to the individual system frontier (e.g. given observation "a" under the organic production system as depicted in figure 3.3 above):

$T E_{i(k)}=\frac{Y_{i}}{e^{x_{i} \beta_{(k)}+v_{i(k)}}}=e^{-u_{i(k)}} \quad$------ (i.e. $T E_{i}=a o / b o$ in figure 3.3)

The second term on the right-hand side of equation (5) is what Battese et al, (2002, 2004) call Technology Gap Ratio (TGR) but O’Donnell et al, (2008) call it Meta Technology Ratio (MTR) for the observation of the sample farms involved in the sector. This is expressed as:

$M T R_{i(k)}=\frac{e^{x_{i} \beta(k)}}{e^{x_{i} \beta^{*}}} \quad$------- (i.e. $M T R_{i}=b o / c o$ in figure 3.3)

This measures the ratio of the output for the frontier production function for the kth production system relative to the potential output that is defined by the metafrontier function, given

\footnotetext{
${ }^{31}$ Is estimated by the conditional expectation of $\mathrm{u}$ given the observed residual $\mathrm{w}(\mathrm{E}[\mathrm{u} \mid \mathrm{w}]$, see (Jondrow et al, 1982) and (Battese et al, 1988).
} 
the observed inputs. This ratio provides an estimate of the technology gap between the group and the industry as a whole. The MTR plays an important part in explaining the ability of one farming system to compete with the other system in the industry. The technology gap ratio has values between zero and one. Values close to one imply that the farmers are producing nearer to the maximum potential output given the technology available for the industry as a whole.

The technical efficiency of the ith pineapple farmer compared to the industrial frontier (metafrontier), is denoted by $T E_{i}^{*}$ and is defined in a similar way to equation (6). It is the ratio of the observed output of the ith pineapple farmer relative to the metafrontier output (i.e. last term on the right hand side of equation(5)) adjusted for the corresponding random error, such that

$T E_{i}^{*}=\frac{Y_{i}}{e^{x_{i} \beta^{*}+v_{i(k)}}} \quad$------ $\left(\right.$ i.e. $T E_{i}^{*}=$ ao/ac in figure 3.3)

Following equations (5), (6), and (7), the $T E_{i}^{*}$ can alternatively be expressed as

$T E_{i}^{*}=T E_{i(k)} \times M T R_{i(k)}$

So the technical efficiency relative to the metafrontier $\left(T E_{i}^{*}\right)$ is the product of the technical efficiency relative to the stochastic frontier of a given production system $\left(T E_{i(k)}\right)$ and the metatechnology ratio $\left(M T R_{i(k)}\right)$ for that system. Because both $T E_{i(k)}$ and $M T R_{i(k)}$ are measures between zero and one, the value of $T E_{i}^{*}$ is also between zero and one (i.e. it could be less than or equal to the technical efficiency relative to the stochastic frontier for the production system of the $i$ th farmer (i.e. $\left.T E_{i}^{*} \leq T E_{i(k)}\right)$ ).

In line with Battese et al, (2004) and O'Donnell et al, (2008) we estimated the parameters and measures associated with the metafrontier model as follows: 
1. We obtained the maximum likelihood estimates, $\hat{\beta}^{\mathrm{k}}$ for the $\beta^{\mathrm{k}}$ parameters of the stochastic frontier for the $k$ th production system (group) using the statistical software OxMetrics version 7 (Doornik, 2008).

2. We then estimated, $\hat{\beta}^{*}$, for the $\beta^{*}$ parameters of the metafrontier function such that the estimated function best envelops the deterministic components of the estimated stochastic frontiers for the different groups.

3. The metafrontier parameters are obtained by minimizing the sum of squares of deviations or the sum of absolute deviations of the metafrontier values from those of the group $^{32}$.

The numerical values of the metafrontier parameters were obtained using the OxMetrics programming language in solving the objective functions in equations (10) and (11) below ${ }^{33}$ :

$\min L P \equiv \sum_{i=1}^{N}\left|\left(\ln f\left(X_{i}, \beta^{*}\right)-\ln f\left(X_{i}, \hat{\beta}_{K}\right)\right)\right| \quad$......Linear optimization function

s.t. $\ln f\left(X_{i}, \beta^{*}\right) \geq \ln f\left(X_{i}, \hat{\beta}_{K}\right)$ for all $i$.

$\min Q P \equiv \sum_{i=1}^{N}\left(\ln f\left(X_{i}, \beta^{\sim}\right)-\ln f\left(X_{i}, \hat{\beta}_{K}\right)\right)^{2} \quad$.......Quadratic optimization function

s.t. $\ln f\left(X_{i}, \beta^{\sim}\right) \geq \ln f\left(X_{i}, \hat{\beta}_{K}\right)$ for all $i$

Estimates for the technical efficiencies of all pineapple farmers relative to the metafrontier function were then obtained by:

$\hat{T E}_{i}^{*}=\hat{T E}_{i(k)} \times T G \hat{R}_{i(k)}$

\footnotetext{
${ }^{32}$ Please refer to Battese et al, (2004) and Rao et al, (2012) and O’Donnell et al, (2008) for detailed outline of how to obtain both the minimum sum of absolute deviations and minimum sum of squares of deviations.

${ }^{33}$ As outlined by Rao et al, (2012) in solving equation (10) and (11), the $\hat{\beta}_{\mathrm{K}}$ are treated as fixed. So that the second term in the summation is constant with respect to the minimization.
} 
Where $T E_{i}$ is the predictor for the technical efficiency relative to the given system frontier as proposed by O'Donnell et al, (2008). The $M T R_{i(k)}$ is the estimate for the $M T R_{i(k)}$ for the $i t h$ farm in the $k t h$ group relative to the industrial potential, obtained by using the estimates for the parameters involved (specifically, the MTR is estimated by substituting estimates of $\beta_{(k)}$ and $\beta^{*}$ into equation (7), the constraints in the LP problem defined by equation (10 and 11) guarantee that metatechnology ratios estimated in this manner will lie in the unit interval).

Standard errors for the estimators for the metafrontier parameters were obtained using statistical simulations (specifically, we used the estimated asymptotic distributions of the zonal frontier estimators to draw $M=5,000$ observations on the zonal frontier parameters. Each draw was then used to calculate the right-hand side of the constraints in the LP/QP problems. The estimated standard errors of the metafrontier estimators were calculated as the standard deviations of the M solutions to these LP/QP problems (Battese et al, 2004).

\subsubsection{Empirical Specification}

Empirical estimation of both systems of production were obtained using translog stochastic frontier production function model. The choice of translog model is based on a statistical test (see table 2). Its flexibility allows us to examine interaction between production inputs. A translog model for pineapple farmers in each production system could be defined as:

$\ln y_{i}^{k}=\beta_{0}^{k}+\sum_{j=1}^{J} \beta_{j}^{k} \ln x_{j i}^{k}+1 / 2 \sum_{j=1}^{J} \sum_{m=1}^{J} \beta_{j m}^{k}\left(\ln x_{j i}^{k}\right)\left(\ln x_{m i}^{k}\right)+\sum_{s=1}^{S} \beta D_{s}+v_{i}^{k}-u_{i}^{k} 34$

ln $y_{i}^{k}$ denotes the natural logarithm of total pineapple output for the ith farmer in the kth production system. $\ln x_{j i}^{k}$ represents the $j$ th input $(j=1,2, \ldots .$.$) of the i$ th farmer $(i=$ $1,2, \ldots N)$ using the $k t h$ production system $(k=1,2, \ldots K) . \beta_{j m}^{k}=\beta_{m j}^{k}$ for all $j$ and $m$. The $\beta$ represent a vector of coefficients associated with the $x$-variables in the translog specification to be estimated. The $x_{s}$ represents the various continuous/discrete production inputs

\footnotetext{
${ }^{34}$ The $u_{i}^{k}$ is assumed to be defined as in equation (2).
} 
variables (i.e. land, labour, fertilizer cost and plant age). $\mathrm{D}_{\mathrm{s}}$ are dummy variables (i.e. extension, irrigation, credit access, gender and farmer association) intended to capture unique regional characteristics which may influence the system's production frontier. The discrete variables in the model were scaled to have unit means so that, the first-order coefficients of the translog function can be interpreted as elasticities of output with respect to inputs evaluated at the sample means (Coelli et al, 2005).

For appropriate policy interventions, it is not enough to only have estimates of technology gaps between production systems and the industrial frontier but also information on what contribute to the formation of these gaps. We therefore specified a multivariate regression function to capture the determinants of the technology gap ratio as follows:

$\operatorname{MTR}_{i}=\beta_{0}+\sum_{j=1}^{J} \beta_{j} q_{i j}+\varepsilon_{i}$

Model (14) specifies climatic, soil, infrastructural and Government program variables outside the control of farmers hypothesised to influence the MTR in Ghana's pineapple production sector (i.e. the $q_{i j}$ are hypothesised explanatory variables influencing MTR). The $\varepsilon_{i}$ captures any statistical noise and is assumed to be identically and independently distributed as $N\left(0, \sigma_{v}^{2}\right)$ random variables.

To analyse the factors influencing adoption of MD2 variety, a simple logistic regression model was specified as follows:

$y^{*}=\alpha+\beta x+\varepsilon \quad$ where $\varepsilon$ is distributed as in equation (16)

$y_{i}=\left\{\begin{array}{l}1 \text { if } y_{i}^{*}>0 \\ 0 \text { if } y_{i}^{*} \leq 0\end{array}\right.$

Where $y^{*}$ is a binary (i.e. dummy) variable (i.e. $1=$ planting MD2 variety; $0=$ Otherwise). The value of $\beta$ is the propensity to adopt the MD2 variety; where higher positive values of $\beta$ 
mean that the adoption of MD2 is more likely. The $\boldsymbol{x}_{\boldsymbol{s}}$ are explanatory variables hypothesised to influence the adoption of MD2 in Ghana's pineapple production sector. The $\varepsilon$ captures any statistical noise and is assumed to have the standard logistic distribution of errors as follow:

$$
\ln \left(\frac{p_{i}}{1-p_{i}}\right)=\sum_{k=0}^{k=n} \beta_{k} x_{i k}
$$

\subsection{Results and Discussion}

Empirical results were obtained with the aid of OxMetrics programming language (Doornik, 2008) and Stata statistical software. Maximum likelihood estimates for the metafrontier model as well as the pooled and group stochastic production function frontier models were obtained using a modified metafrontier estimation template for OxMetrics7. Stata ( $11^{\text {th }}$ edition) was used for all the descriptive and graphic analysis including the estimated average response function for the determinants of the MTR and the logistic model for analysing factors influencing the adoption of MD2 variety. The various variables used in the estimation models and their units of measurement are presented in appendix B.

\subsubsection{Summary Statistics}

The total number of pineapple farmers sampled across the three major pineapple producing regions is 404. Table 8 (in appendix B) presents how the variables are defined and the unit of measurement. Tables 3.9 and 3.10 (in appendix B) present summary statistics of all the variables used in the various analytical models. A look at Table 3.9 shows that farmers using conventional production system on average have higher total farm output, allocated more land and labour to pineapple production compared to their organic production system counterparts. These differences however appear to be moderate yet statistically significant as confirmed by differences of means test.

Table 3.10 which reports on dummy variables used in the various analyses also reveals that a high proportion of males are involved in pineapple production in both systems. The proportion of farmers under contract obligations to supply agro-processing and exporting companies is higher in the conventional system compared to the organic system. No significant propor- 
tional difference could be observed in terms of manure applications, extension visits and access to better road conditions.

\subsubsection{Test of Model Quality}

Before we proceeded to examine the parameter estimates of the various models used in the analysis, we performed a test to examine the appropriateness of the models using generalised likelihood-ratio statistics. These hypotheses were tested using the generalized likelihood-ratio statistic; $L R=-2[\ln \{L(\mathrm{H} 0)\}-\ln \{L(\mathrm{H} 1)\}]$, where $L(H 0)$ and $L(H 1)$ are values of the likelihood function under the null $(H 0)$ and alternative $(H 1)$ hypotheses, respectively. $L R$ has approximately a Chi-square (or mixed Chi-square) distribution if the given null hypothesis is true with a degree of freedom equal to the number of parameters assumed to be zero in $(H 0)$. (Coelli, 1995) proposes that all critical values can be obtained from the appropriate Chisquare distribution. However, if the test of hypothesis involves $\gamma=0$, then the asymptotic distribution necessitates the mixed Chi-square distribution (Kodde and Palm 1986; Table 1).

Table 3.1.: Hypothesis Testing for Stochastic Production Frontier Model

\begin{tabular}{lcccc}
\hline \hline Null hypothesis (Ho) & $x^{2 \text { Stat }}$ & $\begin{array}{l}\text { Deg. Of } \\
\text { freedom }\end{array}$ & $x^{2}$ Critical & P-value \\
\hline \hline Homogenous technology across all production systems & 91.35 & 44 & 60.48 & 0.005
\end{tabular}

Cobb-Douglas functional form is appropriate: $\beta_{i \mathrm{j}}=0$

$\begin{array}{lllll}\text { Organic production system } & 72.87 & 21 & 32.67 & 0.001 \\ \text { Conventional production system } & 41.83 & 21 & 32.67 & 0.050 \\ \text { Pooled model } & 94.80 & 21 & 32.67 & 0.001\end{array}$

No technical Inefficiency effects: $\gamma=0=\delta 1=\ldots=\delta 9=0$

$\begin{array}{lllll}\text { Organic production system model } & 81.40 & 10 & 15.38 & 0.000 \\ \text { Conventional production system model } & 51.62 & 10 & 15.38 & 0.000 \\ \text { Pooled model } & 101.98 & 10 & 15.38 & 0.000\end{array}$

Source: study findings based on 2012 field survey data.

Note: Coefficients and standard errors have been rounded off to three decimal places.

The results of tests for various hypotheses on model quality are presented in Table 3.1 above. The overall result shows that the models used are an appropriate representation of the data. 
For instance, the null hypothesis of homogenous technology across all production systems was rejected justifying the use of metafrontier estimating technique. The null hypothesis that the Cobb-Douglas frontier is an adequate representation of the data of both production systems was also rejected. The null hypothesis that technical inefficiency is not present in both systems was rejected implying majority of farmers operate below the production frontier. This also suggests that all the hypothesised variables included in the inefficiency model collectively and significantly contribute in explaining how inefficiency affects output in the pineapple production sector.

\subsubsection{Adoption of MD2}

To access the response of farmers to shift in international market demand preference for MD2 variety, the proportion of farmers in our data cultivating MD2 was calculated.

\section{Figure 3.4.: Bar Chart of Variety Type under Cultivation (Organic and Conventional farming systems)}

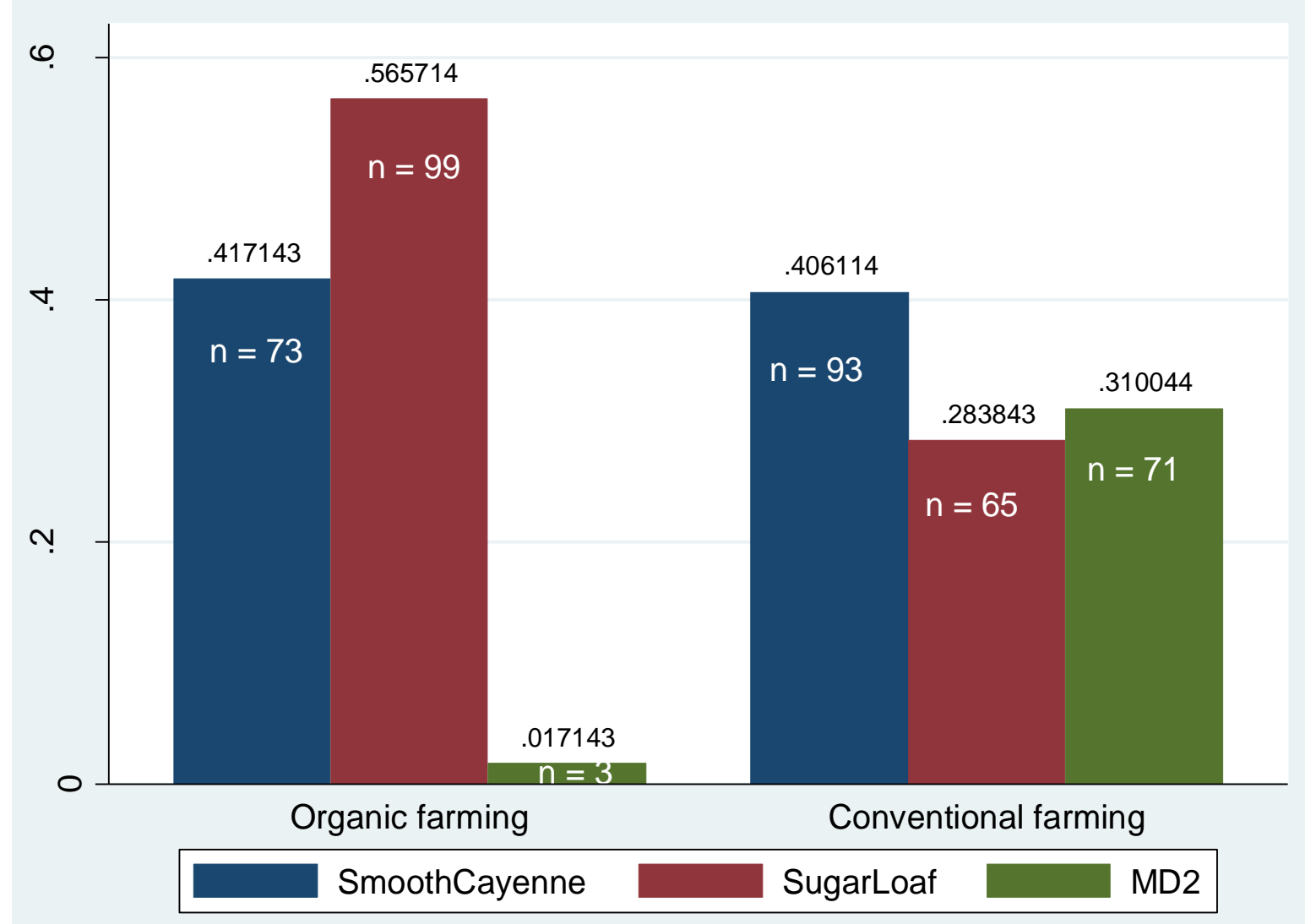

Source: study findings based on 2012 survey data 
Figure 3.4 and 3.5 presents a bar and pie chart summary statistics of the proportion of various varieties under cultivation by farmers in our data set. Out of 404 pineapple farmers sample across the three regions, only $74(18 \%)$ farmers in both systems are cultivating the MD2 variety. Majority of the farmers are still cultivating the local varieties. 166 (42\%) farmers cultivate the smooth cayenne variety while 164 (40\%) cultivate the sugar loaf variety. For farmers producing organic pineapples, only $3(0.02 \%)$ are cultivating the MD2 variety. $71(31 \%)$ farmers under conventional system of production are cultivating the MD2 variety.

These summary statistics show that the rate of adoption in response to market change is very slow as shown by majority of farmers in our sample data. The peak of the market shift crisis was in 2005. We collected data at the end of 2012 production year, so seven years after the crisis, we expected that the majority of farmers will be cultivating the international market preferred MD2 variety; however, as revealed by our data, only $18 \%$ are cultivating the MD2 variety. We therefore proceed to analyse the factors influencing the adoption of MD2 variety by farmers in the pineapple production sector.

\section{Figure 3.5: Pie Chart of Variety Type under Cultivation (Organic and Conventional farming systems)}

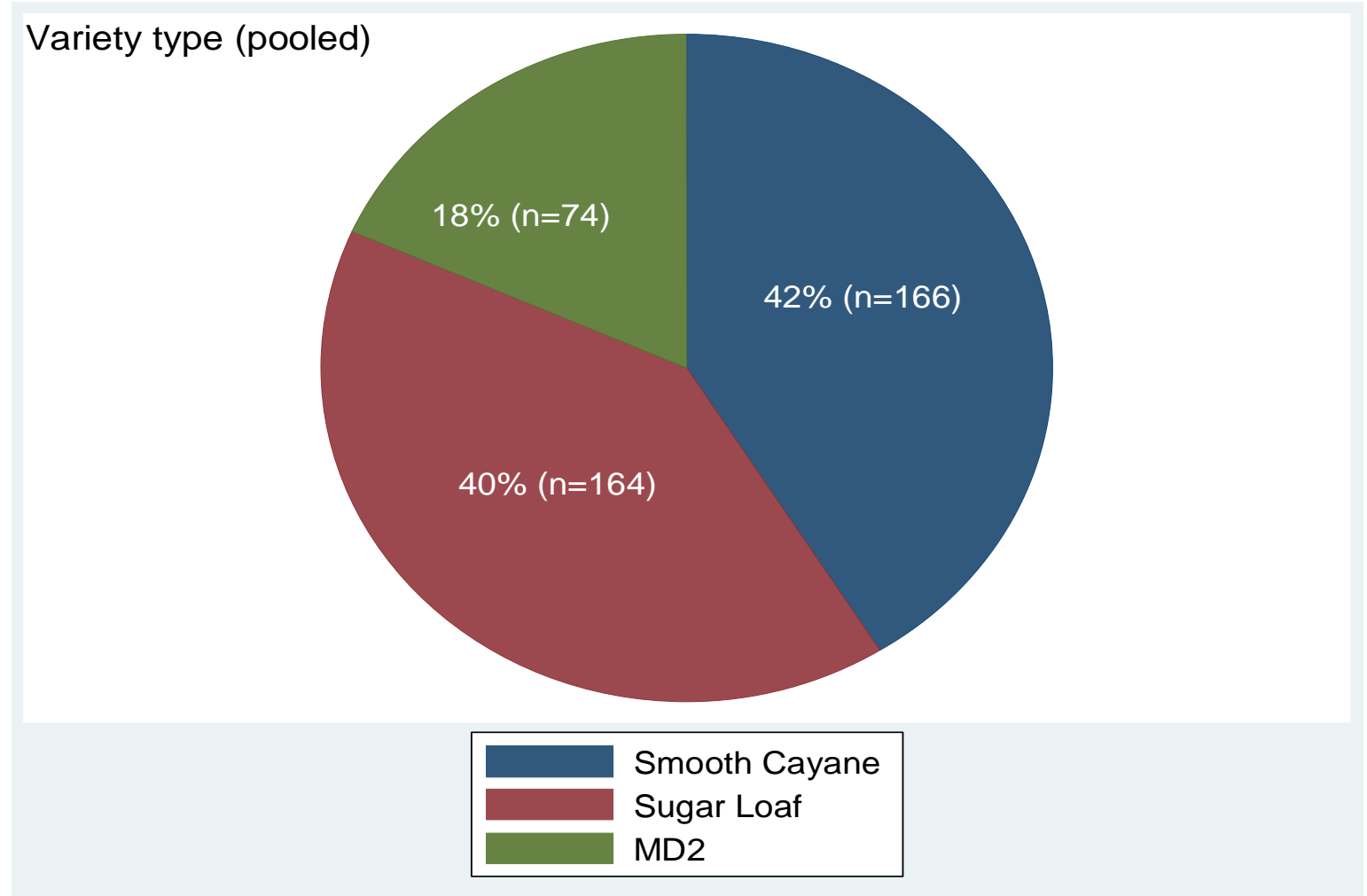

Source: study findings based on 2012 survey data 
The result of a logistic regression model as specified in equation (15) is presented in Table 3.2. The estimates in columns 2,4 and 6 can be interpreted as follows: all things being equal (i.e. ceteris paribus), the odds of a farmer having a unit access to one of the predictor variable will facilitate the adoption of the MD2 variety by a margin of the respective log odd estimate (the $\exp (\log$ odd $)=$ odd ratio). Table 3.2 therefore shows a farmer having an access to irrigation water is 2.832 times more likely to adopt the MD2 variety compare to those who do not have any access to irrigation. The marginal effect represents the slope or the elasticity of adoption with respect to a $1 \%$ increase in irrigation access (i.e. 0.118), this figure imply, once a farmer adopt the MD2 variety, a 1\% increase in irrigation access will influence his/her decision to expand the share of MD2 under cultivation by $0.118 \%$. In general Table 3.2 shows that farmers capable of irrigating their farms, having access to more pineapple buyers with farms located in the eastern regions are more likely to adopt the MD2 variety. The highest marginal effect is however, observed by the type of farming systems (i.e. conventional farmers are more likely to adopt and expand production of the MD2 variety compare to their organic farmers counterparts, see Figure 3.4 above).

Table 3.2.: Factors Influencing Adoption of MD2 Variety (Logistic Model)

\begin{tabular}{|c|c|c|c|c|c|c|}
\hline AdoptMD2 & Log odds & Std. Err. & Odds Ratio & Std. Err. & $\begin{array}{l}\text { Marginal effects } \\
(\mathrm{dy} / \mathrm{dx})\end{array}$ & Std. Err. \\
\hline Off-farm Income & 0.001 & 0.000 & 1.001 & 0.000 & 0.000 & 0.000 \\
\hline Irrigation & $1.041 * *$ & 0.489 & $2.832 * *$ & 1.384 & $0.118 * *$ & 0.054 \\
\hline Farming System & $3.447 * * *$ & 0.642 & $31.412 * * *$ & 20.159 & $0.392 * * *$ & 0.067 \\
\hline Fruit traders & $0.114^{*}$ & 0.063 & $1.121^{*}$ & 0.070 & $0.013^{*}$ & 0.007 \\
\hline extension & $-1.050 * *$ & 0.503 & $0.350 * *$ & 0.176 & $-0.120 * *$ & 0.056 \\
\hline manure & 0.714 & 0.560 & 2.043 & 1.145 & 0.081 & 0.063 \\
\hline Input subsidy & 0.294 & 0.368 & 1.342 & 0.493 & 0.033 & 0.042 \\
\hline Eastern & $1.250 *$ & 0.658 & $3.491 *$ & 2.297 & $0.142 *$ & 0.074 \\
\hline Central & 0.663 & 0.686 & 1.940 & 1.330 & 0.0753 & 0.078 \\
\hline Constant & $-7.140 * * *$ & 1.107 & & & & \\
\hline $\begin{array}{l}\text { Log likelihood } \\
\text { Pseudo R2 } \\
\text { Number of obs. }\end{array}$ & $\begin{array}{l}-140.81071 \\
0.2680 \\
404\end{array}$ & & & & & \\
\hline
\end{tabular}


This observation is not very surprising since unlike the well adopted cayenne varieties to the Ghanaian farm conditions, the recently introduced MD2 variety is more likely to be susceptible to local pineapple diseases (e.g. the phytophthora fungal disease), therefore a relatively high amount and frequency of certain chemical inputs will be required to enable maximum output attainment. Contrary to our expectation, farmers with more extension contacts were less likely to adopt the MD2 variety. This could be due to the fact that the majority of extension workers in the research area were not fully up to date or well trained in understanding the agronomic practices of the MD2 variety and so could not advice farmers to appropriately adjust their cultivation practices to suit the requirement of the MD2 variety.

The low adoption rate of the MD2 variety may also be due to its high production and adjustment $\operatorname{cost}^{35}$. It appears the shockwaves of the crisis is still reverberating in the minds of a lot of farmers, making them more caution in obtaining new loans to enable them finance the recommended inputs and cultivation requirements should they decide to adopt the MD2 variety. Compared to the initial establishment phase while the industry was doing well before the crisis, a lot of farmers took credit to invest in pineapple production. However, the sudden shift of demand to MD2 bankrupted most of these farmers, hence, their unwillingness to further borrow just to finance adoption requirements of the MD2 variety.

Information gathered during field interview indicates that the majority of farmers who survived the market shock and remained in the sector, have decided to stick to the production of the locally well adopted smooth cayenne and sugar loaf varieties which entail very low production cost. Most of such farmers are now concentrating on achieving higher fruit quality to serve emerging new buyers in the fresh cut retail sector and local agro-processing industries demanding high volumes of these local varieties on a weekly basis. The high demand of these new buyers may provide a new opportunity to revive the industry but this could only be achieve on a sustainable basis if farmers radically improve their productivity level.

The subsequent sections of this study therefore assessed current production efficiency level of both conventional and organic farmers. We identified sources of production inefficiency emanating from farmers' technical inefficiency as well as those emanating from factors pre-

\footnotetext{
${ }^{35}$ Cost of certified MD2 crowns/plantlets, also high adjustment cost to meet weather and soil conditions. The MD2 was breed to suit Costa Rican weather and soil conditions; hence, best performance in Ghana is only possible with substantial initial investment in meeting recommended cultivation requirement.
} 
vailing in the production environment. The study concludes by suggesting some potential ways of improving productivity so as to aid boost output in the sector.

\subsubsection{Parameter Estimates of the Stochastic Frontier}

In this section we examine how production factors influence the production frontier (i.e. how factor endowment impacts output). The first order maximum likelihood estimates of the organic and conventional frontiers are presented in Table 3.3 below. The dependent variable is $\log$ of total farm output measured in kilograms ${ }^{36}$. The continuous variables (i.e. log of land, labour, experience, maintenance cost, plant age and crop density) are normalized as proposed by (Battese et al, 1997), hence, estimates of the first order coefficients can directly be interpreted as partial output elasticities at the sample mean.

Total farm output is positively and significantly influenced by total land allocated to pineapple production in both systems. This highlights the importance of access to land in agricultural productivity. Increasing the total number of people working on plantation has positive and significant effect on total farm output in both systems. This reflects the labour intensive requirement nature of pineapple production; hence, an increase in labour input results in real positive impact on output. Increasing experience and maintenance cost have positive effect on output; however, this effect is statistically significant only in the conventional system of production.

Aging plants have a significantly negative effect on the output at the sample mean. This could be attributed to decreasing effectiveness of old plants in converting light into stored energy during photosynthesis. Increasing plant density has positive and significant effect on the output while increasing manure use has the opposite effect. This imply, excessive amount of nitrogen encourages vegetative growth at the expense of fruit set hence the right balance of manure application should be observed by sampled farmers. Farmers irrigating their farms observed a significantly positive output as compared to those who do not. Due to high temperature regimes in tropical countries, low soil moisture content normally prompt plants into dormant state, hence plantations under rain-fed system normally observe lower farm output.

\footnotetext{
${ }^{36}$ Farm output as measured here does not take into account for fruit size, quality and post harvest losses. This could be a draw back and so has to be kept in mind for interpretation.
} 
Famers who are under contracts obligations to supply exporting and agro-processing firms tend to have significantly positive output. This implies, as farmers are assured of secured buyers for their products, they are willing to invest in production inputs to increase output. Due to such binding contractual agreements, buyers and traders are more willing to support such farmers with loans to enhance production.

Positive and significant effects were also observed with farms located in the eastern region. The location of a farm appears to be important for output. This may due to the enormous experience gained by farmers in the eastern region considered as pioneers of commercial pineapple production especially those around the town of Nsawam. It also reflects the regions easy access to technical support, market and the suitability of climate and soil in the Akuapem south district for pineapple production.

Table 3.3.: Estimates of the Translog Stochastic Production Frontier Models

\begin{tabular}{|c|c|c|c|c|}
\hline \multirow{2}{*}{$\begin{array}{l}\text { Variable } \\
\text { Name }\end{array}$} & \multicolumn{2}{|c|}{ Organic production system } & \multicolumn{2}{|c|}{ Conventional production system } \\
\hline & Coefficient & Std. Err. & Coefficient & Std. Err. \\
\hline Constant & $-0.094 * * *$ & 0.021 & $-0.068^{*}$ & 0.044 \\
\hline Land & $0.207 * * *$ & 0.033 & $0.127 * * *$ & 0.037 \\
\hline Labour & $0.069 * * *$ & 0.025 & $0.166 * * *$ & 0.037 \\
\hline Experience & 0.019 & 0.016 & $0.068 * * *$ & 0.021 \\
\hline Maintenance Cost & 0.010 & 0.025 & $0.145^{* * *}$ & 0.031 \\
\hline Plantation Age & $-0.074 * * *$ & 0.021 & $-0.037^{*}$ & 0.020 \\
\hline Density & $0.134 * * *$ & 0.034 & $0.095^{* *}$ & 0.038 \\
\hline Manure & $-0.165 * * *$ & 0.017 & $-0.117 * * *$ & 0.025 \\
\hline Irrigation & $0.202 * * *$ & 0.016 & $0.135 * * *$ & 0.024 \\
\hline Contract & $0.031 * *$ & 0.016 & $0.037 *$ & 0.023 \\
\hline Eastern ${ }^{\#}$ & $0.072 * * *$ & 0.020 & $0.075^{* * *}$ & 0.028 \\
\hline Central $^{\#}$ & 0.012 & 0.016 & 0.013 & 0.026 \\
\hline "RTS & 0.365 & & 0.564 & \\
\hline Log-likelihood & 209.076 & & 217.452 & \\
\hline Gamma & 0.829 & & 0.509 & \\
\hline Number of Obs. & 175 & & 229 & \\
\hline
\end{tabular}

Source: Study findings based on 2012 field survey data.

***,*** Significant at the 10\%, 5\%, and 1\% level, respectively.

\# the reference region is Volta.

Note: squares and cross products have been omitted in this table (please see table 11 of appendix B for full table). Coefficients and standard errors have been rounded off to three decimal places. 
In general, the magnitudes of economic gain as shown by the partial elasticity estimates of the production inputs are very small, though most exhibit statistical significance. Both production systems exhibit decreasing return to scale ${ }^{37}$ (i.e. doubling the amount of inputs employed in production will result in less than double output). This means, given the current technology available to the industry, as more of such inputs are employed in production, proportionately less outputs are obtained. This increases the average cost per unit produced.

Normally, firms experiencing decreasing return to scale are viewed in the economic literature as huge or too big, hence, a need for restructuring into manageable size. However, summary statistics in Table 3.9 reveals that, the average farm size of 5.5ha in the organic and 6.5ha in the conventional system are far too small to justify the argument that, the sizes of production in both systems are too big or overstretched ${ }^{38}$. A plausible explanation to decreasing return to scale as observed in both systems could be attributed to the obsolete nature of current production technique which is unable to squeeze maximum performance from each production input (for instance, the work output of 10 workers using hole and cutlass in land preparation could be far below that of 1 worker using a tractor). This confirms the need for introduction and spread of modern production technologies which could greatly enhances outputs even if the same input levels are employed.

The value of gamma which gives an indication of how much of the deviation in observed output from the production frontier could be associated with inefficiency was estimated to be $83 \%$ and $51 \%$ for the organic and conventional models respectively. This implies that a large percentage in output shortfall could be attributed to farmers' inefficiency in input usage especially those in the organic farming. These values reflect the relative importance of inefficiency in the estimated models (it shows that in the organic system for instance, as high as $83 \%$ change in the level of output in relation to the frontier is due to inefficiency).

\footnotetext{
${ }^{37}$ Return to scale is a very important technical property of any production function (i.e. via the homogeneity properties of the production function).

${ }^{38}$ One have to take note that, the concept of decreasing return to scale is more difficult to justify in empirical work because of indivisibility of certain factors. "Returns to scale" requires that we double all inputs. In the case of farm analysis, we cannot just double the number of farm owners/managers by just doubling the land size etc without running into conflict of ownership issues etc.
} 


\subsubsection{Determinants of Inefficiency}

Table 3.4 presents the result of the inefficiency model as specified in equation (2) which enables us to identify sources of technical inefficiency in each production system. A negative coefficient means that a variable is associated with greater efficiency and a positive coefficient has the opposite effect.

Table 3.4: Parameter Estimates of the Inefficiency Models

\begin{tabular}{lllll}
\hline \multirow{2}{*}{ Nariable } & \multicolumn{2}{l}{ Organic production system } & \multicolumn{2}{l}{ Conventional production system } \\
& Coefficient & Std. Err. & Coefficient & Std. Err. \\
\hline \hline Constant & $-2.503^{* * *}$ & 0.571 & $-7.582^{* * *}$ & 2.258 \\
Land & -0.067 & 0.512 & $-3.432^{* *}$ & 1.584 \\
Maintenance Cost & $-1.869^{* * *}$ & 0.548 & $-2.166^{*}$ & 1.318 \\
Density & $-0.933^{*}$ & 0.475 & $-1.891^{*}$ & 1.210 \\
Age of household head & 0.194 & 0.134 & 1.604 & 1.834 \\
Household size & $-0.610^{*}$ & 0.364 & -0.282 & 0.482 \\
Agrochemical Cost & $1.489 * *$ & 0.552 & -0.582 & 0.453 \\
Distance to market & $0.649 * *$ & 0.272 & $0.967^{* *}$ & 0.425 \\
Education & $0.210^{*}$ & 0.133 & $-0.229 *$ & 0.149 \\
Gender & 0.426 & 0.484 & -0.772 & 0.721 \\
\hline \hline Log-likelihood & 209.076247 & & 217.451824 & \\
Gamma & 0.8293 & & 0.5085 & \\
Number of Observation & 175 & & & \\
\hline \hline
\end{tabular}

Source: study findings based on 2012 field survey data.

$*, * *, * * *$, Significant at the $10 \%, 5 \%$, and $1 \%$ level, respectively.

Note: Coefficients and standard errors have been rounded off to three decimal places.

Increasing the share of land allocated to pineapple production has a positive and significant effect on technical efficiency in both systems of production. This implies farmers with large farm size have more incentive to invest in using modern production technologies which help reduces production inefficiency. Increasing farm maintenance cost as well as the number of plants per hectare reduces inefficiency while as household decision maker becomes older and fragile, inefficiency increases in both systems of production. Increasing household size reduces inefficiency in both systems; however, this effect is significant only in the organic system of production. 
Inefficiency increases significantly the further a farm is located from a market center. This is not very surprising since fruit traders tend to bargain strongly to reduce farm gate prices to compensate for high transportation cost. Low output price discourage farmers from investing more on production inputs which in turn leads to lower total farm output. This implies production efficiency and output could significantly increase with development of market and improvement of road infrastructure linking rural production areas with urban buying centres.

Farmers with higher formal education levels exhibited positive and significant effect on technical efficiency under the conventional system while the opposite effect is observed in the organic system. The gender of household decision makers has no significant effect on technical efficiency in both systems.

\subsubsection{Parameter Estimates of the Metafrontier}

The parameter estimates of the metafrontier presented in table 3.12 (see appendix B) were obtained by solving the linear and quadratic optimization problems of equations (10) and (11) for the entire sample. Simulations were used to get estimates of standard errors of the two metafrontier parameters (i.e. LP and QP in table 12). Both the LP and QP gave similar estimates; hence, the QP estimates were used for computation of MTR and are used for discussion under this section.

Table 3.5 below presents summary statistics of group specific technical efficiency (TE), metatechnology ratio (MTR) and metafrontier technical efficiency (MFTE) as defined in equation (5) and show the degree of production performance for each system. The estimate shows that pineapple farmers across the two groups produce, on average $95 \%$ of the potential output given the current technology available to the pineapple sector as a whole. This means, the average performance of farmers in each production system is pretty high. The average MTR of $95 \%$ means both systems performance is near the industrial frontier with only $5 \%$ performance lag.

Even though farmers under the conventional production system achieved a slightly higher average output of $97 \%$ with respect to their group frontier, their output performance still lag behind the industrial performance with a 5\% technology gap just as those in the organic system. This suggests that farmers operating under either of the two systems faced the same or similar problems prevailing in the production environment; preventing them from reaching 
full industrial output potential. This observation is actually not surprising since in most cases organic and conventional farmers are located in the same production or geographical area and, hence, faces the same external shocks and production constraints.

We therefore use the metafrontier efficiency estimates to aid comparisons of farmers' performance in each group relative to a potential technology available to the industry as a whole. The average efficiency score of farmers in the organic production system relative to the metafrontier was smaller (89\%) than in the conventional system (93\%).

Table 3.5.: Summary statistics of Technical Efficiency (TE), Meta-Technology Ratio (MTR), and Meta-Frontier Technical Efficiency (MFTE)

\begin{tabular}{|c|c|c|c|c|c|c|}
\hline & \multicolumn{3}{|c|}{ Organic system } & \multicolumn{3}{|c|}{ Conventional system } \\
\hline & Group TE & MTR & Metafrontier TE & Group TE & MTR & Metafrontier TE \\
\hline$\overline{\overline{\text { Mean }}}$ & $0.95 * * *$ & $0.95^{* * *}$ & 0.89 *** & $0.97^{* * * *}$ & $0.95^{* * *}$ & $0.93 * * *$ \\
\hline Minimum & 0.50 & 0.81 & 0.48 & 0.57 & 0.76 & 0.54 \\
\hline Maximum & 0.99 & 1.00 & 0.99 & 1.00 & 1.00 & 0.99 \\
\hline Std. dev. & 0.08 & 0.04 & 0.08 & 0.06 & 0.04 & 0.08 \\
\hline Numb Obs. & \multicolumn{2}{|c|}{175} & & \multicolumn{3}{|c|}{229} \\
\hline
\end{tabular}

Source: study findings based on 2012 field survey data

*,**,**, Significant at the $10 \%, 5 \%$, and $1 \%$ level, respectively.

Note: Coefficients and standard errors have been rounded off to three decimal places.

The bar chart distribution in Figure 3.6 below also shows larger variation in the efficiency scores in the organic system compared to that of the conventional system. This means, a lot more farmers in the organic production system have to improve their efficiency of production given the current know-how in the sector. The distribution also shows some farmers in both systems with efficiency scores $\leq 60 \%$ which suggest a large scope of efficiency improvement for such farmers with regard to their group frontier. At the same time, the highly skewed to the left distribution of TE in Figure 3.6 is an indication that a large proportion of farmers in the sample data recorded high efficiency level in both systems $(\geq 98 \%)$.

The distribution of performance scores as shown in Figure 3.6 has consequence for policy design. That is, it provides information on the type of intervention measures needed to be put in place in the sector to enhance productivity. For instance, farmers operating far below their group frontier should be assisted through the extension service to make better use of resources and technologies at their disposal to enable them achieve output levels as close as possible to 
their group frontier maximum. Under competitive production environment such as those prevailing in most developed economies, such inefficient farmers will eventually exit the sector due to market pressure and will therefore need no government assistance, however, in the context of developing countries where a sector of agriculture could be the only source of income and livelihood for rural dwellers, helping such farmers through extension service to maximize output could be judged as a cost effective rural poverty reduction and development policy option.

Figure 3.6.: Histogram, Bar Chart and Box plot of TE, MTR and MFTF for the two production Systems
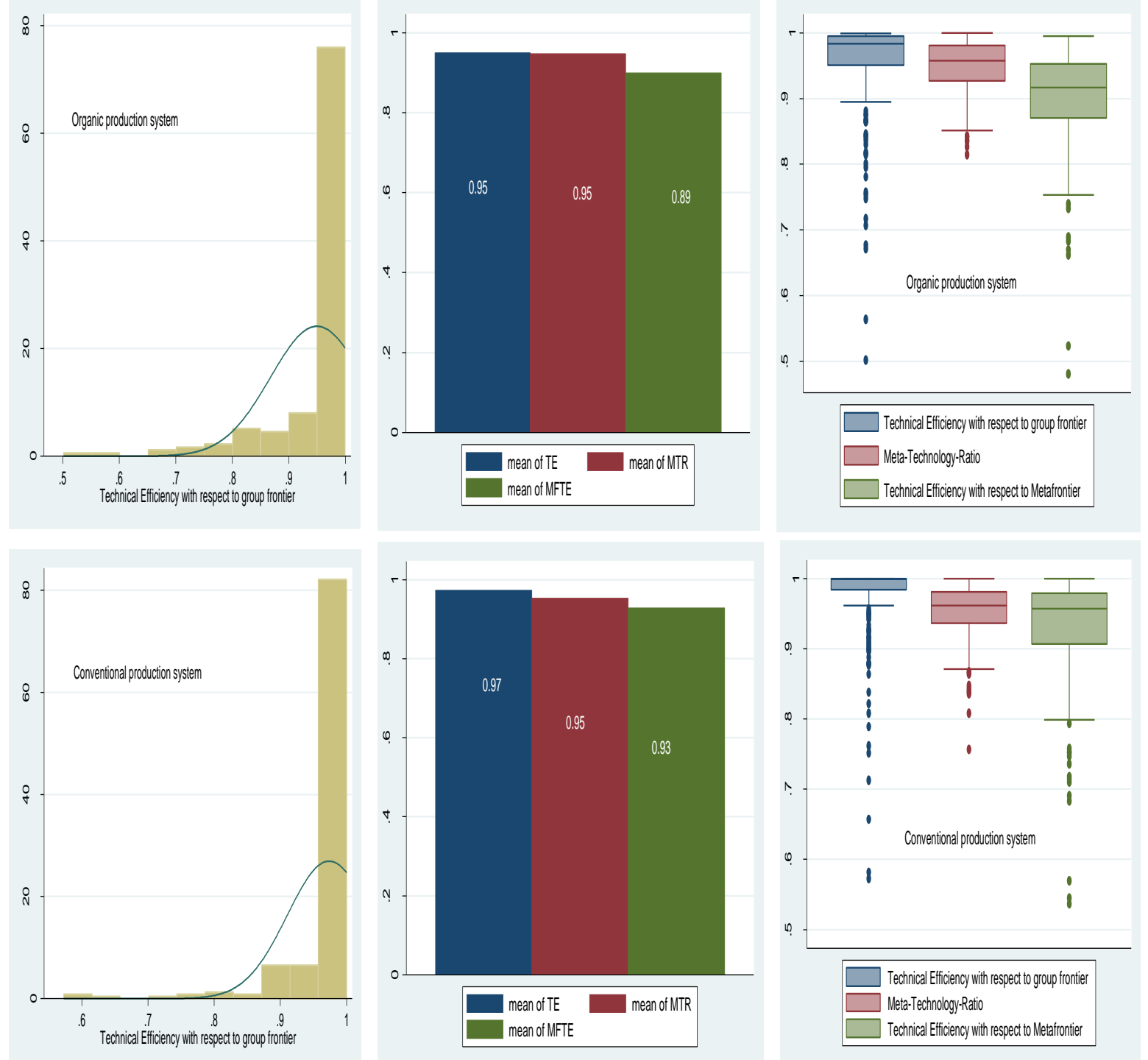

Source: study findings based on 2012 survey data 
The mean MTR scores of $95 \%$ for both systems as well as $97 \%$ and $95 \%$ group mean efficiency scores, indicate that majority of farmers are operating quit near their own frontiers as well as the industrial frontier. This suggest, even with a $100 \%$ (technical efficiency) production performance with current technology, it will contribute just a small percentage change magnitude to overall output gain (i.e.5\% and 3\%) in the sector. This means that, significant improvement in the output level of the Ghanaian pineapple sector could only be achieved through introduction of modern production technologies with capacity to stimulate upwards expansion of current industrial output level using same or even less level of inputs (i.e. technological change which induces outward shift of current industrial production possibility frontier).

Lack of investment to promote technological research and development in the Ghanaian agricultural sector may have hindered transfer of new production technologies to the pineapple subsector. This have stagnated efficiency improvement in the pineapple production sector. As productivity is compromised, farmers' ability to meet export volumes and quality demands are greatly impaired. This causes a spiral negative effect on farmers' income, welfare as well as rural poverty reduction schemes. Since most sectors of the Ghanaian economy depend directly on the fruit industry, the entire economy could suffer a decline if productivity in the industry continues to worsen.

\subsubsection{Drivers of Variation in the Metatechnology Ratio (MTR)}

The MTR estimate captures the effect of factors prevailing in the production environment (i.e. soil and climatic elements, availability of agriculture infrastructural as well as effects of public and private programs). Technology gaps between group frontiers and the industrial frontier is not due to technical inefficiency of farmers but as a result of influence of such external factors which restricts farmers' ability to access the best production techniques in the industry. Hence, measures to bridge these gaps to enable farmers take full advantage of production technologies available to the industry as a whole lies outside the control of individual farmers. Stakeholders and policy makers can improve the production environment using various legal instruments such as reforms in labour laws and land rights etc and infrastructural development instruments such as building roads to facilitate easy transportation and access to both inputs and outputs. 
Availability of such basic agricultural infrastructure facilities does ensure farmers' regular access to much needed technical inputs as well as consumers' access to outputs at all seasons. An average response function as defined in equation (14) was used to identify the drivers of MTR in both systems of production. The R- square values of the analysis presented in table 3.6 reveals that, $81 \%$ (in the organic) and $77 \%$ (in the conventional) of variation in the MTR could be explain by such factors embodied in government programs, private/public participation in input-output markets, infrastructural, soil and climatic variables. In both systems, access to good road condition, connection to the electric grid, access to more fruit buyers, more extension contacts and lower input cost through government subsidies significantly reduces the technology gaps between the group frontiers and the industrial frontier.

Table 3.6.: Determinants of the Meta-Technology Ratio (i.e. variables influencing the nature of the production environment)

\begin{tabular}{|c|c|c|c|c|}
\hline \multirow{2}{*}{$\begin{array}{l}\text { Variable } \\
\text { Name }\end{array}$} & \multicolumn{2}{|c|}{ Organic system } & \multicolumn{2}{|c|}{ Conventional system } \\
\hline & Coefficient & Std. Err. & Coefficient & Std. Err \\
\hline \multicolumn{5}{|l|}{ Infrastructure } \\
\hline Road condition & $0.007 * *$ & 0.003 & $0.008^{*}$ & 0.005 \\
\hline Electricity & $0.025 * * *$ & 0.005 & $0.022 * * *$ & 0.006 \\
\hline \multicolumn{5}{|l|}{ Government programs } \\
\hline Extension & $0.017 * * *$ & 0.005 & $0.006^{*}$ & 0.003 \\
\hline Input subsidy & $0.009 *$ & 0.005 & $0.010^{*}$ & 0.006 \\
\hline \multicolumn{5}{|c|}{ Private and public participation } \\
\hline Fruit traders & $0.004 * * *$ & 0.001 & $0.003 * * *$ & 0.001 \\
\hline Input stores & 0.001 & 0.001 & $0.002 * * *$ & 0.001 \\
\hline \multicolumn{5}{|l|}{ Soil and Weather } \\
\hline Erosion & $-0.0161 * *$ & 0.005 & $-0.011 * *$ & 0.005 \\
\hline Floods & -0.001 & 0.005 & $-0.010 * *$ & 0.005 \\
\hline Bushfires & -0.006 & 0.004 & -0.004 & 0.003 \\
\hline Constant & $0.875 * * *$ & 0.010 & $0.891 * * *$ & 0.009 \\
\hline Number of observations & 175 & & 229 & \\
\hline R squared & 0.81 & & 0.77 & \\
\hline
\end{tabular}

Availability of more input stores have a positive influence on MTR, however, this effect is only significant under the conventional system. This is not surprising since most inputs stores in Ghana sell only conventional chemical inputs (i.e. pesticides, herbicides etc.). 
Seasonal floods and soil erosion negatively affect the MTR in both production systems. This is not very surprising since the impact of such factors on farm output and income could be devastating. This in turn reduces the farmers' ability and willingness to invest or acquire certain technologies. Intervention programs aim at improving those variables with positive effects on the MTR will favourably improve the production environment and therefore enhances farmers' ability to improve output towards the industrial frontier. All the same, the magnitudes of economic gain as revealed by the estimates in Table 3.6 are so small to sustain long term growth development in the sector. This again confirms the need for introduction of better production technologies in the Ghanaian pineapple sector. To facilitate a sustainable productivity growth in the industry, efforts by all stakeholders and researchers should be well coordinated to meet farmers' requirement in the different agro-ecological zones in which pineapple production takes place.

\subsection{Conclusion with Recommendations for Future Policies}

The pineapple production sector plays a very important role in Ghana's economy. The sector's employment generation capabilities were widely cited (Jaeger, 2008; Wolter, 2008) as one of the most effective mechanism of reducing rural-urban poverty. However, the unexpected market shock (i.e. beginning in the 2005 production year) nearly collapsed the industry as farmers were left with tons of outputs with no buyers and no income to finance outstanding production loans.

Seven years after the crisis, we studied how farmers in the Ghanaian pineapple sector have responded to international market demand as well as assessing the accompanying effect on farmer's production efficiency. We analysed the proportion of farmers cultivating the MD2 variety and identify the factors influencing adoption of MD2 variety using a logistic regression function. The result shows that out of 404 pineapple farmers sampled across the three regions, only 74 (18\%) farmers are cultivating the MD2 variety. The majority of the farmers in our data are still cultivating the local varieties. For farmers producing organic pineapples, only $3(0.02 \%)$ are cultivating the MD2 variety as organic produce. $71(31 \%)$ farmers under conventional system of production are cultivating the MD2 variety using convention production input chemicals.

These summary statistics shows that, the rate of adoption in response to market change is very slow as shown by majority of farmers in our data. The analysis of factors influencing the 
adoption of MD2 reveals that farmers capable of installing irrigation facilities to irrigate their farms, having access to regular and reliable pineapple market as well as farms located in the eastern regions are more likely to adopt the MD2 variety.

The observed low adoption level is not very surprising since most farmers were rendered bankrupt by the crisis and have not been able to recovery very well financially. Hence, only farmers with extra source of income who could afford the high adjustment and production cost of the MD2 variety did adopt it. This highlights the need for flexible agricultural credit programs which enable farmers' access modern production techniques.

To assess current productivity level of organic and conventional pineapple producers and factors driving production performance in the sector, a metafrontier analytical technique was employed. Results of our analysis reveal that the majority of farmers in both systems were operating quiet efficiently (see distribution in Figure 3.6 above) given the current technology available to their respective frontiers and the industrial as a whole (i.e. average $\mathrm{TE}_{\mathrm{i}}$ scores of 97\%, 95\% , and 95\% MTR scores) yet the sector is unable to meet market volume demand. This implies that continuous use of current production techniques does not give much scope for large output expansion or productivity gain given the current state of technology available to the industry. Therefore to substantially enhance productivity level in the industry, government policies should aim at agricultural-research $(R \& D)$ development framework which not only encourages but expedite technological progress through introduction of better suited modern production techniques to farmers in the sector. A productivity study by Brümmer et al in 2002 reveal an annual productivity growth of about $6 \%$ by German milk producing firms mainly due to high rate of technological progress in the sector as compared to Poland which experience $5 \%$ productivity decline due to technological regress. This observation reflects the importance of technological progress in any industry to sustain output growth.

As Ghana develops, more people are likely to move from the agricultural production sector to other sectors of the economy just as is the case in many advance economies where relatively few people are directly involved in agriculture. Current high rate of rural urban migration as well as urban expansion into rural area is already having a great toll in the number of people involved in agriculture, hence the need for introduction of new labour saving production technologies. The pineapple sector is likely to face new challenges caused by market transformations (i.e. changes in fruit consumption patterns, the changing demands of private retail companies and newer, stricter quality and health standards imposed by importing coun- 
tries could be the root cause driving some of this change) on a global scale, hence, the need for better production technologies and information dissemination mechanisms to enhance the capabilities of farmers in the sector to adjust accordingly to such future market changes.

To address the challenges facing the sector to enable the sector fully benefit from international trade; design of productivity enhancement programs by policy makers' should aim at making the industry more competitive to meet various demands and challenges in the international market arena. Policy makers should prioritize investment in improving transport and logistics services sector as well as other supporting infrastructures to ensure efficient delivery of high quality pineapple products by the sector. Improving conditions of rural-urban road networks will support quick and effective transportation of fruits to ports, harbours and urban buying centres, thereby reducing the amount of fruits which are rejected due to deterioration resulting from long transportation delays. Similarly, the creation of flexible agricultural credit schemes will enable easy acquisition of better production technologies as well as facilitating the transfer of such technologies to farmers in resource starve regions of the industry.

To sum up, findings from this study support the notion that improvement in the production environment (i.e. improvement in production infrastructures) as well as production efficiency (i.e. technical efficiency) will enhance the capacity of farmers in the sector to meet quality, volume and supply standards of international markets. The study, therefore, recommends; agricultural research and technology development (R \& D) programs should aim at incorporating the needs of farmers in the various production regions. This will facilitate the adoption of such modern production technologies when they are introduced.

Even though, the various analytical techniques employed in this study enabled us to shed light on some of the problems facing the Ghanaian pineapple producing sector and recommend some remedies; it should be stressed that, these recommendations are not in any way a panacea to all the problems facing the sector.

Further studies exploring the intricate interdependence relationships of important stakeholders, especially donor agencies and NGOs actively working in the industry in various capacities and how they impact the performance of the fruit sector are recommended. This will aid policy makers design holistic productivity improvement strategies to strengthen the industry's competitiveness on a sustainable basis. 


\section{$\underline{\text { Appendix B }}$}

\section{Table 3.7.: Variable Name (Units) and Definition}

Variable name (unit)

Definition/meaning of variables

\section{Continuous variables}

Output (kg)

Labour (hours)

Land (ha)

Density

Education (years)

Plant Age (years)

Experience (years)

Age of household head (year)

Household size

Distance to market $(\mathrm{km})$

Agrochemical cost (new Gh cedis)

Maintenance Cost (new Gh cedis)

Fruit traders

Input stores

\section{Dummy variables}

\section{Gender}

Extension

Irrigation

Manure

Input subsidy

Road condition

Electricity

Erosion

Floods

Bushfires

Contract

\section{Total farm output}

Total number farm labourers working on plantation (family + hired)

Total land area under pineapple cultivation only

Number of plants per hectare

Years of schooling of decision maker or household head

Age of the plantation

Number of years as pineapple farmer

Age of farm operator or decision maker

Household size (number of people leaving under the same roof)

Distance from farm household to market

Total cost of Agrochemicals

Total farm maintenance cost (i.e. sum of expenses for mulching and weeding) Number of fruit traders farmer regularly sells fruit to

Number of input stores/dealers in the area farmer regularly patronize

$\operatorname{Dummy}(1=$ male; $0=$ Otherwise $)$

Dummy $(1=$ Receives extension advice; $0=$ Otherwise $)$

$\operatorname{Dummy}(1=$ irrigates; $0=$ Otherwise $)$

Dummy $(1=$ Applies manure; $0=$ Otherwise $)$

Dummy $(1=$ Inputs are subsidized by government or NGOs; $0=$ Otherwise $)$

Dummy $(1=$ Access to good road condition; $0=$ Otherwise $)$

$\operatorname{Dummy}(1=$ Connected to the electric grid, $0=$ Otherwise $)$

Dummy $(1=$ Affected by erosion; $0=$ Otherwise $)$

Dummy $(1=$ Affected by seasonal floods; $0=$ Otherwise $)$

Dummy $(1=$ Affected by seasonal Bushfires; 0 = Otherwise $)$

Dummy $(1=$ Under contract obligation to sell harvest to processing/exporting company; $0=$ Otherwise) 
Table 3.8.: Summary Statistics (continuous variables)

\begin{tabular}{|c|c|c|c|c|c|c|}
\hline \multirow[t]{2}{*}{ Variables } & \multicolumn{3}{|c|}{$\begin{array}{l}\text { Organic production system } \\
(\mathrm{n}=175)\end{array}$} & \multicolumn{3}{|c|}{$\begin{array}{l}\text { Conventional production system } \\
(\mathrm{n}=229)\end{array}$} \\
\hline & Mean & Min & Max & Mean & Min & Max \\
\hline Farm output & $56365.14 * * *$ & 18000 & 108000 & $64709.17 * * *$ & 18000 & 156000 \\
\hline Land & $5.51 * * *$ & 2.00 & 15.00 & $6.42 * * *$ & 3.00 & 15.00 \\
\hline Labour & $5.72 * *$ & 3.00 & 13.00 & $6.32 * *$ & 3.00 & 15.00 \\
\hline Experience & $8.86^{* *}$ & 2.00 & 22.00 & $10.39 * *$ & 2.00 & 23.00 \\
\hline Maintenance cost & $126.18 * *$ & 50.00 & 366.00 & $142.83 * *$ & 50.00 & 395.00 \\
\hline Plant age (years) & 4.99 & 1.10 & 10.00 & 4.66 & 1.00 & 10.00 \\
\hline Density (plants/ha) & 35471.66 & 11000 & 64000 & 35612.23 & 10000 & 65000 \\
\hline Farmer Age & 48.28 & 23.00 & 75.00 & 47.70 & 23.00 & 75.00 \\
\hline Household size & 5.26 & 1.00 & 12.00 & 5.28 & 1.00 & 11.00 \\
\hline Agrochemical cost & $72.30 * * *$ & 40.00 & 120.00 & $296.88 * * *$ & 100 & 928.00 \\
\hline Dist. to market & 6.02 & 1.00 & 15.00 & 6.05 & 1.50 & 20.00 \\
\hline Fruit traders & $10.70^{*}$ & 5.00 & 16.00 & $10.31^{*}$ & 5.00 & 16.00 \\
\hline Input stores & $5.81 * * *$ & 1.00 & 14.00 & $6.84 * * *$ & 1.00 & 15.00 \\
\hline
\end{tabular}


Table 3.9.: Summary Statistics (dummy variables)

Variable Organic production system $(\mathrm{n}=175)$

Conventional production system $(\mathrm{n}=229)$

Gende

Proportion

Std. Error.

$0 \mid$

$1 \mid$

0.03

0.97

0.38

0.62

$1 \mid$

Irrigation

$0 \mid$

$1 \mid$

Manure

$$
0 \mid
$$

$1 \mid$

Contract

$0 \mid$

$1 \mid$

Road condition

$$
0 \mid
$$

$1 \mid$

Electricity

$0 \mid$

$1 \mid$

Input subsidy

$0 \mid$

$1 \mid$

Erosion

0 |

1

Floods

$$
0 \mid
$$

$1 \mid$

Bushfires

$\begin{array}{lll}0 \mid & 0.71 & 0.034 \\ 1 \mid & 0.29 & 0.034\end{array}$

0.037

0.036

$0.34 \quad 0.036$

0.036

$0.67 \quad 0.036$

0.035

$0.30 \quad 0.035$

0.038

$0.51 \quad 0.038$

0.037

$0.63 \quad 0.037$

0.037

$0.59 \quad 0.037$

0.038

$0.50 \quad 0.038$

0.038

$0.47 \quad 0.038$

0.034

Proportion

Std. Error

$\begin{array}{ll}0.03 & 0.011 \\ 0.97 & 0.011\end{array}$

$0.40 \quad 0.032$

$0.60 \quad 0.032$

0.57

0.033

0.43

0.033

0.45

0.033

0.55

0.033

0.31

0.031

0.69

0.031

0.34

0.031

0.66

0.031

0.31

0.031

0.69

0.031

0.38

0.032

0.62

0.032

$0.68 \quad 0.031$

0.32

0.031

0.53

0.033

0.47

0.033

0.71

0.030

0.29

0.030

Source: study findings based on 2012 field survey data.

Note: Coefficients and standard errors have been rounded off to two and three decimal places respectively. 
Table 3.10.: Estimates of Translog Stochastic Production Frontier Models

\begin{tabular}{|c|c|c|c|c|c|c|}
\hline \multirow{2}{*}{$\begin{array}{l}\text { Variable } \\
\text { Name }\end{array}$} & \multicolumn{2}{|c|}{ Pooled model } & \multicolumn{2}{|c|}{ Organic model } & \multicolumn{2}{|c|}{ Conventional model } \\
\hline & Coefficient & SE & Coefficient & SE & Coefficient & SE \\
\hline Constant & $-0.096 * * *$ & 0.022 & $-0.094 * * *$ & 0.021 & $-0.068 *$ & 0.044 \\
\hline logland & $0.177 * * *$ & 0.027 & $0.207 * * *$ & 0.033 & $0.127 * * *$ & 0.037 \\
\hline loglabour & $0.118 * * *$ & 0.021 & $0.069 * * *$ & 0.025 & $0.166 * * *$ & 0.037 \\
\hline logexpir & $0.053 * * *$ & 0.014 & 0.019 & 0.016 & $0.068 * * *$ & 0.021 \\
\hline $\log$ MaintCost & $0.080 * * *$ & 0.020 & 0.010 & 0.025 & $0.145 * * *$ & 0.031 \\
\hline $\log$ PltAge & $-0.048 * * *$ & 0.016 & $-0.074 * * *$ & 0.021 & $-0.037 *$ & 0.020 \\
\hline logdensity & $0.115 * * *$ & 0.025 & $0.134 * * *$ & 0.034 & $0.095 * *$ & 0.038 \\
\hline Manure & $-0.125 * * *$ & 0.016 & $-0.165 * * *$ & 0.017 & $-0.117 * * *$ & 0.025 \\
\hline Irrigation & $0.163 * * *$ & 0.015 & $0.202 * * *$ & 0.016 & $0.135 * * *$ & 0.024 \\
\hline Contract & $0.045 * * *$ & 0.013 & $0.031 * *$ & 0.016 & $0.037 *$ & 0.023 \\
\hline Eastern $^{a}$ & $0.082 * * *$ & 0.017 & $0.072 * * *$ & 0.020 & $0.075 * * *$ & 0.028 \\
\hline Central $^{a}$ & $0.023^{*}$ & 0.015 & 0.012 & 0.016 & 0.013 & 0.026 \\
\hline $.5^{*} \log \operatorname{land}^{\wedge} 2$ & 0.153 & 0.119 & -0.018 & 0.136 & $0.342 *$ & 0.182 \\
\hline $.5 * \log$ labour ${ }^{\wedge} 2$ & $-0.153^{*}$ & 0.101 & -0.106 & 0.123 & -0.055 & 0.211 \\
\hline $.5 * \log \operatorname{expir}^{\wedge} 2$ & 0.013 & 0.041 & -0.032 & 0.052 & -0.060 & 0.068 \\
\hline $.5 * \log \operatorname{MiantCost}^{\wedge} 2$ & -0.032 & 0.049 & $-0.136^{* *}$ & 0.058 & $0.185^{*}$ & 0.103 \\
\hline $.5 * \log \mathrm{PltAge} \mathrm{e}^{\wedge} 2$ & $-0.067 * *$ & 0.035 & $-0.143 * * *$ & 0.045 & -0.062 & 0.048 \\
\hline $.5 * \log$ density $^{\wedge} 2$ & $0.155 * *$ & 0.078 & $0.163 *$ & 0.108 & 0.122 & 0.101 \\
\hline $\log$ land $* \log$ labour & $0.151 * *$ & 0.073 & $0.206^{* *}$ & 0.081 & 0.143 & 0.119 \\
\hline $\operatorname{logland} * \operatorname{logexpir}$ & 0.035 & 0.043 & 0.006 & 0.042 & 0.037 & 0.089 \\
\hline $\log$ land $* \log$ MiantCost & $0.096^{*}$ & 0.059 & $0.240 * * *$ & 0.068 & -0.067 & 0.116 \\
\hline $\log$ land $* \log \mathrm{PltAge}$ & $0.078 * *$ & 0.039 & $0.121 * * *$ & 0.046 & 0.012 & 0.051 \\
\hline $\log$ land $* \log$ density & -0.057 & 0.081 & 0.003 & 0.108 & -0.186 & 0.142 \\
\hline $\operatorname{loglabour*logexpir}$ & 0.044 & 0.043 & $0.107 * *$ & 0.047 & -0.016 & 0.075 \\
\hline $\log$ labour* $\log$ MiantCost & -0.030 & 0.045 & -0.089 & 0.059 & -0.117 & 0.099 \\
\hline $\log$ labour*logPltAge & -0.024 & 0.029 & -0.009 & 0.034 & -0.058 & 0.047 \\
\hline $\log$ labour*logdensity & -0.065 & 0.066 & 0.020 & 0.085 & -0.007 & 0.114 \\
\hline $\log$ expir*logMiantCost & 0.010 & 0.027 & -0.026 & 0.031 & 0.035 & 0.047 \\
\hline logexpir*logPltAge & 0.005 & 0.018 & -0.008 & 0.017 & 0.035 & 0.034 \\
\hline logexpir*logdensity & -0.001 & 0.038 & -0.031 & 0.053 & 0.019 & 0.057 \\
\hline $\log$ MiantCost $* \log$ PltAge & -0.012 & 0.025 & -0.030 & 0.031 & 0.018 & 0.043 \\
\hline $\log$ MiantCost* $\log$ density & -0.024 & 0.034 & -0.010 & 0.056 & -0.013 & 0.058 \\
\hline $\log \mathrm{PltAge} * \log$ density & $0.081 * *$ & 0.029 & $0.158 * * *$ & 0.042 & 0.055 & 0.047 \\
\hline $\begin{array}{l}\text { Log-likelihood } \\
\end{array}$ & 380.853613 & & 209.076247 & & 217.451824 & \\
\hline Gamma & 0.6365 & & 0.8293 & & 0.5085 & \\
\hline Number of Observation & 404 & & 175 & & 229 & \\
\hline
\end{tabular}

Source: empirical results based on 2012 field survey data.

$*, * *, * * *$ Significant at the $10 \%, 5 \%$, and $1 \%$ level, respectively.

${ }^{a}$ The reference region is Volta. 
Table 3.11.: Parameter Estimates of the Metafrontier Model

\begin{tabular}{|c|c|c|c|c|}
\hline \multirow{2}{*}{$\begin{array}{l}\text { Variable } \\
\text { Name }\end{array}$} & \multicolumn{2}{|c|}{ LP (Sum of absolute deviation) } & \multicolumn{2}{|c|}{ QP (Sum of square deviation) } \\
\hline & Coefficient & $\mathrm{SE}$ & Coefficient & SE \\
\hline Constant & $-0.051^{*}$ & 0.027 & $-0.044 *$ & 0.024 \\
\hline logland & $0.144 * * *$ & 0.036 & $0.145^{* * *}$ & 0.032 \\
\hline loglabour & $0.111 * * *$ & 0.030 & $0.115^{* * *}$ & 0.028 \\
\hline logexpir & $0.038 *$ & 0.021 & $0.041 * *$ & 0.021 \\
\hline $\log$ MiantCost & $0.104 * * *$ & 0.028 & $0.100 * * *$ & 0.028 \\
\hline logPltAge & $-0.068 * * *$ & 0.023 & $-0.066 * * *$ & 0.023 \\
\hline $\log$ density & $0.128 * * *$ & 0.034 & $0.123 * * *$ & 0.033 \\
\hline Manure & $-0.150 * * *$ & 0.022 & $-0.149 * * *$ & 0.021 \\
\hline Irrigation & $0.161 * * *$ & 0.020 & $0.160 * * *$ & 0.019 \\
\hline Contract & $0.041 * *$ & 0.017 & $0.042 * *$ & 0.016 \\
\hline Eastern $^{a}$ & $0.067 * * *$ & 0.019 & $0.065^{* * *}$ & 0.019 \\
\hline Central $^{a}$ & 0.010 & 0.018 & 0.004 & 0.018 \\
\hline $.5 * \log \operatorname{land}^{\wedge} 2$ & $0.258 *$ & 0.153 & $0.237^{*}$ & 0.143 \\
\hline $.5 * \log$ labour^2 & 0.058 & 0.129 & 0.031 & 0.122 \\
\hline $.5 * \log \operatorname{expir} \wedge 2$ & 0.017 & 0.062 & 0.009 & 0.060 \\
\hline $.5 * \log$ MiantCost ${ }^{\wedge} 2$ & 0.103 & 0.100 & 0.087 & 0.089 \\
\hline $.5 * \log \mathrm{PltAge} \mathrm{e}^{\wedge}$ & -0.079 & 0.049 & -0.084 & 0.049 \\
\hline $.5 * \log$ density $^{\wedge} 2$ & $0.240 * *$ & 0.109 & $0.219 * *$ & 0.104 \\
\hline $\log$ land $* \log$ labour & $0.187 *$ & 0.105 & $0.186^{*}$ & 0.096 \\
\hline $\log$ land*logexpir & 0.011 & 0.067 & 0.018 & 0.061 \\
\hline $\log$ land $* \log$ MiantCost & -0.001 & 0.096 & -0.001 & 0.088 \\
\hline $\log$ land $* \log \mathrm{PltAge}$ & 0.054 & 0.052 & 0.100 & 0.049 \\
\hline $\log$ land $* \log$ density & -0.062 & 0.104 & -0.049 & 0.100 \\
\hline loglabour*logexpir & 0.012 & 0.060 & 0.008 & 0.058 \\
\hline $\log$ labour* $\log$ MiantCost & -0.062 & 0.076 & -0.042 & 0.066 \\
\hline $\log$ labour*logPltAge & -0.003 & 0.041 & -0.001 & 0.039 \\
\hline $\log$ labour*logdensity & -0.069 & 0.087 & -0.069 & 0.085 \\
\hline $\log$ expir*logMiantCost & -0.003 & 0.048 & 0.002 & 0.046 \\
\hline logexpir*logPltAge & -0.007 & 0.031 & -0.001 & 0.030 \\
\hline logexpir*logdensity & -0.004 & 0.059 & 0.004 & 0.058 \\
\hline $\log$ MiantCost $* \log \mathrm{PltAge}$ & -0.003 & 0.040 & -0.007 & 0.037 \\
\hline $\log$ MiantCost* $\log$ density & 0.026 & 0.066 & 0.013 & 0.062 \\
\hline $\log \mathrm{PltAge} * \log$ density & $0.159 * * *$ & 0.046 & $0.144 * * *$ & 0.044 \\
\hline Number of Observation & 440 & & 40 & \\
\hline
\end{tabular}

*,**, ***, Significant at the $10 \%, 5 \%$, and $1 \%$ level, respectively.

Source: empirical results based on 2012 field survey data.

Note: Coefficients and standard errors have been rounded off to three decimal places. 
Table 3.12.: Detail Summary Statistics for Technical Efficiency with respect to Group Frontier

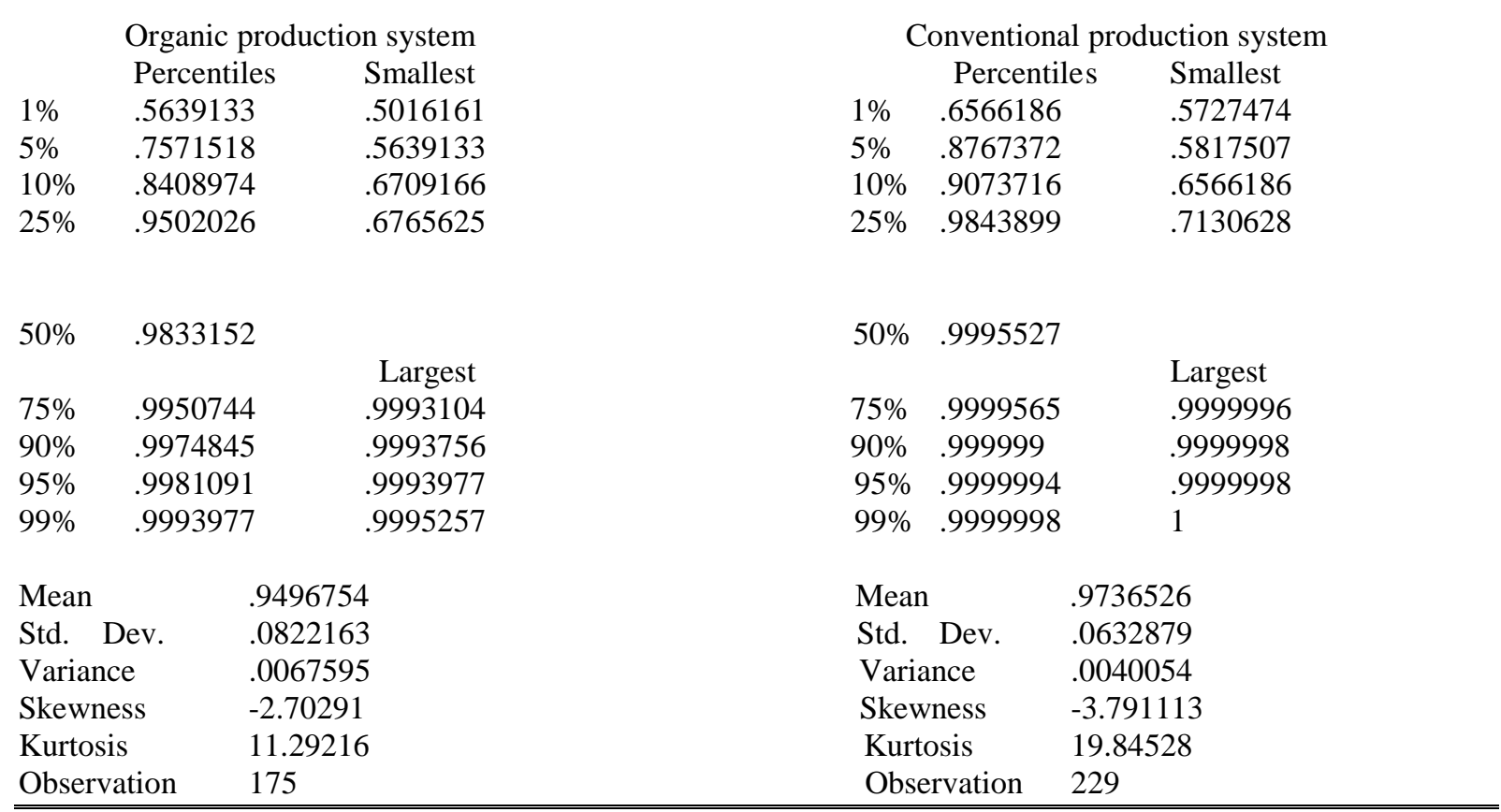

Table 3.13.: Detail Summary Statistics for Meta-Technology-Ratio

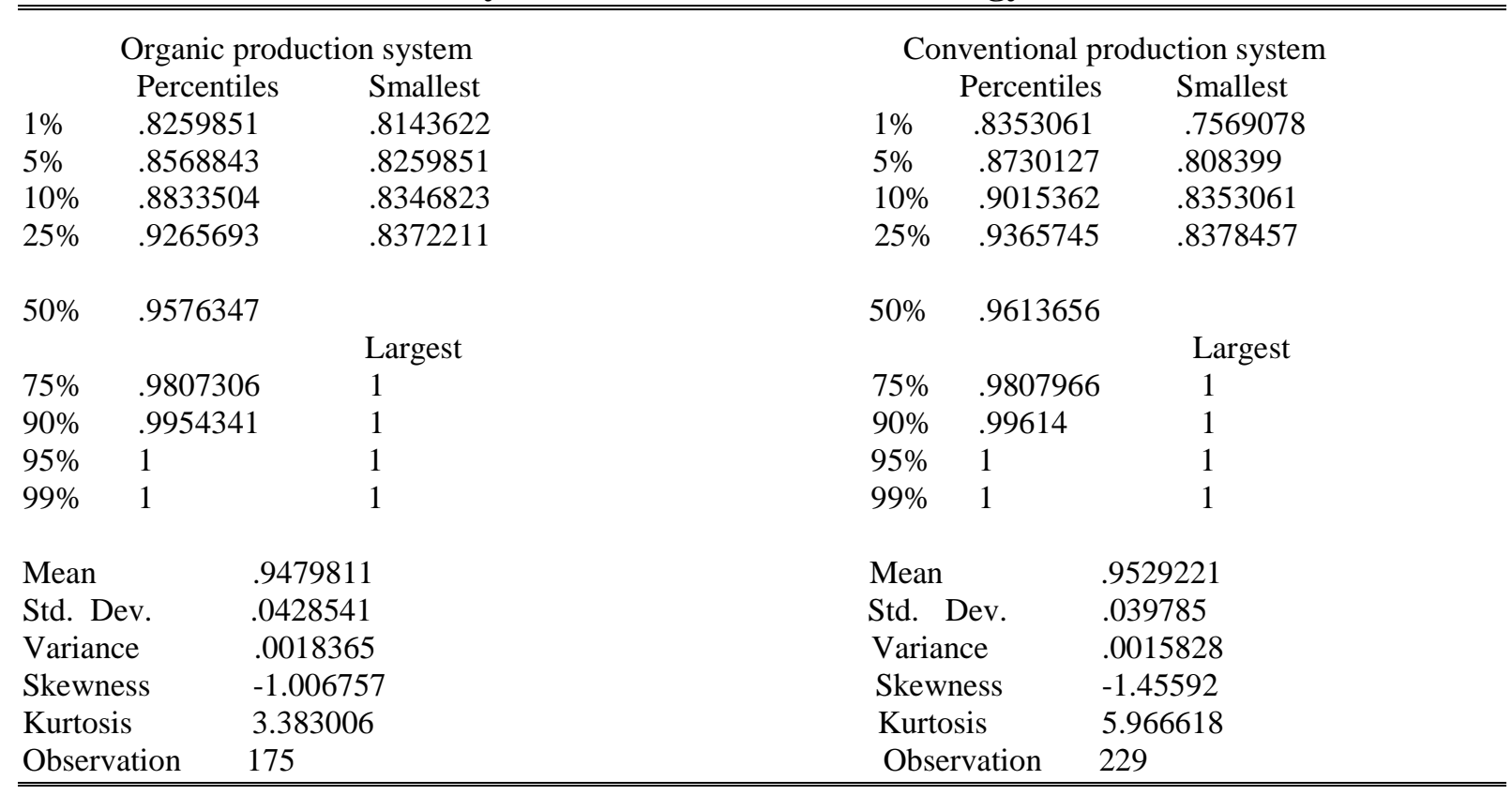


Table 3.14.: Detail Summary Statistics for Meta-Frontier-Technical Efficiency

\begin{tabular}{|c|c|c|c|c|c|c|}
\hline \multicolumn{3}{|c|}{ Organic production system } & \multicolumn{4}{|c|}{ Conventional production system } \\
\hline & Percentiles & Smallest & \multicolumn{3}{|c|}{ Percentiles } & Smallest \\
\hline $1 \%$ & .52284 & .480352 & $1 \%$ & \multicolumn{2}{|c|}{.5693756} & .5359336 \\
\hline $5 \%$ & .7533561 & .52284 & $5 \%$ & \multicolumn{2}{|c|}{.7521945} & .5448529 \\
\hline $10 \%$ & .8153618 & .6618084 & $10 \%$ & \multicolumn{2}{|c|}{.8215644} & .5693756 \\
\hline $25 \%$ & .8697171 & .6695411 & $25 \%$ & \multicolumn{2}{|c|}{.906392} & .6834718 \\
\hline $50 \%$ & .9170924 & & $50 \%$ & \multicolumn{2}{|c|}{.9572059} & \\
\hline & & Largest & & & & Largest \\
\hline $75 \%$ & .9532007 & .9900759 & $75 \%$ & \multicolumn{2}{|c|}{.9790201} & .9999821 \\
\hline $90 \%$ & .9745016 & .9902809 & $90 \%$ & \multicolumn{2}{|c|}{.9918161} & 9999889 \\
\hline $95 \%$ & .9854733 & .9903311 & $95 \%$ & \multicolumn{2}{|c|}{.9996747} & 99999 \\
\hline $99 \%$ & .9903311 & .9948873 & $99 \%$ & \multicolumn{2}{|c|}{9999889} & 9999992 \\
\hline Mean & \multicolumn{2}{|c|}{.8993723} & \multicolumn{2}{|c|}{ Mean } & \multicolumn{2}{|c|}{.9286064} \\
\hline Std. Dev. & \multicolumn{2}{|c|}{.0796053} & \multicolumn{2}{|c|}{ Std. Dev. } & \multicolumn{2}{|c|}{.0799233} \\
\hline Variance & \multicolumn{2}{|c|}{.006337} & \multicolumn{2}{|c|}{ Variance } & \multicolumn{2}{|c|}{.0063877} \\
\hline Skewness & \multicolumn{2}{|c|}{-2.07362} & \multicolumn{2}{|c|}{ Skewness } & \multicolumn{2}{|c|}{-2.225547} \\
\hline Kurtosis & \multicolumn{2}{|c|}{9.560764} & \multicolumn{2}{|c|}{ Kurtosis } & \multicolumn{2}{|c|}{9.115834} \\
\hline Observation & \multicolumn{2}{|l|}{175} & \multicolumn{2}{|c|}{ Observation } & \multicolumn{2}{|c|}{229} \\
\hline
\end{tabular}




\title{
Chapter Four
}

\section{A Multi-Output Production Efficiency Analysis of Commercial Banana Farms in the Volta Region of Ghana: A Stochastic Distance Function Approach}

\begin{abstract}
Government and donor agencies support in the early establishment phase of the banana industry led to a significant rise in output (i.e. banana export to the EU grew from a mere 1,788 tonnes in 2004 to 52,357 tonnes in 2010 (Eurostat)). Revenue generated from production and export of banana helped rural poor and smallholder producers to improve their livelihood. However, lack of continuous policy/technical support to improve production efficiency to help sustain productivity growth in the industry couple with price instability (currency volatility) in international banana trade lead to sharp output decline. This study using a stochastic multi-output distance functions estimation technique provides some relevant empirical information regarding how to improve production efficiency of banana farmers in the Volta region of Ghana.
\end{abstract}

Keywords: Stochastic multi-output distance function, Determinants of Technical efficiency, Commercial banana production in Ghana.

\subsection{Introduction}

The Ghanaian banana sector has experienced significant growth in export mainly to the $\mathrm{EU}^{39}$ fruit market due to growing consumer demand. The EU imported a total of US \$465,797 million worth of banana from 2002 to 2013 from around the world (Trade maps, 2013). Support from government and development agencies during the early establishment phase of the sector led to a significant gain in output (see Figure 4.1 below). The sector's foreign exchange

\footnotetext{
${ }^{39}$ EU is Ghana's main export market for horticultural produce. Ghana's near proximity to Europe couple with free trade agreement may account for phenomena (Mensah et al, 2012).
} 
contribution grew from $€ 2,466$ million in 2000 to a peak value of $€ 38,355$ million in 2010 (Eurostat, 2013). The sector export revenue amounted to a total of $€ 172$ million to the economy (i.e. from 2000 to 2013, (Eurostat, 2013)) making it the second most important foreign exchange contributor sector in the fruit industry. The increase in banana production and export from 2000 - 2013 is as a result of increased cultivation of small scale farmers organised in outgrower schemes to supply local exporters trading in the EU marketplace.

Traditionally banana trade has been dominated by a few multinational companies (e.g. Dole, Chiquita, Del Monte, etc.). However, increasing use of refrigerated containers (i.e. the so called "reefer containers" (Agritrade, 2012)) in ships and increased frequency of direct flight of cargo planes from Ghana to export destinations (mainly the EU) enabled delivery of high quality banana to retailers in the European fruit market.

Figure 4.1.: Banana Sector Annual Export Values

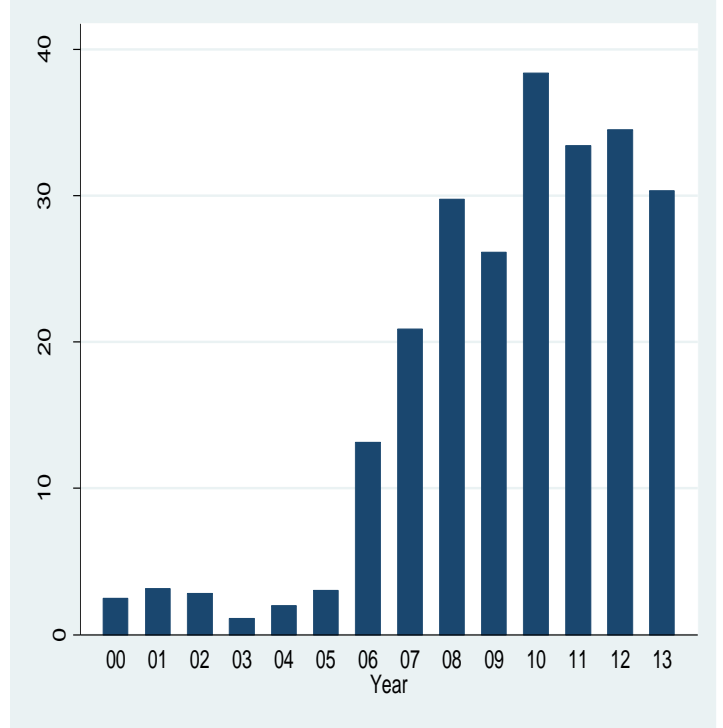

Data source: Eurostat international trade data
Figure 4.2.: Fruit Industry Annual Export Values

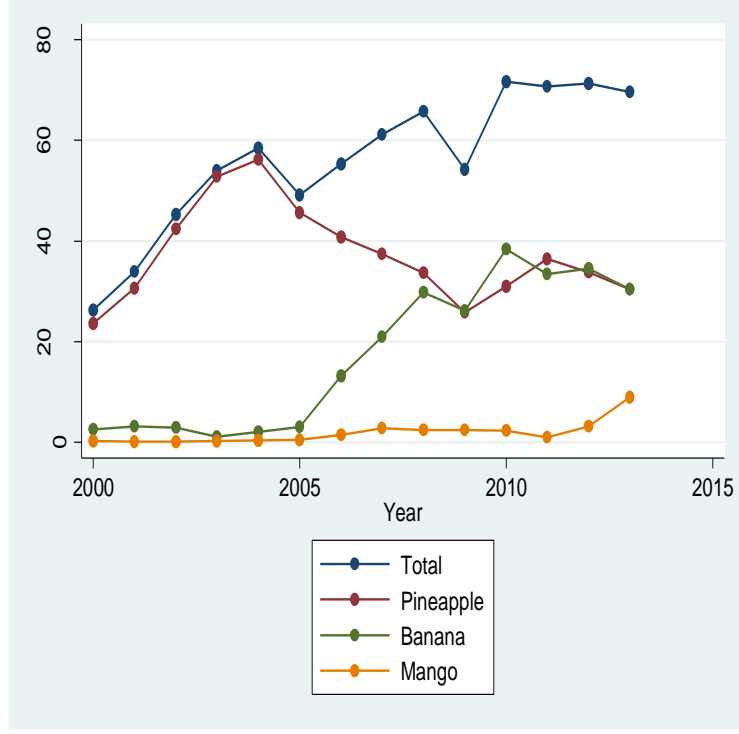

Data source: Eurostat international trade data

This opened up opportunities for local exporters to directly supply supermarkets/retailers in the EU. However, decreasing output trend in the sector since 2011 is hampering the ability of exporters to meet the rapidly increasing export demand (Jaeger, 2003). This, in turn denies the country of urgently needed foreign exchange. Given the important contribution of the sector to the economy as well as Ghana's excellent comparative advantage (in terms of climate, soil, labour and proximity to Europe), more could be done to enhance production in the sector. 
The current trend of decreasing output in the sector (i.e. from 52,632 tonnes in 2010 to 42,612 tonnes in 2013, approximately $19 \%$ decline (eurostat, 2013)) may be attributed to a variety of factors such as:

(1) Low farm gate prices received by farmers. Information gathered from farmers during field survey (in Ghana, 2012) indicated that, most buyers, especially exporters and agro-processors use a bulk purchase discount clauses to dampen farm gate price. This might have forced farmers to seek alternative sources of income by diversifying production to include other crops as a means of complementing income from banana production.

(2) The devastating effect of banana fungal diseases ${ }^{40}$ (banana wilt diseases) may have also forced a lot of farmers to seek alternative income by cultivating other crops (i.e. mixed farming system) as mean of risk averting strategy.

(3) Lack of continuous technical support programs in the form of innovative production technologies may have affected production performance of farmers.

(4) Inadequate agricultural infrastructure development to help sustain productivity growth in the sector (e.g. poor conditions of feeder road networks linking rural production areas to urban market centres).

The consequence of farmers cultivating more crops beside banana includes a decrease in the total share of land allocated to banana production which in turn affects total banana output. Also, farmer's time and other production resources have to be shared for competing crops either on the same piece of land or adjacent lands. The side effect of mixed culture is not only competition for a farmer's managerial time, but also plant competition for space, nutrient and sunlight may cause decline in output.

The deteriorating ${ }^{41}$, unsecure and unstable returns from banana production may have forced farmers to reduce their dependence on banana revenue, by reducing the share of banana under cultivation. However, recent banana trade liberalization in the EU couple with growing consumer interest in organic banana (where consumers are willing to pay premium price for quality organic produce) presents a great opportunity (in terms of capital accumulation and liveli-

\footnotetext{
${ }^{40}$ Fungal wilt diseases are considered very destructive to banana plantations and there are no known control mechanisms yet, hence the disease can remain on plantations for long time (Taylor et al, 1986).

${ }^{41}$ Between June and August 2011, EU banana prices collapsed, with bananas 'being sold for as little as US\$1 to US\$3 per 40-lb box due to oversupply from Ecuador and the EU's new import-licensing system, which had seen more importers enter the EU banana trade. (Agritrade, 2012)
} 
hood improvement) for local exporters and farmers as they access such premium markets in the EU. Sales of organic banana are growing fast in niche EU markets. Increased sales of organic and tropical fruits are expected to provide the biggest impetus for future market growth in the EU fruit market (Pay, 2009). Attaining high level of production efficiency to meet regular demand volume and quality is of paramount importance in light of high competitiveness requirement in the arena of international trade.

Considering the high economic potential and employment generation opportunities in the sector, efficiency studies which provide relevant empirical information regarding how to improve production efficiency of banana farmers in the Volta region will aid better formulation of future policies and design of intervention programs to help boost output.

Policy implication and expected contribution to the existing literature: Technical efficiency studies using either data envelopment analysis (DEA) or stochastic production function (SPF) framework have been reported for a wide range of agricultural products from many countries across the globe, however, a multi-output, multi-input technical efficiency analysis for farmers producing a mixture of crops with banana on commercial scale in Ghana are rare and so our study aim to fill this void in the literature while providing relevant empirical information which could guide policy makers design adequate measure to improve performance in the sector.

\subsubsection{Research Objectives}

This study seeks to identify and analyse socioeconomic characteristics and management practices which influences production performance of commercial banana producers (using mixed crop production system) in the Volta region of Ghana.

Specific objectives include:

1. To assess how current output levels are affected by farmers' production efficiency

2. Identifying what drives technical efficiency of farmers in the Volta region of Ghana

3. To assess the elasticities of the output distance function as well as examining complementarity and input substitution effects on banana-other crop mixed production system. 


\subsubsection{Study Area}

The Volta region located in the south-east part of Ghana represents one of the most important banana producing regions in Ghana. It is regarded as a pioneer region for both large and small scale commercial banana production for export market. Also the climate and soil conditions in this region are considered particularly suitable for banana production. The non-seasonal bearing characteristics of banana enable year-round production in this region. Ghana's competitive advantage in banana production therefore stem from such suitable growing condition prevailing in this region of Ghana.

Commercial banana producers often employ monoculture system of production, however, due to declining revenue and food security issues (i.e. ensuring self sufficiency in staple food), sampled farmers in the study area inter-crop banana plantation with other crops such as cassava, cocoyam, yam and or maize.

\section{Figure 4.3.: study area in Ghana}

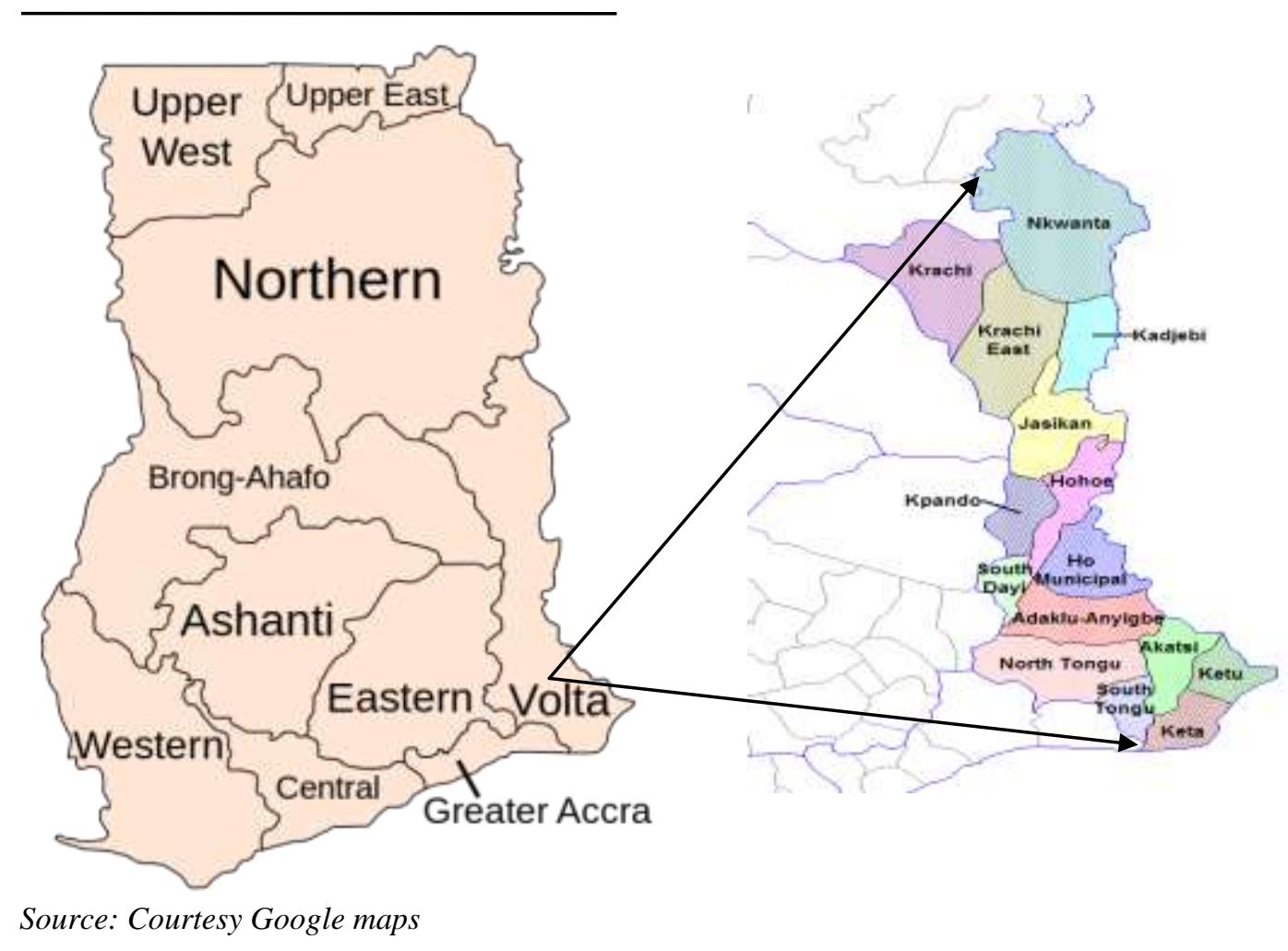

In situations where banana is cultivated as monoculture, farmers most often allocate portions of same or adjacent land to producing these other crops including vegetables. All farmers 
sampled for this study produce a mixture of crops beside banana. Banana is mostly cultivated for the export market while the other crops are cultivated for either household consumption or sold in the local market to supplement income.

\subsubsection{Data Set}

This study uses an integrated approach that draws upon both quantitative and qualitative methods of primary data collection. Based on information from district extension officers in the study region, list of villages (depicted in figure 1 above) where households produce banana for commercially is obtained. Farmers producing banana on commercial basis in each of these villages were then sampled randomly. Using structured questionnaire, detailed production information (i.e. input usage and outputs produced) as well as some socioeconomic characteristics of sampled farmers was obtained. In total our sample comprises 120 commercial banana producers.

\subsection{Analytical Framework}

\subsubsection{Theoretical Concept}

Many studies in the field of production frontier analysis employ a single output multi-input framework. However, in most instances the majority of rural farmers produces several outputs using several inputs (i.e. multi-input multi output process), either using the same piece of land or adjacent lands. In most rural areas of developing countries multiple outputs are a common feature of agricultural production. This is largely driven by farmers' strategy of spreading or reducing risk as well as achieving self sufficiency. Volatility in international market prices couple with erratic and unreliable rainfall patterns has increased production risk and uncertainty for farmers in this region who largely practice rain-fed agriculture.

The use of a single output production function framework to measure performance of farmers in situations where farmers produced several outputs imposes a number of restrictive assumptions which may bias the performance estimates (e.g. it ignores the allocative effects regarding the outputs, (Brümmer et al, 2002)). According to (Färe et al, 1990); if a farmer produces only one output using the various inputs at his/her disposal, then the production technology may be represented by a simple production function to capture performance, how- 
ever, if two or more outputs are produced, an alternative representation of the technology must considered (Färe et al, 1990).

An alternative to a single output specification to capture performance is the use of multioutput distance function specification ${ }^{42}$ which helps us to overcome the problems associated with the implicit assumptions imposed on the structure of single output production function. Another advantage of distance function is that estimation is possible without price information or imposing any behavioural assumptions (e.g. profit or revenue maximization, cost minimization) to provide a valid representation of the underlying production technology (Brummer et al, 2002).

According to (Coelli et al, 2005), the output oriented distance frontier function measures how much an output vector can be radially or proportionally expanded holding inputs fixed and still remain in the feasible production region as specified in equation (1) below:

$D_{o}(\boldsymbol{x}, \boldsymbol{y})=\inf \{\theta: \boldsymbol{y} / \theta \in P(\boldsymbol{x})\}$

Where, $\mathbf{y}$ (outputs) in the output distance function $\left(D_{o}(\boldsymbol{x}, \boldsymbol{y})\right)$ is non-decreasing, linearly homogeneous and convex while $\boldsymbol{x}$ (inputs) is non-increasing and quasi-convex. $P(\boldsymbol{x})$ represents the set of feasible output vector $(\boldsymbol{y})$ which can be produced using the input vector $(\boldsymbol{x}) . D_{o}(\boldsymbol{x}, \boldsymbol{y})$ is the distance from the farm's output set to the efficient frontier, and $\theta$ is the corresponding level of efficiency (i.e. $\theta$ is a scalar parameter which denotes how much the output vector should be radially expanded to the feasible efficient frontier). $\mathrm{D}_{\mathrm{o}}(\boldsymbol{x}, \boldsymbol{y})$ takes a value of 1 whenever the output vector $(\mathbf{y})$ lies on the outer boundary of the output $\operatorname{set}(D(\mathbf{x}, \mathbf{y})=\theta=1)$.

In terms of graphical representation, Figure 4.4 below could be used to depict the concept of the output distance frontier function.

\footnotetext{
${ }^{42}$ This estimation technique (i.e. output distance function) for capturing performance of farmers producing several outputs has been used by many authors, see for example Brümmer et al, (2002); (Tim Coelli et al, 1999); ( Färe, Grosskopf, Lovell, \& Pasurka, 1989)(Grosskopf et al, 1993).
} 


\section{Figure 4.4.: Illustration of Output Distance Function}

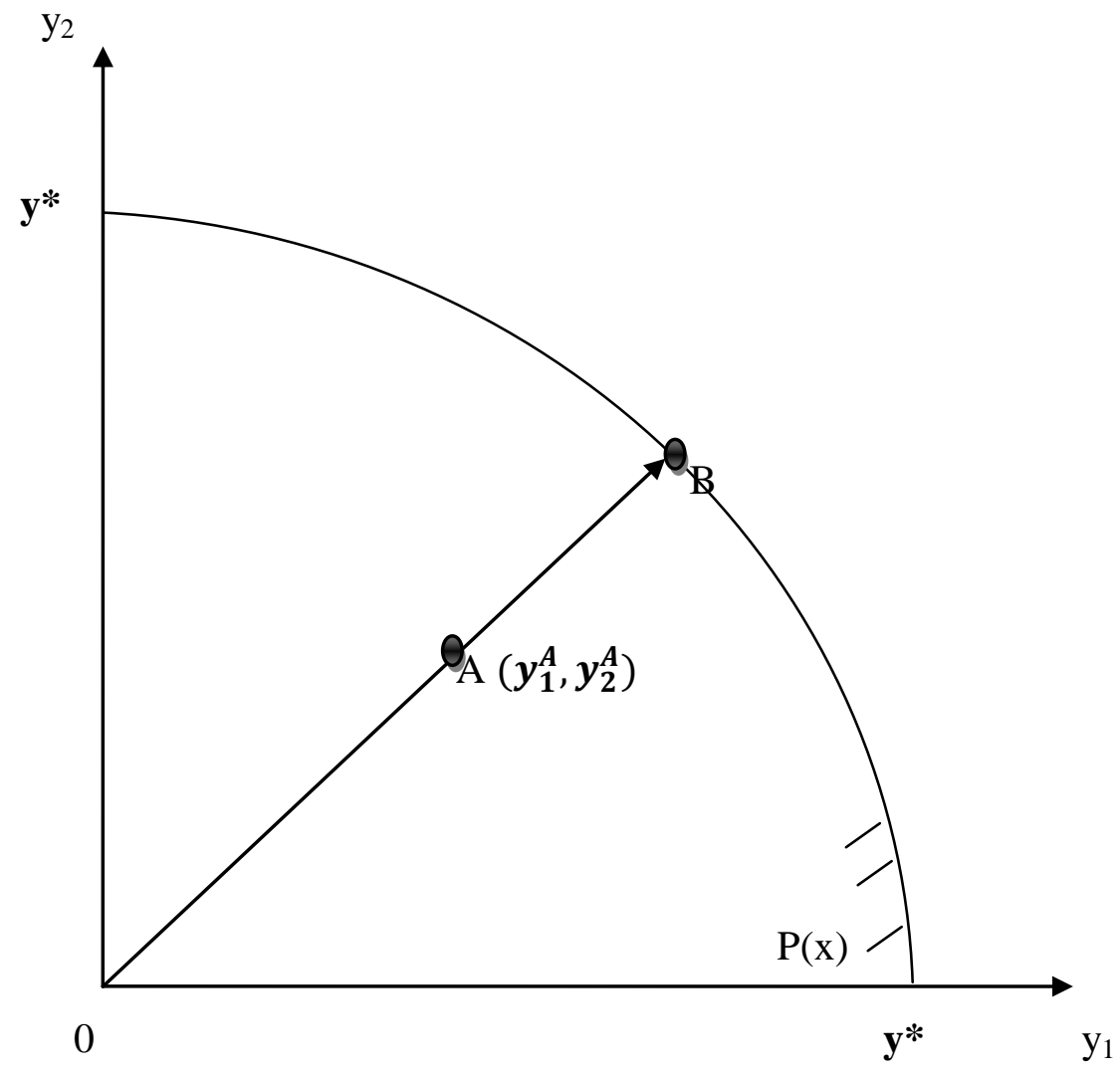

Source: author's owned conceptual depiction

Using Figure 4.4 above, the concept of multi-output multi-input production technology for our cross sectional data set could be illustrated as follows: Assume a farmer produces two outputs $\left(\boldsymbol{y}_{1}^{\boldsymbol{A}}, \boldsymbol{y}_{2}^{\boldsymbol{A}}\right)$ using input vector $(\boldsymbol{x})$ and where $\mathbf{y}^{*}$ represent the production possibility frontier (PPF) as depicted in Figure 4.4. From production theory, the PPF curve describes all the possible combinations of technically efficient production points of the outputs $\left(y_{1}, y_{2}\right)$ that could be produced using the input vector $(\boldsymbol{x})$ and still remains in the feasible production region $\mathbf{P}(\mathbf{x})$. The $\mathrm{P}(\mathrm{x})$ is therefore bounded by the PPF. Based on principles derived from stochastic frontier production theory, production at any point other than on the frontier (e.g. B) represents sub-optimal performances (e.g. point $\boldsymbol{A}$ in Figure 4.4 above). Output point $\mathbf{A}$ represent departure from feasible technically efficient production points (located on the PPF frontier) hence the distance from point $\mathbf{A}$ to $\mathbf{B}$ signifies the level of inefficiency in the production process. As suggested by (Coelli et al, 2005), proportional expansion of output $\mathbf{A}$ towards the efficient production point $\mathbf{B}$ requires upward scaling of point $\mathbf{A}$ by a scalar $\boldsymbol{\theta}$ which needs to be minimized. 


$$
D_{0}(x, y)=0 A / O B \leq 1 \quad \text { i.e. } D_{0}(x, y) \leq 1
$$

$D_{0}(x, y)=1 / T E_{0} \quad$ i.e. $T E_{0} \geq 1$

The output distance $D_{0}(x, y)$ gives the reciprocal of the maximum proportional expansion of the output vector (y), given the input vector (x) and characterized the technology completely. The reciprocal of the distance function according to (Brümmer et al, 2006) (Brummer et al, 2002) can be viewed as performance measure which is in line with (Debreu, 1959) and (Farrell, 1975) measure of output-oriented technical efficiency $\left(\mathrm{TE}_{0}\right)$.

\subsubsection{Translog Output Distance Function}

In order to estimate the distance function in a parametric setting, a translog functional form is assumed $^{43}$ (Coelli et al, 1999). The inclusion of square and interaction terms presents a high degree of flexibility. The translog distance function specification for the case of $K$ inputs and $M$ outputs could be depicted in equation form as follows:

$$
\begin{aligned}
\ln D_{0 i}(x, y)=\alpha_{0}+ & \sum_{m=1}^{M} \alpha_{m} \ln y_{m i}+1 / 2 \sum_{m=1}^{M} \sum_{n=1}^{M} \alpha_{m n} \ln y_{m i} \ln y_{n i}+\sum_{k=1}^{K} \beta_{k} \ln x_{k i} \\
& +1 / 2 \sum_{k=1}^{K} \sum_{l=1}^{K} \beta_{k l} \ln x_{k i} \ln x_{l i}+\sum_{k=1}^{K} \sum_{m=1}^{M} \delta_{k m} \ln x_{k i} \ln y_{m i}
\end{aligned}
$$

Where $i=1,2 \ldots, N$, and denotes the $i^{\text {th }}$ farmer in the sample. In order to obtain the production frontier surface, we set $D_{0}(x, y)=1$ which implies $\ln D_{0}(x, y)=0$.

According to O'Donnel and Coelli (2005) and (Coelli and Perelman, 2000) the parameters of the above distance function must theoretically satisfy linear homogeneity in outputs and regularity conditions (i.e. monotonicity ${ }^{44}$ and curvature ${ }^{45}$ ).

\footnotetext{
${ }^{43}$ Since the Cobb Douglas functional form has the wrong curvature in the $y_{1} / y_{2}$ space.

${ }^{44}$ non-increasing inputs, non-decreasing outputs

${ }^{45}$ convexity in outputs
} 
Symmetry is imposed as:

$\alpha_{m n}=\alpha_{n m} ; m, n=1,2, \ldots, M$, and

$\beta_{k l}=\beta_{l k} ; k, l=1,2, \ldots, K$.

According to Lovell et al, (1994) and Coelli et al, (1999) normalizing the output distance function by one of the outputs ${ }^{46}$ enables imposition of homogeneity of degree +1 as follows:

By setting $\theta=1 / y_{M}$ and substituting it in equation $(1) \Rightarrow D_{0}\left(x, y / y_{M}\right)=D_{0}(x, y) / y_{M}$.

Therefore for the $i^{\text {th }}$ farmer, the above expression can be rewritten in translog form as:

$\ln \left(D_{0 i}(x, y) / y_{M i}\right)=T L\left(x_{i}, y_{i} / y_{M i}, \alpha, \beta, \delta\right), i=1,2, \ldots, N$,

Where the translog $(T L)$ equation is written in full as:

$T L\left(x_{i}, y_{i} / y_{M i}, \alpha, \beta, \delta\right)=\alpha_{0}+\sum_{m=1}^{M-1} \alpha_{m} \ln \left(y_{m i} / y_{M i}\right)+1 / 2 \sum_{m=1}^{M-1} \sum_{n=1}^{M-1} \alpha_{m n} \ln \left(y_{m i} / y_{M i}\right) \ln \left(y_{n i} / y_{M i}\right)+$ $\sum_{k=1}^{K} \beta_{k} \ln x_{k i}+1 / 2 \sum_{k=1}^{K} \sum_{l=1}^{K} \beta_{k l} \ln x_{k i} \ln x_{l i}+1 / 2 \sum_{k=1}^{K} \sum_{m=1}^{M-1} \delta_{k m} \ln x_{k i} \ln \left(y_{m i} / y_{M i}\right)$.

By rearranging terms in equation (6), the above function can be rewritten as follows:

$-\ln \left(y_{M i}\right)=T L\left(x_{i}, y_{i} / y_{M i}, \alpha, \beta, \delta\right)-\ln D_{0 i}(x, y), i=1,2, \ldots, N$,

Where $-\ln D_{0 i}(x, y)$ corresponds to the radial distance function from the boundary. Consequently, if we set $u=-\ln D_{0 i}(x, y)$ and add up a term $v_{i}$ to capture noise, we end up obtaining

\footnotetext{
${ }^{46}$ According to Coelli and Perelman (1999), the transformed output variables in a ratio form are measures of output mix which are more likely to be exogenous. Also, Schmidt (1988) and Mundlak (1996) find that the ratio of two input variables does not suffer from endogeneity.
} 
the Battese and Coelli, (1988) version of the traditional stochastic frontier model proposed by Aigner et al, (1977) and Meeusen \& van den Broeck, (1977) as follows:

$-\ln \left(y_{M i}\right)=T L\left(x_{i}, y_{i} / y_{M i}, \alpha, \beta, \delta\right)+\varepsilon_{i}$, where $\varepsilon_{i}=v_{i}+u_{i}$

Where $\varepsilon_{i}$ is the composed error term ${ }^{47}, u=-\ln D_{0 i}(x, y)$ captures farmers inefficiency since it represent the distance to the efficient frontier or the boundary. It is a non-negative random term assumed to be independently distributed as truncation at zero of the $N\left(0, \sigma_{u i}^{2}\right)$ distribution (Wang and Schmidt, (2002)). The $v_{i}$ captures random noise (i.e. events beyond the control of farmers) and assumed to be iid $N\left(0, \sigma_{v}^{2}\right)$. Both terms are assumed to be independently distributed (i.e. $\sigma_{u v}=0$ ).

\subsubsection{Empirical Specification}

A translog stochastic output distance function with two outputs $\left(y_{1}, y_{2}\right)$ and four inputs $x=\left(x_{1}\right.$, $x_{2}, x_{3}, x_{4}$ ) was specified as follows:

$$
\begin{aligned}
& -\ln \left(y_{1 i}\right)=\alpha_{0}+\alpha_{1} \ln \left(y_{2 i} / y_{1 i}\right)+1 / 2 \alpha_{11} \ln \left(y_{2 i} / y_{1 i}\right) \ln \left(y_{2 i} / y_{1 i}\right)+\sum_{k=1}^{K=4} \beta_{k} \ln x_{k i}+1 / 2 \sum_{k=1}^{K=4} \sum_{l=1}^{K=4} \beta_{k l} \\
& \ln x_{k i} \ln x_{l i}+1 / 2 \sum_{k=1}^{K=4} \delta_{k} \ln x_{k i} \ln \left(y_{2 i} / y_{1 i}\right)+v_{i}+u_{i}
\end{aligned}
$$

Where $y_{1 i}$ represent value of banana produced in cedis (i.e. new Ghana cedis) by the $i^{\text {th }}$ farmer for the 2012 production year. $y_{2 i}$ is the normalized output which is equal to the "output ratio" of the value of other crops (i.e. value of maize + cassava + cocoyam + yam) relative to the value of banana produced by the $i^{\text {th }}$ farmer in 2012 production year. The inputs (x) included in the model are $\operatorname{land}\left(\mathrm{x}_{1}\right)$, labour $\left(\mathrm{x}_{2}\right)$, maintenance $\operatorname{cost}\left(\mathrm{x}_{3}\right)$ and cost of planting material/sucker $\left(\mathrm{x}_{4}\right)$, and $\alpha, \beta$ and $\delta$ are the parameters to be estimated.

\footnotetext{
${ }^{47}$ Please see Jondrow et al, (1982) for detail discursion on the composed error term $\left(\varepsilon_{i}\right)$ and how to obtain $u_{\mathrm{i}}$
} 
To examine how management and specific household socioeconomic characteristics influence the performance of farmers, we employed a heteroskedasticity corrected inefficiency model as proposed by Wang and Schmidt, (2002) and specified as follows:

$\sigma_{u_{i}}=\exp \left\{z_{i j} \delta_{j}\right\}$

Model (9) is based on the assumption that hypothesized explanatory variables $Z_{i j}$ (i.e. education level, farm experience, contact to extension workers, household size and age of household head) affects the degree of technical inefficiency and so produces technical efficiency scores that incorporate these factors.

\subsection{Results and Discussion}

Coefficients of the output oriented technical efficiency as well as determinants of inefficiency were obtained by jointly estimating equation (8) and (9) using the maximum likelihood estimation procedure with Stata statistical software ( $11^{\text {th }}$ edition). The use of distance function estimation procedure enables us to examine the production performance of farmers in the Volta region of Ghana producing both banana and other crops.

\subsubsection{Summary Statistics}

For estimating the translog distance function, outputs were aggregated into two categories (i.e. value of Banana and other crops produced). The data set contains information on the quantity of banana and other crops produced and sold as well as the farm gate price received by farmers from exporters and or other customers. The farm gate price received by a farmer and the quantity he/she sold were used to calculate the value of the two outputs (i.e. quantity sold * price received). The farm gate price depends on the quality of the products as well as the location of the farm to urban centres, however, we could not obtain any information on quality grading standards since this is a purely subjective assertion by buyers just to drive down prices, hence, value of crops as calculated here do not take into account direct quality differences but indirectly through price received. The labour input consists of the total number of people who work on a farm/plantation (i.e. family plus hired labour). The land input is meas- 
ured in hectares. Table 4.1 below presents a complete overview of all the variables used in the estimation.

Table 4.1.: Characteristics of the Sample Data (Number of Observation $=120$ )

\begin{tabular}{llllll}
\hline Variable & Unit & Mean & Min. & Max. & std. Dev. \\
\hline Banana & 100 Cedis (2012 value) & 337.375 & 120 & 620 & 132.367 \\
Other Crops & 100 Cedis (2012value) & 18.725 & 5 & 38 & 8.903 \\
Land & hectares & 7.075 & 4 & 14 & 2.708 \\
Labour & Number of on-farm workers & 5.308 & 2 & 10 & 2.176 \\
Maintenance cost & Cedis (2012 value) & 278.633 & 100 & 800 & 151.965 \\
Planting mat. Cost & Cedis (2012 value) & 132.483 & 35 & 600 & 74.495 \\
Education & Years & 13.100 & 1 & 24 & 5.975 \\
Experience & Years & 23.067 & 2 & 60 & 14.184 \\
Household size & Number of people in a Hh & 5.792 & 1 & 15 & 2.456 \\
Age of Hh head & Years & 49.125 & 25 & 86 & 13.617 \\
Extension & Number of extension contacts & 6.75 & 2 & 24 & 4.499 \\
\hline
\end{tabular}

Source: own estimate from 2012 field survey data.

\subsubsection{Distance Elasticities}

Before estimation, the data was normalized at the sample mean; this means the first order distance coefficients can be interpreted as partial elasticities of the distance function with respect to the inputs. Inclusion of more input variables created convergence problems due to multicollinearity; hence, likelihood ratio test was used to check for admissible variables to be included in the estimation model (i.e. as a variable selection procedure). Based on the value of loglikelihood for the various models we explored, no further reduction in variables was admissible. The model we estimated had the highest log-likelihood value among all the possible models we explored. Table 4.2 below summarises the result of the maximum likelihood estimates of the translog output distance function as specified in equation (8). It presents an overview of the technological properties of the estimated model based on the average elasticities of the distance function with respect outputs and inputs (i.e. the coefficients are indicative of the distance elasticity of "banana output" with respect to the "other crops output" and the "inputs" (Koundouri et al, 2002). In line with the way equation (8) is specified, a negative sign 
in front of the input distance elasticities is interpreted as positive contribution of $(x)$ to the production of banana. Similarly, a positive sign in front of other crops distance elasticity, implies a negative shadow share contribution of other crops relative to banana output in the overall production (i.e. reflecting some degree of substitution, MRTS = the slope of PPF).

Table 4.2.: Average Distance Elasticities

\begin{tabular}{lll}
\hline Variables & Coefficient & std. Err. \\
\hline Banana & 0.7611 & \\
Other Crops & $0.2389^{* * *}$ & 0.0238 \\
Land & $-0.1123^{* *}$ & 0.0518 \\
Labour & $-0.2288^{* * *}$ & 0.0438 \\
Maintenance cost & $-0.1035^{* *}$ & 0.0446 \\
Planting material Cost & -0.0227 & 0.0316 \\
\hline RTS & 0.468 & \\
\hline Source: study findings based on 2012 field survey data. & \\
$*, * * * * *$ significant at the $10 \%, 5 \%$, and 1\% level respectively \\
Note; square and interaction terms are omitted in this table (please see appendix C for full table).
\end{tabular}

Table 4.2 above shows that all the first order inputs distance elasticities possess the expected $\operatorname{sign}^{48}$ and satisfy the monotonicity condition at the sample mean. With exception of planting material cost (i.e. cost of banana suckers), the rest of the inputs (i.e. land, labour and maintenance cost) are significantly different from zero; this implies, these inputs contribute significantly to the production of banana. The elasticity effect on other crops is simply the opposite, because of homogeneity constraint in outputs (Brümmer et al, 2002). The inputs labour and land had the biggest marginal productivity impact on banana output as indicated by their respective distance elasticities. This reflects the importance of labour and land requirement in the production set up in this region. The shadow share of banana in the total farm output is computed as 0.761 (i.e. 76\%) while that of other crops is 0.239 (i.e. 24\%). Majority of farmers in our data cultivate banana (as cash crop) mainly for the export market and therefore its large share to total revenue with respect to other crops is consistent with the data and our expectation. The relatively lower estimate of other crop output elasticity reflects the low shadow

\footnotetext{
${ }^{48}$ The distance elasticities for a "well-behaved" input must be negative according to (Brümmer et al, 2006) (Brümmer and Glauben, 2004)
} 
share of other crop in the multi-output production set up. The coefficients of the outputs also represent the slope of the PPF at the sample mean (i.e. it captures the MRT between banana and other crops produced relative to the output mix).

The positive and significant value for the square term of other crops (see table 4.5 of appendix C) confirms evidence of convexity curvature property in the outputs at the sample mean. The positive square terms of land, labour and maintenance cost conforms to the monotonicity property for these inputs. For the cross-term, we found significant evidence of input substitution effect between land and maintenance cost. This means, farmers with limited or small land size compensate with high post planting operation such as weed, disease and pest control (i.e. high maintenance cost) to achieve high output. Complementarity effects observed between other outputs, land and labour means; joint effects of such variables contribute significantly to the production of the other outputs.

Overall, the magnitudes of estimates (i.e. economic gain) as shown by the partial elasticity estimates of the production inputs are very small. At the sample mean, the production systems exhibit decreasing return to scale ${ }^{49}$ (i.e. RTS $=0.468^{50}$; implying, doubling the amount of inputs employed in production will result in less than double output). This means, given the current technology available to the industry, as more of such inputs are employed in production, proportionately less outputs are obtained. This increases the average cost per unit produced. Normally, firms experiencing decreasing return to scale are viewed as huge or too big, hence, a need for restructuring into manageable size. However, the average farm size of $7.1 \mathrm{ha}$ is far too small to justify the argument that the individual farm size is too big or overstretched. A plausible explanation for the decreasing return to scale could therefore be attributed to the archaic or obsolete nature of current production technique. This re-enforced the need for the introduction of modern production technologies to the sector. Introduction of modern production technologies which take into account the needs of farmers in the sector could greatly enhance outputs, even if less or same input levels are employed.

\footnotetext{
${ }^{49}$ Return to scale is a very important technical property of any production function (i.e. via the homogeneity properties of the production function).

${ }^{50}$ RTS was calculated as the sum of the absolute value for the first order input elasticities
} 


\subsubsection{Technical Efficiency}

Table 4.3 and Figure 4.2 present summary information of technical efficiency in production for sampled farmers in the Volta region. Table 4.3 reveals that, sampled farmers in the Volta region produce on average $86 \%$ of the potential output given the current technology available to them. This implies an average of $14 \%$ increase in output margins is possible if production inefficiency is eliminated.

Table 4.3.: Summary Statistics of Technical Efficiency (TE)

\begin{tabular}{lllll}
\hline Number Obs. & Mean & Std. Dev. & Minimum & Maximum \\
\hline & & & \\
120 & 0.8644 & 0.0748 & 0.6584 & 0.9743 \\
\hline \multicolumn{5}{l}{ Source: study findings based on 2012 field survey data. }
\end{tabular}

Figure 4.5.: Bar and Boxplot Distribution of Technical Efficiency Scores
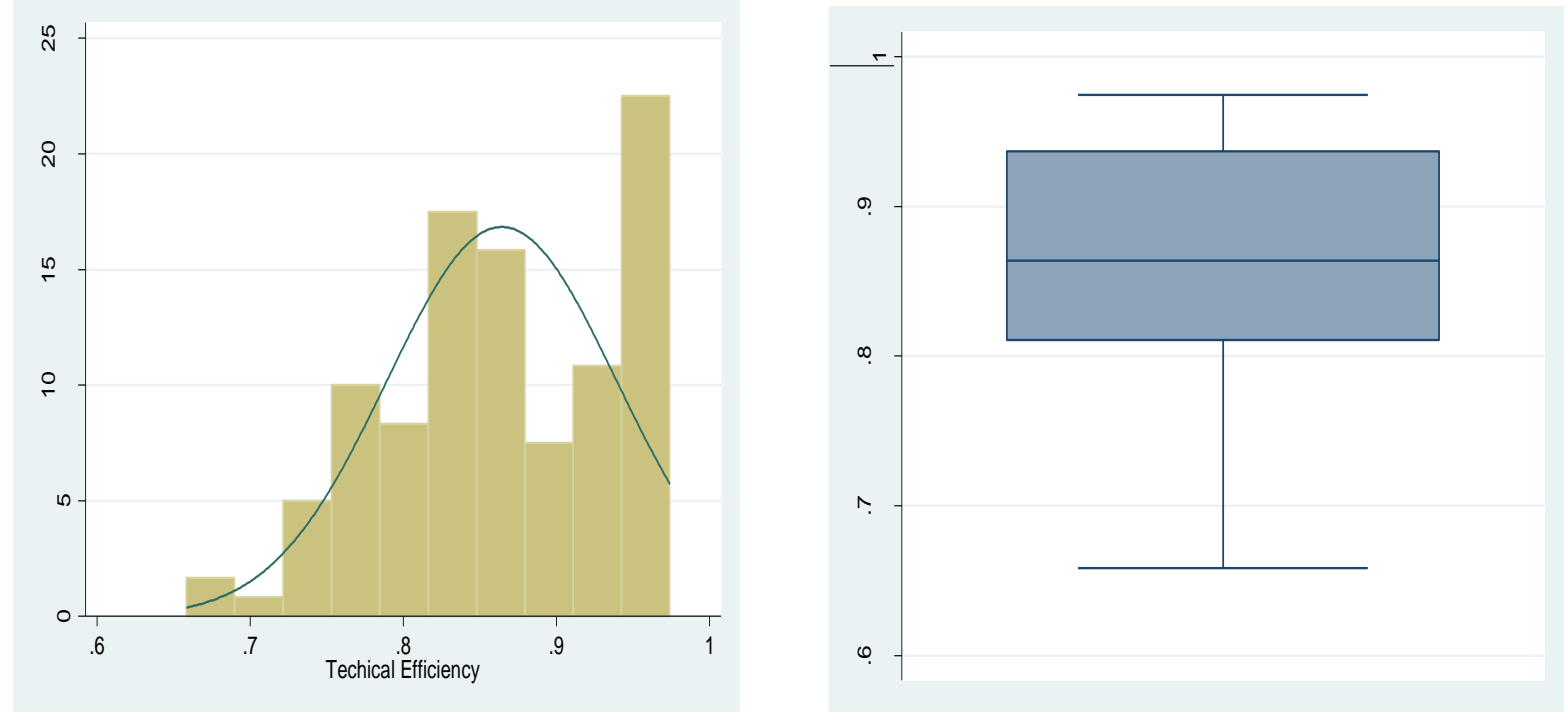

Source: study findings based on 2012 field survey data

Figure 4.5 shows the distribution of the efficiency scores where performance scores of farmers are distributed ranging from a minimum of 0.66 to a maximum of 0.97 . Most scores are located around the median efficiency score (see boxplot). This narrow spread of efficiency scores around the sample mean and median (i.e. Std. Dev. $=0.07$ ) implies a low performance variation within the sampled farmers. The tails of the boxplot give an indication of the level of 
variability for the upper and lower $25 \%$ quartile. The long tail toward the lower $25 \%$ indicate, there is more variability in performance score for those farmers located within the lower $25 \%$ quartile.

\subsubsection{Determinants of Inefficiency}

Result of the inefficiency model (i.e. equation 13) presented in Table 4.4 enables identification of sources of variation in the technical efficiency estimates. Farmers' education level, experience, household size and regular contact to extension workers have a significantly positive effect in reducing production inefficiency. The level of farmers' efficiency reduces significantly as farmers grow old. This may be due to the fact that as farmers grow old and weak, it reduces their willingness to take risk by experimenting with new production technologies. It also shows experience is more relevant in reducing production inefficiencies as compared to the age of the farmer. The significant effect of education in reducing inefficiency reflects the fact that, educated farmers are more capable of sourcing new information on prices and better production technologies. Farmers with regular contact to extension workers are able to improve their production practices as new agronomic information is regularly passed to such farmers.

Table 4.4: Drivers of Inefficiency

\begin{tabular}{lcc}
\hline Variables & Coefficient & Standard Error \\
\hline Constant & $0.333^{* * *}$ & 0.077 \\
Education & $-0.015^{* * *}$ & 0.003 \\
Experience & $-0.002^{*}$ & 0.001 \\
Household size & $-0.008^{*}$ & 0.004 \\
Age of Household head & $0.002^{*}$ & 0.001 \\
Extension & $-0.006^{*}$ & 0.003 \\
\hline
\end{tabular}

Source: study findings based on 2012 field survey data. $*, * *, * * *$ significant at the $10 \%, 5 \%$, and $1 \%$ level respectively

Note: values of coefficients and standard errors have been rounded off to three decimal places.

Even though these variables are statistically significant and contribute to reducing inefficiencies in the sector, the magnitude of economic value derived as a result of addressing issues of 
inefficiency based solely on these variables are very small, hence further studies with long observation data may provide helpful information to aid identification of all the factors driving inefficiency in the sector. The nature of technological development trends in the sector could only be reveal with such data set (i.e. whether the sector is experiencing technology progress or regress or standstill).

\subsection{Conclusion with Recommendations for Future Policies}

This paper analysed the production performance of commercial banana producers using a cross-section data of 120 randomly sampled farmers in the Volta region of Ghana. By means of the stochastic frontier approach, output distance function estimation technique was used to estimate technical efficiency and explore complementarity and substitution effects in production inputs. Farmers in our sample data produce a mixture of crops in addition to banana production. Hence, output distance function was deemed appropriate because it allows us to explore changes in the levels of outputs in relation to the frontier output mix (PPF). The empirical result showed that, the marginal rate of transformation MTR between banana and other crops produced by farmers is negative and significantly different from zero (see Table 4.1).

The result of the first order input elasticities also reveals that, all inputs monotonicitly increased banana production in the region. However, evidence of a decreasing return to scale $(\mathrm{RTS}=0.468)$ could not be attributed to farm size as prescribe by economic theory. A plausible explanation could be due to the obsolete nature of production technique ${ }^{51}$ (dominated by traditional production tools) currently being employed in the region. Measures to improve production techniques using modern production tools will therefore help boost overall output.

The result of the efficiency model shows an average performance score of $86 \%$, which implies a scope of $14 \%$ increase in output through improvement in technical efficiency is theoretically possible given the current production technology in the region. Household and socioeconomic factors such as farmers' education level, experience, household size and regular contact to extension workers were found to improve production performance (i.e. reduce inefficiency). However, the low economic magnitude of output gain as revealed by the estimate of these variables will not be enough to sustain the sector in the long run given the highly com-

\footnotetext{
${ }^{51}$ An obsolete production technique such as the "slush and burn" land preparation technique destroys certain important species (flora and fauna) in the ecosystem. This negatively impacts soil micro-organisms necessary for fertility and crop yield.
} 
petitive nature of international trade. Hence, policy measures which facilitate transition from current traditional production techniques to use of modern production technologies in conjunction with improvement in technical support and logistics services ${ }^{52}$ will enhance productivity gain on a sustainable basis. For instance the traditional production technique of transplanting part of underground pseudostem or suckers with soil and roots intact facilitates transmission of the devastating banana wilt diseases from farm to farm, making control of these diseases very difficult. Therefore, introduction of modern production techniques where planting materials (i.e. banana suckers) are propagated by means of tissue culture could ensures disease free planting material and subsequently high quality output with minimum production cost.

Finally, policy makers in conjunction with all stakeholders should prioritize investment in agricultural research and development (R \& D) programs which facilitates development and transfer of such modern production technologies to farmers in the sector (e.g. various hybridization and genetic engineering programs working on creating a disease-resistant cultivars).

\footnotetext{
52 including mechanisms for proper post harvest handling, packaging, storage or park-houses etc
} 


\section{Appendix C}

Table 4.5.: Distance Function and Determinants of Efficiency Estimates

$\begin{array}{llr}\text { Stoc. frontier normal/truncated-normal model } & \text { Number of obs }= & 120 \\ & \text { Wald chi2(20) } & =815.44 \\ \text { Log likelihood }=103.90385 & \text { Prob }>\text { chi2 } & =0.0000\end{array}$

\begin{tabular}{|c|c|c|c|c|c|c|}
\hline logBanana & Coef. & std. Err. & z & $>|z|$ & {$[95 \% \mathrm{Co}$} & Interv \\
\hline $\begin{array}{r}\text { logBanana } \\
\text { logothercr s } \\
\text { logLand } \\
\text { logLabor } \\
\text { logMaintcost } \\
\text { logPltmatc t } \\
\text { logothCrp_sq } \\
\text { logLand_sq } \\
\text { loglabor_sq } \\
\text { logMntc_sq } \\
\text { logPltmc_sq } \\
\text { OthcrpLand } \\
\text { OthCrplabor } \\
\text { othCrpMtc } \\
\text { othcrpPltcut } \\
\text { Landlabor } \\
\text { LandMtcost } \\
\text { LandPltcost } \\
\text { laborMtcost } \\
\text { laborpltcost } \\
\text { MtcPltc } \\
\text { _cons }\end{array}$ & $\begin{array}{r}.2389215 \\
-.1122955 \\
-.2288005 \\
-.1035104 \\
-.0227278 \\
.0887739 \\
.6198345 \\
.2799156 \\
.0743782 \\
-.0191697 \\
.1152901 \\
.1663858 \\
-.1376469 \\
.1170092 \\
-.0831588 \\
-.3769015 \\
.1304358 \\
-.0801307 \\
.1142105 \\
-.0472661 \\
-.2226902\end{array}$ & $\begin{array}{l}.0238222 \\
.0517895 \\
.0437634 \\
.0445786 \\
.0315989 \\
.0328941 \\
.1487642 \\
.1113392 \\
.1081806 \\
.0395355 \\
.1089936 \\
.0788976 \\
.1070109 \\
.0563158 \\
.1605524 \\
.1863923 \\
.140947 \\
.1467067 \\
.1077131 \\
.1447216 \\
.0345333\end{array}$ & $\begin{array}{r}10.03 \\
-2.17 \\
-5.23 \\
-2.32 \\
-0.72 \\
2.70 \\
4.17 \\
2.51 \\
0.69 \\
-0.48 \\
1.06 \\
2.11 \\
-1.29 \\
2.08 \\
-0.52 \\
-2.02 \\
0.93 \\
-0.55 \\
1.06 \\
-0.33 \\
-6.45\end{array}$ & $\begin{array}{l}0.000 \\
0.030 \\
0.000 \\
0.020 \\
0.472 \\
0.007 \\
0.000 \\
0.012 \\
0.492 \\
0.628 \\
0.290 \\
0.035 \\
0.198 \\
0.038 \\
0.604 \\
0.043 \\
0.355 \\
0.585 \\
0.289 \\
0.744 \\
0.000\end{array}$ & $\begin{array}{r}.1922308 \\
-.2138011 \\
-.3145753 \\
-.1908828 \\
-.0846605 \\
.0243027 \\
.3282621 \\
.0616948 \\
-.1376519 \\
-.096658 \\
-.0983335 \\
.0117493 \\
-.3473844 \\
.0066323 \\
-.3978358 \\
-.7422238 \\
-.1458153 \\
-.3676706 \\
-.0969034 \\
-.3309151 \\
-.2903743\end{array}$ & $\begin{array}{r}.2856121 \\
-.0107899 \\
-.1430258 \\
-.016138 \\
.0392049 \\
.153245 \\
.9114069 \\
.4981365 \\
.2864083 \\
.0583185 \\
.3289137 \\
.3210224 \\
.0720905 \\
.2273861 \\
.2315182 \\
-.0115793 \\
.4066869 \\
.2074091 \\
.3253243 \\
.236383 \\
-.1550062\end{array}$ \\
\hline $\begin{array}{r}\text { Education } \\
\text { expirence } \\
\text { hhsize } \\
\text { age_Hh } \\
\text { Extension } \\
\text { _cons }\end{array}$ & $\begin{array}{r}-.0153386 \\
-.0019242 \\
-.0075697 \\
.001791 \\
-.0055717 \\
.3329708\end{array}$ & $\begin{array}{r}.0029265 \\
.0010207 \\
.0047377 \\
.0011651 \\
.00297 \\
.0771882\end{array}$ & $\begin{array}{r}-5.24 \\
-1.89 \\
-1.60 \\
1.54 \\
-1.88 \\
4.31\end{array}$ & $\begin{array}{l}0.000 \\
0.059 \\
0.110 \\
0.124 \\
0.061 \\
0.000\end{array}$ & $\begin{array}{r}-.0210744 \\
-.0039247 \\
-.0168555 \\
-.0004926 \\
-.0113927 \\
.1816846\end{array}$ & $\begin{array}{r}-.0096027 \\
.0000764 \\
.0017161 \\
.0040745 \\
.0002494 \\
.4842569\end{array}$ \\
\hline $\begin{array}{l}\text { /lnsigma2 } \\
\text { /ilgtgamma }\end{array}$ & $\begin{array}{l}-4.569339 \\
-6.259429\end{array}$ & $\begin{array}{l}.1291786 \\
8.200591\end{array}$ & $\begin{array}{r}-35.37 \\
-0.76\end{array}$ & & & $\begin{array}{r}-4.316154 \\
9.813435\end{array}$ \\
\hline $\begin{array}{r}\text { sigma2 } \\
\text { gamma } \\
\text { sigma_u2 } \\
\text { sigma_v2 }\end{array}$ & $\begin{array}{l}.0103648 \\
.0019087 \\
.0000198 \\
.010345\end{array}$ & $\begin{array}{r}.0156225 \\
.000162 \\
.0013412\end{array}$ & & & $\begin{array}{r}.0080464 \\
2.00 \mathrm{e}-10 \\
-.0002978 \\
.0077162\end{array}$ & $\begin{array}{r}.0133511 \\
.9999453 \\
.0003373 \\
.0129738\end{array}$ \\
\hline
\end{tabular}


Table 4.6.: Deciles Distribution of the Technical Efficiency Scores

\begin{tabular}{|c|c|c|c|c|}
\hline $\begin{array}{r}1 \% \\
5 \% \\
10 \% \\
25 \%\end{array}$ & $\begin{array}{c}\text { Percentiles } \\
.6807501 \\
.7305996 \\
.7624692 \\
.8104722\end{array}$ & $\begin{array}{l}\text { Smallest } \\
.6584068 \\
.6807501 \\
.7162744 \\
.7235486\end{array}$ & $\begin{array}{l}\text { Obs } \\
\text { Sum of wgt. }\end{array}$ & $\begin{array}{l}120 \\
120\end{array}$ \\
\hline $50 \%$ & .8638412 & & Mean & .8643571 \\
\hline $75 \%$ & .93657 & $\begin{array}{l}\text { Largest } \\
.9684875\end{array}$ & Std. Dev. & .0748286 \\
\hline $90 \%$ & .9619923 & .9691051 & Variance & .0055993 \\
\hline $95 \%$ & .966436 & .9723546 & skewness & -.363013 \\
\hline $99 \%$ & .9723546 & 9742917 & Kurtosis & 2.388534 \\
\hline
\end{tabular}




\section{Chapter Five}

\section{Summary}

\subsection{Summary of Research}

This study investigates the causes of declining output performance in the Ghanaian fruit production industry. Average industrial output level is lagging far behind that of competing nations (for instance, the productivity of Ghana pineapple farms is $60 \mathrm{~T} / \mathrm{Ha}$ compared to 120 T/Ha for Cost Rica (Gatune et al, 2013) despite Ghana's excellent relative comparative advantage (i.e. labour, climate, location) for fruit production. The inability of the industry to meet both local and export demand-volumes has caused some major processing and exporting companies struggling to get raw materials to close down or relocated to other countries leading to job losses in both rural and urban areas, loss of international market share and foreign exchange the country urgently need. The aim of this study is therefore to identify and analysed the factors hindering successful and efficient performance of the fruit crop industry (i.e. we assessed why Ghana's fruit crop production industry remains below its potential).

In light of the above mentioned problems, our study, which uses cross-country farmhousehold survey data to identify and analyze potential ways of enhancing farmers' efficiency of production in the fruit industry, is a giant step in the right direction. Empirical insight gained from this study could serve as a valuable guideline to policy makers in formulating future performance enhancing programs to boost output in the industry.

In order to effectively study the industry, the three major fruit sectors (i.e. mango production sector, pineapple production sector and banana production sector) of the industry were selected and subjected to a detailed empirical analysis. The empirical results are obtained using a cross-country farm-household survey data of fruit farmers in all the major fruit producing regions of Ghana. Therefore, this dissertation is a collection of three papers organised into three chapters $(2-4)$. Each chapter studied in detail a sector of the industry and the major findings are summarised below. Based on economic theory and statistical tests, different econometric estimation techniques were employed to analyse the research questions which were posed in each essay. 


\subsection{Summary of Findings in Each Essays/Papers}

Chapter Two (first essay/paper): The study uses metafrontier estimation technique to derive performance estimates of mango farmers given the technology available to both their zonal production frontier and the industrial production frontier (metaproduction). This estimation technique enables us to distinguish production shortfall due to technological gaps (which we argue is outside the control of farmers) from that of technical inefficiency (which is under the control of farmers). The data and estimation technique used in this study revealed that, besides technical inefficiency, technology gaps plays an important part in explaining the production performance of farmers in one zone in comparison with farmers in other zones.

This has important implication for policy targeting program design. For instance, in the northern zone where $94 \%$ of farmers are estimated to be making full use of available technologies yet lag behind the industrial output by 52\%, imply; policy intervention programs designed to improve the production environment (e.g. building roads and power supplies, or creating a favourable credit market for farmers etc.) which aid facilitation of technology transfer to bridge the technology gap will have a huge impact on output performance.

The middle and southern zones have an average zonal technical efficiency of $79 \%$ and $80 \%$ respectively, with relatively high proportions of farmers having less than $50 \%$ efficiency score. In these two zones, it will be economically more prudent to design programs which enhance farmers' managerial capabilities or skills; thereby enabling them to increase output towards their zonal frontier by making better use of existing technologies ${ }^{53}$.

In general the study reveals that there is much scope for output improvement in all zones, however, attainment of maximum output is possible only if the causes of inefficiency due to technology gaps and farmers effectiveness of using available resources are properly addressed.

Chapter Three (second essay/paper): This study employs both logistic and metafrontier models to analyse stated research objectives. For example, we analysed the proportion of farmers cultivating the MD2 variety in each production system and identify the factors influ-

\footnotetext{
${ }^{53}$ Efficient use of current know-how implies more output can be produced with existing input endowment.
} 
encing the adoption of MD2 variety using a logistic regression model. The result shows that, out of 404 pineapple farmers sampled across the three regions, only 74 (18\%) farmers are cultivating the MD2 variety. The analysis of factors influencing the adoption of MD2 reveals that; farmers with higher off-farm income, capable of installing irrigation facilities to irrigate their farms, having access to regular and reliable pineapple market as well as farms located in the eastern regions are more likely to adopt the MD2 variety.

Metafrontier analytical technique was used to assess the current productivity level of organic and conventional pineapple producers using a cross sectional data set gathered from 404 farm-households in three regions where commercial production is most concentrated. The results of our analysis reveal that the majority of farmers in both systems was operating on or near their group as well as the industrial frontier (i.e. 97\% mean TE and 95\% mean MTR). This implies that there is not much scope for output expansion or productivity gain given the current state of technology available to the industry. Therefore, to substantially enhanced productivity level in the industry, government policies should aim at agricultural-research (R\&D) development framework which not only encourages but expedites technological progress through the introduction of modern production techniques. Design of productivity enhancement programs by policy makers' aim at making the industry more competitive should prioritize investment in agricultural infrastructures which support technology transfer. For instance, improving conditions of rural-urban road networks to support quick and effective transportation of inputs/outputs will aid facilitation of technology transfer to the less develop and resource starved regions of the industry.

Chapter Four (third essay/paper): This paper analyses the production performance of commercial banana producers using a cross-section data of 120 randomly sampled farmers in the Volta region of Ghana ${ }^{54}$. By means of stochastic frontier approach, output distance function estimation technique was used to estimate technical efficiency and explore complementarity and substitution effects in production inputs and outputs. Farmers in our sample data produce a mixture of crops in addition to banana production. Hence, an output distance function was deemed appropriate because it allows us to explore changes in the levels of outputs in relation to the frontier output mix (PPF). The empirical result showed that, the marginal

\footnotetext{
${ }^{54}$ Field survey was carried in 2012.
} 
rate of transformation (MTR) between banana and other crops produced by farmers is negative and significantly different from zero (see table 4.2 in chapter four).

The result of the first order input elasticities also reveals that, all inputs monotonicitly increased banana production in the region. However, evidence of a decreasing return to scale $(\mathrm{RTS}=0.468)$ could not be attributed to farm size as prescribe by economic theory. A plausible explanation could be due to the obsolete nature of production technique ${ }^{55}$ (dominated by traditional production tools) currently being employed in the region.

The result of the efficiency model as defined in equation (9) and presented in Table 4.3 shows an average performance score of $86 \%$. This implies given the current state of production technology in the region, a $14 \%$ improvement in output is theoretically possible if causes of production inefficiency could be eliminated. Household and socioeconomic factors such as farmers' education level, experience in farming, household size and regular contact with extension workers were found to improve production performance (i.e. reduce inefficiency). However, the magnitude of economic gain as revealed by the estimated coefficients (see table 4.4 in chapter four) is not high enough to sustain the industry in the long run given the highly competitive nature of international trade. Hence, Policy measures which facilitate the transition from current traditional production techniques to use of modern production technologies in conjunction with improvement in transport, logistics and technical support services will enhance performance on a sustainable basis in the sector (i.e. such measures which enhances both quality and volume supplied could help improve the comparative advantage of the industry).

\subsection{Summary of Observed Constraints in the Industry}

The following observations were made during the countrywide field survey of the industry (in 2012) and from the empirical results of this study:

- Fruit production in the industry is largely rain-fed causing output levels to vary according to weather conditions. Ghana's irrigation potential remains almost untapped.

- Traditional systems of farming (e.g. slush and burn land preparation method) still prevailing in most parts of the country.

\footnotetext{
55 An obsolete production technique such as the "slush and burn" land preparation technique currently being practiced in Ghana negatively impacts soil micro-organisms necessary for soil fertility and hence crop yield.
} 
- Lack of modern production technologies (i.e. hoe and cutlass are the main farming tools). There is little mechanization in the industry.

- Lack of adequate resources, training and motivation to enhance effective extension delivery.

- Bad condition of most rural roads coupled with absence of proper transportation (i.e. vehicles with reefer containers) and storage/park houses infrastructure increases post harvest losses and this significantly impact the amount and quality of fruits exported (a study by Fold and Gough in (2008) estimated fruits lost due to rough roads delays at $10 \%)$.

- Small production units (i.e. majority of farm holdings are less than 2 hectares in size). This prohibits economies of scale use of certain farm machines and therefore causes sub-optimal yields. The size and diversity of farms in the industry makes the widespread usage of certain efficient precision farming machineries unprofitable.

- The industry also suffers from public and private underinvestment (lack of agricultural credit schemes, most banks do not lend to farmers). A more flexible and innovative agricultural financing schemes are needed.

\subsection{Summary of Potentials which could be Explored to Push the Industry Forward}

Besides constraints, some positive and encouraging potentials of the industry were also observed. Below are highlights of some potential opportunities which, when properly utilized could consolidate improvement in the industry:

$>$ Organization of most small scale farms into cooperatives could enhance farmers' access to production credits and other financial schemes. It will also make dissemination of market information more rapid thereby enabling farmers to better prepare and withstand market shocks while enhancing their bargaining power in price negotiations (a model similar to large entities).

Supporting existing and emerging fruits farmers to become efficient and more competitive in niche markets offered by fairtrade and organic markets in the EU could enhance the export earning potential of the industry. This could be achieved through development of quality assurance schemes that gives importers and consumers confidence that fruit from Ghana consistently meet specified safety and quality standards. 
Linking of smallholders to international companies can be beneficial for the industry in terms of capital and technology transfer.

$>$ The industry should take advantage of domestic and sub-regional (neighbouring countries) growing demand of fruits as an opportunity for developing and strengthening the industry.

\subsection{Summary of Policies to Guide Design of Future Intervention Strategies}

The implications of our study for the development of improved productivity strategies to enhance the competitiveness of the industry entail two policy aspects:

1. Pragmatic action plans/programs of improving production technologies in the industry (i.e. modernisation of production techniques in the industry is imperative) and

2. Appropriately finance/investment programs to support the development and dissemination of such efficient modern production technologies.

To make the industry more productive and competitive to enhance its performance in the arena of international trade; it is imperative that, policy makers and all stakeholders cooperate in harmonising the various efforts (i.e. to avoid waste of resources due to program duplication). Such efforts should prioritize the promotion of investment in agricultural research and technology development (R \& D) programs. Similarly, such efforts should incorporate the needs of farmers in the various agro-ecological zones in a way which encourages the use of modern production technologies (like high yielding varieties, labour saving production technologies, etc.).

To sum up, introduction of modern production equipments, efficient logistic service delivery and strong capacity/managerial skills of farmers are essential in transforming the industry into a more competitive force in the arena of international market (i.e. intervention measures which ensures not only output increases but also improvement in quality, reliability in delivery frequency are essential).

Given the high economic and direct/indirect employment creation potential of the industry, it is necessary that policy makers and all stakeholders pay more attention to the fruit crop industry. Even though any potential improvement programs will entail some substantial cost, the potential rewards justify an assertive policy to encourage investment in such programs. 


\subsection{Research Limitation and Potential Extensions}

Even though our analysis shed some insights into the problems facing the fruit producing industry and make some policy recommendations for future intervention programs, it should be stressed that these recommendations are not in any way a panacea to all the problems facing the industry ${ }^{56}$. The ultimate goal of harnessing the maximum output potential of the industry does not depend solely on efficiency improvement of farmers but also improvement in related service sectors such as transport, logistics and port/harbour service sectors. Improvement in the performance of these sectors would assist any transformation measures aim at improving the performance of the industry since they are directly connected to the industry. For instance the volume and quality of fruits exported is generally influenced by conditions (such as temperature, light and humidity) prevailing in park houses or in transporting vehicles as well as road conditions linking rural areas of production to ports or urban processing/buying centres. Thus, improvement in conditions of rural roads, better storage and packaging houses and flexible credit market which enable farmers' access modern production technologies could prove vital in promoting successful and efficient performance of the industry.

While this study identifies and analyses factors affecting performance in the fruit industry using the three major fruits sectors, it omitted many other fruits sectors for which there is a lack of trade data due to the small volumes traded both locally and internationally. However, some of these fruit products are very important for the local economy and food security (e.g. pawpaw) and further research is needed to quantify their significance and contribution in enhancing the performance of the industry. There is also a need to expand this research by collecting additional data on fruit crops that target regional markets and/or domestic markets to reflect appropriately the productive contribution of such emerging fruits sectors (e.g. cashew, citrus and guava) gradually gaining importance also in international markets and how they impact the performance of the industry. To increase the usefulness of such empirical study, consideration needs to be given to the exploration of other data type (e.g. panel and or time series data) to help reveal localized deficits or patterns/trends within the industry. Also modelling the various traditional customs, norms and values which influence production practices in

\footnotetext{
56 Improvement in production efficiency by farmers is necessary but not sufficient in overcoming all the problems facing the industry. Important intermediate processes such as post harvest quality maintenance through packaging, storage, transportation, technical support in marketing etc all contribute to the improvement of the fruit industry. Research into ways of improving these aspects of the industry is therefore highly recommended.
} 
a specific production area is a very difficult task. Hence, further studies with models which capture effects of such cultural variations across the country could be helpful.

Finally, due to lack of data, the influence of very important actors in the industry such as donor agencies, NGOs and multinational fruit companies could not be directly captured in the analysis, this may lead to over simplification of a very complex situation in the fruit industry and so this has to be kept in mind during policy design. 


\section{Bibliography}

Ablordeppey, S. D., \& Arku, J. (2013). Fruit processing companies look offshore for fruits (Business News of Ghana Daily Graphic). Tuesday, 15 October 2013. Retrieved from http://96.127.180.162/ graphicc/business/business-news/9663-fruit-processingcompanies-look-offshore-for-fruits.html\#sthash.Cz0rRS97.dpuf

Achuonjei, P., Pilkes, J., Waardenburg, R., \& Hoogendoorn, B. (2003). Ghana Sustainable horticultural export chain.

Afari-sefa, V. (2007). The dynamics of horticultural export value chains on the livelihood of small farm households in Southern Ghana. African Journal of Agricultural Research, 2(September), 435-440.

Agritrade. (2012). Banana sector: Agritrade Informed Analysis, Expect Opinion Executive brief.

Aigner, D. J., Lovell, C. A. K., \& Schmidt, P. (1977). Formulation and estimation of stochastic frontier production function models. Journal of Econometrics, 6, 21-37.

Amor, T.B., and Muller, C. (2010). Application of Stochastic Production Frontier in the Estimation of Technical Efficiency of Irrigated Agriculture in Tunisia. Agricultural Journal, 5(2), 50 - 56.

Andrew, C. W. (2010). A review of frontier approaches to efficiency and productivity measurement in urban water utilities.

Ashitey, E., Rondon, M. (2012). Assessments of Commododity and Trade Issues. Ghana Exporter Guide 2012.

Battese, G. E., Rambaldi, A. N., \& Wan, G. H. (1997). A Stochastic Frontier Production Function with Flexible Risk Properties. Journal of Productivity Analysis, 8, 269-280. Retrieved from http://dx.doi.org/10.1023/A:1007755604744 
Battese, G. E., \& Rao, D. S. P. (2002). Technology Gap, Efficiency, and a Stochastic Metafrontier Function. International Journal of Business and Economics, 1, 87-93. Retrieved from http://ideas.repec.org/a/ijb/journl/v1y2002i2p87-93.html

Battese, G. E., Rao., D. S. P., \& O’Donnell, C. J. (2004). A Metafrontier Production Function for Estimation of Technical Efficiencies and Technology Gaps for Firms Operating Under Different Technologies. Journal of Productivity Analysis, 21(2002), 91-103.

Battese G.E and T.J. Coelli. (1988). Prediction of Firm-Level Technical Efficiencies with A Generalized Frontier Production Function and Panel Data. Journal of Econometrics, 38(October 1986), 387-399.

Bravo-ureta, B. E., \& Pinheiro, A. E. (1977). Efficiency Analysis of Developing Country Agriculture: A Review of the Frontier Function Literature. Agricultural and Resource Economics Review, 88-101.

Brummer, B., \& Glauben, T. (2004). Measuring and explaining productivity growth: A distance function approach. Jahrbucher Fur Nationalokonomie Und Statistik, 224, 420444. Retrieved from <Go to ISI $>$ ://000223672200003

Brümmer, B., Glauben, T., \& Lu, W. C. (2006). Policy Reform and Productivity Change in Chinese Agriculture: A Distance Function Approach. Journal of Development Economics, 8(August), 28-31. doi:10.1016/j.jdeveco.2005.04.009

Brummer, B., Glauben, T., \& Thijssen, G. (2002). Decomposition of Productivity Growth Using Distance Functions: The Case of Dairy Farms in Three European Countries. American Journal of Agricultural Economics, 84, 628-644.

Coelli, T. (1995). Estimators and Hypothesis Tests for a Stochastic Frontier Function - a Monte-Carlo Analysis. Journal of Productivity Analysis, 6, 247-268. doi:Doi 10.1007/Bf01076978

Coelli, T. (1995). Estimators and hypothesis tests for a stochastic frontier function: A Monte Carlo analysis. Journal of Productivity Analysis, 6, 247-268. doi:10.1007/BF01076978 
Coelli, T. (2005). An introduction to efficiency and productivity analysis. Biometrics (Vol. 41, p. 349). doi:10.2307/2531310

Coelli, T. J. (1995). RECENT DEVELOPMENTS I N FRONTIER MODELLING AND EFFICIENCY MEASUREMENT. Australian Journal of Agricultural Economics, 39(3).

Coelli, T., \& Perelman, S. (2000). Technical efficiency of European railways: a distance function approach. Applied Economics, 32(15), 1967-1976. doi:10.1080/00036840050155896

Coelli, T., Perelman, S., \& Romano, E. (1999). Accounting for Environmental Influences in Stochastic Frontier Models: With Application to International Airlines. Journal of Productivity Analysis, 11, 251-273.

Coelli, T., Rao, D. S. . P., O’Donnel, J., \& Battese, G. E. (2005). An introduction to efficiency and productivity analysis. Biometrics (Vol. 41, p. 349). doi:10.2307/2531310

Dadzie, S. K. N., \& Dasmani, I. (2010). Gender difference and farm level efficiency: Metafrontier production function approach. Journal of Development and Agricultural Economics, 2(December), 441-451.

Debreu, G. (1959). Theory of Value. Capital Class (Vol. 33, pp. 13-29). doi:10.2307/1909300

DG Agric, R. D. (2012). Monitoring Agri-trade Policy The EU and major world players in Fruit and Vegetable Trade. DG Agricuture and Rural Development: Agriculture Trade Analysis Unit., pp. 1-14.

Doornik, J. A. (2008). Econometric Computing Using the Ox Matrix Language Hilary Term 2008 , week 0 , Thu / Fri 1pm.

Eurostat. (2013). Eurostat international trade data. EU Fruit Import from Ghana (2000 2013). (Eurostat is the Offical Statistical Office of the European Union). Retrieved from http://ec.europa.eu/eurostat 
Färe, R., Grosskopf, S., Lovell, C. A. K., \& Pasurka, C. (1989). Multilateral productivity comparisons when some outputs are undesirable: a nonparametric approach. The Review of Economics and Statistics, 71, 90-98. doi:10.2307/1928055

Färe, R., \& Primont, D. (1990). A Distance Function Approach to Multioutput Technologies. Southern Economic Journal, 56(4), 879-891.

Farrell, M. J. (1975). The Measurement of Productive Efficiency. Journal of the Royal Statistical Society, 120(3), 253-290. doi:10.1016/S0377-2217(01)00022-4

Fold, N., \& Gough, K. V. (2008). From smallholders to transnationals: The impact of changing consumer preferences in the EU on Ghana's pineapple sector. Geoforum, 39, 1687-1697. doi:10.1016/j.geoforum.2008.06.004

Ganry, J. (2007). Mango The Next Big Product of Ghana. Tropical and Subtropical Fruits Newsletter.

Gatune, J., Chapman-Kodam, M., Korboe, K., Mulangu, F., \& Rakotoarisoe, M. A. (2013). FAO COMMODITY AND TRADE POLICY RESEARCH WORKING PAPER NO. 41 "Analysis of Trade Impacts on the Fresh Pineapple Sector in Ghana," (41).

GEPC. (2005). Ghana Export Promotion Counci1 (2003 - 2005). Comparison of Export Performance of Non-Traditional Exports in Ghana.

Ghana Forestry Commision. (2006). Ghana's Forests, Timber and Wildlife. Ghana Gazette A newsletter about Ghana's forests, timber and wildlife No. 38, First Quarter 2006, Accra.

Ghana Statistical Service. (2010). Ghana Statistical Service (News Brief) New Series of the Gross Domestic Product ( GDP) Estimates, 1-5.

Grosskopf, S., Fried, H. O., Lovell, C. A. K., \& Schmidt, S. S. (1993). Efficiency and Productivity. The Measurement of Productive Efficiency: Techniques and Applications. New York: Oxford University Press. 
Hayami, Y. (1969). Sources of agricultural productivity gap among selected countries. American Journal of Agricultural Economics, 51, 564 - 575.

Hayami, Y., \& Ruttan, V. W. (1970). KOREAN RICE, TAIWAN RICE, AND JAPANESE AGRICULTURAL STAGNATION: AN ECONOMIC CONSEQUENCE OF COLONIALISM. Quarterly Journal of Economics, 84, 562-589. Retrieved from http://search.ebscohost.com/login.aspx?direct=true $\& d b=b$ th $\& A N=5048340 \&$ site $=$ ehostlive $\&$ scope $=$ site

Hayami, Y., Ruttan, V. W. (1971). Agricultural development: an international perspective. John Hopkins University Press, Baltimore.

Jaeger, P. (2003). Regional Study on Agricultural Trade Facilitation/Export Promotion in SSA. Ghana Horticulture Sector Development Study including Agricultural Sub-Sector Investment Program Restructuring.

Jaeger, P. (2008). Ghana Export Horticulture Cluster Strategic Profile Study Part I - Scoping review. Prepared for World Bank Sustainable Development Network (WB-SDN), The Republic of Ghana Ministry of Food and Agriculture and European Union All ACP Agricultural Commodities.

Jondrow, J., Knox, C. A., Materov, I. S., Schmidt, P., \& Lovell, K. C. A. (1982). ON THE ESTIMATION OF TECHNICAL INEFFICIENCY IN THE STOCHASTIC FRONTIER PRODUCTION FUNCTION MODEL. Journal of Econometrics, 19, 233-238. doi:10.1016/0304-4076(82)90004-5

Kleemann, L. (2011). Organic Pineapple Farming in Ghana - A Good Choice for Smallholders?.

Kleemann, L. (2014). Knowing Where Organic Markets Move Next - An Analysis of Developing Countries in the Pineapple Market. Journal of Economic Literature.

Kodde. D.A. and Palm F.C. (1986). Wald Criterial for Jointly Testing Equality and Inequality Restrictions. Econometrica, 54(5), 1243 - 1248. 
Kyei, L., Foli, G., \& Ankoh, J. (2011). Analysis of factors affecting the technical efficiency of cocoa farmers in the Offinso district -Ashanti region , Ghana Department of Earth and Environmental Science, University for Development Studies ,. American Journal of Social and Management Sciences, 208-216. doi:10.5251/ajsms.2011.2.2.208.216

Lakner, S., Muñoz, T. B., Aedo, E. R., Brümmer, B., Brenes Muñoz, T., \& Rivera Aedo, E. (2012). Technical Efficiency in the Chilean Agribusiness Sector - a Stochastic MetaFrontier Approach. Productivity and Its Impacts on Global Trade (pp. 1-20). Retrieved from http://iatrc.software.umn.edu/activities/symposia/upcomingsymposium.html

Lovell, C.A.K., Richardson, S., Travers, P., Wood, L. . (1994). Resources and Functioning: A new view of Inequality in Australia. Models and Measurement Welfare and Inequality, Berlin. Springer Verlag Press, Germany (Vol. 38, p. 225). doi:10.2307/2683664

Manasseh, D. (2007). The role of certification in fair trade: FAIRTRADE FOUNDATION PRODUCER PROFILE.

Meeusen, W., \& van den Broeck, J. (1977). Technical efficiency and dimension of the firm: Some results on the use of frontier production functions. Empirical Economics, 2, 109122. doi:10.1007/BF01767476

Mensah, A.O., Oehmke, J. F. (2012). Trade and Investment Program for a Competitive Export Economy in ghana, (January), 1-4.

Nishimizu, M., \& Page, J. M. (1982). Total factor productivity growth, technological progress and technical efficiency change: dimensions of productivity change in Yugoslavia, 196578. Economic Journal. doi:10.2307/2232675

Nkamleu, G. B. G., Nyemeck, J., Gockowski, J., Abdul, B., \& John, C. (2010). Technology Gap and Efficiency in Cocoa Production in West and Central Africa: Implications for Cocoa Sector Development. Retrieved from http://core.kmi.open.ac.uk/download/pdf/6429072.pdf

O’Donnell, C. J., Rao, D. S. P., \& Battese, G. E. (2008). Metafrontier frameworks for the study of firm-level efficiencies and technology ratios. Empirical Economics, 34, 231255. doi:10.1007/s00181-007-0119-4 
Okon, U. E., Enete, A. A., \& Bassey, N. E. (2010). Technical Efficiency and its Determinants in Garden Egg ( Solanum Spp ) Production In Uyo Metropolis , Akwa Ibom State , Nigeria. Field Actions Science Report, 1-6.

Onumah, E. E., \& Acquah, H. D. (2010). Frontier analysis of aquaculture farms in the Southern sector of Ghana. World Applied Sciences Journal, 9, 826-835. Retrieved from http://ugspace.ug.edu.gh/handle/123456789/1566

Onumah, E. E., Brümmer, B., \& Hörstgen-Schwark, G. (2010). Elements Which Delimitate Technical Efficiency of Fish Farms in Ghana. Journal of the World Aquaculture Society, 41(4), 506-518.

Onumah, J. A., Onumah, E. E., Al-hassan, R.M., \& Brümmer, B. (2013). Meta-frontier analysis of organic and conventional cocoa production in Ghana. Agriculture Economics CZECH, 6(59), 271-280.

Pay, E. (2009). THE MARKET FOR ORGANIC AND FAIR-TRADE MANGOES AND PINEAPPLES. Study prepared in the framework of FAO project GCP / RAF / 404 / GER. " Increasing incomes and food security of small farmers in West and Central Africa through exports of organic and fair-trad, (September).

Phoebe, K., Bjorndal, T., \& Pascoe, S. (2002). Multi-Output Distance Function for the North Sea Beam Trawl Fishery. Journal of Economic Literature, 44(22), 1-28.

Rao, E. J. O. E., Brümmer, B., Qaim, M., \& Brummer, B. (2012). Farmer Participation in Supermarket Channels, Production Technology, and Efficiency: The Case of Vegetables in Kenya. American Journal of ..., 94(February), 891-912. doi:10.1093/ajae/aas024

Safa-Dedeh, S. (2007). Fresh produce from Ghana: poised to be the preferred consumer choice ., 1-3.

Taylor, T. G., Drummond, H. E., \& Gomes, A. T. (1986). Agricultural Credit Programs and Production Efficiency: An Analysis of Traditional Farming in Southeastern Minas Gerais, Brazil. American Journal of Agricultural Economics, 68, 110-119. Retrieved from http://www.jstor.org/stable/1241655 
Trade maps. (2013). Trade Maps international trade statistics and data.

USAID/TIPCEE. (2005). Ghana's High Value Horticulture.

USAID/TIPCEE. (2009). Trade and Investment Program for a Competitive Export Economy TIPCEE Components, (February).

Villano, R., Boshrabadi, H. M., \& Fleming, E. (2010). When Is Metafrontier Analysis Appropriate? An Example of Varietal Differences in Pistachio Production in Iran. Journal of Agricultural Science and Technology, 12, 379-389.

Wang, H. J., \& Schmidt, P. (2002). One-step and two-step estimation of the effects of exogenous variables on technical efficiency levels. Journal of Productivity Analysis, $18(2), 129-144$.

Wardy, W., Saalia, F. K., Steiner-asiedu, M., \& Budu, A. S. (2009). A comparison of some physical , chemical and sensory attributes of three pineapple ( A nanas comosus ) varieties grown in Ghana. African Journal of Food Science, 3(1), 22-25.

Wolter, D. (2008). Ghana Agriculture is Becoming a Business. Business for Development. OECD Development Centre.

Zakari, A. K. (2012). Ghana National Mango Study: Support of the PACT II Program and the International Trade Centre (Geneva). 


\section{2 field Survey questionnaire}

Please introduce yourself to respondent: I am... from ... gathering data on behalf of Mr. Amos Mensah, (a Ph.D. student of the above mention university) on how farmers cultivate fruit crop in Ghana. Your responses are very helpful to improve future development policies and programs. Your responses will be strictly used for research purposes and will be treated as confidential. I respect all answers you give and appreciate your cooperation.

Do your HH grow any of the following fruit crops (pineapple, Banana, Mango) commercially? Yes ( ) No ( )

(If no, please stop the interview here!) If Yes, Please mention the type of fruit crop(s):

Date of interview (day/month/year):

Name of interviewer:

Mobile number:

Name of Supervisor:

\section{Location details}

Region:

District:

sub district

name of village

\section{Part I: Basic Household Characteristics of Farmer}

\subsection{Household information}

\begin{tabular}{|c|c|c|c|c|c|c|c|c|c|c|c|}
\hline \multirow{3}{*}{$\begin{array}{l}\text { Is respondent } \\
\text { the head of } \\
\text { the house- } \\
\text { hold? }\end{array}$} & \multirow{3}{*}{$\begin{array}{l}\text { If NO, please } \\
\text { state relation } \\
\text { of respondent } \\
\text { to household } \\
\text { head } \\
\text { (Code 1) }\end{array}$} & \multirow[t]{3}{*}{$\begin{array}{l}\text { Age of } \\
\text { household } \\
\text { head }\end{array}$} & \multirow[t]{3}{*}{$\begin{array}{l}\text { Gender of } \\
\text { household } \\
\text { head }\end{array}$} & \multirow{3}{*}{$\begin{array}{l}\text { Marital } \\
\text { status } \\
\\
\text { (Code2) }\end{array}$} & \multirow{2}{*}{\multicolumn{2}{|c|}{$\begin{array}{l}\text { Household Size and } \\
\text { gender distribution }\end{array}$}} & \multirow{2}{*}{\multicolumn{2}{|c|}{$\begin{array}{l}\text { Number of adult } \\
\text { resident in } \underline{\mathbf{H h}} \text { and } \\
\text { helping in farming } \\
\text { activities }\end{array}$}} & \multicolumn{3}{|c|}{$\begin{array}{l}\text { Household Composition: please state } \\
\text { the number of household members } \\
\text {...... Years of age }\end{array}$} \\
\hline & & & & & & & & & \multirow{2}{*}{$\begin{array}{l}\text { Less than } \\
<18\end{array}$} & \multirow{2}{*}{$\begin{array}{c}\text { between } \\
18-50\end{array}$} & \multirow{2}{*}{$\begin{array}{c}\text { Greater than } \\
>50\end{array}$} \\
\hline & & & & & Male(s) & Female(s) & Male(s) & Female(s) & & & \\
\hline Yes( ) No( ) & & & $\mathrm{M}(\mathrm{f}) \mathrm{F}(\mathrm{)}$ & & & & & & & & \\
\hline
\end{tabular}

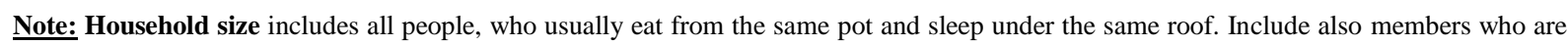
absent for less than two months!

\begin{tabular}{|l|l|}
\hline \multicolumn{2}{|l|}{ Code 1: Relation with head of family } \\
\hline 1. husband/wife & 7. father/mother-in-law \\
2. father/mother & 8. cousin \\
3. grandfather/-mother & 9. uncle/aunt \\
4. child & 10. brother/sister-in-law \\
5. grand-child & 11. nephew/nice \\
6. brother/sister & $\begin{array}{l}\text { 12. no relation with fam. } \\
\text { head }\end{array}$
\end{tabular}

\section{Code 2: marital status}

1.Married

2.Divorced

3.Separated

4.Widow or widower

5.Never married 


\subsection{Educational status (human capital)}

\begin{tabular}{|l|l|l|l|l|l|}
\hline $\begin{array}{l}\text { Can respondent read and } \\
\text { write? }\end{array}$ & $\begin{array}{l}\text { Please state number of } \\
\text { years of schooling }\end{array}$ & $\begin{array}{l}\text { Please state final } \\
\text { education level } \\
\text { reached (Code3) }\end{array}$ & $\begin{array}{l}\text { Number of years of } \\
\text { farming (farming } \\
\text { experience) }\end{array}$ & $\begin{array}{l}\text { Number of } \\
\text { years as Fruit } \\
\text { crop farmer }\end{array}$ & $\begin{array}{l}\text { How many people in the } \\
\text { hh can read and write }\end{array}$ \\
\hline Yes( ) No( ) & & & & \\
\hline
\end{tabular}

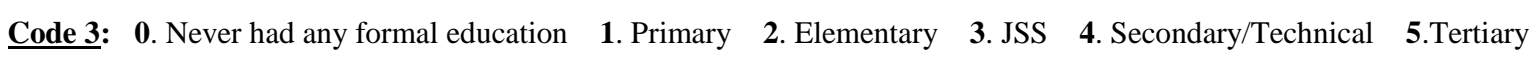

\subsection{Access to water and electricity}

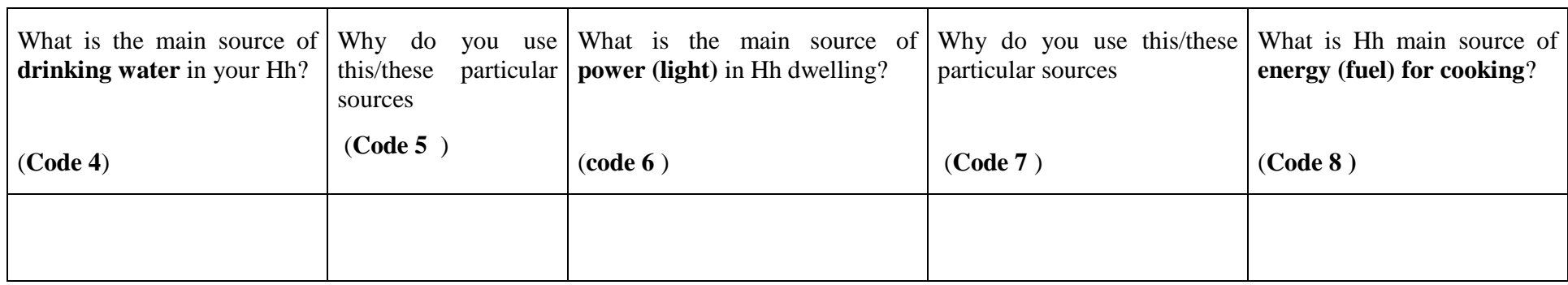

\begin{tabular}{|c|c|c|c|c|}
\hline Code 4 & Code 5 & $\underline{\text { Code } 6}$ & $\underline{\text { Code } 7}$ & $\underline{\text { Code } 8}$ \\
\hline 1. Bottled water & $\begin{array}{l}\text { 1.Because it is the only source } \\
\text { available in this area }\end{array}$ & 1.Electricity & $\begin{array}{l}\text { 1. Because it is the only source } \\
\text { available in this area }\end{array}$ & 1. Fire wood/charcoal \\
\hline 2. water in plastic & $\begin{array}{l}\text { 2. Because it is convenient and } \\
\text { affordable }\end{array}$ & $\begin{array}{l}\text { 2. generator } \\
\text { 3. kerosene lamp }\end{array}$ & $\begin{array}{l}\text { 2. Because it is convenient and } \\
\text { affordable }\end{array}$ & $\begin{array}{l}\text { 2. kerosene } \\
\text { 3. Gas }\end{array}$ \\
\hline $\begin{array}{l}\text { bag } \\
\text { 3. Tab or pipe born water } \\
\text { 4. Well }\end{array}$ & $\begin{array}{l}\text { 3. Because of health and } \\
\text { sanitation reasons } \\
\text { 4. Because the distance to } \\
\text { source is shorter }\end{array}$ & $\begin{array}{l}\text { 4. candle } \\
\text { 5. Other reasons please } \\
\text { specify.... }\end{array}$ & $\begin{array}{l}\text { 3. Because of health reasons } \\
\text { 4. Other reasons please spec- } \\
\text { ify... }\end{array}$ & $\begin{array}{l}\text { 4. Electricity } \\
\text { 5. Dried animal waste } \\
\text { 6. Others, please specify... }\end{array}$ \\
\hline 5. River & 5. Others please specify..... & & & \\
\hline 6. Lake & & & & \\
\hline 7. Pond & & & & \\
\hline 8. Rain & & & & \\
\hline 5. Others please specify..... & & & & \\
\hline
\end{tabular}




\subsection{Access to other basic social facilities}

\begin{tabular}{|c|c|c|c|c|c|}
\hline Facility & $\begin{array}{l}\text { Do you or any of } \\
\text { HH-member use } \\
\text { facility? } \\
\text { Yes (1) No (0) }\end{array}$ & $\begin{array}{l}\text { If no, why don't } \\
\text { you use facility? } \\
\text { (Code 9) }\end{array}$ & $\begin{array}{l}\text { How far is facility } \\
\text { from your house? } \\
(\mathrm{km})\end{array}$ & $\begin{array}{l}\text { How do you normally } \\
\text { travel to facility? } \\
\text { (Code 10) }\end{array}$ & $\begin{array}{l}\text { How long does it take to get to } \\
\text { facility? } \\
\text { (minutes or hours or days) }\end{array}$ \\
\hline Schools (primary \&se & & & & & \\
\hline Health centers (clinic/ & & & & & \\
\hline Bank (rural \& comme & & & & & \\
\hline Post office & & & & & \\
\hline Police station & & & & & \\
\hline Market place & & & & & \\
\hline Agric Extension Offic & & & & & \\
\hline Public Toilet Facility & & & & & \\
\hline
\end{tabular}

\begin{tabular}{|c|c|}
\hline Code 9: facility use & Code 10: travel to facility \\
\hline 1. don't need to use & 1. walk \\
\hline 2. too far away & 2. bicycle \\
\hline 3. too expensive & 3. car \\
\hline 4. don't know & 4. bus \\
\hline 5. we don't have such & 5. riding horse \\
\hline facility in our area & 6. motorbike \\
\hline 4. other (specify) & 7. other (specify) \\
\hline
\end{tabular}




\subsection{Household time allocation for farm and Off-Farm activities}

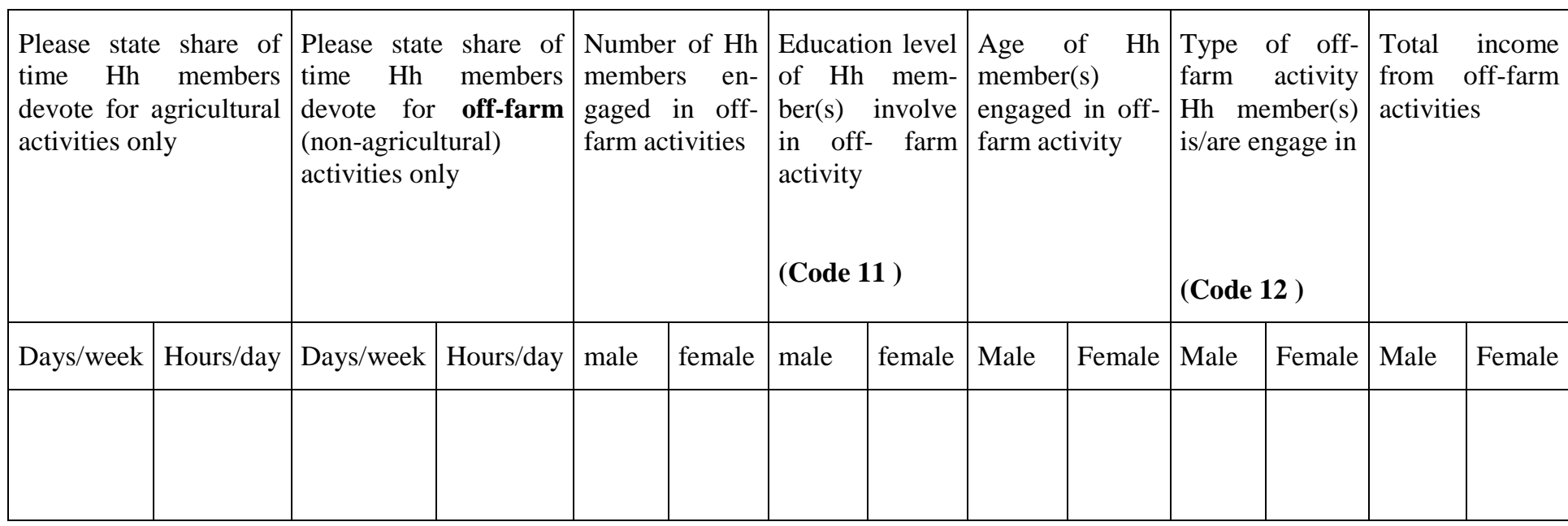

\section{Code:11}

1. No formal education

2. Up to primary school level

3. Up to secondary/technical school level

4. Up tertiary education level

\section{Code:12}

1. Salary/wage employment (e.g. nurse, teacher, doctor, agric officer, driver etc)

2. Self employed ( e.g. carpenter, mason, painter, auto mechanic etc)

3. Petty trader/Retailing (e.g. kiosk or store operator, buying and selling at road side or market etc)

4. Others, please specify

\subsection{Access and Use of credit}

\begin{tabular}{|c|c|c|c|c|c|c|c|c|}
\hline $\begin{array}{l}\text { If you would need a } \\
\text { loan today, could you } \\
\text { get one? (Access to } \\
\text { credit) }\end{array}$ & $\begin{array}{l}\text { If No, please } \\
\text { provide } \\
\text { reasons } \\
\\
\text { (Code 13) }\end{array}$ & $\begin{array}{l}\text { Did you obtain } \\
\text { any credit during } \\
\text { the last two }(2) \\
\text { years? (Credit } \\
\text { status) }\end{array}$ & $\begin{array}{l}\text { If yes, Please } \\
\text { state credit } \\
\text { source } \\
\\
\text { (Code 14) }\end{array}$ & $\begin{array}{l}\text { Could you get } \\
\text { the full amount } \\
\text { you applied for? } \\
\text { (credit con- } \\
\text { strained) }\end{array}$ & $\begin{array}{l}\text { What was } \\
\text { the total } \\
\text { amount } \\
\text { borrowed? }\end{array}$ & $\begin{array}{l}\text { How much do } \\
\text { you have to } \\
\text { pay back? } \\
\text { i.e. } \\
\text { (loan+interest) }\end{array}$ & $\begin{array}{lr}\text { How } & \text { much } \\
\text { time } & \text { did } \\
\text { you } & \text { have } \\
\text { to } & \text { pay } \\
\text { back } & \text { the } \\
\text { loan? }\end{array}$ & $\begin{array}{l}\text { Reason(s) for } \\
\text { borrowing/ } \\
\text { taking credit } \\
\\
\text { (Code 15) }\end{array}$ \\
\hline Yes( ) No( ) & & Yes( ) No( ) & & Yes( ) No( ) & & & & \\
\hline
\end{tabular}




\begin{tabular}{|l|l|l|}
\hline Code 13: Reasons: & Code 14: & Code 15: \\
1.lack of collateral & 1.Commercial banks & 1.consumption (food) \\
2.could not repay last loan & 2.Rural banks & 2. purchase of agricultural inputs \\
3.political & 3.Credit unions (susu groups) & 3. purchase of household items (tv, radio etc) \\
4.religious & 4.Governmental credit programme & 4. paying of medical and other bills \\
5.ethnic & 5.NGO credit programme & 5. others (please specify) \\
6.other reasons(please specify) & 6.Shopkeeper/traders in the village/town & \\
& 7.Relatives & \\
& 8.Friends & \\
& 9. Money lenders & \\
& 9. Other persons outside the village/town & \\
& & \\
\hline
\end{tabular}

\subsection{Are you a member of any credit or saving group? Yes ( ) No ( )}

\subsection{If yes, please mention which group/institution}

\subsection{Income sources}

\begin{tabular}{|l|l|l|l|l|}
\hline $\begin{array}{l}\text { What is the main source(s) of Household } \\
\text { cash income? } \\
\text { (Code 16) }\end{array}$ & $\begin{array}{l}\text { Please state (in \%) how much of HH } \\
\text { cash income is from }\end{array}$ & $\begin{array}{l}\text { From agricultural cash income, please state (in \%) how much is } \\
\text { from }\end{array}$ \\
\hline \multirow{2}{*}{$\begin{array}{l}\text { Agricultural } \\
\text { activities only }\end{array}$} & $\begin{array}{l}\text { Non-Agricultural } \\
\text { wage income }\end{array}$ & $\begin{array}{l}\text { Fruit crop production (i.e. } \\
\text { banana, pineapple, mango, } \\
\text { pawpaw etc) }\end{array}$ & $\begin{array}{l}\text { Non-fruit crop production (i.e. cereals, } \\
\text { vegetables etc) }\end{array}$ \\
\cline { 2 - 4 } & & & \\
\hline
\end{tabular}


Do you or any member of your household posses any of the following?

\begin{tabular}{|c|c|c|c|c|c|c|}
\hline Item & Yes & No & Item & Yes & No & How many \\
\hline 1. Car/Bus & & & 1. Cattle & & & \\
\hline 2. Motor bike & & & 2. Donkey & & & \\
\hline 3. Bicycle & & & 3. Horse & & & \\
\hline 4. Own house & & & 4. Sheep & & & \\
\hline 5.Television & & & 5. Goat & & & \\
\hline 6. Refrigerator & & & 6. Chicken & & & \\
\hline 7. Tape recorder & & & 7. Guinea fowl & & & \\
\hline 8. Mobile phone & & & 8. Others please specify... & & & \\
\hline
\end{tabular}

\subsection{Access to road and extension services}

\begin{tabular}{|c|c|c|c|c|c|c|c|}
\hline $\begin{array}{l}\text { How far is } \\
\text { your farm } \\
\text { to the next } \\
\text { usable } \\
\text { road? }(\mathrm{km})\end{array}$ & $\begin{array}{l}\text { How would you } \\
\text { describe the condi- } \\
\text { tion of the road net- } \\
\text { work linking your } \\
\text { farm to the district } \\
\text { capital? } \\
\text { (Code 17) }\end{array}$ & $\begin{array}{l}\text { How long does } \\
\text { it take to reach } \\
\text { the district } \\
\text { extension } \\
\text { office? (hours) }\end{array}$ & $\begin{array}{l}\text { Have you ever } \\
\text { seek any assis- } \\
\text { tance/advice } \\
\text { from an exten- } \\
\text { sion worker? }\end{array}$ & $\begin{array}{l}\text { If No, } \\
\text { please } \\
\text { state rea- } \\
\text { sons } \\
\\
\\
\\
\text { (Code 18) }\end{array}$ & $\begin{array}{l}\text { How many } \\
\text { times did an } \\
\text { extension } \\
\text { worker visit } \\
\text { you in the } \\
\text { last } 12 \\
\text { months? }\end{array}$ & $\begin{array}{l}\text { What is the } \\
\text { main activity } \\
\text { of your meet- } \\
\text { ings? } \\
\text { (Code 19) }\end{array}$ & $\begin{array}{l}\text { Do you use (at } \\
\text { least) one of } \\
\text { recommended } \\
\text { practices? } \\
\\
\text { (Code 20) }\end{array}$ \\
\hline & & & Yes ( ) No ( ) & & & & \\
\hline
\end{tabular}

\begin{tabular}{|l|l|l|l|}
\hline $\begin{array}{l}\text { Code 17 } \\
\text { 1. Good }\end{array}$ & $\underline{\text { Code 18 }}$ & $\underline{\text { Code 19 }}$ & Code 20 \\
2. Bad & $\begin{array}{l}\text { 1. Not interested } \\
\text { 2. Too far }\end{array}$ & 2. Information sharing, e.g. input usage & 2. Partly \\
$\begin{array}{l}\text { 3. Deplorable } \\
\text { 4. Unusable }\end{array}$ & $\begin{array}{l}\text { 3. Don't know where extension office is } \\
\text { 4. Not enough time }\end{array}$ & 3. Others, please specify & 3. No, not at all \\
5. Others, please specify & & 4. Others please specify \\
\hline
\end{tabular}




\subsection{Social capital}

\begin{tabular}{|l|l|l|l|l|}
\hline $\begin{array}{l}\text { Are you or any member of your Hh member of any } \\
\text { of the following associations /organisation /groups? }\end{array}$ & Yes & No & $\begin{array}{l}\text { How often do you } \\
\text { attend association } \\
\text { meetings (num- } \\
\text { ber/month?) }\end{array}$ & $\begin{array}{l}\text { Please state any reason(s) or benefits of } \\
\text { being a member of this/these associa- } \\
\text { tion } \\
\text { (Code 21) }\end{array}$ \\
\hline Farmers association/groups & & & & \\
\hline Religious organisation & & & & \\
\hline Credit and savings group & & & & \\
\hline Community/neighbourhood committee & & & & \\
\hline Political party & & & & \\
\hline Professional association & & & & \\
\hline
\end{tabular}

\section{Code 39:}

1. Credit 2. Market information

4. Solidarity and moral support community

7. Others, please specify
3. Information on new farm technology or management practice

5. Feeling of belonging or being a part

6. Safe guarding/protecting the

\subsection{Agricultural Information Sources}

\begin{tabular}{|c|c|c|c|}
\hline \multirow[t]{9}{*}{$\begin{array}{l}\text { Please mention how you usually } \\
\text { hear/learn of New production tech- } \\
\text { nology (e.g. new variety, new } \\
\text { chemicals, new farming practices } \\
\text { etc) }\end{array}$} & $\begin{array}{l}\text { How would you rank the following information } \\
\text { sources? } \\
1 \text { = very helpful } \\
2 \text { = not helpful at all }\end{array}$ & \multicolumn{2}{|c|}{$\begin{array}{l}\text { How often do you receive agricultural information } \\
\text { from these sources? } \\
\qquad 1 \text { = very often } 2=\text { not often }\end{array}$} \\
\hline & $\begin{array}{l}\text { Mass media (i.e. TV, Radio, News } \\
\text { papers) }\end{array}$ & $\begin{array}{l}\text { Mass media (i.e. TV, Radio, News } \\
\text { papers) }\end{array}$ & \\
\hline & Extension officers & Extension officers & \\
\hline & Family and relatives & Family and relatives & \\
\hline & Farm neighbours & Farm neighbours & \\
\hline & Input dealers & Input dealers & \\
\hline & Farmers cooperative /association & Farmers cooperative /association & \\
\hline & NGOs & NGOs & \\
\hline & Market organisation & Market organisation & \\
\hline
\end{tabular}




\section{Part II: Input Data}

\subsection{Land access, ownership and use}

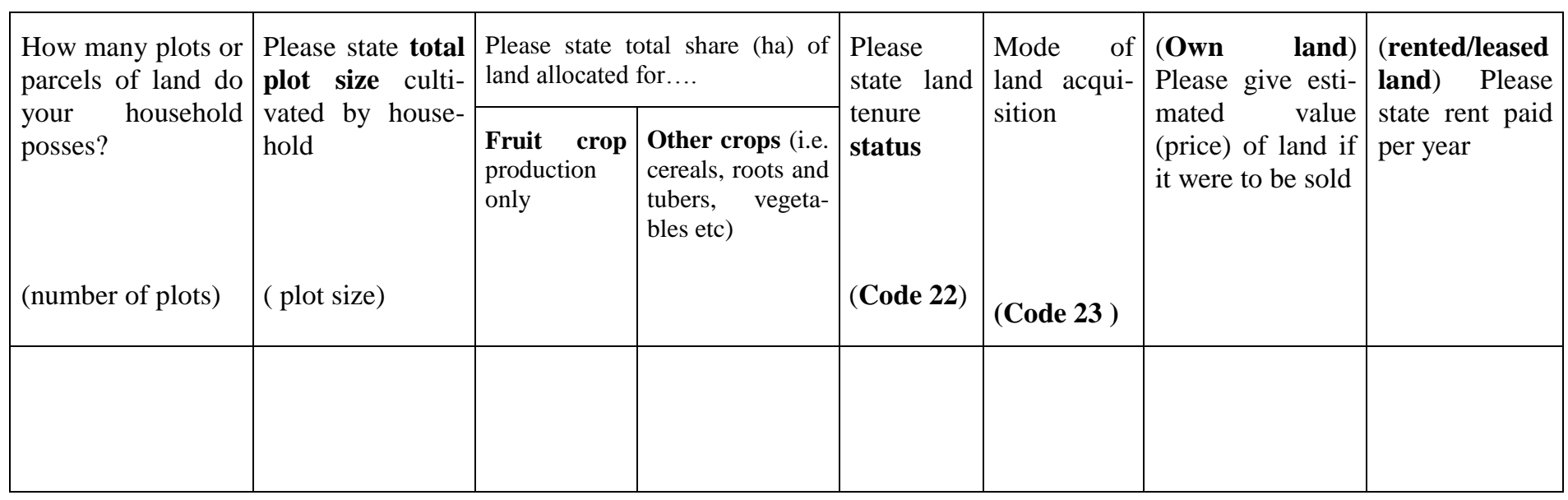

\begin{tabular}{|l|l|}
\hline$\underline{\text { Code 22 }}$ & $\underline{\underline{\text { Oode 23 }}}$ \\
1. Own land & 1. Granted by local leader/chief etc \\
2. Rented/lease land & 2. Inherited \\
3. Shared family land & 3. Through family of spouse \\
4. Others please specify.... & 4. Purchased with official title \\
& 5. Purchased without any title \\
& 6. Leased \\
& 7. Renting \\
& 8. Others please specify.... \\
\hline
\end{tabular}

\section{0 soil quality measures}

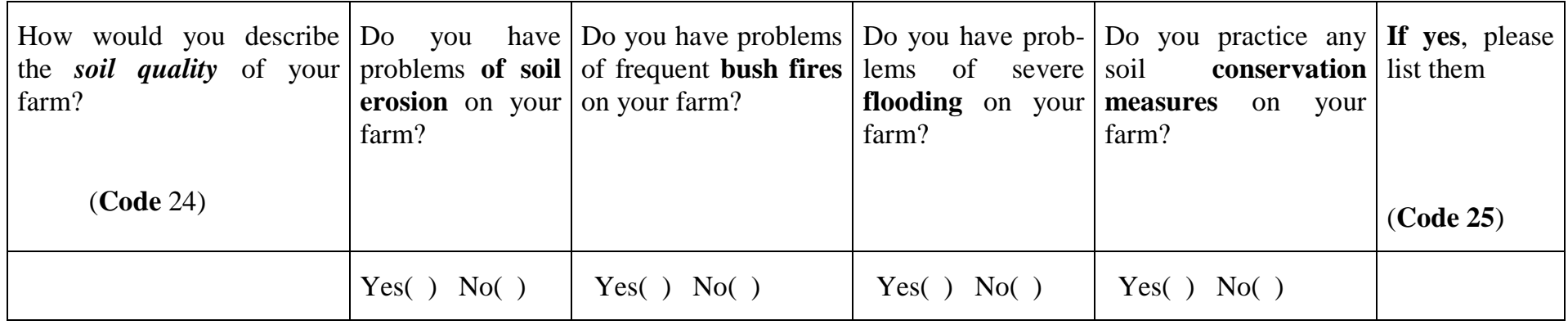

\begin{tabular}{|l|l|}
\hline Code 24 & $\underline{\text { Code } 25}$ \\
$\begin{array}{l}\text { 1. Very fertile, } \\
\text { 2. medium fertile, }\end{array}$ & $\begin{array}{l}\text { 1. intercropping with legumes } \\
\text { 2. use of compost }\end{array}$ \\
\hline
\end{tabular}




\begin{tabular}{|l|l|}
\hline 3. less fertile & 3. manure or crop residues \\
& 4. cover crops \\
& 5. terracing \\
& 6. building of barriers \\
& 7. drainage \\
& 8. fences \\
& 9. others please specify \\
\hline
\end{tabular}

\subsection{Fruit Crop production activities}

\begin{tabular}{|l|l|l|l|l|}
\hline $\begin{array}{l}\text { Please mention the main Fruit(s) crop } \\
\text { cultivated on your farm } \\
\text { (Banana, pineapple, mango) }\end{array}$ & $\begin{array}{l}\text { Please state the age } \\
\text { of the plantation(s) }\end{array}$ & $\begin{array}{l}\text { At what age do the plants } \\
\text { start production? } \\
\text { (age at first harvest) }\end{array}$ & $\begin{array}{l}\text { At what age do you } \\
\text { expect the plants to } \\
\text { reach their peak } \\
\text { production limit? }\end{array}$ & $\begin{array}{l}\text { What is the crop density of } \\
\text { your plantation? }\end{array}$ \\
\hline (i.e. number of plants/hectare)
\end{tabular}

\subsection{Cultivation of other crop(s)}

\begin{tabular}{|l|l|l|l|l|}
\hline $\begin{array}{l}\text { Apart from fruits, Please mention which other crop(s) you cultivate either on plantations or adjoining } \\
\text { fields (measure of crop diversification) }\end{array}$ & $\begin{array}{l}\text { Please give reason(s) for } \\
\text { cultivating these crops } \\
\text { (Code 30) }\end{array}$ \\
\hline $\begin{array}{l}\text { Cereals } \\
\text { (code 26) }\end{array}$ & $\begin{array}{l}\text { Vegetables } \\
\text { (Code 27) }\end{array}$ & $\begin{array}{l}\text { Roots and tubers } \\
\text { (Code 28) }\end{array}$ & $\begin{array}{l}\text { Spices } \\
\text { (Code 29) }\end{array}$ & \\
\hline & & & \\
\end{tabular}

\begin{tabular}{|c|c|c|c|c|}
\hline Code 26 & Code 27 & Code 28 & Code 29 & $\underline{\text { Code } 30}$ \\
\hline 1. Maize & 1. Groundnut & 1. Yam & 1. Black pepper & 1. Sold to supplement household \\
\hline 2. Rice & 2. Pepper & 2. Cassava & 2. Ginger & income \\
\hline 3. Wheat & 3. Tomato & 3. Potatoes & 3. Garlic & 2. Produce mainly for household \\
\hline 4. Millet & 4. Onion & 4. Cocoyam & 4.Pumpkin seeds (egusi) & consumption \\
\hline 5. Sorghum & 5. Garden egg & 5. Others (please & 5. Others (please specify) & 3. Soil conservation purposes \\
\hline \multirow[t]{2}{*}{ 6. Others (please specify) } & 6. Okra & & & 4. Parts are sold and the rest are \\
\hline & 7. Others (please specify) & & & consumed \\
\hline
\end{tabular}




\subsection{Labour requirement in fruit crop production}

\begin{tabular}{|l|l|l|l|l|l|l|}
\hline Farm activity & $\begin{array}{l}\text { Please state the number } \\
\text { of farm labours used for } \\
\text { each of these production } \\
\text { activities }\end{array}$ & $\begin{array}{l}\text { Of this number, how } \\
\text { many are/is }\end{array}$ & $\begin{array}{l}\text { Number of } \\
\text { days required } \\
\text { to complete } \\
\text { hired factivity } \\
\text { labours }\end{array}$ & $\begin{array}{l}\text { family } \\
\text { hours/day do } \\
\text { labours spend on the } \\
\text { farm working? }\end{array}$ & $\begin{array}{l}\text { Cost of hired } \\
\text { labour per day } \\
\text { (cedis/day) }\end{array}$ \\
\hline Land preparation & & & & & & \\
\hline Planting & & & & & & \\
\hline Shading/staking/holing & & & & & & \\
\hline $\begin{array}{l}\text { Fertilizer/manure appli- } \\
\text { cation }\end{array}$ & & & & & & \\
\hline Weed control & & & & & & \\
\hline Dieses/pest control & & & & & & \\
\hline Irrigation & & & & & \\
\hline pruning & & & & & \\
\hline
\end{tabular}

\subsection{Access and utilization of farm inputs}

\begin{tabular}{|c|c|c|c|c|c|c|c|}
\hline \multirow[t]{2}{*}{ inputs } & \multirow[t]{2}{*}{$\begin{array}{l}\text { Please indicate } \\
\text { which of the ff } \\
\text { inputs is/are ap- } \\
\text { plied during pro- } \\
\text { duction season. }\end{array}$} & \multirow[t]{2}{*}{$\begin{array}{l}\text { How often do } \\
\text { you apply } \\
\text { these inputs } \\
\text { in a produc- } \\
\text { tion season }\end{array}$} & \multirow[t]{2}{*}{$\begin{array}{l}\text { quantities } \\
\text { of applied } \\
\text { inputs } \\
\text { per } \\
\text { farm(plot) } \\
\text { in a season }\end{array}$} & \multirow{2}{*}{$\begin{array}{l}\text { Can you please } \\
\text { tell me how } \\
\text { much was the } \\
\text { input prices for } \\
\text { this year? } \\
\text { (i.e. cedis/bag or } \\
\text { bottle etc) }\end{array}$} & \multicolumn{2}{|c|}{$\begin{array}{l}\text { Can you please } \\
\text { tell me how } \\
\text { much money you } \\
\text { invested on these } \\
\text { inputs }\end{array}$} & \multirow{2}{*}{$\begin{array}{l}\text { How much do } \\
\text { you intend to } \\
\text { invest on these } \\
\text { inputs } \\
\text { Next year }\end{array}$} \\
\hline & & & & & $\begin{array}{l}\text { Last } \\
\text { year }\end{array}$ & $\begin{array}{l}\text { This } \\
\text { year }\end{array}$ & \\
\hline \multicolumn{8}{|c|}{$\begin{array}{l}\text { Fertilizer (urea, phos- } \\
\text { phate, NPK etc) }\end{array}$} \\
\hline \multicolumn{8}{|l|}{ Organic manure } \\
\hline \multicolumn{8}{|l|}{ Pesticide } \\
\hline \multicolumn{8}{|l|}{ Fungicide } \\
\hline \multicolumn{8}{|l|}{ Insecticide } \\
\hline Weedicide/herbicide & & & & & & & \\
\hline
\end{tabular}




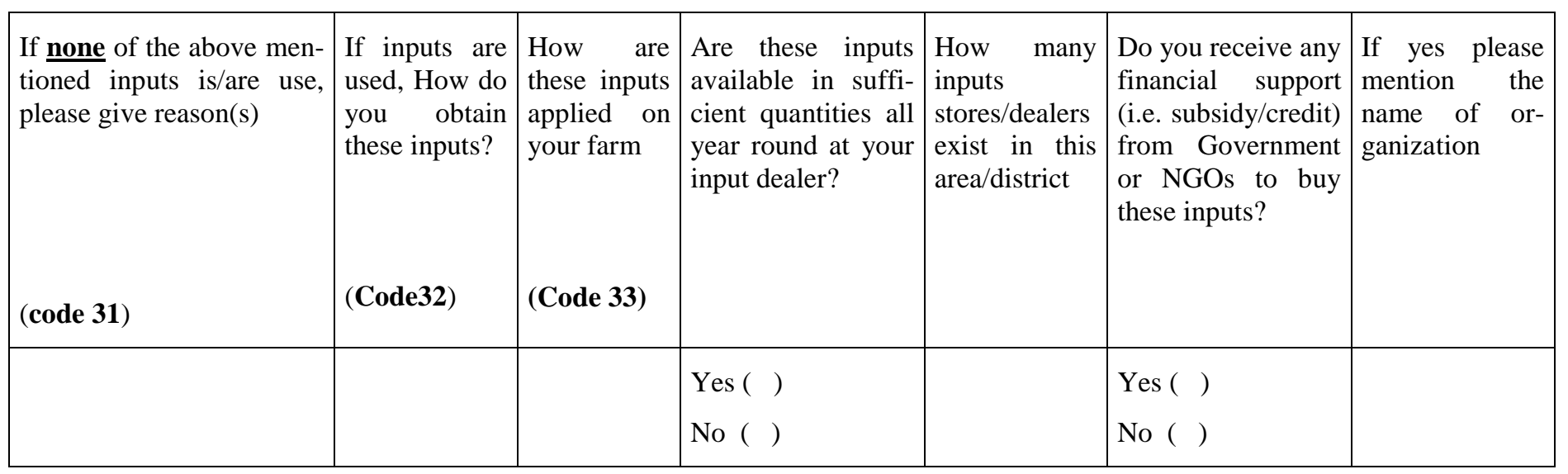

\begin{tabular}{|c|c|c|}
\hline$\underline{\text { Code } 31}$ & $\underline{\text { Code } 32}$ & $\underline{\text { Code } 33}$ \\
\hline 1. Too expensive & 1. Buying from traders in local shops or in town & 1. Manual application using hand and cans \\
\hline 2. No knowledge of use & 2. Buying from extension workers/NGOs at market price & 2. Tractor mounted with spraying machine \\
\hline & 3. Buying from extension workers/NGOs at subsidized price & 3.Motorised backpack spraying machine \\
\hline 4. Not necessary & 4. Receiving from extension workers/NGOs for free & 4. Manual backpack spraying machine \\
\hline $\begin{array}{l}\text { 5. Converting farm to organic system } \\
\text { 5. Others, please specify }\end{array}$ & 5. Others, please specify & 5. Others, please specify \\
\hline
\end{tabular}

\subsection{Please indicate the type of planting material used, name of plant variety, quantity ap- plied and the cost (expenditure) incurred}

\begin{tabular}{|c|c|c|c|c|c|}
\hline & $\begin{array}{l}\text { Type of planting } \\
\text { material used* }\end{array}$ & Quantity (kg or Nr/ha) & Cost (cedis/kg or ha) & $\begin{array}{l}\text { Name of variety } \\
\text { (botanic name)\# }\end{array}$ & $\begin{array}{l}\text { Are you using } \\
\text { RHYV or LV }\end{array}$ \\
\hline \multicolumn{6}{|c|}{ Pineapple } \\
\hline \multicolumn{6}{|l|}{ Banana } \\
\hline \multicolumn{6}{|l|}{ Mango } \\
\hline \multicolumn{6}{|c|}{$\begin{array}{l}\text { *types of planting material: (1)seeds, (2)seedlings, (3)grafted seedlings, (4)crowns, (5)slips, (6)suckers from mother plant, (7)pla } \\
\text { §Please use RHYV or LV to indicate whether the variety planted is a } \underline{\text { Recommended High Yielding Variety or a Local Variety }} \\
\text { \#Variety name: pineapple(MD2 or Smooth cayenne etc), Banana(Cavendish or Gros Michel etc), mango(alphonso or kent etc) }\end{array}$} \\
\hline
\end{tabular}


20.0 Type of farm implement and/or animals used for production

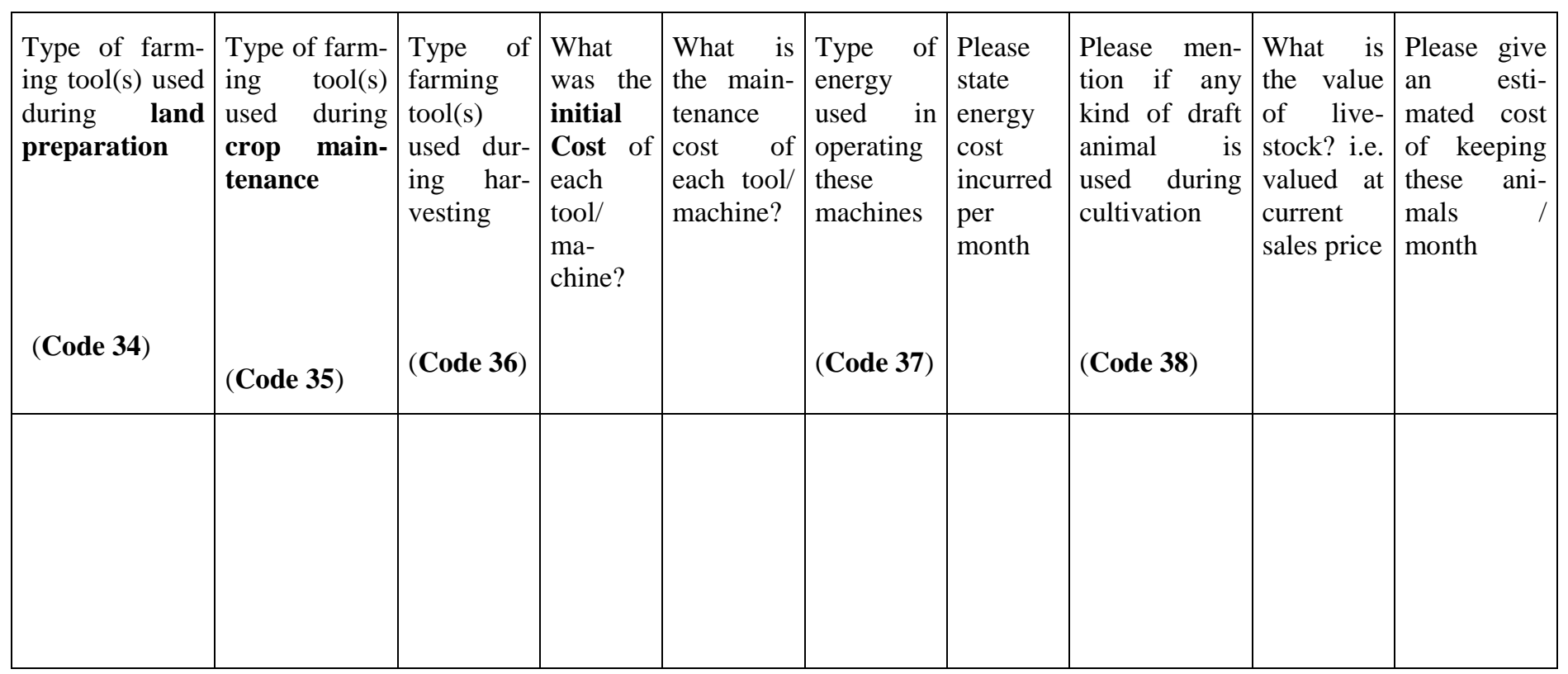

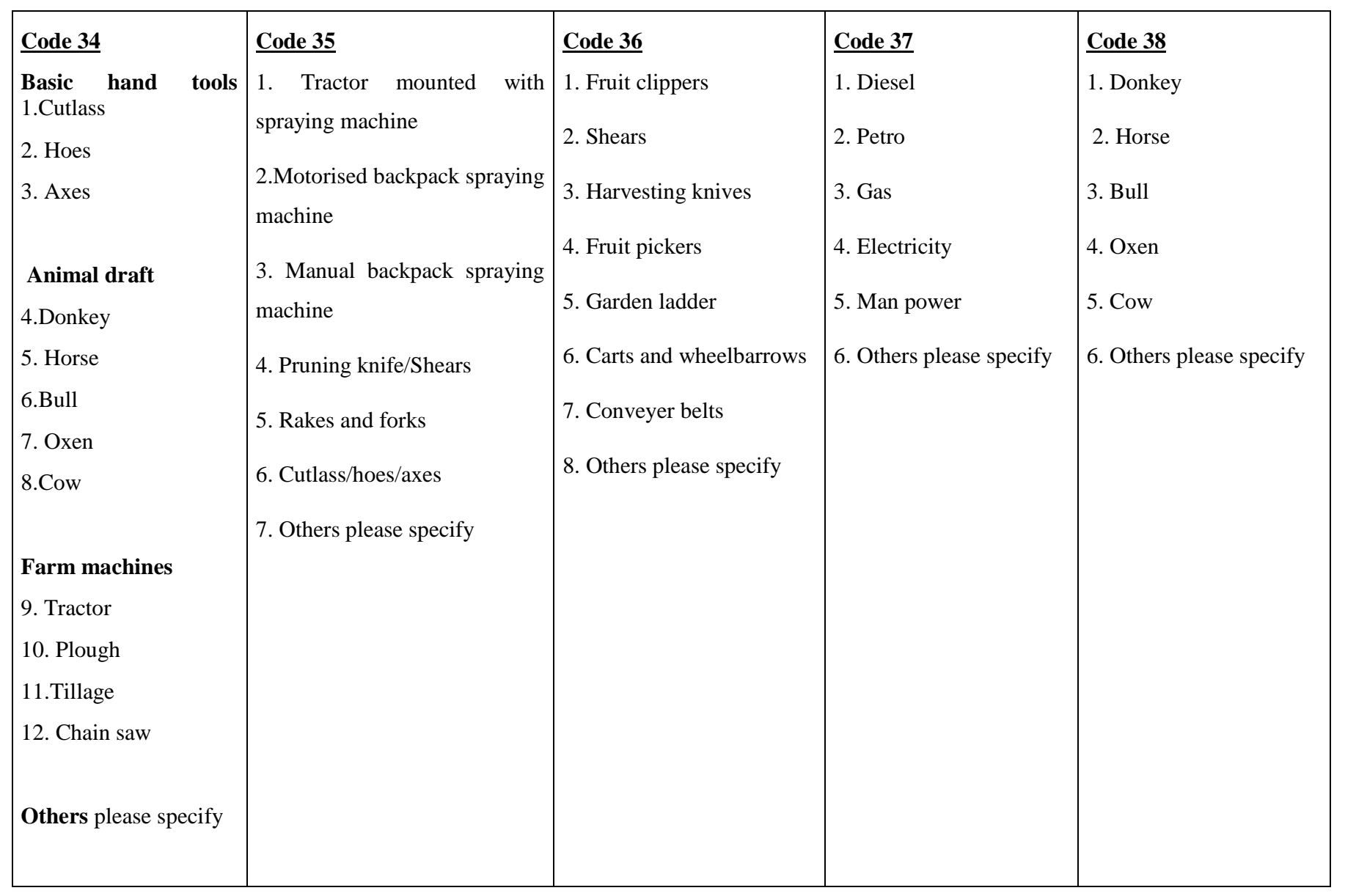




\subsection{Water use/Irrigation systems}

\begin{tabular}{|c|c|c|c|c|c|c|c|}
\hline $\begin{array}{l}\text { Do you practice } \\
\text { any form of irri- } \\
\text { gation on your } \\
\text { farm? }\end{array}$ & $\begin{array}{l}\text { If no, please } \\
\text { give rea- } \\
\text { son(s) } \\
\text { (Code 39) }\end{array}$ & $\begin{array}{l}\text { if yes, Please } \\
\text { state sources } \\
\text { of irrigation } \\
\text { water } \\
(\text { Code 40) }\end{array}$ & $\begin{array}{l}\text { Please state } \\
\text { method of } \\
\text { irrigation } \\
\text { (Code 41) }\end{array}$ & $\begin{array}{l}\text { Please state } \\
\text { total area of } \\
\text { irrigated land } \\
\text { (ha) }\end{array}$ & $\begin{array}{l}\text { How often } \\
\text { do you } \\
\text { irrigate } \\
\text { your farm? }\end{array}$ & $\begin{array}{l}\text { Please state how } \\
\text { much water is } \\
\text { used whenever } \\
\text { you irrigate your } \\
\text { farm (liters) }\end{array}$ & $\begin{array}{l}\text { Cost incurred for } \\
\text { irrigation purposes } \\
\text { per month (or year) }\end{array}$ \\
\hline $\begin{array}{l}\text { Yes( ） } \\
\operatorname{No}(\quad)\end{array}$ & & & & & & & \\
\hline
\end{tabular}

\begin{tabular}{|l|l|l|}
\hline Code 39 & $\underline{\text { Code } \mathbf{4 0}}$ & Code 41 \\
1. Too expensive & 1. River & 1. Ditch/Canal/furrow irrigation \\
2. Lack of finance & 2. Streams & 2. Terraced/trenches irrigation \\
3. No knowledge of use & 3. Dams & 3. Drip irrigation \\
4. Not necessary & 4. Ponds & 4. Sprinkler irrigation \\
5.Others, please specify & 5. Boreholes/wells & 5. Manual irrigation using buckets or watering cans \\
& 6. Others, please specify & 6. Others, please specify
\end{tabular}

\subsection{Major Investment indicators}

Have you invested in any of the following equipments (capital assets) since the establishment of your of your farm?

\begin{tabular}{|l|l|l|l|l|}
\hline Equipment/capital assets & Yes & No & Year of investment & Total amount invested \\
\hline Irrigation equipment(s) & & & & \\
\hline Storage or cooling house(s) & & & & \\
\hline New spraying machine(s) & & & & \\
\hline New harvesting equipment(s) & & & & \\
\hline Replacement of old stocks with new plant varieties & & & & \\
\hline Land expansion (through leasing or buying) & & & & \\
\hline
\end{tabular}




\section{Part III: Output Data}

\section{0 crop output}

\begin{tabular}{|c|c|c|c|c|c|c|c|c|}
\hline \multirow[t]{2}{*}{ Fruit Crop } & \multirow[t]{2}{*}{$\begin{array}{l}\text { How many times } \\
\text { do you harvest your } \\
\text { fruit in a year (i.e. } \\
\text { number of har- } \\
\text { vesting seasons in } \\
\text { a year) }\end{array}$} & \multicolumn{2}{|c|}{$\begin{array}{l}\text { Total output (yield) for } \\
\text { the production year ... } \\
\text { (i.e. quantity of fruits } \\
\text { harvested from all farms } \\
\text { or plots combined) }\end{array}$} & \multicolumn{2}{|c|}{$\begin{array}{l}\text { Producer price in } \\
\text { cedis } / \mathrm{kg} \text { or tone }\end{array}$} & \multicolumn{2}{|c|}{$\begin{array}{l}\text { How much cost did } \\
\text { you incurred during } \\
\text { harvesting (i.e. cost of } \\
\text { labour, machinery, } \\
\text { fuel, food etc) }\end{array}$} & \multirow[t]{2}{*}{$\begin{array}{l}\text { If you were to sell your } \\
\text { farm including all } \\
\text { equipments on it today, } \\
\text { how much are you } \\
\text { prepared to accept as } \\
\text { your last price? (i.e. } \\
\text { current value of the } \\
\text { farm) }\end{array}$} \\
\hline & & 2011 & 2012 & 2011 & 2012 & 2011 & 2012 & \\
\hline \multicolumn{9}{|l|}{ Pineapple } \\
\hline \multicolumn{9}{|l|}{ Banana } \\
\hline \multicolumn{9}{|l|}{ Mango } \\
\hline \multicolumn{9}{|l|}{ Other crops } \\
\hline \multicolumn{9}{|l|}{ Cereals } \\
\hline \multicolumn{9}{|l|}{ vegetables } \\
\hline $\begin{array}{l}\text { Roots and } \\
\text { tubers }\end{array}$ & & & & & & & & \\
\hline
\end{tabular}

* Please state clearly what unit is/are used to measure output (kg or tone or bags etc)

23.1 How do you measure the quantity of fruit harvested on your farm?

(1) By counting

(2) By weighing using scales

(3) By visual inspection and judgment base on my experience

(4) Others; please specify...... 


\subsection{Which of the following production system are you currently practicing?}

(1) Organic farming system (i.e. uses no chemical inputs like pesticide, herbicide etc)

(2) Conventional farming system (uses input chemicals like pesticide, herbicide etc)

\subsection{Marketing channels and the role of middlemen}

\begin{tabular}{|c|c|c|c|c|c|c|c|}
\hline $\begin{array}{l}\text { Harvested } \\
\text { fruits are sold } \\
\text { mainly to? } \\
\text { (Code 42) }\end{array}$ & $\begin{array}{l}\text { How far is } \\
\text { your farm to } \\
\text { the nearest } \\
\text { selling } \\
\text { point/market? } \\
\text { (in } \mathrm{km} \text { ) }\end{array}$ & $\begin{array}{l}\text { How does the } \\
\text { farm produce } \\
\text { (fruit) reach } \\
\text { the selling } \\
\text { point/market? } \\
\text { (Code 43) }\end{array}$ & $\begin{array}{l}\text { What is the } \\
\text { transportation } \\
\text { cost incurred in } \\
\text { bringing the } \\
\text { produce to the } \\
\text { selling point(s) }\end{array}$ & $\begin{array}{l}\text { Are you } \\
\text { obliged to sell } \\
\text { your produce to } \\
\text { cooperatives/ } \\
\text { organisations } \\
\text { due to contract } \\
\text { agreement? }\end{array}$ & $\begin{array}{l}\text { If yes, please } \\
\text { mention } \\
\text { name }(\mathrm{s}) \quad \text { of } \\
\text { organisation }\end{array}$ & $\begin{array}{lr}\text { Are fruits } & \text { sold } \\
\text { directly } & \text { to } \\
\text { these organiza- } \\
\text { tions } & \text { or } \\
\text { through } & \text { mid- } \\
\text { dlemen? } & \\
(\text { Code } 44) & \end{array}$ & $\begin{array}{l}\text { What is your } \\
\text { opinion on the } \\
\text { role of middle- } \\
\text { men in the } \\
\text { marketing proc- } \\
\text { ess? } \\
\text { (Code } 45 \text { ) }\end{array}$ \\
\hline & & & & $\begin{array}{l}\text { Yes ( ) } \\
\text { No ( ) }\end{array}$ & & & \\
\hline
\end{tabular}

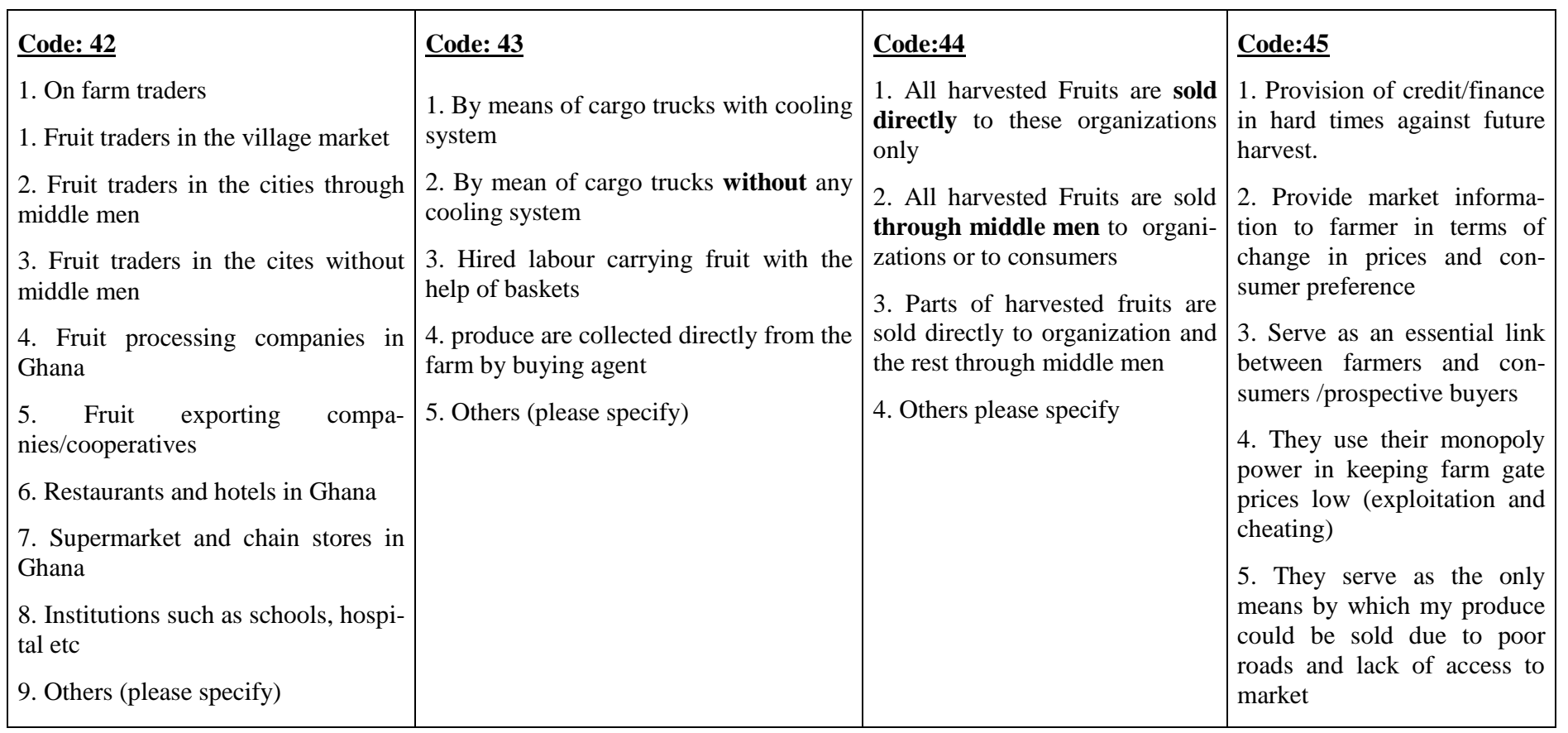




\section{0 output level and causes of post harvest loses}

\begin{tabular}{|c|c|c|c|c|c|c|}
\hline $\begin{array}{l}\text { How would } \\
\text { you rank this } \\
\text { year's yield } \\
\text { compare to } \\
\text { previous years } \\
\\
\\
\text { (Code 46) }\end{array}$ & $\begin{array}{l}\text { Can you give } \\
\text { any reason(s) } \\
\text { which lead to } \\
\text { this output } \\
\text { level } \\
\\
\text { (Code 47) }\end{array}$ & $\begin{array}{l}\text { What would be your } \\
\text { expectation for next } \\
\text { year's output level, } \\
\text { under normal weather } \\
\text { conditions (i.e. no } \\
\text { drought, no floods, no } \\
\text { bush fires etc) } \\
\text { (Code 48) }\end{array}$ & $\begin{array}{l}\text { Are you required } \\
\text { to adhere to } \\
\text { particular farm- } \\
\text { ing standards } \\
\text { because of certi- } \\
\text { fication? }\end{array}$ & $\begin{array}{l}\text { if yes, please } \\
\text { mention the } \\
\text { name of organi- } \\
\text { zation where } \\
\text { certification is } \\
\text { obtained }\end{array}$ & $\begin{array}{l}\text { Estimate how } \\
\text { much of your } \\
\text { output could } \\
\text { not be sold due } \\
\text { to post harvest } \\
\text { loses (in \%) }\end{array}$ & $\begin{array}{l}\text { What would you } \\
\text { say is the main } \\
\text { causes of post } \\
\text { harvest loses on } \\
\text { your farm } \\
\text { (Code 49) }\end{array}$ \\
\hline & & & $\begin{array}{l}\text { Yes }(\quad) \\
\text { No }(\quad)\end{array}$ & & & \\
\hline
\end{tabular}

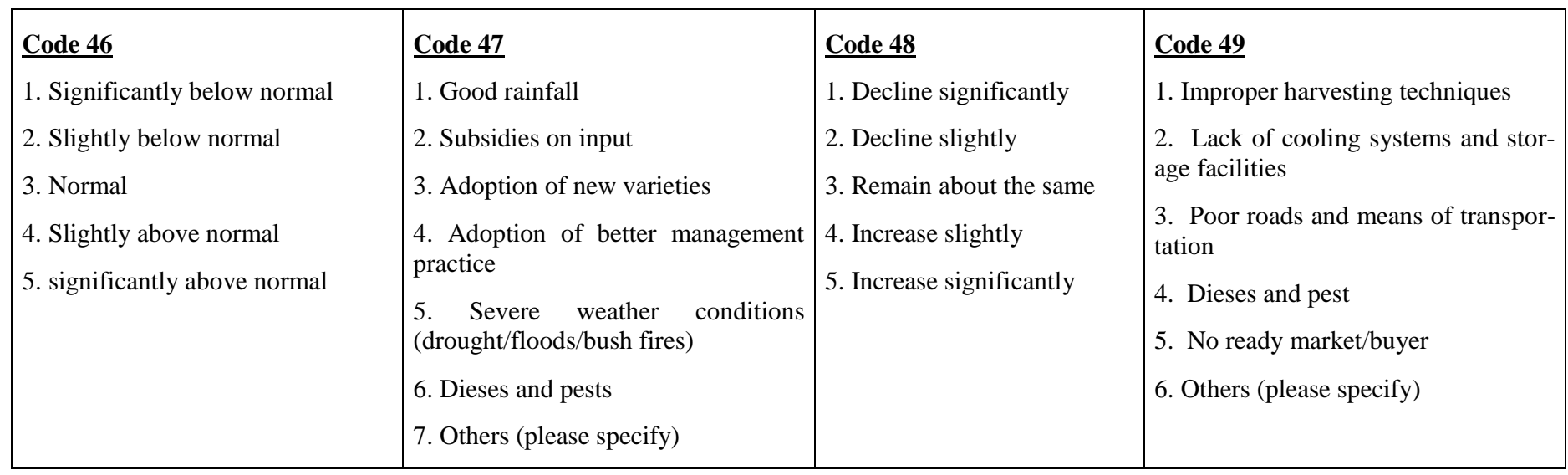

\section{0 weather effects on output}

\begin{tabular}{|c|c|c|c|c|c|}
\hline $\begin{array}{l}\text { Have you ever experienced drastic } \\
\text { yield decline or crop failure due } \\
\text { to severe weather conditions like } \\
\text { drought/ floods/ bush fires? }\end{array}$ & $\begin{array}{l}\text { If yes, how } \\
\text { often in the last } \\
\text { five (5) years? }\end{array}$ & $\begin{array}{l}\text { Ware there any } \\
\text { severe weather } \\
\text { effect on this } \\
\text { year's output? }\end{array}$ & $\begin{array}{l}\text { If yes, To what } \\
\text { extent (in \%) } \\
\text { were the yield } \\
\text { decline? } \\
\text { (Code 50) }\end{array}$ & $\begin{array}{l}\text { Please mention the } \\
\text { type of weather } \\
\text { condition which } \\
\text { affected this year's } \\
\text { output } \\
\text { (Code 51) }\end{array}$ & $\begin{array}{l}\text { What would you say } \\
\text { is the main factor(s) } \\
\text { hindering agricultural } \\
\text { activity in this vil- } \\
\text { lage? } \\
\text { (Code 52) }\end{array}$ \\
\hline Yes ( ) No ( ) & & Yes ( ) No ( & & & \\
\hline
\end{tabular}




\begin{tabular}{|c|c|c|}
\hline Code 50 & Code 51 & Code 52 \\
\hline 1. Up to $100 \%=$ total crop failure, & 1. Drought & 1. Lack of credit and financial support \\
\hline 2. Up to $75 \%$ yield decline $=3 / 4$ the normal yield & & 2. Lack of land and other production inputs \\
\hline 3. Up to $50 \%$ yield decline $=$ half the normal yield & 2. Heavy rains/ floods & 3. Lack of new technology or technical knowhow \\
\hline 4. Up to $25 \%$ yield decline $=1 / 4$ the normal yield & 3. Bush fires & 4. Lack of ready market and market information \\
\hline & & $\begin{array}{l}\text { 5. Lack of water/irrigation facilities } \\
\text { 6. Diseases and pest } \\
\text { 7. Drought and other severe weather phenomena }\end{array}$ \\
\hline
\end{tabular}

Note: please take pictures of farmers in their plantations (this could be used for power point presentation).

- Thank you very much for taking your valuable time to complete this survey. Your answers are greatly appreciated. 


\section{CURRICULUM VITAE}

\section{Mensah Amos}

Current address

Ostlandweg 3

37075 Göttingen, Germany

Mobil: $+49176 / 27823623$

Landline: $+49551 / 394817$

Email: amensah@gwdg.de

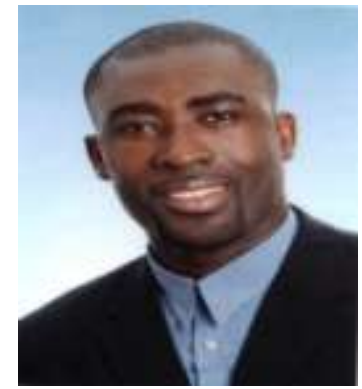

\section{ACADAMIC QUALIFICATIONS}

2010 - To date: PhD student and Research Assistant. Department of Agricultural Economics and Rural Development. Georg-August-Universität Göttingen.

Specialization: Agriculture and Rural Development Economics

Research topic: Efficiency and Productivity Analysis of the Ghanaian Fruit Crop Industry

2002 - 2004: Master of Science (M.Sc.): Tropical and International Agriculture.

Georg-August-Universität Göttingen.

Specialization: Socioeconomics of Rural Development.

Research topic: Farmers' Participation in Credit Markets and its Impact on Adoption of Agricultural Technology in Central Sulawesi-Indonesia.

1996 - 2000: Bachelor of Science (B.Sc. Honours) in Agriculture.

Kwame Nkrumah University of Science and Technology. Ghana.

Specialisation: Agronomy, Plant pathology and breeding. 
Research topic: Evaluation of F2 and F3 Generations of an Interspecific cross of Tomato (i.e.

L. Pimpinellifolium $(\mathrm{CH}) * \mathrm{NR} 46)$.

1995 - 1996: Internship (Agronomy and Farm management) at Bonsu Cocoa Research Institute. Bonsu - Ghana.

1991 - 1994: Senior Secondary School Certificate.

Pope John Secondary School, Koforidua-Ghana.

\section{PROFESSIONAL EXPERIENCE}

2010 - To date: PhD. student at the Department of Agricultural Economics and

Rural Development. Georg-August-Universität Göttingen.

Current research areas:

Efficiency and Productivity Analysis.

$>$ Development and Experimental Economics

Environmental Impact Assessment.

\section{LANGUAGES}

English and German (Full professional proficiency).

Four Ghanaian languages (Ashanti, Ga, Krobo and Fanti)

\section{COMPUTER KNOWLEDG/SKILLS}

Working proficiency with all Microsoft office and spread sheet applications.

Expert working knowledge with the following statistical software's SPSS, STATA, R and OxMetrics. 


\section{VOLUNTARY SERVICE}

Contact person for Ghanaian and African students who wish to study at GeorgAugust-University of Göttingen, Germany. I provide such prospective students with information and advisory service concerning living and studying in Göttingen from an African point of view and helping them to integrate quickly in the German university system when they arrive.

Founder of Brentu Secondary \& Technical School HIV/AIDS awareness club responsible for educating the student population and the surrounding villages about the facts of aids and prevention methods.

\section{REFEREES}

Prof. Dr. Bernhard Brümmer

Department of Agricultural Economics and Rural Development.

Platz der Göttinger Sieben 5

37073 Göttingen, Germany

Tel: 0049551394811

Email: bbruemm@gwdg.de
Prof. Dr. Stephan v. Cramon-Taubadel

Department of Agricultural Economics and Rural Development.

Platz der Göttinger Sieben 5

37073 Göttingen, Germany

Tel.: +49 (0) 551 / 39-22872

Email: scramon@gwdg.de 


\section{E C L A R A T I O N S}

1. I, hereby, declare that this Ph.D. dissertation has not been presented to any other examining body either in its present or a similar form. Furthermore, I also affirm that I have not applied for a Ph.D. at any other higher school of education.

Göttingen

(Signature)

(Name in block capitals)

2. I, hereby, solemnly declare that this dissertation was undertaken independently and without any unauthorised aid.

Göttingen,

(Signature)

(Name in block capitals) 